MicroRNAs

in Normal

and Malignant

Myelopoiesis

Mir Farshid Alemdehy 
Layout and printing: Off Page, Amsterdam, www.offpage.nl

ISBN: 978-94-6182-539-1

Copyright $\odot 2015$ by Mir Farshid Alemdehy

The work presented in this thesis was performed at the Department of Hematology at the Erasmus Medical Center in Rotterdam and was financially supported by the Dutch Cancer Society (KWF). Printing of this thesis was financially supported by the Erasmus University Rotterdam and the Dutch Cancer Society (KWF).

All rights reserved. No part of this thesis may be reproduced, stored in a retrieval system of any nature, or transmitted in any form or by any means, without prior permission of the author. 


\section{MicroRNAs in Normal and Malignant Myelopoiesis}

MicroRNAs in normale en maligne myelopoiese

Thesis

to obtain the degree of Doctor from the

Erasmus University Rotterdam

by command of the

rector magnificus

Prof.dr. H. A. P. Pols

and in accordance with the decision of the Doctorate Board The public defence shall be held on

Wednesday 11 March 2015 at 13:30

by

Mir Farshid Alemdehy

born in Teheran, Iran

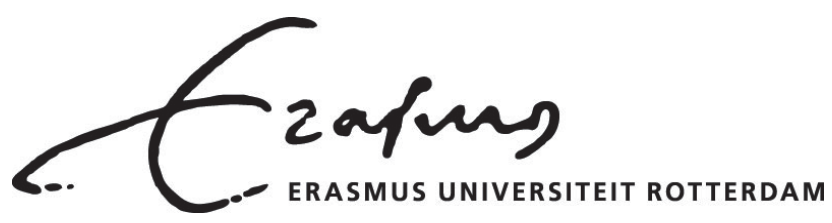




\section{Doctoral Committee}

Promotor:

Prof.dr. I. P. Touw

Other members:

Prof.dr. L. H. J. Looijenga

Dr. M. M. von Lindern

Dr. E. A. C. Wiemer

\section{Copromotor:}

Dr. S. J. Erkeland 
To my love, Setareh, to our Ryan,

and to my parents 



\section{CONTENTS}

$\begin{array}{lll}\text { Chapter } 1 & \text { Introduction } & 9\end{array}$

Chapter 2 MicroRNAs: Key Players of Normal and Malignant Myelopoiesis

Chapter 3 Dicer1 Deletion in Myeloid-Committed Progenitors Causes Neutrophil Dysplasia and Blocks Macrophage/Dendritic Cell

Development in Mice

Chapter 4 Stop the Dicing in Hematopoiesis; What have we Learned?

Chapter 5 Interstrand Cross-link Induced miR-139-3p and miR-199a-3p have Opposite Roles in Hematopoietic Cell Expansion and Leukemic Transformation

Chapter 6 Summary and General Discussion

Addendum List of Abbreviations $\quad 171$

Nederlandse Samenvatting $\quad 175$

Words of Thanks 177

Curriculum Vitae 181

Phd Portfolio Summary 183 


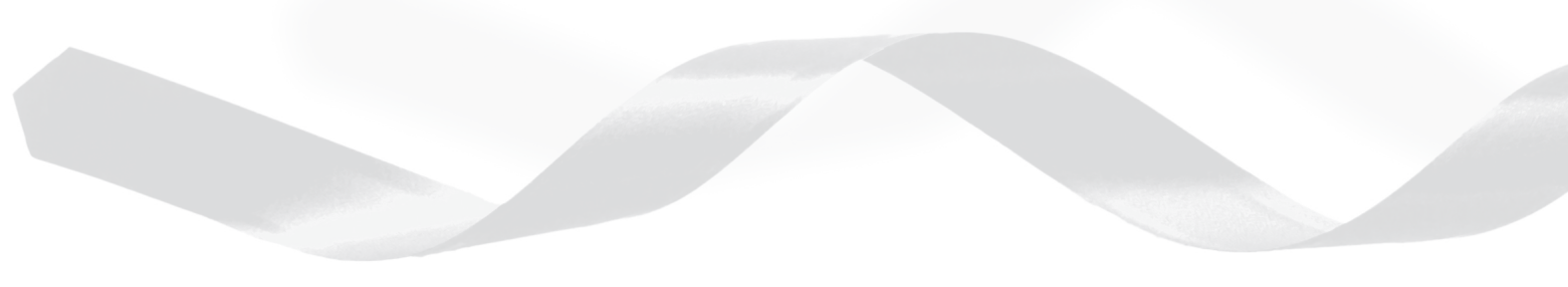




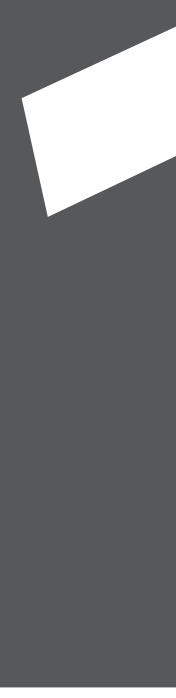

Introduction 



\section{HEMATOPOIESIS}

Hematopoiesis is the lifelong continuous process in which hematopoietic stem and progenitor cells (HSPCs) proliferate and differentiate towards mature blood cells. Hematopoiesis is tightly controlled by a network of growth factors and the hematopoietic niche in the bone marrow (BM). This ensures the balanced blood cell production under homeostatic conditions and allows for transient elevation of specific blood cell types production in response to infections or bleeding ${ }^{1}$. In mammalian organisms, long-term hematopoietic stem cells (LT-HSCs) reside in the BM and have self-renewal capacity over the lifespan of the organism ${ }^{2,3}$. The estimated amount of LT-HSCs is approximately $0.007 \%$ of all hematopoietic cells in the BM ${ }^{4}$. LT-HSCs give rise to short-term HSCs (ST-HSCs) and multipotent progenitors (MPPs) (Figure 1). These cells have the potential to differentiate into all the different hematopoietic cell types but have less self-renewal capacity ${ }^{4}$. Together, LT-HCSs, ST-HCSs and MPPs constitute $0.05 \%$ of mouse BM cells ${ }^{2}$. MPPs differentiate into common lymphoid progenitors (CLPs) and common myeloid progenitors (CMPs) (Figure 1). Subsequently, CLPs differentiate into B-cell and T-cell lineages. CMPs first develop into more specified myeloid progenitors, which are megakaryocyte/erythroid progenitors (MEPs) and granulocyte/monocyte progenitors (GMPs). Granulocytes, monocytes and macrophages arise from GMPs, whereas MEPs differentiate towards erythrocytes and thrombocytes (platelets) (Figure 1). The process of differentiation of HSPCs towards mature myeloid cells is referred as myelopoiesis. In adult mammalian organisms, myelopoiesis occurs in the BM.

Disruption of the balance between cell proliferation, differentiation and cell death leads to different hematopoietic disorders, e.g., leukemia, characterized by proliferation of undifferentiated cells, or bone marrow failure (BMF), characterized by impaired hematopoiesis involving one or multiple hematopoietic lineages ${ }^{5,6}$. Proliferation and differentiation of HSPCs are coordinated by gene expression programs driven by endogenous and exogenous factors. MicroRNAs (miRNAs) are a class of non-coding RNAs which function as regulators of gene expression. In the studies described in this thesis the role of miRNAs in normal myelopoiesis and their involvement in acute myeloid leukemia (AML) and Fanconi anemia (FA), the most frequent inherited form of BMF syndromes are investigated. AML, FA and miRNAs will be further introduced in the following sections.

\section{ACUTE MYELOID LEUKEMIA}

AML is a type of blood cancer characterized by a block in myeloid differentiation and an uncontrolled clonal outgrowth of malignant myeloid progenitor cells, which overgrow normal blood cells and interfere with their functions. Lack of functional blood cells leads to the classical symptoms of AML, i.e., fatigue (due to lack of erythrocytes), infections (due to lack of functional granulocytes and monocytes) and hemorrhage (due to lack of platelets) ${ }^{7}$. AML is mainly a disease of the elderly. The incidence of AML increases with age with 1.7 per 100,000 individuals below the age of 65 compared with 16 per 100,000 individuals over the age of 65 (based on the Surveillance, Epidemiology, and End Results (SEER) cancer statistics review of the National Cancer Institute ${ }^{8}$ ). The average age at diagnosis is 67 years ${ }^{8}$. 


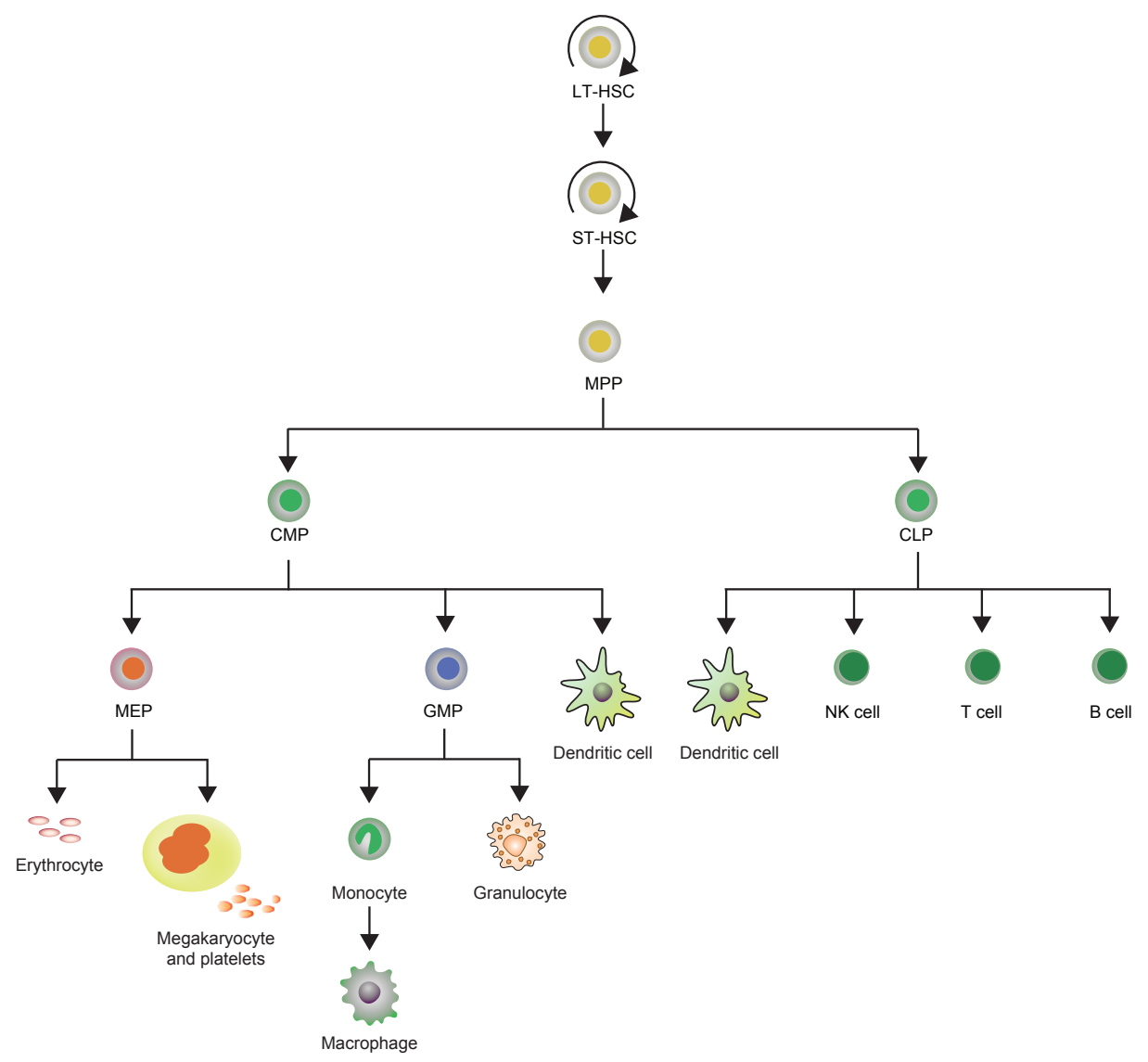

Figure 1. Schematic representation of the hematopoiesis. The hematopoietic stem cells (HSCs) consist of long-term HSCs (LT-HSCs), short-term HSCs (ST-HSCs) and multipotent progenitors (MPPs). HSCs differentiate into common lymphoid progenitors (CLPs) and common myeloid progenitors (CMPs). Subsequently, CLPs differentiate into B cell and T cell lineages, as well as natural killer cells (NK cells) and dendritic cells. CMPs first develop into more specified myeloid progenitors, which are megakaryocyte/erythroid progenitors (MEPs) and granulocyte/monocyte progenitors (GMPs). Granulocytes, monocytes and macrophages as well as dendritic cells arise from GMPs, whereas MEPs differentiate towards erythrocytes and thrombocytes (platelets). Figure adapted from Reya et al. and Blank et al. ${ }^{1,2}$.

AML is a heterogeneous group of diseases characterized by different genetic abnormalities such as chromosomal defects including translocation, deletion or inversion, as well as molecular aberrations such as mutations in the genes encoding important transcription factors. The most recurrent chromosomal aberrations and frequently mutated genes in AML and their prognostic significance are listed in Table 1. 
Table 1. Recurrent cytogenetic and genetic abnormalities in adult AML.

\begin{tabular}{|c|c|c|c|}
\hline $\begin{array}{l}\text { Recurrent cytogenetic } \\
\text { and genetic aberration }\end{array}$ & $\begin{array}{l}\text { Related } \\
\text { fusion gene }\end{array}$ & Frequency (\%) & Prognostic significance \\
\hline \multicolumn{4}{|l|}{ Cytogenetic abnormalities } \\
\hline Normal karyotype & & 45 & \\
\hline Complex karyotype ${ }^{*}$ & & 11 & Unfavorable \\
\hline+8 & & 9 & Intermediate \\
\hline$-7 /-7 q$ & & 8 & Unfavorable \\
\hline $\mathrm{t}(15 ; 17)(\mathrm{q} 22 ; \mathrm{q} 21)$ & PML-RARA & $5-10$ & Favorable \\
\hline$-5 /-5 q$ & & 7 & Unfavorable \\
\hline $\mathrm{t}(8 ; 21)(\mathrm{q} 22 ; \mathrm{q} 22)$ & AML1-ETO & 6 & Favorable \\
\hline $\operatorname{inv}(16)(\mathrm{p} 13.1 \mathrm{q} 22)$ & CBFB-MYH11 & 5 & Favorable \\
\hline$-\mathrm{Y}$ & & 4 & Intermediate \\
\hline $11 \mathrm{q} 23$ & MLL fusions & 3 & Unfavorable \\
\hline $\operatorname{abn}(12 p)$ & & 3 & Intermediate \\
\hline $\mathrm{t}(9 ; 11)(\mathrm{p} 22 ; \mathrm{q} 23)$ & MLLT3-MLL & 2 & Unfavorable \\
\hline $\begin{array}{l}\operatorname{inv}(3)(\mathrm{q} 21 \mathrm{q} 26.2) \text { or } \mathrm{t}(3 ; 3) \\
(\mathrm{q} 21 ; \mathrm{q} 26.2)\end{array}$ & RPN1-EVI1 & 2 & Unfavorable \\
\hline+21 & & 2 & Intermediate \\
\hline $\operatorname{del}(9 q)$ & & 2 & Intermediate \\
\hline $\mathrm{t}(9 ; 22)(\mathrm{q} 34 ; \mathrm{q} 11)$ & BCR-ABL & 1 & Intermediate/Unfavorable \\
\hline $\mathrm{t}(6 ; 9)(\mathrm{p} 23 ; \mathrm{q} 34)$ & DEK-NUP214 & 1 & Unfavorable \\
\hline \multicolumn{4}{|l|}{ Molecular abnormalities } \\
\hline ASXL1 & & 11 & Unfavorable \\
\hline CEBPA & & $10-18$ & Favorable \\
\hline c-KIT & & 17 in CBF leukemia & Unfavorable in $\mathrm{t}(8 ; 21)$ \\
\hline DNMT3A & & 22 & Unfavorable \\
\hline FLT3-ITD & & $20-40(50$ in $\mathrm{CN})$ & Unfavorable \\
\hline FLT3-TKD & & $11-14$ & - \\
\hline IDH1/2 & & 16 & Unfavorable \\
\hline MLL-PTD45 & & $3-5$ & Unfavorable \\
\hline NPM1 & & $35(53$ in $\mathrm{CN})$ & $\begin{array}{l}\text { Favorable in absence of } \\
\text { FLT3-ITD }\end{array}$ \\
\hline N-Ras/K-Ras & & $9-14 / 5$ & - \\
\hline PTPN11 & & 2.5 & $\begin{array}{l}\text { Unfavorable in absence of } \\
\text { NPM1 mutation }\end{array}$ \\
\hline RUNX1 & & $5-13$ & Unfavorable \\
\hline TET2 & & $8-17$ & Unfavorable \\
\hline
\end{tabular}


Table 1. Recurrent cytogenetic and genetic abnormalities in adult AML. (Continued)

\begin{tabular}{llll}
\hline $\begin{array}{l}\text { Recurrent cytogenetic } \\
\text { and genetic aberration }\end{array}$ & $\begin{array}{l}\text { Related } \\
\text { fusion gene }\end{array}$ & Frequency (\%) & Prognostic significance \\
\hline TP53 & & $\begin{array}{l}<10(56-78 \text { complex } \\
\text { caryotype) }\end{array}$ & Unfavorable \\
\hline WT1 & 10 in CN & $\begin{array}{l}\text { Unfavorable combined with } \\
\text { FLT3-ITD }\end{array}$ \\
\hline
\end{tabular}

Cytogenetic abnormalities are ordered based on frequency, moleculare abnormalities are ordered alphabetically, $\mathrm{t}=$ translocation, $-=$ loss,$+=$ gain, inv = inversion, $\mathrm{abn}=$ abnormality, del = deletion, $\mathrm{CN}=$ cytogenetically normal AML, $\mathrm{CBF}=$ core binding factor $\mathrm{AML}$, i.e., with inv(16), $\mathrm{t}(16 ; 16)$ or $\mathrm{t}(8 ; 21)$.

${ }^{*}$ Complex karyotype has been defined as the presence of 3 or more cytogenetic abnormalities in the absence of $\mathrm{t}(8 ; 21)$, inv(16) and $\mathrm{t}(15 ; 17)$

Based on Marcucci et al., $2011^{152}$; Mrozek et al., $2004^{153}$; Takahashi, $2011^{154}$; Walker and Marcucci, $2012^{155}$

The treatment of AML patients is performed in two phases. The main objective in the first phase is to induce a remission ${ }^{7}$. The aim of second phase is to prevent relapse by eliminating all undetected remaining leukemic blasts ${ }^{7}$. Remission is defined morphologically when the amount of blasts in the BM decreases to below $5 \%{ }^{7}$. Both phases are performed via intensive combinatorial chemotherapy, and depending on the age of the patient, the presence of a suitable stem cell donor and the molecular characteristics of the AML, the second phase may involve allogenic or autologous stem cell transplantation ${ }^{7}$. New insights into the biology of AML are needed to allow introduction of targeted therapies that improve the efficiency of the therapeutic approach. Particularly, AML arising from BMF is associated with a poor prognosis that is probably due to the mechanism of disease progression.

\section{FANCONI ANEMIA}

FA, the most frequently inherited form of BMF syndromes ${ }^{6}$, results from mutations in one of the Fanconi (FANC) genes involved in interstrand cross-link (ICL) DNA damage repair ${ }^{9-11}$. Cells with mutations in FANC genes are hypersensitive to DNA cross-linking agents such as mitomycin $\mathrm{C}$ (MMC), and show a dramatic increase in the number of chromosomal aberrations ${ }^{12-15}$. FA is characterized by developmental abnormalities, BMF and an increased susceptibility to develop cancers, including leukemia. Approximately $80 \%$ of young FA patients develop BMF of which 16\% develop myelodysplastic syndrome (MDS) and AML, with a median age of leukemia onset of 11 years ${ }^{16-18}$. The cumulative incidence of MDS and AML increases to $33 \%$ by the age of 40 . Typically, the AMLs in older patients are characterized by a poor prognosis ${ }^{19}$.

\section{3-1. The FA pathway and ICL repair}

Hematopoietic progenitor cells possess a robust proliferative capacity that provides approximately $10^{12}$ blood cells daily in adult $\mathrm{BM}^{20}$. Consequently, the genomic integrity of HSPCs is constantly threatened by replication errors or damages induced by endogenously 
formed metabolic products and by-products, such as free radicals, reactive oxygen species (ROS), endogenous alkylating agents and reactive aldehydes ${ }^{21,22}$. Unrepaired DNA damages will ultimately result in accelerated senescence, increased cell death, abnormal cell expansion and an increased risk of cancer ${ }^{23,24}$. To maintain genomic integrity, HSPCs must respond appropriately to genotoxic DNA damages. The DNA repair systems in mammalian cells include nucleotide excision repair (NER), base excision repair (BER), double strand break (DSB) repair, mismatch repair and ICL repair ${ }^{25}$. An ICL consists of a covalent bond between two strands of DNA, leading to a block in DNA replication and transcription, and is an extremely toxic DNA lesion ${ }^{26}$. The FA pathway is involved in swift repair of ICL in higher eukaryotic cells ${ }^{27}$. Eight different FA proteins (FANCA, -B, -C, -E, -F, -G, -L and -M) assemble to form a core protein complex in the nucleus. The FANCL subunit is an E3 ubiquitin ligase ${ }^{28}$. In response to DNA-damage, the FA core complex ubiquitylates two other FA proteins: FANCI and FANCD2 (ID) ${ }^{29,30}$ (Figure 2). Monoubiquitylation of (FANC)ID by the FA core complex is required for ICL recognition ${ }^{12}$. Ubiquitylated (FANC)ID recruits FANCP (SLX4) in complex with structure-specific endonuclease complexes including FAN1, MUS81-EME1 and XPF(FANCQ)-ERCC1, to the ICL lesion site ${ }^{9}$ (Figure 2). FANCQ-ERCC1 makes incisions

A)

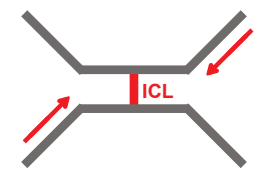

D)

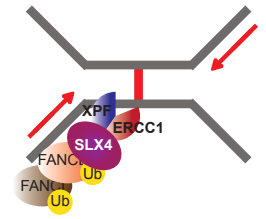

B)

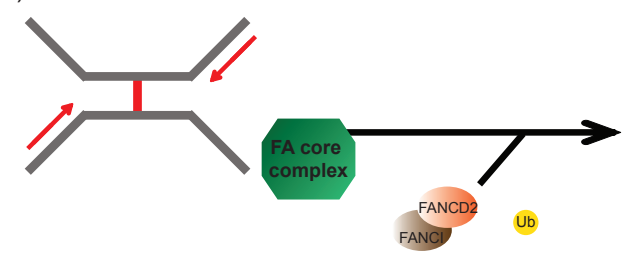

E)

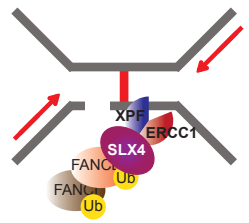

C)

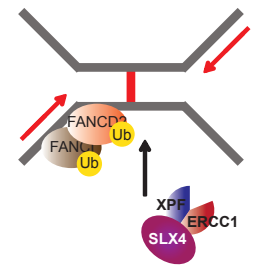

G)

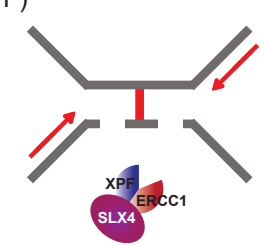

Figure 2. FA pathway and ICL repair. A) An interstrand cross-link (ICL) is a covalent bond between two strands of DNA, blocking DNA replication and transcription. B) Eight different FA proteins (FANCA, - B, -C, -E, -F, - G, -L and -M) assemble to form FA core complex in the nucleus. In response to ICL DNA-damage, FA core complex ubiquitylates two other FA proteins: FANCD2 and FANCI (ID). Monoubiquitylation of ID is required for ICL recognition. C) Ubiquitylated ID recruits SLX4 in complex with XPF-ERCC1. D-E-F) XPF-ERCC1 makes incisions around the ICL site by cutting first 3'- and possibly then 5'- sides, to unhook the cross-linked DNA. G) The intact parental strand could then serve as a template for the extension by translesion synthesis (TLS). Figure is adapted from Hodskinson et al. ${ }^{31}$. 
around the ICL site by cutting first 3' and possibly then 5' sides, to unhook the cross-linked DNA and therefore is an essential endonuclease for ICL repair ${ }^{31,32}$ (Figure 2).

\section{3-2. Leukemic transformation in FA}

How FA progresses to leukemia is still largely elusive. A genetic reversion of the mutation was reported in an AML cell line from a patient with a biallelic FANCD1 mutation ${ }^{33}$ and it was suggested that this phenomenon may play a general role in FA-related MDS/AML oncogenesis. However, an analysis on 57 FA patients, including 18 FA-MDS and 11 FA-AML patients shows no reversion of the FA mutation, indicating that this does not occur frequently ${ }^{34}$. Further investigation of this group of patients included karyotype analysis of the BM samples and selected oncogene sequencing, which revealed specific patterns of chromosomal abnormalities in FA-MDS and FA-AML ${ }^{34}$. These included gain of $1 \mathrm{q}(44.8 \%$ of FA- MDS/AML) and $3 \mathrm{q}$ (containing the EVI1 gene) (41.4\%), and loss of 7/7q (17.2\%) and 11q (13.8\%). Whereas RUNX1/AML1 lesions (translocations, deletions, or mutations) are observed in $20.7 \%$ of FA patients with MDS or AML, other abnormalities that are frequently found in de novo AML, e.g., mutations in NRAS, FLT3-ITD, MLL-PTD, ERG amplification, and ZFP36L2-PRDM16 translocation, were rare ${ }^{34}$. Mutations in TP53, TET2, CBL, NPM1, and CEBPA were also rare in FA-AML ${ }^{34,35}$. Abrogation of the DNA damage checkpoints in the cell cycle and resistance to tumor necrosis factor-alpha (TNF- $\alpha$ ) have been described as mechanisms favoring the clonal expansion of FA cells ${ }^{36,37}$.

\section{MICRORNAS}

Recent data from high-throughput sequencing platforms have established that in mammalian organisms nearly the entire genome is transcribed ${ }^{38}$. Remarkably, only $2 \%$ of the transcripts are translated into proteins ${ }^{38}$. The majority of the transcripts $(98 \%)$ are so-called noncoding RNAs (ncRNAs) and are roughly categorized into small $(<200$ nucleotides (nt)) and large ncRNAs. The small ncRNAs include small nucleolar RNAs, PIWI-interacting RNAs, endogenous small interfering RNAs (siRNAs), and microRNAs (miRNAs). While proteincoding sequences have been extensively investigated in the last decennia, the functions of non-coding RNAs have just recently been addressed ${ }^{39}$. The major features of miRNA functions related to this thesis are introduced below.

MiRNAs are 19-23 nt single-stranded RNA molecules ${ }^{40}$. The first miRNA, Lin-4, discovered by Ambros, Ruvkun and colleagues, controls the timing of Caenorhabditis elegans (C. elegans) larval development ${ }^{41,42}$. Since then, thousands of miRNA encoding genes have been identified in animals, plants and viruses, making them one of the largest gene families ${ }^{40,43-45}$. All 35828 confirmed miRNAs, in up to 223 species, are listed in the miRNA-base database (www.mirbase.org). This database includes 2603 human and 1920 mouse miRNA sequences. Notably, miRNAs are highly conserved between species. For instance, more than half of C. elegans miRNAs share sequence homology with miRNAs encoded also in both Drosophila melanogaster and human genomes ${ }^{46}$. Furthermore, more than $70 \%$ of the miRNAs are 
identical between human and mouse ${ }^{47}$, indicating that there is a high degree of conservation during animal evolution. Each cell type expresses a unique set of miRNAs at specific levels, suggesting that they are important for cellular identity and functions ${ }^{45}$.

\section{1- MiRNA biogenesis}

MiRNAs are abundantly expressed with levels reaching thousands of molecules per cell, a copy number that is much higher than what is normally found for mRNAs ${ }^{48}$. Most miRNA genes are located in intergenic regions or in antisense orientation in introns of annotated genes, implying that they are expressed from an independent transcription unit ${ }^{49-51}$. About $25-30 \%$ of the murine and human miRNA genes are located in introns of other genes in the same orientation of their host genes, suggesting that these miRNAs are co-transcribed and processed from the introns ${ }^{40,52}$. In mammals, $61 \%$ of miRNA genes are clustered in the genome and are simultaneously expressed as polycistronic transcripts ${ }^{52}$. Examples of such transcripts are the miR-17 92 cluster and the miR-290-295 cluster of miRNAs ${ }^{53,54}$.

MiRNAs arise from primary sequences (pri-miRNAs) of various sizes, typically more than $1 \mathrm{~kb}$, which fold into hairpins ${ }^{40}$ (Figure 3). Pri-miRNAs contain cap structures and poly(A) tails, and are mainly transcribed by RNA polymerase II (pol II) ${ }^{55}$. However, some miRNAs are transcribed by RNA polymerase III (Pol III), especially those with upstream Alu sequences ${ }^{56}$. Each pri-miRNA hairpin structure contains potentially two mature miRNA sequences, positioned respectively at the 5'-and the 3 '-arm of the pri-miRNA sequence. In the first step of processing, pri-miRNAs are cleaved by the microprocessor complex consisting of the highly conserved RNase III endoribonuclease DROSHA and its obligate RNA-binding partner DGCR8 ${ }^{57}$. The product of pri-miRNA cleavage by DROSHA is a $\sim 60-70 \mathrm{nt}$ stem loop intermediate, the so-called precursor miRNA (pre-miRNA) ${ }^{58}$. Importantly, DROSHA cleavage defines the 5 ' -end of the $5 \mathrm{p}$ miRNA and the 3 ' -end of the $3 p$ miRNA. Next, the pre-miRNAs are exported to the cytoplasm by the karyopherin family member Exportin- 5 (EXP5) and its cofactor Ran-GTP ${ }^{59}$.

\section{4-2. DICER1}

In the cytoplasm, the pre-miRNA is further processed by the enzyme DICER $1{ }^{60}$. DICER 1 is a large $(\sim 200 \mathrm{kDa})$ and evolutionarily conserved member of the RNase III family of endoribonucleases ${ }^{61}$. DICER1 contains three $\mathrm{N}$-terminal helicase domains (HEL1, HEL2i, HEL2), a DUF283 domain, which is presumably involved in binding of double stranded RNA (dsRNA), a "Platform" domain that is tightly associated with the pre-miRNA binding domain PAZ, two tandem RNase III domains a and b, and a C-terminal dsRNA Binding Domain (dsRBD) ${ }^{62-64}$. The RNase III domains of DICER1 cleave pre-miRNAs and double-stranded RNA (dsRNA) substrates into small 5'-phosphorylated and 2 nt 3'-overhangs duplex RNAs of typically 21-23 nt ${ }^{63,65}$ (Figure 3).

Genetic studies in plants, zebrafish and mice show that Dicerl is essential for normal development ${ }^{66-68}$. For instance, genetic deletion of Dicer1 in mice depletes the Oct-4positive pluripotent embryonic stem (ES) cell population at around embryonic day 6-7, and 


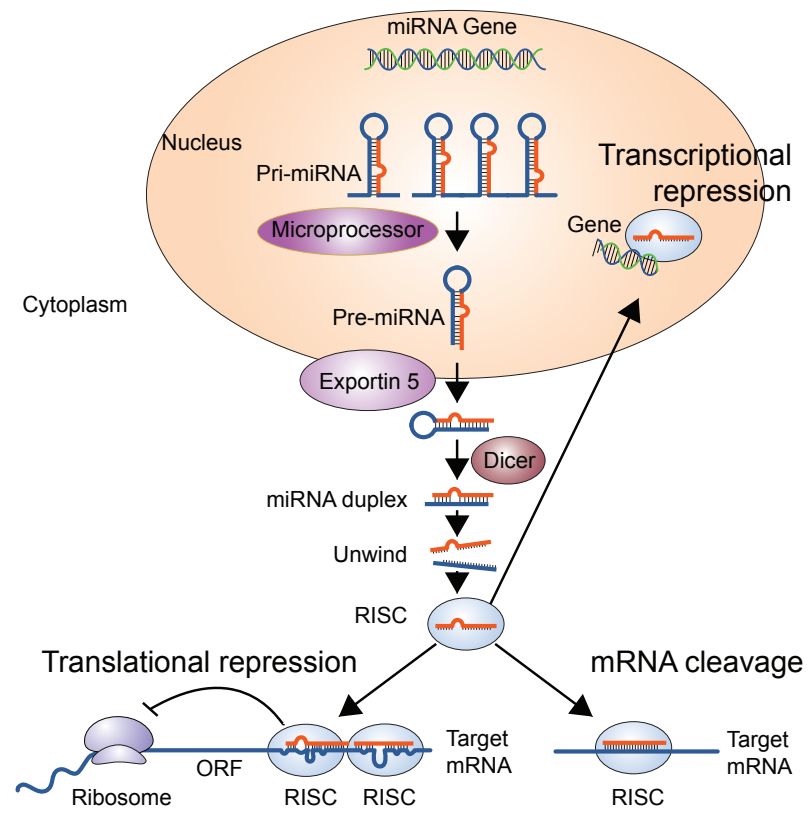

Figure 3. Schematic overview of miRNA biogenesis and activities. Pri-miRNAs are processed by the Microprocessor complex, consisting of the RNase III endoribonuclease DROSHA and its partner DGCR8, exported to the cytoplasm and further cleaved by another endoribonuclease, DICER1. MiRNAs are loaded into RISC and bind to partially complementary sequences of target mRNAs that are predominantly located in the 3' -UTRs. MiRNA-containing RISC may regulate gene expression by transcript destabilization, inhibition of protein translation and transcriptional repression.

results in early embryonic lethality ${ }^{68}$. Because Dicer1-null ES cells are incapable to process miRNA hairpins, the lack of miRNAs critical for embryonic development is most likely fully responsible for this lethal phenotype ${ }^{69-71}$.

The DICER1 generated double-stranded RNAs become incorporated as single-stranded RNAs in the so-called RNA-induced silencing complex (RISC) of which the AGO proteins (AGO1-4 in mammalian cells) are the main components ${ }^{72}$ (Figure 3). Typically, the passenger

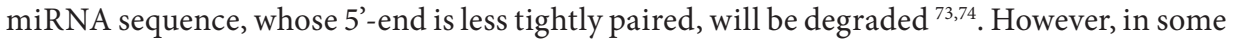
cases both sequences are loaded into RISC ${ }^{72,75}$.

\section{4-3. MiRNA activity}

The 5'-regions of miRNAs are the most conserved among species. They match conserved elements in the untranslated regions (UTR) of mRNA targets and thereby mediate translational repression and mRNA decay ${ }^{48,76}$. This region of the miRNA (2-8 nt) is called the "seed" sequence. Disruption of this sequence by nucleotide substitutions abrogates miRNA functions ${ }^{77}$. The 3 '-end of the miRNA modifies miRNA binding to its target or may 
compensate for seed mismatches ${ }^{78}$. Targeting mediated by regions outside the seed sequence has also been reported, but this is uncommon ${ }^{79,80}$.

Immunoprecipitation of AGO proteins and identification of co-precipitating mRNAs by RNA sequencing showed that miRNA recognition sites are mainly located in the 3'-UTR of the target genes ${ }^{81}$. After being processed from the primary hairpin structure and RISC loading, the miRNAs pair with the 3'-UTR of mRNAs to control expression of the target mRNA via different mechanisms ${ }^{82}$ (Figure 3). MiRNAs may also act at the level of transcriptional regulation ${ }^{83-87}$ (Figure 3). These mechanisms are summarized in Table 2.

Individual miRNAs may exert their function by targeting multiple genes. In silico analysis showed that functionally related genes are enriched among the targets of some miRNAs ${ }^{88-90}$. For instance, genes involved in growth control are enriched in the predicted targets of $m i R$ 17 92 cluster miRNAs ${ }^{91}$. Among those are several genes of the TGF- $\beta$ signaling pathway (including TGF- $\beta$ receptor II, Smad2, Smad6, Smad7, and SARA), SOCS genes (SOCS1, SOCS3, SOCS5, and SOCS6), p130, and PTEN ${ }^{91}$.

Table 2. Proposed mechanisms of miRNA action

\begin{tabular}{|c|c|c|c|}
\hline & Mechanism & Additional comments & Reference \\
\hline I & $\begin{array}{l}\text { Inhibition of } \\
\text { translation } \\
\text { initiation }\end{array}$ & $\begin{array}{l}\text { Inhibition of Cap-40S ribosomoal subunit } \\
\text { association, inhibition of ribosomal } 60 \mathrm{~S} \\
\text { and } 40 \mathrm{~S} \text { subunits joining }\end{array}$ & $\begin{array}{l}\text { (Pillai et al., 2005) } \\
\text { (Chendrimada et al., } \\
\text { 2007) }\end{array}$ \\
\hline II & $\begin{array}{l}\text { Inhibition of } \\
\text { translation } \\
\text { elongation }\end{array}$ & & $\begin{array}{l}\text { (Olsen and Ambros, } \\
\text { 1999) (Petersen et al., } \\
\text { 2006) }\end{array}$ \\
\hline III & $\begin{array}{l}\text { Pre-mature } \\
\text { termination of } \\
\text { translation }\end{array}$ & Causing ribosomal drop-off & $\begin{array}{l}\text { (Petersen et al., 2006) } \\
\text { (Wang et al., 2006) }\end{array}$ \\
\hline IV & $\begin{array}{l}\text { Co-translational } \\
\text { protein degradation }\end{array}$ & & $\begin{array}{l}\text { (Nottrott et al., 2006) } \\
\text { (Petersen et al., 2006) }\end{array}$ \\
\hline $\mathrm{V}$ & $\begin{array}{l}\text { Sequestration of the } \\
\text { target mRNA }\end{array}$ & $\begin{array}{l}\text { Sequestration into different structures } \\
\text { in the cytoplasm including processing } \\
\text { (p)-bodies and stress-granules, where the } \\
\text { translational machinery is absent and } \\
\text { degradation enzymes are enriched }\end{array}$ & $\begin{array}{l}\text { (Pillai et al., 2005) } \\
\text { (Sen and Blau, 2005) }\end{array}$ \\
\hline VI & $\begin{array}{l}\text { Destabilization of } \\
\text { mRNA }\end{array}$ & Leading to its complete degradation & $\begin{array}{l}\text { (Bagga et al., 2005) } \\
\text { (Coller and Parker, } \\
\text { 2004) (Guo et al., 2010a) }\end{array}$ \\
\hline VII & $\begin{array}{l}\text { Transcriptional } \\
\text { regulation }\end{array}$ & $\begin{array}{l}\text { Chromatin modifications at target } \\
\text { promoters, important for cellular } \\
\text { senescence and differentiation }\end{array}$ & $\begin{array}{l}\text { (Kim et al., 2008) } \\
\text { (Khraiwesh et al., 2010) } \\
\text { (Benhamed et al., 2012) } \\
\text { (Ketting, 2011) } \\
\text { (Zardo et al., 2012) }\end{array}$ \\
\hline
\end{tabular}


The expression level of a miRNA is critical for its activity on the target mRNA. Using synthetic miRNA target sites cloned downstream of a reporter gene as miRNA activity sensor, the level of target repression in response to different miRNA expression levels was investigated ${ }^{92,93}$. These studies demonstrated that miRNAs expressed below $\sim 100$ copies per cell have little regulatory capacity and only the most abundant miRNAs mediate target suppression ${ }^{92,93}$ (Figure 4A). Likewise, when the target mRNAs are expressed below a threshold level, protein production is highly repressed by miRNA activity. However, once the target mRNA levels pass this threshold, miRNAs cannot repress the translation efficiently ${ }^{94}$ (Figure 4B). Different mRNA targets having binding sites for the same miRNA may compete for the miRNA (Ebert et al., 2007) (Figure 4C). Also, an mRNA may be targeted by multiple miRNAs. Together, the level of miRNA, the number of miRNAs bound to a target, the level of the target mRNA of interest and the level of competing mRNAs are important parameters determining the miRNA activity on a given mRNA target.

A)
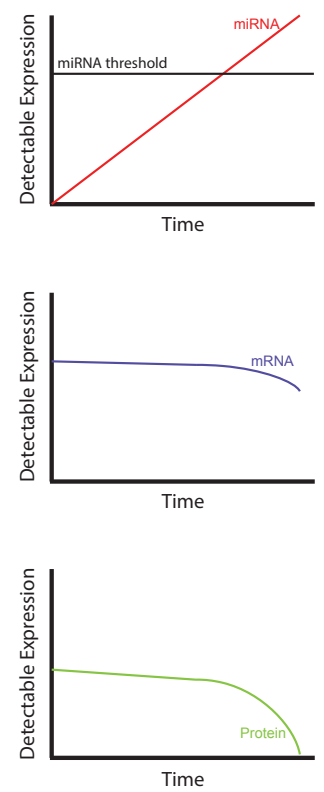

B)
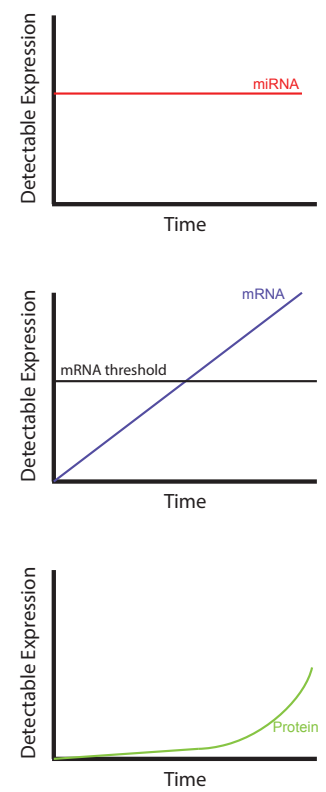

C)
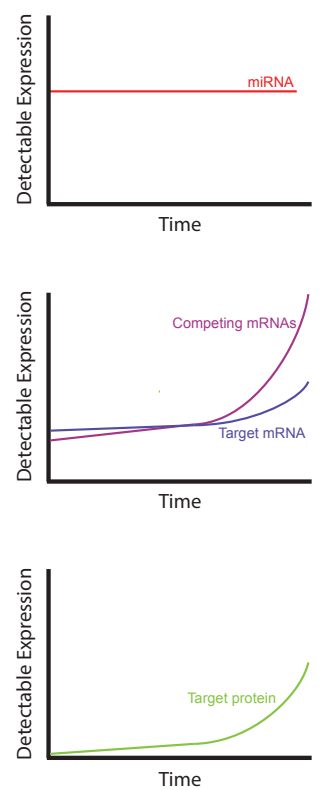

Figure 4. Expression levels of miRNA, target mRNA and target mimics mRNAs affect miRNA activity. The protein output of an mRNA is dependent on the expression level of both miRNA and the mRNA target, as well as the level of the other competing target mRNAs. A) MiRNAs expressed below a threshold ( 100 molecules per cell) have little regulatory capacity and only the most abundant miRNAs mediate target suppression. B) When a particular mRNA target level exceeds the maximum quantity that can be repressed by miRNA, translation of mRNA target is not anymore inhibited by the miRNA. C) Expression of a target mRNA is not regulated anymore by a miRNA when the levels of other mRNAs targeted by the same miRNA (competing mRNAs) are increased. Figure is adapted from Leung and Sharp ${ }^{141}$. 


\section{MIRNAS IN HEMATOPOIETIC STEM AND PROGENITOR CELLS}

To investigate the role of miRNAs in the development and function of different hematopoietic cell populations, miRNAs have been depleted in different experimental models. As introduced earlier in this chapter, Dicerl is essential for normal development and its deletion results in an early embryonic lethality. To bypass this and to enable investigation of miRNA functions in adult tissues in mice, a floxed Dicerl allele $\left(\right.$ Dicer $\left.^{f l}\right)$ has been generated that allows conditional deletion of Dicer1 in a cell type- and developmental stage- specific fashion ${ }^{95}$. To address the role of miRNAs in the development and function of hematopoietic cells, different hematopoietic cell specific Cre transgenic strains have been crossed with Dicerl floxed mice. For instance, by using an Mx-Cre mouse model, floxed Dicerl alleles are efficiently deleted in HSCs by poly I:C injection. Dicer1 ablation in BM HSCs in this mouse model, results in depletion of all miRNAs ${ }^{96}$. This, results in a rapid induction of apoptosis and consequently causes total disruption of hematopoiesis, mainly due to the lack of $m i R-125 a$, and thereby de-repression of the proapoptotic gene BAK $1{ }^{96}$.

What is the role of Dicerl in myelopoiesis? We addressed this question in chapter 3 by conditional deletion of Dicerl in myeloid progenitors in mice. Furthermore, different hematopoietic cell specific Dicerl deletion mouse models are reviewed in chapter 4 . In addition, we discuss what we have learned from these models about miRNAcontrolled pathways in hematopoiesis.

Using computational approaches, cell specific sets of miRNAs and their putative targets that show an inverse pattern of expression have been identified for different subsets of HSCs and myeloid progenitors ${ }^{97,98}$. For instance, 25 miRNAs are expressed at significantly higher level in mouse BM HSCs as compared to more differentiated progenitor populations such as CMP, GMP and MEP ${ }^{97}$. In total, 115 target genes with one or more binding sites for these miRNAs show an inverse pattern of expression with their targeting miRNAs. The network composed of miRNA targets in HSCs is enriched for genes involved in hematological malignancies, cellto-cell signaling, inflammatory response, hematopoiesis and blood cell function ${ }^{97}$.

Other studies focused on the functions of individual miRNAs in HSCs. For example, $m i R$ 142-3p expressed in HSCs maintains the population of HSCs in the aorta-gonad-mesonephros (AGM) region, one of the regions in embryonic mesoderm in which definitive HSCs are formed ${ }^{99,100}$. Mechanistically, miR-142a-3p regulates HSC formation and differentiation through the repression of Interferon regulatory factor-7 (IRF7)-mediated inflammation signaling ${ }^{99}$. Another example is $m i R-29 a$, which is highly expressed in HSCs and downregulated in MPPs and in differentiated myeloid cells. MiR-29 promotes self-renewal and blocks the transition of MPPs towards CMPs ${ }^{101}$. Together, these findings indicate that some miRNAs are critical for cell survival and functions of HSPCs. 


\section{MIRNA CONTROLLED MYELOID DIFFERENTIATION}

Myelopoiesis is mainly driven by transcription factors such as CCAAT enhanced-binding protein alpha (C/EBPa) and Spleen focus forming virus proviral integration oncogene (SPI, also known as PU.1). These transcription factors activate essential genes for proper expansion and maturation of precursor cells ${ }^{102}$. Several miRNA-encoding genes are activated by these transcription factors.

The transcription factor $\mathrm{C} / \mathrm{EBPa}$ is critical for granulopoiesis ${ }^{103,104}$. C/EBPa is expressed at very low level in HSCs, but its expression increases in a small fraction of MPPs and is strongly induced during the transition from CMP toward GMP ${ }^{105-107}$. C/EBPa promotes myeloid differentiation of MPPs by activating myeloid-specific genes and suppressing a gene expression program that drives lymphoid differentiation ${ }^{107}$. Deletion of C/ebp $\alpha$ in HSCs results in an accumulation of myeloid progenitors because it blocks CMP to GMP transition ${ }^{104}$. C/EBPa regulates multiple miRNAs, including $m i R-223, m i R-27$ and $m i R-$ $34 a$. For instance, $\mathrm{C} / \mathrm{EBPa}$ directly binds to the promoter of $m i R-223$ and activates its expression ${ }^{108}$. This finding is consistent with studies reporting a myeloid specific expression of $m i R-223$ that follows the expression pattern of $\mathrm{C} / \mathrm{EBPa}{ }^{109}$. The transcription factor Nuclear factor I/A (NFIA) competes with C/EBPa for binding to the miR-223 promoter ${ }^{108}$. NFIA represses the expression of $m i R-223$. Interestingly, NFIA itself is a target of $m i R-223{ }^{108}$. During the granulocytic differentiation, C/EBPa induces miR-223 expression, which leads to the repression of NFIA, resulting in a feed-forward loop ${ }^{108}$. Inhibition of NFIA is a critical step in myeloid differentiation ${ }^{108}$. In addition, $m i R-223$ targets the cell cycle regulator E2F1, whose repression blocks cell cycle progression and contributes to differentiation ${ }^{110}$ (Figure 5). Altogether, these data suggest that C/EBPa-mediated miR-223 expression may play critical roles in granulopoiesis. However, genetic deletion of $m i R-223$ in mice did not result in a block of granulocytic differentiation ${ }^{111}$. Conversely, miR-223-deficient mice have an increased number of circulating neutrophils resulting from an enhanced differentiation and proliferation of the granulocyte progenitor pool ${ }^{111}$. MEF2C, a transcription factor that promotes myeloid progenitor proliferation, is a bona fide target of $m i R-223^{111}$. Interestingly, genetic ablation of $M e f 2 c$ suppresses progenitor expansion and corrects the neutrophilic phenotype in $m i R-223$ null mice ${ }^{111}$. This demonstrates that although $m i R-223$ is dispensable for granulopoiesis, it is essential for normal neutrophil maturation and controls the number of granulocytes ${ }^{111}$.

$\mathrm{C} / \mathrm{EBP} \alpha$ also induces the expression of $m i R-27$ that targets the transcription factor RUNX1, a potent repressor of G-CSF receptor expression and granulocytic differentiation ${ }^{112}$. Finally, C/EBPa induces the transcription of $m i R-34 a$, which represses E2F3. The E2F3 repression is a pivotal step in the induction of granulopoiesis ${ }^{113}$ (Figure 5). Thus, C/EBPa up-regulated miRNAs control the switch of a progenitor cell state towards a differentiation program that is needed for granulocytic development. 


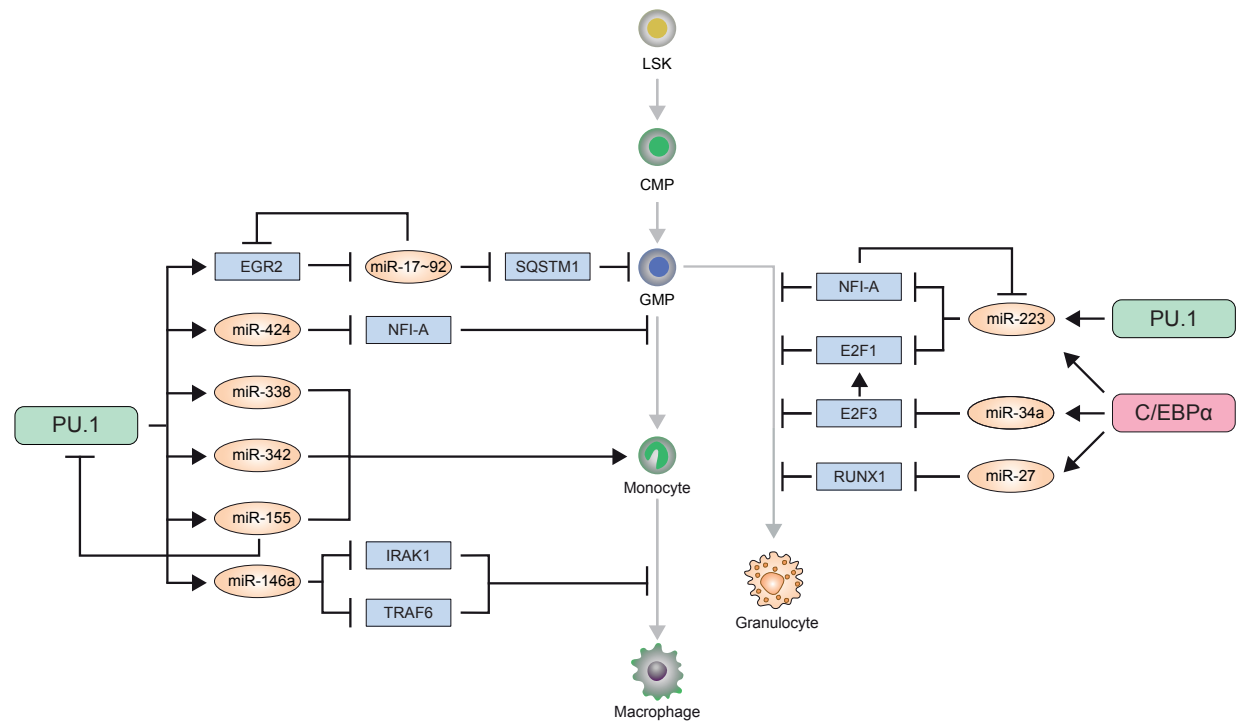

Figure 5. C/EBP $\alpha$ - and PU.1-regulated miRNAs in myelopoiesis. PU.1 regulates transcription of $m i R-424, m i R-146 a, m i R-342, m i R-338$ and $m i R-155$ in monocyte/macrophage development. PU.1 also induces EGR2 expression, which in turn causes epigenetic silencing of the miR-17 92 promoter. Both, C/EBP $\alpha$ and PU.1 enhance the expression of $m i R-223$, an important miRNA for the control of progenitor expansion and granulocytic functions. Finally, the C/EBPa controlled transcriptions of $m i R-34 a$ and $m i R-27$, repressing E2F family of proteins and RUNX1 respectively, which are together pivotal for the induction of granulopoiesis.

In the studies described in this thesis, we used the Cebpa-Cre mice ${ }^{107}$. Cebpa promoter-driven CRE recombinase, allowed us to delete our gene of interest specifically in myeloid committed progenitors, among all different populations of HSPCs. In chapter 3, we used this model to delete Dicer1 in myeloid progenitors. In chapter 4 , we generated myeloid specific conditional Dicer1; $p 53$ deleted strains, which were used for transplantation experiments to assess the role of Dicer1 in leukemia development. Finally, in chapter 5, to investigate whether enhanced expression of miR-199a promotes myeloid leukemia, we overexpressed miR-199a in Cebpa fl/Cre HSPCs and investigated their leukemogenic potential in transplantation experiments. The Cre enzyme recombines the floxed Cebpa allele, resulting in loss of Cebpa mainly in myeloid precursors, which leads to a differentiation block at CMP level.

The transcription factor PU.1 is another pivotal regulator of myelopoiesis. PU.1 regulates the expansion of myeloid progenitors, induces myeloid differentiation by repression of 
miR-17 92 cluster of miRNAs ${ }^{114,115}$, and controls macrophage development, mainly via inducing the transcription of $m i R-146 a, m i R-342, m i R-338$ and $m i R-155^{114}$ (Figure 5).

PU.1 controlled miRNAs are summarized in chapter 2. Moreover, we discuss how

PU.1 and miRNAs interact to regulate myelopoiesis.

Together, regulatory circuits generated by transcription factors and miRNAs allow for a tight control of myeloid development. Aberrant expression of any of these key components may ultimately lead to pathological conditions, including hematopoietic disorders and myeloid malignancies.

\section{MIRNAS IN MALIGNANT MYELOPOIESIS}

Like in most types of human cancer, miRNAs are aberrantly expressed in AML ${ }^{38,116,117}$. Similar to gene expression profiles, which allow classification of AML ${ }^{118,119}$, miRNA-expression signatures also define different subtypes of AML ${ }^{116,120-123}$. Unsupervised miRNA expression analysis reveals distinctive miRNA signatures that correlate with cytogenetic and molecular subtypes of AML, such as the translocation involving chromosomes 8 and $21(\mathrm{t}(8 ; 21)), \mathrm{t}(15 ; 17)$, inversion of chromosome 16 (inv.(16)), and NPM1 and CEBPA mutations ${ }^{116}$. Intriguingly, miRNA expression signatures could predict cytogenetically normal AML with mutations in the genes encoding NPM1, C/EBPa and FLT3-ITD with similar accuracy as mRNA probe set combinations defined by gene expression profiling ${ }^{116}$. As expected from the above described observations, patterns of miRNA expression provide useful information for AML classification and prognosis ${ }^{116,117,120,121,124,125}$. For instance, high $m i R-212$ expression levels are significantly associated with a prolonged overall- , event-free- and relapse-free survival of AML patients, independent from other known prognostic factors ${ }^{126}$. In a different study, AML patients with high expression of $m i R-199 a$ and $m i R-191$ were found to have significant shorter overall- and event-free survival ${ }^{121}$. These data suggest an important role for miRNAs in the pathophysiology of AML.

There are strong indications that the deregulated expression of miRNAs plays a role in leukemogenesis. Several aberrantly expressed miRNAs in hematological malignancies show oncogenic activities in experimental models. For example, a subset of AML and MDS patients carrying the translocation $\mathrm{t}(2 ; 11)(\mathrm{p} 21 ; \mathrm{q} 23)$ or $\mathrm{t}(15 ; 17)(\mathrm{q} 22 ; \mathrm{q} 21)$, or megakaryoblastic leukemia patients with trisomy 21(Down syndrome) show a 6-90-fold increased miR-125 expression compared with AML cases lacking these translocations ${ }^{116,127,128}$. Enhanced miR-125 expression in mouse HSPCs caused an enhanced expansion of white blood cells, myeloproliferative disorder, lymphoid leukemia and AML, phenotypes which were largely dependent on the level of $m i R-125$ overexpression ${ }^{128-132}$. 
Enhanced miR-125 expression in HSPCs have been investigated in different studies and, surprisingly, caused different hematopoietic phenotypes, including an enhanced expansion of white blood cells, myeloproliferative disorder, lymphoid leukemia or AML. In chapter 2 we review these studies and discuss the networks regulated by $m i R-125$ in normal and malignant myelopoiesis. Furthermore, we discuss the contradictory and confusing observations in relation to the experimental models used.

Global depletion of miRNAs is found in human cancer including different types of leukemia ${ }^{133}$. These data suggest that DICER1 may be a tumor suppressor. Indeed, investigation of the role of Dicerl in human cancer development in immune-deficient mice indicated that Dicerl is a haploinsufficient tumor suppressor ${ }^{134}$. Deletion of a single copy of Dicer1 in a genetically engineered mouse model of K-Ras driven lung cancer, led to reduced survival compared with controls ${ }^{134}$. These tumors exhibited impaired miRNA processing but failed to lose the wild-type (wt) Dicerl allele. Consistent with selection against full loss of Dicer1, enforced homozygous deletion of Dicer1, although tolerated, strongly reduced cell proliferation capacity of the tumor cells ${ }^{134}$. In agreement, heterozygous deletion of Dicer1, but not its complete loss, accelerated tumor formation in a mouse model of retinoblastoma ${ }^{135}$.

In chapter 4 , we investigate a role for Dicer1 in myeloid leukemia by conditional deletion of both Dicerl and the tumor suppressor Trp53 in myeloid-committed progenitors. We show evidence for Dicerl dose-dependent tumor suppressor activity in mouse leukemia and discuss the role for DICER1 in AML.

\section{MIRNAS IN STRESS CONDITIONS}

Following stress conditions and genetic perturbations, cells try to restore homeostasis. The stress response decision is mediated by multiple mechanisms such as rapid clearance of the damaged macromolecules ${ }^{136}$, growth arrest ${ }^{137}$, reprogrammed gene expression patterns to cope with the new situation ${ }^{138}$, or activation of programmed cell death mechanisms when cell damages is excessive ${ }^{139}$. Because miRNAs are potent regulators of gene expression, they contribute significantly to the establishment of the stress responses ${ }^{140-142}$.

The functions of miRNAs are modified under stress conditions. Emerging data indicate that stress conditions influence miRNA activities at four different levels:

I) MiRNA expression: Stress conditions can alter the biogenesis of miRNAs by affecting their transcription, their processing by DROSHA and DICER1 or their stability (Figure 6A). 
A)

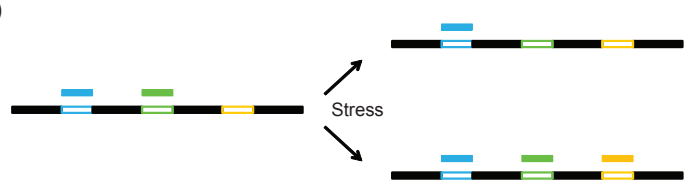

B)
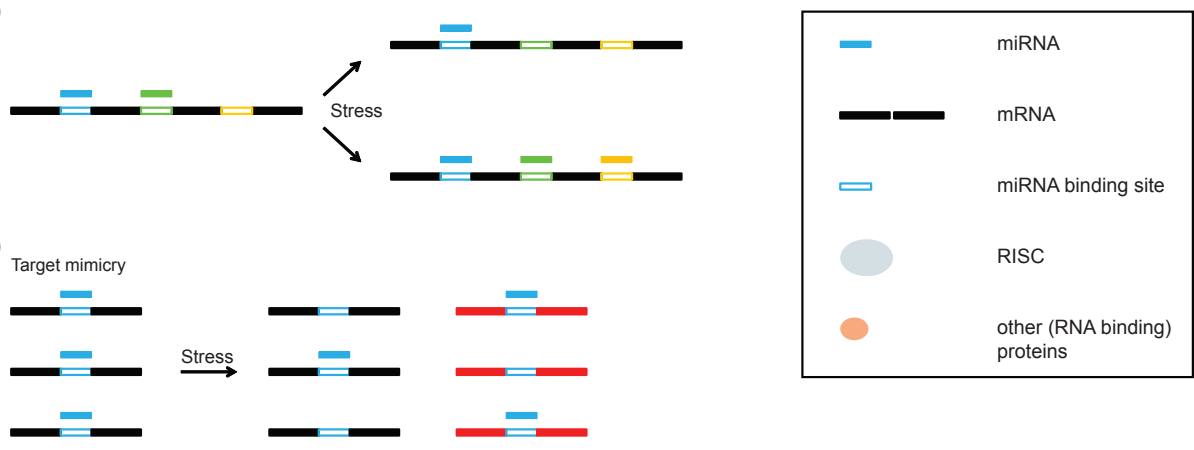

Deletion of miRNA binding site

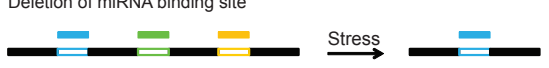

Occupation of binding site by

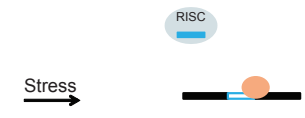

C)

Delocalization of RISC complex

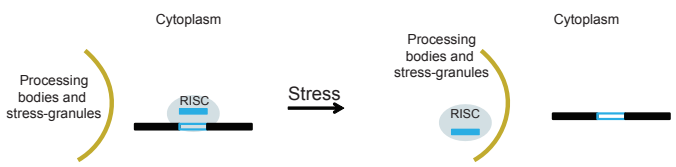

Activation/repression by modification or association with other cofactors

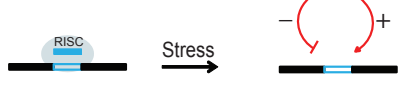

D)
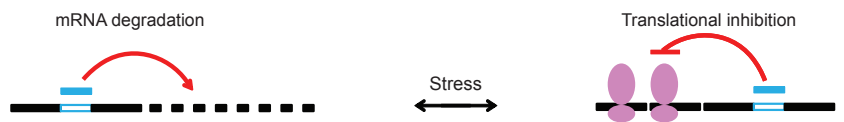

Figure 6. Stress conditions modify miRNA activity. The miRNA function can be modulated at multiple levels: (A) by changing the level of mature miRNAs, (B) modification of the availability of the target mRNA, (C) modification of RISC complex, and (D) a switch in the mode of miRNA action. A) Modification of expression level of miRNAs: An mRNA target containing binding sites for three different miRNAs (blue, green and orange) is depicted. In a non-stressed condition, the target is 
For instance, p53, induced upon DNA damage, upregulates the expression of several miRNAs at the transcription or the processing levels ${ }^{143,144}$.

II) Expression level and accessibility of target mRNA: The modification of the expression levels of mRNA targets and the accessibility of the miRNA binding sites in the 3'-UTR region of a target mRNA, for example via an alternative splicing and polyadenylation, may change the target selection of miRNAs ${ }^{145}$ (Figure 6B). Furthermore, RNA Binding Proteins (RBPs) bound nearby miRNA binding sites on the same mRNA target, may hamper the binding of miRNAs and thereby relieve the repression caused by miRNAs (Figure 6B). Intriguingly, AU-rich elements (AREs), which are binding sites for at least of 20 different RBPs, e.g. HuR and $\mathrm{HuD}$, are enriched near miRNA binding sites ${ }^{146,147}$, raising the possibility that differential activity of these RBPs under stress condition changes the availability of the miRNA binding site and thereby interact with the activity of miRNAs.

III) RISC stability and localization: The activity of miRNAs could be changed upon stress, via destabilization and relocalization of the RISC complex caused by post-translational modifications of RISC components ${ }^{148}$ (Figure 6C). For instance, hydroxylation of AGO2 upon hypoxia increases the stability of RISC ${ }^{149}$. Also, phosphorylation of AGO2 by MAPKactivated protein kinase-2 (MAPKAPK2) in response to the activation of the p38 MAPK pathway, facilitates the localization of miRNA-loaded RISC and the target mRNA into different structures in the cytoplasm including processing (p)-bodies and stress-granules, where the translational machinery is absent and degradation enzymes are enriched ${ }^{150}$.

IV) MiRNA mode of action: Stress can alter the mode of action of RISC, from acceleration of mRNA decay to translational inhibition, or vice versa ${ }^{151}$ (Figure 6D). The consequences of these two modes of action for mRNA targets are different because the degradation of mRNA is an irreversible process.

repressed by two different miRNAs (blue and green). Upon stress, the expression of one of miRNAs (green) decreases, resulting in a situation where only one site is bound by miRNA and the level of the mRNA target will increase. Alternatively, when the level of another miRNA (orange) increases, three sites are now bound by miRNAs, resulting in a stronger repression of the target. B) Modification of availability of target mRNA: Due to competition, the expression of mRNA target (black) increases when the expression of another mRNA with binding sites for the same miRNA (red) increases upon stress. Alternatively, upon stress, cells could express different isoforms of the mRNA targets where miRNA binding sites are added or deleted. Finally, RNA-binding proteins interacting with the 3'-UTR of mRNAs, may inhibit the adjacent interaction of miRNAs and prevent mRNA targets from miRNA-controlled repression. C) Modification of RISC complex: A change in the activity of RISC complex upon stress could be caused by differential subcellular localization of the RISC complex, posttranslational modifications of RISC components or direct association with other stress-specific cofactors which hamper or stimulate miRNA activities. D) Switch in the Mode of miRNA action: Stress may alter the balance between mRNA decay and inhibition of translation. Figure is adapted from Leung and Sharp ${ }^{141}$. 
Because miRNAs are potent regulators of gene expression, these precise modifications of miRNA activities determine the specificity and timing of stress responses, which is crucial for regaining homeostasis ${ }^{140}$. However, excessive stress deregulates miRNA expression and activity and hampers the appropriate miRNA-mediated stress response ${ }^{141,142}$. This results in damages in normal physiological processes such as proliferation, differentiation and apoptosis, and thereby contributes to diseases, including cancers ${ }^{141,142}$.

Do miRNAs play a role in the response to ICL DNA damage in hematopoietic cells? This question has been addressed in chapter 5 , where we present evidence for the role of two miRNAs, miR-139-3p and miR-199a-3p, in ICL-induced BMF and its progression towards leukemia. 


\section{REFERENCES}

1. Blank U, Karlsson G, Karlsson S. Signaling pathways governing stem-cell fate. Blood. 2008;111(2):492-503.

2. Reya T, Morrison SJ, Clarke MF, Weissman IL. Stem cells, cancer, and cancer stem cells. Nature. 2001;414(6859):105-111.

3. Ogawa M. Differentiation and proliferation of hematopoietic stem cells. Blood. 1993;81(11):2844-2853.

4. Morrison SJ, Wandycz AM, Hemmati HD, Wright DE, Weissman IL. Identification of a lineage of multipotent hematopoietic progenitors. Development. 1997;124(10):1929-1939.

5. Bagby GC, Meyers G. Bone marrow failure as a risk factor for clonal evolution: prospects for leukemia prevention. Hematology Am Soc Hematol Educ Program. 2007:40-46.

6. Shimamura A, Alter BP. Pathophysiology and management of inherited bone marrow failure syndromes. Blood Rev. 2010;24(3):101-122.

7. Lowenberg B, Downing JR, Burnett A. Acute myeloid leukemia. $N$ Engl J Med. 1999;341(14):1051-1062.

8. SEER. Surveillance Epidemiology and End Results cancer statistic review. Vol. 2014: National Cancer Institute; 2011.

9. Crossan GP, Patel KJ. The Fanconi anaemia pathway orchestrates incisions at sites of crosslinked DNA. J Pathol.2012;226(2):326337.

10. Bogliolo M, Schuster B, Stoepker C, et al. Mutations in ERCC4, encoding the DNArepair endonuclease XPF, cause Fanconi anemia. Am J Hum Genet. 2013;92(5):800-806.

11. Kashiyama K, Nakazawa Y, Pilz DT, et al. Malfunction of nuclease ERCC1-XPF results in diverse clinical manifestations and causes Cockayne syndrome, xeroderma pigmentosum, and Fanconi anemia. Am J Hum Genet. 2013;92(5):807-819.

12. Kim H, D'Andrea AD. Regulation of DNA cross-link repair by the Fanconi anemia/BRCA pathway. Genes Dev. 2012;26(13):1393-1408.
13. Otsuki T, Wang J, Demuth I, Digweed M, Liu JM. Assessment of mitomycin C sensitivity in Fanconi anemia complementation group $\mathrm{C}$ gene (Fac) knock-out mouse cells. Int J Hematol. 1998;67(3):243-248.

14. Prasher JM, Lalai AS, HeijmansAntonissen C, et al. Reduced hematopoietic reserves in DNA interstrand crosslink repair-deficient Erccl-/- mice. EMBO J. 2005;24(4):861-871.

15. Weeda G, Donker I, de Wit J, et al. Disruption of mouse ERCC1 results in a novel repair syndrome with growth failure, nuclear abnormalities and senescence. Curr Biol. 1997;7(6):427-439.

16. Auerbach AD. Fanconi anemia and its diagnosis. Mutat Res. 2009;668(1-2):4-10.

17. Kutler DI, Singh B, Satagopan J, et al. A 20-year perspective on the International Fanconi Anemia Registry (IFAR). Blood. 2003;101(4):1249-1256.

18. Rosenberg PS, Greene MH, Alter BP. Cancer incidence in persons with Fanconi anemia. Blood. 2003;101(3):822-826.

19. Langmuir PB, Aplenc R, Lange BJ. Acute myeloid leukaemia in children. Best Pract Res Clin Haematol. 2001;14(1):77-93.

20. Doulatov S, Notta F, Laurenti E, Dick JE. Hematopoiesis: a human perspective. Cell Stem Cell. 2012;10(2):120-136.

21. Garaycoechea JI, Crossan GP, Langevin F, Daly M, Arends MJ, Patel KJ. Genotoxic consequences of endogenous aldehydes on mouse haematopoietic stem cell function. Nature. 2012;489(7417):571-575

22. Gates KS. An Overview of Chemical Processes That Damage Cellular DNA: Spontaneous Hydrolysis, Alkylation, and Reactions with Radicals. Chemical Research in Toxicology. 2009;22(11):1747-1760.

23. Niedernhofer LJ. DNA repair is crucial for maintaining hematopoietic stem cell function. DNA Repair. 2008;7(3):523-529.

24. Rossi DJ, Bryder D, Seita J, Nussenzweig A, Hoeijmakers J, Weissman IL. Deficiencies in DNA damage repair limit the function of 
haematopoietic stem cells with age. Nature. 2007;447(7145):725-729.

25. Hoeijmakers JH. Genome maintenance mechanisms for preventing cancer. Nature. 2001;411(6835):366-374

26. Deans AJ, West SC. DNA interstrand crosslink repair and cancer. Nat Rev Cancer. 2011;11(7):467-480.

27. Kim H, Yang K, Dejsuphong D, D’Andrea AD. Regulation of Revl by the Fanconi anemia core complex. Nat Struct Mol Biol. 2012;19(2):164-170.

28. Meetei AR, de Winter JP, Medhurst AL, et al. A novel ubiquitin ligase is deficient in Fanconi anemia. Nat Genet. 2003;35(2):165170.

29. Garcia-Higuera I, Taniguchi T, Ganesan $S$, et al. Interaction of the Fanconi anemia proteins and BRCA1 in a common pathway. Mol Cell. 2001;7(2):249-262.

30. Smogorzewska A, Matsuoka S, Vinciguerra $\mathrm{P}$, et al. Identification of the FANCI protein, a monoubiquitinated FANCD2 paralog required for DNA repair. Cell. 2007;129(2):289-301.

31. Hodskinson MR, Silhan J, Crossan GP, et al. Mouse SLX4 is a tumor suppressor that stimulates the activity of the nuclease XPFERCC1 in DNA crosslink repair. Mol Cell. 2014;54(3):472-484.

32. Klein Douwel D, Boonen RA, Long DT, et al. XPF-ERCC1 acts in Unhooking DNA interstrand crosslinks in cooperation with FANCD2 and FANCP/SLX4. Mol Cell. 2014;54(3):460-471.

33. Ikeda H, Matsushita M, Waisfisz Q, et al. Genetic reversion in an acute myelogenous leukemia cell line from a Fanconi anemia patient with biallelic mutations in BRCA2. Cancer Res. 2003;63(10):2688-2694.

34. Quentin S, Cuccuini W, Ceccaldi R, et al. Myelodysplasia and leukemia of Fanconi anemia are associated with a specific pattern of genomic abnormalities that includes cryptic RUNX1/AML1 lesions. Blood. 2011;117(15):e161-170.

35. Ceccaldi R, Parmar K, Mouly E, et al. Bone marrow failure in Fanconi anemia is triggered by an exacerbated p53/p21 DNA damage response that impairs hematopoietic stem and progenitor cells. Cell Stem Cell. 2012;11(1):36-49.

36. Ceccaldi R, Briot D, Larghero J, et al. Spontaneous abrogation of the G2 DNA damage checkpoint has clinical benefits but promotes leukemogenesis in Fanconi anemia patients. The Journal of Clinical Investigation. 2011;121(1):184-194.

37. Li J, Sejas DP, Zhang X, et al. TNF- $\alpha$ induces leukemic clonal evolution ex vivo in Fanconi anemia group $\mathrm{C}$ murine stem cells. The Journal of Clinical Investigation. 2007;117(11):3283-3295.

38. Carninci P, Kasukawa T, Katayama S, et al. The transcriptional landscape of the mammalian genome. Science. 2005;309(5740):1559-1563

39. Cech Thomas R, Steitz Joan A. The Noncoding RNA Revolution-Trashing Old Rules to Forge New Ones. Cell. 2014;157(1):77-94.

40. Bartel DP. MicroRNAs: genomics, biogenesis, mechanism, and function. Cell. 2004;116(2):281-297.

41. Ambros V. A hierarchy of regulatory genes controls a larva-to-adult developmental switch in C. elegans. Cell. 1989;57(1):49-57.

42. Wightman B, Ha I, Ruvkun G. Posttranscriptional regulation of the heterochronic gene lin-14 by lin- 4 mediates temporal pattern formation in C. elegans. Cell. 1993;75(5):855-862.

43. Murchison EP, Hannon GJ. miRNAs on the move: miRNA biogenesis and the RNAi machinery. Curr Opin Cell Biol. 2004;16(3):223-229.

44. Kozomara A, Griffiths-Jones S. miRBase: annotating high confidence microRNAs using deep sequencing data. Nucleic Acids Research. 2014;42(D1):D68-D73.

45. Landgraf P, Rusu M, Sheridan R, et al. A mammalian microRNA expression atlas based on small RNA library sequencing. Cell. 2007;129(7):1401-1414.

46. Ibanez-Ventoso C, Vora M, Driscoll $M$. Sequence relationships among C. elegans, 
D. melanogaster and human microRNAs highlight the extensive conservation of microRNAs in biology. PLoS One. 2008;3(7):e2818.

47. MeunierJ,LemoineF,SoumillonM,etal.Birth and expression evolution of mammalian microRNA genes. Genome Research. 2013;23(1):34-45.

48. Lim LP, Lau NC, Weinstein EG, et al. The microRNAs of Caenorhabditis elegans. Genes Dev. 2003;17(8):991-1008.

49. Lagos-Quintana M, Rauhut R, Lendeckel W, Tuschl T. Identification of novel genes coding for small expressed RNAs. Science. 2001;294(5543):853-858.

50. LauNC,LimLP, WeinsteinEG,BartelDP.An abundant class of tiny RNAs with probable regulatory roles in Caenorhabditis elegans. Science. 2001;294(5543):858-862.

51. LeeRC,AmbrosV.Anextensiveclass of small RNAs in Caenorhabditis elegans. Science. 2001;294(5543):862-864.

52. Chiang HR, Schoenfeld LW, Ruby JG, et al. Mammalian microRNAs: experimental evaluation of novel and previously annotated genes. Genes Dev. 2010;24(10):992-1009.

53. Concepcion CP, Bonetti C, Ventura A. The microRNA-17-92 family of microRNA clusters in development and disease. Cancer J. 2012;18(3):262-267.

54. Houbaviy HB, Dennis L, Jaenisch R, Sharp PA. Characterization of a highly variable eutherian microRNA gene. RNA. 2005;11(8):1245-1257.

55. LeeY,KimM,HanJ,etal.MicroRNAgenesare transcribed by RNA polymerase II. EMBO J. 2004;23(20):4051-4060.

56. Borchert GM, Lanier W, Davidson BL. RNA polymerase III transcribes human microRNAs. 2006;13(12):1097-1101.

57. KimVN,HanJ,SiomiMC.Biogenesisofsmall RNAs in animals. Nat Rev Mol Cell Biol. 2009;10(2):126-139.

58. Lee Y, Ahn C, Han J, et al. The nuclear RNase III Drosha initiates microRNA processing. Nature. 2003;425(6956):415-419.
59. Yi R, Qin Y, Macara IG, Cullen BR. Exportin-5 mediates the nuclear export of pre-microRNAs and short hairpin RNAs. Genes Dev. 2003;17(24):3011-3016.

60. LeeY,JeonK,LeeJT,KimS,KimVN.MicroRNA maturation: stepwise processing and subcellular localization. $E M B O \quad J$. 2002;21(17):4663-4670.

61. CarmellMA,Hannon GJ.RNaseIIIenzymes and the initiation of gene silencing. Nat Struct Mol Biol. 2004;11(3):214-218.

62. Dlakic M.DUF283 domain of Dicer proteins has a double-stranded RNA-binding fold. Bioinformatics. 2006;22(22):2711-2714.

63. LauPW,GuileyKZ,DeN,PotterCS,Carragher B, Macrae IJ. The molecular architecture of human Dicer. Nat Struct Mol Biol. 2012.

64. Qin H, Chen F, Huan X, Machida S, Song J, Yuan YA. Structure of the Arabidopsis thaliana DCL4 DUF283 domain reveals a noncanonical double-stranded RNAbinding fold for protein-protein interaction. RNA. 2010;16(3):474-481.

65. BernsteinE,CaudyAA,HammondSM,Hannon GJ. Role for a bidentate ribonuclease in the initiation step of RNA interference. Nature. 2001;409(6818):363-366.

66. ReinhartBJ,WeinsteinEG,RhoadesMW,Bartel B, Bartel DP. MicroRNAs in plants. Genes Dev. 2002;16(13):1616-1626.

67. WienholdsE,KoudijsMJ,vanEedenFJ,Cuppen E, Plasterk RH. The microRNA-producing enzyme Dicerl is essential for zebrafish development. Nat Genet. 2003;35(3):217218.

68. BernsteinE, KimSY,CarmellMA, etal.Dicer is essential for mouse development. Nat Genet. 2003;35(3):215-217.

69. Calabrese JM, Seila AC, Yeo GW, Sharp PA. RNA sequence analysis defines Dicer's role in mouse embryonic stem cells. Proc Natl Acad Sci U S A. 2007;104(46):18097-18102.

70. Kanellopoulou C, Muljo SA, Kung AL, et al. Dicer-deficient mouse embryonic stem cells are defective in differentiation and centromeric silencing. Genes Dev. 2005;19(4):489-501. 
71. Murchison EP, Partridge JF, Tam OH, Cheloufi S, Hannon GJ. Characterization of Dicer-deficient murine embryonic stem cells. Proc Natl Acad Sci U S A. 2005;102(34):12135-12140.

72. Mourelatos Z, Dostie J, Paushkin S, et al. miRNPs: a novel class of ribonucleoproteins containing numerous microRNAs. Genes Dev. 2002;16(6):720-728.

73. Khvorova A, Reynolds A, Jayasena SD. Functional siRNAs and miRNAs exhibit strand bias. Cell. 2003;115(2):209-216.

74. Schwarz DS, Hutvagner G, Du T, Xu Z, Aronin N, Zamore PD. Asymmetry in the assembly of the RNAi enzyme complex. Cell. 2003;115(2):199-208.

75. Hutvagner G, Zamore PD. A microRNA in a multiple-turnover RNAi enzyme complex. Science. 2002;297(5589):2056-2060.

76. Lai EC. Micro RNAs are complementary to 3' UTR sequence motifs that mediate negative post-transcriptional regulation. Nat Genet. 2002;30(4):363-364.

77. Doench JG, Sharp PA. Specificity of microRNA target selection in translational repression. Genes Dev. 2004;18(5):504-511.

78. Yekta S, Shih IH, Bartel DP. MicroRNAdirected cleavage of HOXB8 mRNA. Science. 2004;304(5670):594-596.

79. Shin C, Nam JW, Farh KK, Chiang HR, Shkumatava A, Bartel DP. Expanding the microRNA targeting code: functional sites with centered pairing. Mol Cell. 2010;38(6):789-802.

80. Lal A, Navarro F, Maher CA, et al. miR-24 Inhibits cell proliferation by targeting E2F2, MYC, and other cell-cycle genes via binding to "seedless" 3'UTR microRNA recognition elements. Mol Cell. 2009;35(5):610-625.

81. Beitzinger M, Peters L, Zhu JY, Kremmer E, Meister G. Identification of Human microRNA Targets From Isolated Argonaute Protein Complexes. rnabiology. 2007;4(2):76-84.

82. Morozova N, Zinovyev A, Nonne N, Pritchard LL, Gorban AN, Harel-Bellan A.
Kinetic signatures of microRNA modes of action. RNA. 2012;18(9):1635-1655.

83. Benhamed M, Herbig U, Ye T, Dejean A, Bischof O. Senescence is an endogenous trigger for microRNA-directed transcriptional gene silencing in human cells. Nat Cell Biol. 2012;14(3):266-275.

84. Ketting RF. The many faces of RNAi. Dev Cell. 2011;20(2):148-161.

85. Khraiwesh B, Arif MA, Seumel GI, et al. Transcriptional Control of Gene Expression by MicroRNAs. Cell. 2010;140(1):111-122.

86. Kim DH, Saetrom P, Snove O, Jr., Rossi JJ. MicroRNA-directed transcriptional gene silencing in mammalian cells. Proc Nat Acad Sci U S A. 2008;105(42):16230-16235.

87. Zardo G, Ciolfi A, Vian L, et al. Polycombs and microRNA-223 regulate human granulopoiesis by transcriptional control of target gene expression. Blood. 2012;119(17):4034-4046.

88. Krek A, Grun D, Poy MN, et al. Combinatorial microRNA target predictions. Nat Genet. 2005;37(5):495-500.

89. Grun D, Wang YL, Langenberger D, Gunsalus KC, Rajewsky N. microRNA target predictions across seven Drosophila species and comparison to mammalian targets. PLoS Comput Biol. 2005;1(1):e13.

90. Tsang JS, Ebert MS, van Oudenaarden A. Genome-wide dissection of microRNA functions and cotargeting networks using gene set signatures. MolCell.2010;38(1):140 153.

91. Lewis BP, Burge CB, Bartel DP. Conserved seed pairing, often flanked by adenosines, indicates that thousands of human genes are microRNA targets. Cell. 2005;120(1):1520.

92. Brown BD, Gentner B, Cantore A, et al. Endogenous microRNA can be broadly exploited to regulate transgene expression according to tissue, lineage and differentiation state. Nat Biotechnol. 2007;25(12):1457-1467.

93. Mullokandov G, Baccarini A, Ruzo A, et al. High-throughput assessment of microRNA 
activity and function using microRNA sensor and decoy libraries. Nat Methods. 2012;9(8):840-846.

94. Mukherji S, Ebert MS, Zheng GX, Tsang JS, Sharp PA, van Oudenaarden A. MicroRNAs can generate thresholds in target gene expression. Nat Genet. 2011;43(9):854-859.

95. Harfe BD, McManus MT, Mansfield JH, Hornstein E, Tabin CJ. The RNaseIII enzyme Dicer is required for morphogenesis but not patterning of the vertebrate limb. Proc Natl Acad Sci U S A. 2005;102(31):10898-10903.

96. Guo S, Lu J, Schlanger R, et al. MicroRNA miR-125a controls hematopoietic stem cell number. Proc Natl Acad Sci U S A. 2010;107(32):14229-14234.

97. Heiser D, Tan YS, Kaplan I, et al. Correlated miR-mRNA Expression Signatures of Mouse Hematopoietic Stem and Progenitor Cell Subsets Predict "Stemness" and "Myeloid" Interaction Networks. PLoS One. 2014;9(4):e94852.

98. Raghavachari N, Liu P, Barb JJ, et al. Integrated analysis of miRNA and mRNA during differentiation of human CD34+ cells delineates the regulatory roles of microRNA in hematopoiesis. Exp Hematol. 2014;42(1):14-27 e11-12.

99. Lu X, Li X, He Q, et al. miR-142-3p regulates the formation and differentiation of hematopoietic stem cells in vertebrates. Cell Research. 2013;23(12):1356-1368.

100. Medvinsky A, Dzierzak E. Definitive hematopoiesis is autonomously initiated by the AGM region. Cell. 1996;86(6):897-906.

101. Han YC, Park CY, Bhagat G, et al. microRNA-29a induces aberrant selfrenewal capacity in hematopoietic progenitors, biased myeloid development, and acute myeloid leukemia. J Exp Med. 2010;207(3):475-489.

102. Rosenbauer F, Tenen DG. Transcription factors in myeloid development: balancing differentiation with transformation. Nat Rev Immunol. 2007;7(2):105-117.
103. Radomska HS, Huettner CS, Zhang P, Cheng T, Scadden DT, Tenen DG. CCAAT/ enhancer binding protein alpha is a regulatory switch sufficient for induction of granulocytic development from bipotential myeloid progenitors. Mol Cell Biol. 1998;18(7):4301-4314.

104.Zhang P, Iwasaki-Arai J, Iwasaki H, et al. Enhancement of hematopoietic stem cell repopulating capacity and self-renewal in the absence of the transcription factor $\mathrm{C} /$ EBP alpha. Immunity. 2004;21(6):853-863.

105. Akashi K, Traver D, Miyamoto T, Weissman IL. A clonogenic common myeloid progenitor that gives rise to all myeloid lineages. Nature. 2000;404(6774):193-197.

106. Traver D, Miyamoto T, Christensen J, Iwasaki-Arai J, Akashi K, Weissman IL. Fetal liver myelopoiesis occurs through distinct, prospectively isolatable progenitor subsets. Vol. 98; 2001.

107. Wolfler A, Danen-van Oorschot AA, Haanstra JR, et al. Lineage-instructive function of C/EBPalpha in multipotent hematopoietic cells and early thymic progenitors. Blood. 2010;116(20):4116-4125.

108. Fazi F, Rosa A, Fatica A, et al. A minicircuitry comprised of microRNA-223 and transcription factors NFI-A and C/ EBPalpha regulates human granulopoiesis. Cell. 2005;123(5):819-831.

109. Fukao T, Fukuda Y, Kiga K, et al. An evolutionarily conserved mechanism for microRNA-223 expression revealed by microRNA gene profiling. Cell. 2007;129(3):617-631

110. Pulikkan JA, Dengler V, Peramangalam PS, et al. Cell-cycle regulator E2F1 and microRNA-223 comprise an autoregulatory negative feedback loop in acute myeloid leukemia. Blood. 2010;115(9):1768-1778.

111. Johnnidis JB, Harris MH, Wheeler RT, et al. Regulation of progenitor cell proliferation andgranulocytefunctionbymicroRNA-223. Nature. 2008;451(7182):1125-1129.

112. Feng J, Iwama A, Satake M, Kohu K. MicroRNA-27 enhances differentiation of myeloblasts into granulocytes by post- 
transcriptionally downregulating Runx1. Br J Haematol. 2009;145(3):412-423.

113. PulikkanJA,PeramangalamPS,DenglerV,et al. C/EBPalpha regulated microRNA-34a targets E2F3 during granulopoiesis and is down-regulated in AML with CEBPA mutations. Blood. 2010;116(25):5638-5649.

114. GhaniS,RiemkeP,SchonheitJ,etal.Macrophage development from HSCs requires PU.1coordinated microRNA expression. Blood. 2011;118(8):2275-2284.

115. PospisilV,VargovaK,KokavecJ,etal.Epigenetic silencing of the oncogenic miR-17-92 cluster during PU.1-directed macrophage differentiation. EMBO J. 2011;30(21):44504464.

116. Jongen-LavrencicM,SunSM,DijkstraMK,Valk PJ, Lowenberg B. MicroRNA expression profiling in relation to the genetic heterogeneity of acute myeloid leukemia. Blood. 2008;111(10):5078-5085.

117. Marcucci G, Mrozek K, Radmacher MD, Garzon R, Bloomfield CD. The prognostic and functional role of microRNAs in acute myeloid leukemia. Blood. 2011;117(4):11211129.

118. BullingerL,DohnerK,BairE,etal.Useofgeneexpression profiling to identify prognostic subclasses in adult acute myeloid leukemia. N Engl J Med. 2004;350(16):1605-1616.

119. Valk PJ, Verhaak RG, Beijen MA, et al. Prognostically useful gene-expression profiles in acute myeloid leukemia. $N$ Engl J Med. 2004;350(16):1617-1628.

120. Garzon R, Garofalo M, Martelli MP, et al. Distinctive microRNA signature of acute myeloid leukemia bearing cytoplasmic mutated nucleophosmin. Proc Natl Acad Sci US A. 2008;105(10):3945-3950.

121. Garzon R, VoliniaS, Liu CG, etal. MicroRNA signatures associated with cytogenetics and prognosis in acute myeloid leukemia. Blood. 2008;111(6):3183-3189.

122. Li Z, Lu J, Sun M, et al. Distinct microRNA expression profiles in acute myeloid leukemia with common translocations. Proc
Natl Acad Sci U S A. 2008;105(40):1553515540 .

123. WangY,LiZ,HeC,etal.MicroRNAsexpression signatures are associated with lineage and survival in acute leukemias. Blood Cells $\mathrm{Mol}$ Dis. 2010;44(3):191-197.

124. Calin GA, Croce CM. MicroRNA signatures in human cancers. Nat Rev Cancer. 2006;6(11):857-866.

125. RuckerFG,RussAC,CocciardiS,etal.Altered miRNA and gene expression in acute myeloid leukemia with complex karyotype identify networks of prognostic relevance. Leukemia. 2012.

126. Sun SM, Rockova V, Bullinger L, et al. The prognostic relevance of miR-212 expression with survival in cytogenetically and molecularly heterogeneous AML. Leukemia. 2012.

127. Bousquet M, Quelen C, Rosati R, et al. Myeloid cell differentiation arrest by miR125b-1 in myelodysplastic syndrome and acute myeloid leukemia with the $\mathrm{t}(2 ; 11)$ (p21;q23) translocation. J Exp Med. 2008;205(11):2499-2506.

128. Klusmann JH, Li Z, Bohmer K, et al. miR$125 \mathrm{~b}-2$ is a potential oncomiR on human chromosome 21 in megakaryoblastic leukemia. Genes Dev. 2010;24(5):478-490.

129. Bousquet M, Harris MH, Zhou B, Lodish HF. MicroRNA miR-125b causes leukemia. Proc Natl Acad Sci U S A. 2010;107(50):2155821563.

130. GerritsA,WalasekMA,OlthofS,etal.Genetic screen identifies microRNA cluster 99b/ let-7e/125a as a regulator of primitive hematopoietic cells. Blood. 2012;119(2):377387.

131. O'Connell RM, Chaudhuri AA, Rao DS, Gibson WS, Balazs AB, Baltimore D. MicroRNAs enriched in hematopoietic stem cells differentially regulate long-term hematopoietic output. Proc Natl Acad Sci U S A. 2010;107(32):14235-14240.

132. OoiAG,SahooD,AdornoM,WangY,Weissman IL, Park CY. MicroRNA-125b expands hematopoietic stem cells and enriches for 
the lymphoid-balanced and lymphoidbiased subsets. Proc Natl Acad Sci U S A. 2010;107(50):21505-21510.

133. Lu J, Getz G, Miska EA, et al. MicroRNA expression profiles classify human cancers. Nature. 2005;435(7043):834-838.

134. Kumar MS, Pester RE, Chen CY, et al. Dicer1 functions as a haploinsufficient tumor suppressor. Genes Dev. 2009;23(23):27002704.

135. Lambertz I, Nittner D, Mestdagh P, et al. Monoallelic but not biallelic loss of Dicer1 promotes tumorigenesis in vivo. Cell Death Differ. 2010;17(4):633-641.

136. Kroemer G, Marino G, Levine B. Autophagy and the integrated stress response. Mol Cell. 2010;40(2):280-293.

137. Hoffman B, Liebermann DA. Gadd45 modulation of intrinsic and extrinsic stress responses in myeloid cells. Journal of Cellular Physiology. 2009;218(1):26-31.

138. Spriggs KA, Bushell M, Willis AE. Translational regulation of gene expression during conditions of cell stress. Mol Cell. 2010;40(2):228-237.

139. Kültz D. MOLECULAR AND EVOLUTIONARY BASIS OF THE CELLULAR STRESS RESPONSE. Annual Review of Physiology. 2005;67(1):225-257.

140. Ebert MS, Sharp PA. Roles for microRNAs in conferring robustness to biological processes. Cell. 2012;149(3):515-524.

141. Leung AK, Sharp PA. MicroRNA functions in stress responses. MolCell.2010;40(2):205215.

142. Mendell JT, Olson EN. MicroRNAs in stress signaling and human disease. Cell. 2012;148(6):1172-1187.

143. He L, He X, Lim LP, et al. A microRNA component of the p53 tumour suppressor network. Nature. 2007;447(7148):11301134.

144. Suzuki HI, Yamagata K, Sugimoto K, Iwamoto T, KatoS, Miyazono K. Modulation of microRNA processing by p53. Nature. 2009;460(7254):529-533.

145. Elkon R, Ugalde AP, Agami R. Alternative cleavage and polyadenylation: extent, regulation and function. Nat Rev Genet. 2013;14(7):496-506.

146. Jacobsen A, Wen J, Marks DS, Krogh A. Signatures of RNA binding proteins globally coupled to effective microRNA target sites. Genome Res. 2010;20(8):10101019.

147. Barreau C, Paillard L, Osborne HB. AUrich elements and associated factors: are there unifying principles? Nucleic Acids Research. 2005;33(22):7138-7150.

148. Heo I, Kim VN. Regulating the regulators: posttranslational modifications of RNA silencing factors. Cell. 2009;139(1):28-31.

149. Qi HH, Ongusaha PP, Myllyharju J, et al. Prolyl 4-hydroxylation regulates Argonaute 2 stability. Nature. 2008;455(7211):421-424.

150.Zeng Y, Sankala H, Zhang X, Graves PR. Phosphorylation of Argonaute 2 at serine-387 facilitates its localization to processing bodies. Biochem J. 2008;413(3):429-436.

151. Holtz J, Pasquinelli AE. Uncoupling of lin-14 mRNA and protein repression by nutrient deprivation in Caenorhabditis elegans. RNA. 2009;15(3):400-405.

152. Marcucci G, Haferlach T, Dohner H. Molecular genetics of adult acute myeloid leukemia: prognostic and therapeutic implications. J Clin Oncol. 2011;29(5):475486.

153. Mrozek K, Heerema NA, Bloomfield CD. Cytogenetics in acute leukemia. Blood Rev. 2004;18(2):115-136.

154. Takahashi S. Current findings for recurring mutations in acute myeloid leukemia. $J$ Hematol Oncol. 2011;4:36.

155. Walker A, Marcucci G. Molecular prognostic factors in cytogenetically normal acute myeloid leukemia. Expert Rev Hematol. 2012;5(5):547-558. 


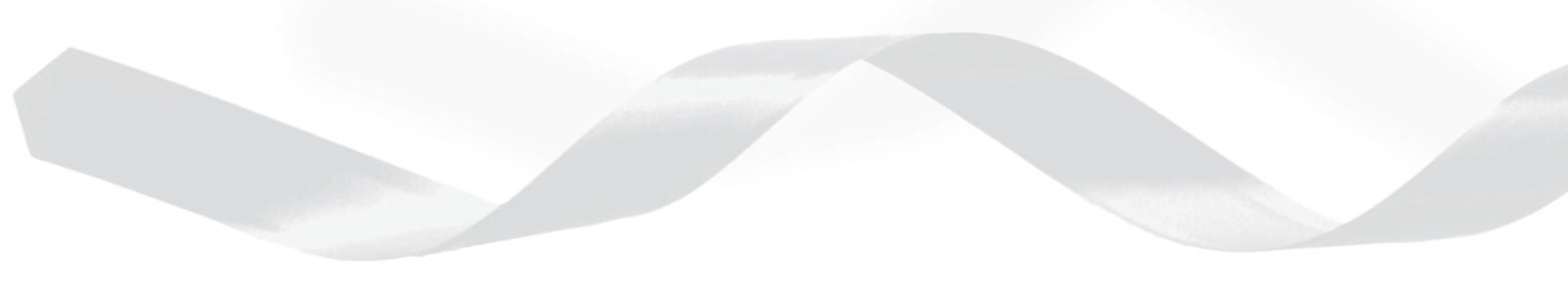




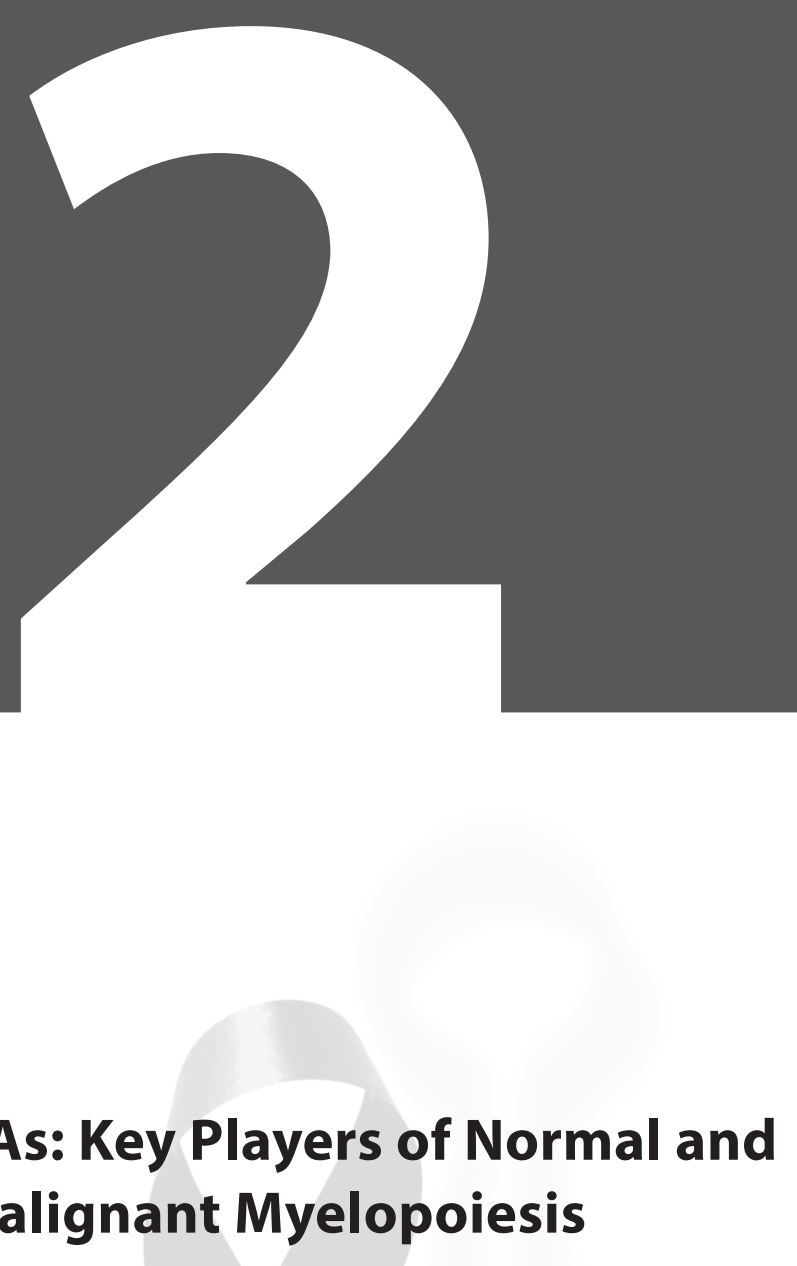

\section{MicroRNAs: Key Players of Normal and Malignant Myelopoiesis}

Mir Farshid Alemdehy and Stefan J. Erkeland

Department of Hematology, Erasmus University Medical Center, Rotterdam, the Netherlands

Current Opinion in Hematology. 2012; 19(4):261-7 


\section{ABSTRACT}

Purpose of the review: Recent data show that microRNAs (miRNAs) play critical roles in the regulation of the developmental process of hematopoietic stem and progenitor cells toward mature myeloid cells. The main focus of the article is the function of some evolutionary conserved miRNAs that are abundantly expressed and tightly regulated during myelopoiesis.

Recent findings: Global miRNA depletion studies in hematopoietic stem cells have shown the importance of miRNA-controlled pathways for hematopoiesis. Recent insights from genetic mouse models and overexpression or deletion of miRNAs in developmental cell intermediates demonstrate strong evidence for evolutionary conserved miRNAregulated pathways involved in tight control of cellular processes such as proliferation, differentiation and apoptosis at different stages of blood cell development. It is becoming evident that the myeloid transcription factor PU.1 regulates the expression of critical miRNAs including miR-17 92 and miR-146a during myelopoiesis. Furthermore, there is evidence for the contribution of aberrant miR-125 activities in hematopoietic disorders including myeloid leukemia.

Summary: Despite the large number of articles describing differential miRNA expression during hematopoiesis, miRNA functions and their downstream pathways in myeloid lineage decisions and leukemia are only recently emerging. Here we discuss new findings concerning PU.1-controlled miRNAs and miR-125-regulated networks in normal and malignant myelopoiesis. 


\section{INTRODUCTION}

MicroRNAs (miRNAs) are 19-23 nucleotide RNA molecules and belong to a class of small single-stranded noncoding RNAs. They arise from primary sequences of various sizes (pri-miRNAs) that are further processed by two RNase III endoribonucleases DROSHA and DICER1. MiRNAs are loaded into the RNA-induced silencing complex (RISC) and bind to complementary sequences of target mRNAs that are predominantly located in the 3'-untranslated regions and regulate gene expression by transcript destabilization and inhibition of protein translation. As other transcripts, the expression of miRNAs is regulated at different levels. For instance, the transcription of miRNA genes is controlled by transcription factors, such as E2F, c-MYC, hematopoietic transcription factor spleen focus forming virus proviral integration oncogene (SPI1 or PU.1) and CCAAT/enhancer binding-protein alpha $(\mathrm{CEBP} \alpha)^{1-4}$. Recently, multiple factors have been identified that posttranscriptionally regulate miRNA biogenesis, such as Argonaute-2 (AGO-2) ${ }^{5}$, arsenic resistance protein-2 (ARS2) ${ }^{6}$, monocyte chemoattractant protein 1-induced protein-1 (MCP1P1) ${ }^{7}$, and LIN28 and its cofactors Musashi-1 (MSI1) and uridylyltransferase-4 (TUT4) ${ }^{8,9}$.

There is mounting evidence that miRNAs are potent regulators of hematopoiesis ${ }^{10}$. First, miRNA expression profiling studies showed dynamic expression of miRNAs during blood cell development, strongly suggesting that miRNAs play critical roles during this process ${ }^{11,12}$ (for review ${ }^{13}$ ). Second, the importance of miRNAs for normal hematopoiesis has been demonstrated by targeted disruption of miRNA biogenesis in mice. For example, hematopoietic stem cells (HSCs) are impaired by loss of Dicerl and these miRNA-depleted HSCs are unable to reconstitute hematopoiesis in mice ${ }^{14}$. In addition, conditional deletion of Ago-2, a factor that is critical for miRNA functions, results in impaired differentiation of B-lymphocytes and erythroid cells ${ }^{15}$. Also, hematopoietic lineage-specific conditional deletion of Dicer1 has revealed the involvement of miRNAs in the survival, maturation and homeostasis of peripheral T-lymphocytes, and antibody diversity and survival of B-lymphocytes ${ }^{16-18}$. Third, several studies demonstrate an interplay of miRNAs and transcription factors, such as the critical regulators of hematopoiesis CEBP $\alpha$ and transcription factor PU. ${ }^{2,4}$. Fourth, forced expression of miRNAs such as miRs-17/20/93/106 promotes expansion of hematopoietic stem and progenitor cells (HSPCs) in mice ${ }^{19}$. Finally, genetic ablation of individual miRNAs such as miR-223 and miR-146 in HSCs causes hematopoietic phenotypes ${ }^{20-22}$. Different functions of miRNAs in normal and malignant hematopoiesis have been described previously and have recently been reviewed ${ }^{23-27}$. Here, we discuss new insights concerning a set of miRNAs including PU.1-controlled miRNAs and miR-125, of which extensive knowledge has been gained in the past year. These miRNAs are abundantly expressed at different stages of myelopoiesis and are aberrantly expressed in malignant hematopoiesis. Furthermore, we will shed a light on some contradictory and confusing observations in relation to the experimental models used. 


\section{PU.1 UPREGULATED MIRNAS}

The transcription factor PU.1 is a pivotal regulator of hematopoiesis. PU.1 inhibits GATA1 activity, which shifts the cellular differentiation program from erythroid toward myeloidlymphoid lineages ${ }^{28}$. In human myeloid leukemia and promyelocytic cell line NB4, miR-424 has been reported as a direct PU.1 target and regulates tetradecanoylphorbol-13-acetate (TPA)-induced monocytic differentiation by repressing the critical transcription factor nuclear factor I-A (NFI-A) and thereby activating differentiation-specific genes such as colony stimulating factor 1 receptor (CSF1R or M-CSFR) ${ }^{4}$. Human $m i R-424$ is not conserved in mice but belongs to a family of miRNAs that consist of $m i R-15 / 16 / 195 / 322 / 424 / 497 / 1907$. Using a mouse hematopoietic PU.1 knockout (K.O.) cell line derived from PU.1 K.O. fetal livers and transduced with tamoxifen-inducible PU.1 expression constructs, Ghani et al., identified a list of 20 PU.1-regulated miRNAs of which 10 miRNAs were downregulated and 10 upregulated ${ }^{29}$. Strikingly, none of the miR-15/16/195/322/424/497/1907 family members were found to be controlled by PU.1, indicating that this pathway is either not conserved between species or is cell type- and differentiation status-dependent. In mouse progenitors only four miRNAs, namely $m i R-146 a, m i R-342, m i R-338$ and $m i R-155$ are directly controlled by PU.1 ${ }^{29}$ (Figure 1). PU.1 permanently regulates the expression of $m i R-146 a, m i R-342$ and $m i R-338$ during differentiation, but only initiates $m i R-155$ expression at the early stage of myeloid development and is not necessary for its maintenance during myelopoiesis ${ }^{29}$. The identification of $m i R-342$ and the PU.1 binding site in its promoter confirmed the previously published data by De Marchis et al. concerning all-trans retinoic acid (ATRA)-mediated differentiation of acute promyelocytic leukemia (APL) cells toward mature granulocytes by De Marchis et al. ${ }^{30}$. Notably, this finding indicates that $m i R-342$ functions are not myeloidlineage restricted. The expression of $m i R-146 a, m i R-342$ and $m i R-338$ steadily increases during myeloid differentiation and is the highest in mature macrophages, whereas $m i R-155$ transiently increases in cell developmental intermediates but decreases during terminal differentiation ${ }^{29}$. Only $m i R-146 a$ and $m i R$-155 are upregulated by PU.1 independently from other cooperative factors ${ }^{29}$. However, these data do not exclude a role for additional factors in fine-tuning of miRNA expression in different cell types.

To further assess the functions of miR-146a in normal myeloid development, Ghani et al. isolated Lineage negative ( $\left.\mathrm{Lin}^{-}\right) \mathrm{Sca}-1^{+} \mathrm{cKit}^{+}$(LSK) cells, infected these cells with retroviruses expressing $m i R-146 a$, transplanted these cells in lethally-irradiated mice and analyzed these mice 6-8 weeks posttransplantation. In contrast to previously published observations at 4 weeks posttransplantation by Starczynowski et al. ${ }^{31}$, Ghani et al. did not observe a transient myeloid expansion ${ }^{29}$. However, this discrepancy can be largely explained by the time point of the phenotypic analysis. Accordingly, Ghani et al. found that enforced miR-146a expression drives differentiation of HSCs into peritoneal macrophages 8 weeks post-transplantation in mice, an important analysis that was omitted by Starczynowski et al. These data largely explain the loss of myeloid cells in the bone marrow, blood and other hematopoietic tissues in both studies. 


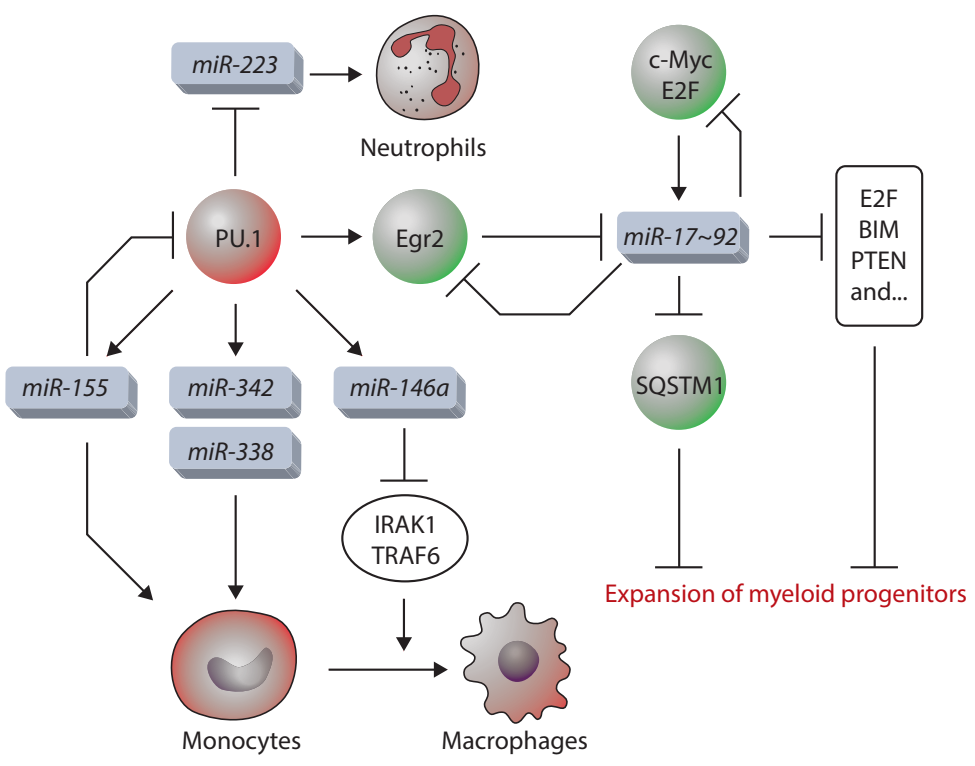

Figure 1. PU.1-regulated miRNAs in myelopoiesis. PU.1 upregulates transcription of miR-146a, $m i R-342$, miR-338 and miR-155, which control macrophage development. PU.1 also controls the expansion of myeloid progenitors by repression of Egr2-mediated transcription of miR-17 92 cluster of miRNAs.

In a further analysis of the role of miR-146a in myelopoiesis, Ghani et al. performed $m i R$ $146 a$ knockdown studies with antisense oligonucleotides and observed a strong reduction of myelopoiesis in zebrafish, indicating that myelopoiesis requires miR-146a activity ${ }^{29}$. Whereas the expression pattern and function of PU.1 and the miR-146a seed sequence is highly conserved between zebrafish and mammals, miR-146a-deficiency in mice results in massive expansion of myeloid cells and causes myeloid malignancies ${ }^{20,22}$. The discrepancy in experimental outcome between mice and fish demonstrates that evolutionary conservation of molecular networks does not exclude differential functions in species. Notably, many regulatory functions of $m i R-146 a$ in inflammatory responses and hematopoietic disorders have been described in the past year and are previously reviewed ${ }^{23,24,32}$.

\section{PU.1 DOWNREGULATED MIRNAS}

Fifty percent of the PU.1-controlled miRNAs identified by Ghani et al. were transcriptionally downregulated and include several members of the $m i R-17 \sim 92$ cluster such as $m i R-20, m i R-19$ and $m i R-92$. Although negatively regulated targets of PU.1 are rarely identified, the authors did not further confirm these potentially interesting PU.1 targets that play important roles at the myeloid progenitor stage. We recently identified miR-17/20/93/106, all AAAGUGC 
seed-containing miRNAs that promote myeloid progenitor expansion by targeting SQSTM1-regulated pathways ${ }^{19}$. Furthermore, Pospidil et al. reported that downregulation of miR-17 92 family of miRNAs is required for PU.1-orchestrated induction of myeloid differentiation ${ }^{33}$. Pospisil et al. used the same PU.1 null model as published by Ghani et al., and this study identified all miRNAs encoded by miR-17 92 and $m i R-106 b \sim 25$ clusters to be indirectly downregulated during PU.1-controlled macrophage development ${ }^{33}$. In their model, PU.1 induces Egr2 expression that is in turn involved in epigenetic silencing of the miR-17 92 promoter during macrophage development ${ }^{33}$. In addition, they found that Egr2 itself is a direct target of $m i R-17 \sim 92$, thereby generating a negative feedback loop of Egr2 in proliferating cells and of miR-17 92 in differentiating cells (Figure 1) ${ }^{33}$. Interestingly, a correlative analysis of gene and miRNA expression data confirmed a direct association of these factors in human leukemia samples in which low Egr2 expression could largely explain the observed overexpression of $m i R-17 \sim 92$ in clinical acute myeloid leukemia (AML) samples ${ }^{33}$. Together, these recent data demonstrate evidence for a model in which PU.1 controls normal and malignant myelopoiesis at least in part by the regulation of critical miRNAs (Figure 1).

\section{MIR-125 IN MYELOPOIESIS}

miR-125 (also known as Lin-4) was first identified in Caenorhabditis elegans and regulates cell fate progression and differentiation by targeting Lin-28 and Lin-14 (for recent review ${ }^{34}$ ). This miRNA is evolutionary conserved and three miR-125 family members located at different loci in the human genome exist in mammals (Figure 2A). Several recent publications show differential expression of $m i R-125$ family members at different stages of myelopoiesis. First, we showed by quantitative PCR that miR-125b is highly expressed in human myeloblasts and promyelocytes isolated from the bone marrow (BM) and is strongly downregulated in metamyelocytes and mature neutrophils, whereas $m i R-125 a$ expression remains similar during differentiation ${ }^{35}$. In addition, others showed that in long-term HSCs the endogenous $m i R-125 a / b$ expression is high but decreases rapidly at the progenitor state ${ }^{14,36-38}$. Next, Surdziel et al. reported that $m i R-125 b$ expression, but not $m i R-125 a$, is enhanced (6-fold) during long-term granulocyte colony-stimulating factor (G-CSF) stimulation of the murine myeloid progenitor cell line 32 $\mathrm{D}^{39}$. Last, Monk et al. demonstrated that miR-125a is strongly induced in BM-derived monocytes in response to Candida albicans and lipopolysaccharide (LPS) ${ }^{40}$, whereas in macrophages total $m i R-125$ levels are downregulated in response to LPS in a protein kinase B AKT-dependent way ${ }^{41}$. Together, these expression data strongly suggest that $m i R-125$ regulates cellular processes by various mechanisms at different stages of myelopoiesis.

Several recent studies describe cell type and developmental stage specific functions of $m i R-125$. For instance, forced expression of $m i R-125$ in HSCs promotes cell expansion and BM engraftment in mice ${ }^{14,36-39}$, eventually resulting in exhaustion of the HSC compartment as recently reported by Gerrits et al ${ }^{38}$. In transplantation experiments by Surdziel et al., myeloid 
cells of different origin, but not lymphoid cells overexpressing miR-125b, exhibit a competitive growth advantage over non-transduced cells. In full agreement, Gerrits et al. found that miR-125 overexpressing HSPCs exhibit an increased myeloid differentiation in vivo ${ }^{38}$. A most intriguing finding was published by Surdziel et al., in which $m i R-125 b$ overexpression in BMderived HSPCs causes a shift in differentiation of myeloid progenitors toward macrophages in G-CSF-supplemented colony assays ${ }^{39}$. These data indicate that $m i R-125 b$ controls the lineagedecision at the granulocyte-macrophage progenitor stage, however this finding still needs to be confirmed in vivo. The mechanisms behind the observed miR-125-induced myeloid lineage decisions remain elusive. The above described results are in full agreement with data from Klusmann et al. ${ }^{42}$, showing that forced expression of $m i R-125 b$ in HSPCs enhances proliferation and blocks myeloid differentiation of promyelocytes ${ }^{42}$. However, unlike similar effects on proliferation, $m i R-125$ overexpression does not affect the differentiation capacity of megakaryocytic progenitors and megakaryocytic/erythroid progenitors ${ }^{42}$.

\section{MIR-125 TARGETS IN NORMAL HEMATOPOIESIS}

The above discussed studies show some evidence for the downstream targets of $m i R-125$. In the study of Surdziel et al., Bak1, Stat 3 and Stat 3 cofactors C-Jun and Jund are direct targets ${ }^{39}$. However short hairpin RNAs (shRNAs) against these factors could only partially phenocopy $m i R-125$ overexpression, suggesting that other additional repressed targets are involved in the observed phenotype ${ }^{39}$. Klusmann et al. identified Dicerl and the tumor suppressor St18 as direct targets for $m i R-125 b^{42}$. RNA interference (RNAi)-mediated knockdown of these factors does copy the hyperproliferative phenotype of $m i R-125 b$ overexpression in colony forming units megakaryocytic assays ${ }^{42}$, showing the importance of these targets for the phenotype observed. Notably, these targets still remain to be confirmed in vivo. Of the large list of $m i R-125$ predicted targets, only Bakl and $K l f 13$ are verified by different research groups and could be considered as bona fide targets ${ }^{14,38}$. As antiapoptotic events cannot explain all the observed phenotypes, other miR-125-controlled mechanisms remain to be determined to enable full understanding of $m i R-125$ functions in hematopoiesis. However, their identification is currently one of the main challenges in the field. Recently, it has been shown that the repressing activity of miRNAs on a specific target is dependent on the level of the target transcripts, the level of competing sequences, the abundance of the miRNAs and the activity of RNA binding proteins that shield miRNA binding sequences ${ }^{43-45}$. For these reasons, miRNA-overexpression studies may present confusing results caused by an abnormal potency of $m i R-125$ to regulate sets of transcripts that reached aberrant targeting thresholds. RISC cross-linking and immunoprecipitation can be helpful to identify endogenous targets ${ }^{46}$, but these strategies need large number of cells and the final sequence results are difficult to analyze. For detailed investigation of the cellular mechanisms controlled by endogenous miR-125 levels during normal myelopoiesis, cell-type and developmental-stage specific $m i R-125$ family knockout mice are needed. These mouse models will eventually give insights in the molecular pathways controlled by endogenous miR-125 levels. 


\section{MIR-125 IN LEUKEMIA}

Several studies show aberrant expression of $m i R-125$ in hematological disease. For example, miRNA profiling studies show a 6-fold to 90 -fold increased-miR-125 expression in AML and myelodysplastic syndrome (MDS) patients carrying the translocation $\mathrm{t}(2 ; 11)(\mathrm{p} 21 ; \mathrm{q} 23)$ compared with healthy controls and other MDS and AML cases ${ }^{47}$ and a 20 -fold higher expression in AML cases characterized by $\mathrm{t}(15 ; 17)(\mathrm{q} 22 ; \mathrm{q} 21)$ compared with the AML cases lacking this translocation ${ }^{48}$. $m i R-125 b$ is also upregulated 26.4 -fold in leukemic blasts of children with trisomy 21/Down syndrome with megakaryoblastic leukemia and 18.5-fold in transient leukemia compared with normal CD34 ${ }^{+}$HSPCs ${ }^{42}$.

Multiple recent studies addressed the question whether miR-125 plays a role in transformation of normal HSPCs toward leukemia. Lin et al. reported that miR-125 is upregulated by the aberrantly expressed homeobox transcription factor CDX2 in myeloid leukemia ${ }^{49}$. In addition, these authors reported that enhanced mir-125b levels block progenitor cell differentiation, which is a hallmark of leukemia, through repression of the core binding factor ${ }^{49}$. The study of Klusmann et al. also addressed this question. Their data present some evidence that miR-125-mediated repression of Dicerl results in global downregulation of miRNAs and may explain a functional role of miR-125 in human megakaryoblastic leukemia. Furthermore, this study suggests that enhanced miR-125 levels cause expansion of tumorigenic populations of megakaryocytic progenitor cells.

Some other recent reports present strong evidence for a role of $m i R-125$ in oncogenic transformation in mice, although most published data are contradictory for the observed leukemia phenotypes. For instance, a 1000-fold miR-125b overexpression in HSPCs caused an enhanced expansion of white blood cells including myeloid and lymphoid cells and platelets, and a dose-dependent myeloproliferative disorder with progression toward a rapid and lethal myeloid leukemia ${ }^{36}$. However, Ooi et al. found that $m i R-125 b$ overexpression in HSCs using a lentivirus that results in an approximately 35 -fold overexpression of $m i R-125 b$ causes a significant expansion of exclusively early lymphoid progenitors ${ }^{37}$. Interestingly, a small subset of secondary transplanted mice developed a lymphoproliferative disease that is characterized by splenomegaly, abnormal large thymi and expansion of particularly $\mathrm{CD}^{+} \mathrm{T}$ lymphocytes. In the study of Bousquet et al., miR-125b overexpression in fetal liver HSCs increased white blood cell counts and caused macrocytic anemia 16 weeks posttransplantation. In striking contrast with data from Klusmann et al. ${ }^{42}$, no difference in platelet number was observed ${ }^{50}$. Instead, fifty percent of transplanted mice developed different types of leukemia, such as $\mathrm{T}$ cell or B cell acute lymphoblastic leukemia and myeloproliferative neoplasms ${ }^{50}$. These tumors were characterized by particular levels of miR-125b overexpression of 500 -fold, 1000 -fold and up to 1500 -fold, respectively ${ }^{50}$. In agreement, Gerrits et al. reported that mice reconstituted with HSPCs with a 1500 -fold miR-125a overexpression, develop myeloproliferative neoplasms ${ }^{38}$.

How can we explain the phenotypic discrepancies? It is clear that most cell developmental aberrations and leukemic phenotype variations in the studies mentioned are largely dependent 
on the level of $m i R-125$ overexpression. The higher the level of $m i R-125$, the more targets will be considerably repressed by reaching the targeting thresholds, apparently resulting in different types of disease ${ }^{43}$. Also, as suggested by Gerrits et al., the mature forms of $m i R-125 a$ and $m i R-125 b$ share the seed sequence but are different at the 3 '-end, presumably influencing the level of repression of a set of targets. In addition, the genes that are deregulated because of viral insertional mutagenesis, which is largely dependent on the characteristics of the viral miRNA-expression system used, collaborate in oncogenic transformation and may play a role in the different leukemia phenotypes observed ${ }^{51,52}$. Therefore, it would be of interest to investigate whether the tumors are clonal or polyclonal. Also, the investigators used a miRNA-expression system that is either retroviral and can only transduce dividing cells such as progenitors, or lentiviral, which also transduces nondividing cells such as dormant HSCs. For that reason, it is essential to investigate whether transformation occurred in HSCs or in specific progenitor fractions, which is very likely to be different in the studies discussed and may explain the observed phenotypic differences.

\section{CRITICAL MIR-125 TARGETS IN LEUKEMIA}

Despite some evidence for $m i R$-125-regulated transcripts that are involved in miRNA processing or the regulation of apoptosis such as $B A K 1$ and $B M F$, the mechanisms behind cellular transformation are still elusive (Figure $2 \mathrm{~B}$ ). The recently published $m i R-$ 125 -controlled p53 network is a very attractive candidate ${ }^{53}$, however its role in leukemia development is not yet investigated. Strikingly, $m i R-125$ has recently been identified as a tumor suppressor, for instance by regulating the ETS-1 proto oncogene in human breast cancer ${ }^{54}$ and by targeting the oncogene $L I N 28 B$ in human liver cancer ${ }^{55}$. Furthermore, it remains unclear whether the endogenously coexpressed miR-99 and Let-7, both known to exhibit tumor-suppressing activities ${ }^{56,57}$, modulate or even counteract the oncogenic activities of $m i R-125$.

\section{CONCLUSION}

Recent data show that miRNAs are controlled by critical transcription factors such as PU.1 during myelopoiesis. An important question to resolve is whether miRNAs function through repression of a single or a few targets, or via the cumulative impact of repressing large sets of targets. Some studies show evidence for only a few significant targets making dominant contributions to functions of some miRNAs, for example $m i R-150$ and $m i R-155^{58,59}$, but this may be different for other miRNAs or may even be cell type and cell developmental stage dependent. Therefore, tissue and developmental stage-specific mouse models, and experimental target identification approaches are needed for the understanding of miRNA functions. Further investigation of miRNAcontrolled mechanisms may open new possibilities to develop specific therapies for clinical leukemias. 
A)

19q13.14+

miR-125a UCCCUGAGACCCUUUAACCUGUGA

let-7e UGAGGUAGGAGGUUGUAUAGUU

miR-99b CACCCGUAGAACCGACCUUGCG

11q24.1-

miR-125b-1 UCCCUGAGACCCUAACUUGUGA

let-7a-2 UGAGGUAGUAGGUUGUAUAGUU

miR-100 AACCCGUAGAUCCGAACUUGUG

\section{1q21.1+}

miR-125b-2 UCCCUGAGACCCUAACUUGUGA

let-7c UGAGGUAGUAGGUUGUAUGGUU

miR-99a AACCCGUAGAUCCGAUCUUGUG

B)

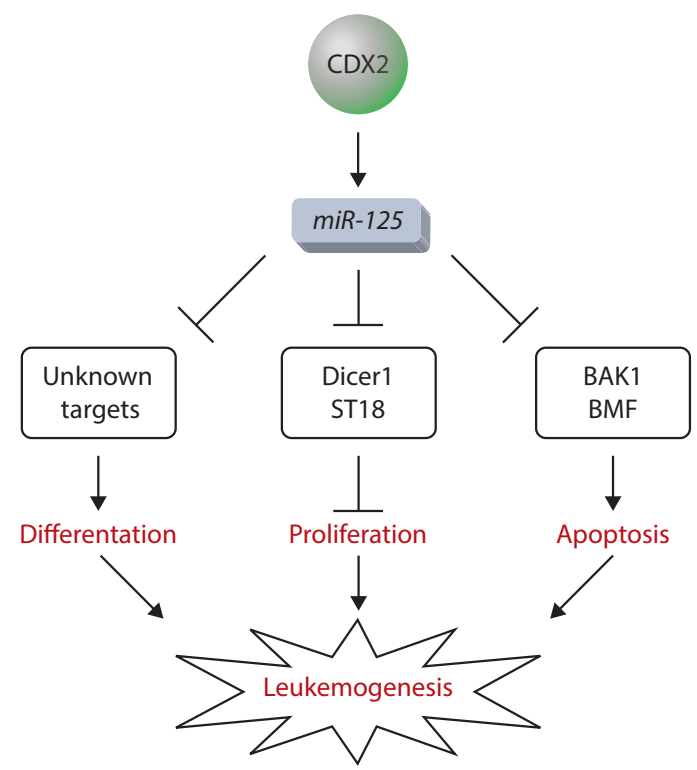

Figure 2. miR-125 network in leukemia. A) Sequence alignments of miRNAs expressed from three miR-125 containing clusters: $m i R-125 a, m i R-125 b-1$ and $m i R-125 b-2$. MiR-125 family members are cotranscribed with the members of Let-7 and miR-99 family of miRNAs. The color code indicates the miRNAs with the same seed sequence. B) A schematic model of miR-125 contribution to leukemogenesis. MiR-125 family members repress genes that mediate apoptosis, inhibit proliferation, and induce differentiation of hematopoietic stem and progenitor cells. 


\section{ACKNOWLEDGEMENTS}

We thank Dr. T Cupedo and Dr. M. Buitenhuis for critical reading of the article and E. Simons for assistance with the preparation of the figures. Our work was supported by grants from the Netherlands Organisation for Scientific Research (NWO-VENI) and the Dutch Cancer Society (KWF). 


\section{REFERENCES}

1. Biyashev D, Qin G. E2F and microRNA regulation of angiogenesis. Am J Cardiovasc Dis. 2011;1(2):110-118.

2. Fazi F, Rosa A, Fatica A, et al. A minicircuitry comprised of microRNA-223 and transcription factors NFI-A and C/ EBPalpha regulates human granulopoiesis. Cell. 2005;123(5):819-831.

3. Lin $\mathrm{CH}$, Jackson AL, Guo J, Linsley PS, Eisenman RN. Myc-regulated microRNAs attenuate embryonic stem cell differentiation. EMBO J. 2009;28(20):31573170 .

4. Rosa A, Ballarino M, Sorrentino A, et al. The interplay between the master transcription factor PU.1 and miR-424 regulates human monocyte/macrophage differentiation. Proc Natl Acad Sci U S A. 2007;104(50):19849-19854.

5. Diederichs $S$, Haber DA. Dual role for argonautes in microRNA processing and posttranscriptional regulation of microRNA expression. Cell. 2007;131(6):1097-1108.

6. Gruber JJ, Zatechka DS, Sabin LR, et al. Ars2 links the nuclear cap-binding complex to RNA interference and cell proliferation. Cell. 2009;138(2):328-339.

7. Suzuki HI, Arase M, Matsuyama H, et al. MCPIP1 Ribonuclease Antagonizes Dicer and Terminates MicroRNA Biogenesis through Precursor MicroRNA Degradation. Mol Cell. 2011;44(3):424-436.

8. Heo I, Joo C, Cho J, Ha M, Han J, Kim VN. Lin28 mediates the terminal uridylation of let-7 precursor MicroRNA. Mol Cell. 2008;32(2):276-284.

9. Heo I, Joo C, Kim YK, et al. TUT4 in concert with Lin28 suppresses microRNA biogenesis through pre-microRNA uridylation. Cell. 2009;138(4):696-708.

10. Havelange V, Garzon R. MicroRNAs: emerging key regulators of hematopoiesis. Am J Hematol. 2010;85(12):935-942.

11. Chen CZ, Li L, Lodish HF, Bartel DP. MicroRNAs modulate hematopoietic lineage differentiation. Science. 2004;303(5654):83-86.

12. Neilson JR, Zheng GX, Burge CB, Sharp PA. Dynamic regulation of miRNA expression in ordered stages of cellular development. Genes Dev. 2007;21(5):578-589.

13. Vasilatou D, Papageorgiou S, Pappa V, Papageorgiou E, Dervenoulas J. The role of microRNAs in normal and malignant hematopoiesis. Eur J Haematol. 2010;84(1):1-16.

14. Guo S, Lu J, Schlanger R, et al. MicroRNA miR-125a controls hematopoietic stem cell number. Proc Natl Acad Sci U S A. 2010;107(32):14229-14234.

15. O'Carroll D, Mecklenbrauker I, Das PP, et al. A Slicer-independent role for Argonaute 2 in hematopoiesis and the microRNA pathway. Genes Dev. 2007;21(16):19992004.

16. Cobb BS, Nesterova TB, Thompson E, et al. $\mathrm{T}$ cell lineage choice and differentiation in the absence of the RNase III enzyme Dicer. J Exp Med. 2005;201(9):1367-1373.

17. Koralov SB, Muljo SA, Galler GR, et al. Dicer ablation affects antibody diversity and cell survival in the B lymphocyte lineage. Cell. 2008;132(5):860-874.

18. Muljo SA, Ansel KM, Kanellopoulou C, Livingston DM, Rao A, Rajewsky K. Aberrant T celldifferentiation in the absence of Dicer. J Exp Med. 2005;202(2):261-269.

19. Meenhuis $A$, van Veelen $P A$, de Looper $H$, et al. MiR-17/20/93/106 promote hematopoietic cell expansion by targeting sequestosome 1-regulated pathways in mice. Blood. 2011;118(4):916-925.

20. Boldin MP, Taganov KD, Rao DS, et al. miR146 a is a significant brake on autoimmunity, myeloproliferation, and cancer in mice. $J$ Exp Med. 2011;208(6):1189-1201.

21. Johnnidis JB, Harris MH, Wheeler RT, et al. Regulation of progenitor cell proliferation andgranulocytefunctionbymicroRNA-223. Nature. 2008;451(7182):1125-1129. 
22. Zhao JL, Rao DS, Boldin MP, Taganov KD, O'Connell RM, Baltimore D. NF-kappaB dysregulation in microRNA-146a-deficient mice drives the development of myeloid malignancies. Proc Natl Acad Sci U S A. 2011;108(22):9184-9189.

23. El Gazzar M, McCall CE. MicroRNAs regulatory networks in myeloid lineage development and differentiation: regulators of the regulators. Immunol Cell Biol. 2011.

24. O'Connell RM, Zhao JL, Rao DS. MicroRNA function in myeloid biology. Blood. 2011;118(11):2960-2969.

25. Turner ML, Schnorfeil FM, Brocker T. MicroRNAs regulate dendritic cell differentiation and function. J Immunol. 2011;187(8):3911-3917.

26. O'Connell RM, Rao DS, Chaudhuri AA, Baltimore D. Physiological and pathological roles for microRNAs in the immune system. Nat Rev Immunol. 2010;10(2):111-122.

27. Bissels U, Bosio A, Wagner W. MicroRNAs are shaping the hematopoietic landscape. Haematologica. 2011.

28. Zhang $\mathrm{P}$, Zhang $\mathrm{X}$, Iwama A, et al. PU.1 inhibits GATA-1 function and erythroid differentiation by blocking GATA-1 DNA binding. Blood. 2000;96(8):2641-2648.

29. Ghani S, Riemke P, Schonheit J, et al. Macrophage development from HSCs requires PU.1-coordinated microRNA expression. Blood. 2011;118(8):2275-2284.

30. De Marchis ML, Ballarino M, Salvatori B, Puzzolo MC, Bozzoni I, Fatica A. A new molecular network comprising PU.1, interferon regulatory factor proteins and miR-342 stimulates ATRA-mediated granulocytic differentiation of acute promyelocytic leukemia cells. Leukemia. 2009;23(5):856-862.

31. Starczynowski DT, Kuchenbauer F, Wegrzyn J, et al. MicroRNA-146a disrupts hematopoietic differentiation and survival. Exp Hematol. 2011;39(2):167-178 e164.

32. Hua Z, Chun W, Fang-Yuan C. MicroRNA$146 \mathrm{a}$ and hemopoietic disorders. Int $J$ Hematol. 2011;94(3):224-229.
33. Pospisil V, Vargova K, Kokavec J, et al. Epigenetic silencing of the oncogenic miR-17-92 cluster during PU.1-directed macrophage differentiation. EMBO J. 2011;30(21):4450-4464.

34. Ambros V. MicroRNAs and developmental timing. Curr Opin GenetDev.2011;21(4):511517.

35. Sun SM, Dijkstra MK, Bijkerk AC, et al. Transition of highly specific microRNA expression patterns in association with discrete maturation stages of human granulopoiesis. $\mathrm{Br} J$ Haematol. 2011;155(3):395-398.

36. O'Connell RM, Chaudhuri AA, Rao DS, Gibson WS, Balazs AB, Baltimore D. MicroRNAs enriched in hematopoietic stem cells differentially regulate long-term hematopoietic output. Proc Natl Acad Sci U S A. 2010;107(32):14235-14240.

37. Ooi AG, Sahoo D, Adorno M, Wang Y, Weissman IL, Park CY. MicroRNA-125b expands hematopoietic stem cells and enriches for the lymphoid-balanced and lymphoid-biased subsets. Proc Natl Acad Sci U S A. 2010;107(50):21505-21510.

38. Gerrits A, Walasek MA, Olthof S, et al. Genetic screen identifies microRNA cluster $99 \mathrm{~b} /$ let-7e/125a as a regulator of primitive hematopoietic cells. Blood. 2011.

39. Surdziel E, Cabanski M, Dallmann I, et al. Enforced expression of miR-125b affects myelopoiesis by targeting multiple signaling pathways. Blood. 2011;117(16):4338-4348.

40. Monk CE, Hutvagner G, Arthur JS. Regulation of miRNA transcription in macrophages in response to Candida albicans. PLoS One. 2010;5(10):e13669.

41. Androulidaki A, Iliopoulos D, Arranz A, et al. The kinase Akt1 controls macrophage response to lipopolysaccharide by regulating microRNAs. Immunity. 2009;31(2):220-231.

42. Klusmann JH, Li Z, Bohmer K, et al. miR$125 \mathrm{~b}-2$ is a potential oncomiR on human chromosome 21 in megakaryoblastic leukemia. Genes Dev. 2010;24(5):478-490. 
43. Mukherji S, Ebert MS, Zheng GX, Tsang JS, Sharp PA, van Oudenaarden A. MicroRNAs can generate thresholds in target gene expression. Nat Genet. 2011;43(9):854-859.

44. van Kouwenhove M, Kedde M, Agami R. MicroRNA regulation by RNA-binding proteins and its implications for cancer. Nat Rev Cancer. 2011;11(9):644-656.

45. Ebert MS, Sharp PA. Emerging roles for natural microRNA sponges. Curr Biol. 2010;20(19):R858-861.

46. Hafner $M$, Landthaler $M$, Burger $L$, et al. Transcriptome-wide identification of RNAbinding protein and microRNA target sites by PAR-CLIP. Cell. 2010;141(1):129-141.

47. Bousquet M, Quelen C, Rosati R, et al. Myeloid cell differentiation arrest by miR$125 \mathrm{~b}-1$ in myelodysplastic syndrome and acute myeloid leukemia with the $t(2 ; 11)$ (p21;q23) translocation. $J$ Exp Med. 2008;205(11):2499-2506.

48. Jongen-Lavrencic M, Sun SM, Dijkstra MK, Valk PJ, Lowenberg B. MicroRNA expression profiling in relation to the genetic heterogeneity of acute myeloid leukemia. Blood. 2008;111(10):5078-5085.

49. Lin KY, Zhang XJ, Feng DD, et al. miR125b, a Target of CDX2, Regulates Cell Differentiation through Repression of the Core Binding Factor in Hematopoietic Malignancies. J Biol Chem. 2011;286(44):38253-38263.

50. Bousquet M, Harris MH, Zhou B, Lodish HF. MicroRNA miR-125b causes leukemia. ProcNatlAcadSciUSA.2010;107(50):2155821563.

51. Schroder AR, Shinn P, Chen H, Berry C, Ecker JR, Bushman F. HIV-1 integration in the human genome favors active genes and local hotspots. Cell. 2002;110(4):521-529.

52. WuX, LiY, CriseB, Burgess SM. Transcription start regions in the human genome are favored targets for MLV integration. Science. 2003;300(5626):1749-1751.

53. Le MT, Shyh-Chang N, Khaw SL, et al. Conserved regulation of p53 network dosage by microRNA-125b occurs through evolving miRNA-target gene pairs. PLoS Genet. 2011;7(9):e1002242.

54. Zhang Y, Yan LX, Wu QN, et al. miR-125b is methylated and functions as a tumor suppressor by regulating the ETS1 protooncogene in human invasive breast cancer. Cancer Res. 2011;71(10):3552-3562.

55. Liang L, Wong CM, Ying Q, et al. MicroRNA-125b suppressesed human liver cancer cell proliferation and metastasis by directly targeting oncogene LIN28B2. Hepatology. 2010;52(5):1731-1740.

56. Boyerinas B, Park SM, Hau A, Murmann $\mathrm{AE}$, Peter ME. The role of let-7 in cell differentiation and cancer. Endocr Relat Cancer. 2010;17(1):F19-36.

57. Sun D, Lee YS, Malhotra A, et al. miR99 family of MicroRNAs suppresses the expression of prostate-specific antigen and prostate cancer cell proliferation. Cancer Res. 2011;71(4):1313-1324.

58. O'Connell RM, Chaudhuri AA, Rao DS, Baltimore D. Inositol phosphatase SHIP1 is a primary target of miR-155. Proc Natl Acad Sci U S A. 2009;106(17):7113-7118.

59. Xiao C, Calado DP, Galler G, et al. MiR-150 controls $\mathrm{B}$ cell differentiation by targeting the transcription factor c-Myb. Cell. 2007;131(1):146-159. 



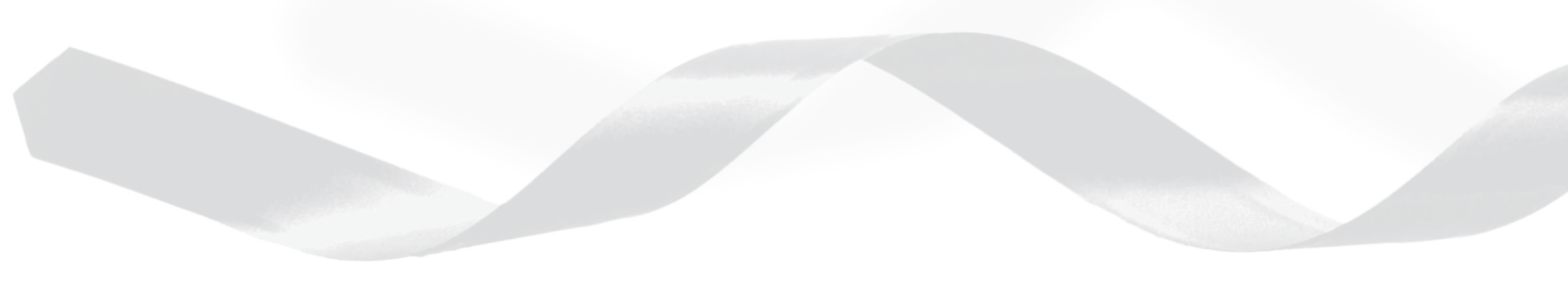




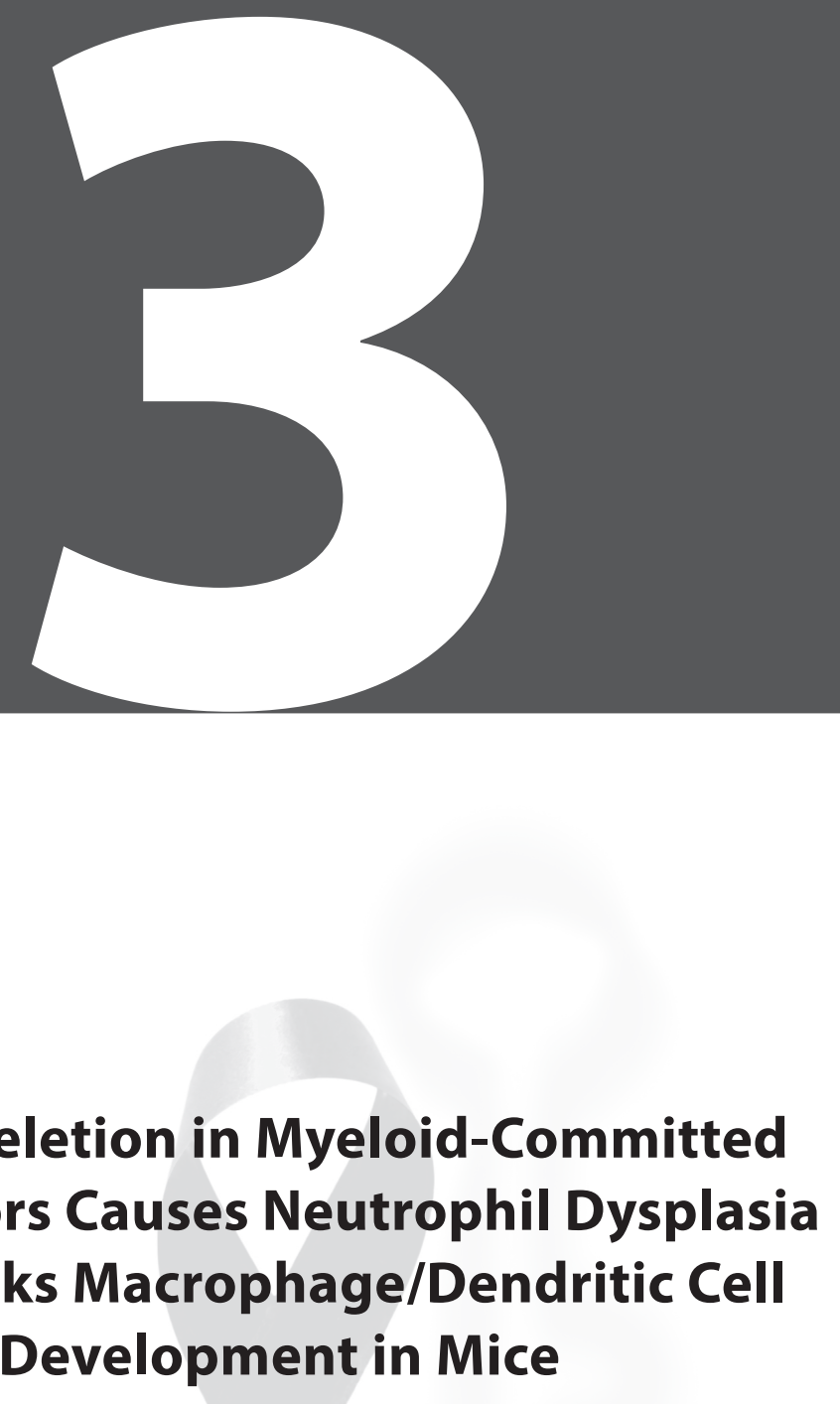

Mir Farshid Alemdehy, Nicole G.J.A. van Boxtel, Hans W.J. de Looper, Iris J. van den Berge, Mathijs A. Sanders, Tom Cupedo, Ivo P. Touw, and Stefan J. Erkeland

Department of Hematology, Erasmus University Medical Center, Rotterdam, the Netherlands Blood. 2012; 119(20):4723-30 


\section{ABSTRACT}

MicroRNAs (miRNAs) have the potential to regulate cellular differentiation programs; however, miRNA deficiency in primary hematopoietic stem cells (HSCs) results in HSC depletion in mice, leaving the question of whether miRNAs play a role in early-lineage decisions unanswered. To address this issue, we deleted Dicerl, which encodes an essential RNase III enzyme for miRNA biogenesis, in murine CCAAT/enhancer-binding protein a (C/EBPA)-positive myeloid-committed progenitors in vivo. In contrast to the results in HSCs, we found that miRNA depletion affected neither the number of myeloid progenitors nor the percentage of C/EBPA-positive progenitor cells. Analysis of gene-expression profiles from wild-type and Dicerl-deficient granulocyte-macrophage progenitors (GMPs) revealed that 20 miRNA families were active in GMPs. Of the derepressed miRNA targets in Dicer1null GMPs, 27\% are normally exclusively expressed in HSCs or are specific for multipotent progenitors and erythropoiesis, indicating an altered gene-expression landscape. Dicer1deficient GMPs were defective in myeloid development in vitro and exhibited an increased replating capacity, indicating the regained self-renewal potential of these cells. In mice, Dicer 1 deletion blocked monocytic differentiation, depleted macrophages, and caused myeloid dysplasia with morphologic features of Pelger-Huët anomaly. These results provide evidence for a miRNA-controlled switch for a cellular program of self-renewal and expansion toward myeloid differentiation in GMPs. 


\section{INTRODUCTION}

Hematopoiesis is a tightly regulated process of proliferation and differentiation of hematopoietic stem and progenitor cells (HSPCs) toward mature blood cells. Lineage commitment and differentiation of HSPCs are orchestrated by transcription factors that are expressed at specific developmental stages. For example, CCAAT/Enhancer-Binding Protein-Alpha (C/EBPA) is a master regulatory transcription factor that is not expressed in hematopoietic stem cells (HSCs), but starts to be expressed in a small fraction of multipotent progenitor (MPP) cells and increases steeply during the transition from the common myeloid progenitor (CMP) toward the granulocyte-macrophage progenitor (GMP). C/EBPA drives granulopoiesis by controlling the expression of myeloid specific genes ${ }^{1,2}$.

MicroRNAs (miRNAs) belong to a class of small (approximately $22 \mathrm{nt}$ ) noncoding RNAs. The RNA-induced silencing complex-bound miRNAs bind to complementary sequences that are predominantly located in the 3 '-untranslated regions of target mRNAs and regulate gene expression by transcript destabilization and inhibition of protein translation ${ }^{3}$. Recently, the function of miRNAs in myeloid cells has been investigated using mouse models. For example, miRs-17/20/93/106 promote progenitor cell expansion by targeting Sequestosome-1-regulated pathways ${ }^{4}$. In addition, miR-223 negatively regulates myeloid progenitor proliferation, and fine-tunes granulocyte differentiation and activity ${ }^{5}$. Also, miR-146a inhibits the activity of both myeloid and lymphoid cell lineages and plays key roles in the regulation of inflammation ${ }^{6}$.

DICER1 is an evolutionarily conserved member of the RNase III family of endoribonucleases that is critical for processing of specific precursor hairpin sequences, the so-called pre-miRNAs, into miRNAs ${ }^{7}$. Genetic deletion of Dicerl in mice results in early embryonic mortality due to depletion of the Oct-4-positive pluripotent embryonic stem cell pool at embryonic day 6-7 (E6-E7) ${ }^{8}$. A floxed Dicer1 allele (Dicer $\left.1^{f}\right)$ has been generated that allows conditional deletion of Dicerl in a cell type- and developmental stage-specific fashion ${ }^{9}$. Hematopoietic lineage-specific conditional deletion of Dicer1 has revealed the involvement of miRNAs in the survival, maturation and homeostasis of peripheral T lymphocytes, and in $\mathrm{Ab}$ diversity and survival of $\mathrm{B}$ lymphocytes ${ }^{10-12}$. In addition, conditional Dicerl deletion in osteoprogenitors using mice that have Cre recombinase under the transcriptional control of the osterix promoter (Osx-GFP-Cre) results in myeloid dysplasia and acute myelogenous leukemia with acquired genetic abnormalities but intact Dicer ${ }^{13}$.

Mouse primary HSCs are impaired by Dicerl loss and are unable to reconstitute hematopoiesis ${ }^{14}$. In addition, conditional deletion of Ars2, another gene required for miRNA biogenesis, in HSCs results in BM failure and increased apoptosis of hematopoietic cells in thymus and spleen ${ }^{15}$. Therefore, the overall contribution of miRNAs to myeloidlineage specification remains elusive. To address this issue, we generated a myeloid specific, Cebpa-Cre-driven Dicer1 deleter mouse strain that also harbors a conditional CRE reporter containing a loxp-flanked stop sequence (LSL) and the enhanced yellow fluorescent protein (Eyfp) in the ROSA26 locus (R26-LSL-Eyfp $)^{16}$. We show that Cebpa-Cre-driven Dicer1 deletion 
did not affect the numbers of myeloid-committed progenitors but did play a critical role in the regulation of a developmental program required for normal granulocyte and monocyte/ dendritic cell (DC)/macrophages in mice.

\section{METHODS}

\section{Mice and reconstitution experiments}

To generate Cebpa-Cre;R26-LSL-Eyfp;Dicer $1^{\text {tt/fl}} /$ Dicer $^{\text {flflfl }}$ mice, we crossed mice that contain floxed Dicer1 alleles (Dicer1 ${ }^{f l}$; ; kind gift of Dr. P.A. Sharp, David H. Koch Institute for Integrative Cancer Research, Cambridge, MA) with Cebpa-Cre;R26-LSL-Eyfp reporter mice ${ }^{2}$. Fetal livers were obtained on E13.5. Routine genotyping of Dicer1; Cebpa-Cre;R26-LSL-Eyfp mice was performed by PCR assays of DNA from tail or toe biopsies. Sequences of primers are available on request. All primers were obtained from Biolegio. For transplantation, 6 - to 8-week-old recipient mice (C57Bl/6; The Jackson Laboratory) were irradiated (8.5 Gy) and tail-vein injected with fetal liver single-cell suspensions. Typically, cells from each fetal liver were transplanted into 2 recipient mice. Hematopoietic tissues were analyzed 6-10 weeks after transplantation. The percentage of chimerism in hematopoietic tissue was detected by flow cytometric analysis of CD45.1 (recipient) and CD45.2 (Dicer1 ${ }^{f / f l}$ and Dicer ${ }^{f / / w t}$ donor) cells in a total of 8 mice. All animal experiments were approved by the Animal Welfare/ Ethics Committee of the Erasmus Medical Center.

\section{Cell culture, colony assays and cytospins}

DCs were derived from BM cultures in the presence of GM-CSF as described previously ${ }^{17}$. GM-CSF-induced colony formation assays with progenitors from E13.5 fetal livers were performed as described previously ${ }^{4}$. Colonies were counted after 7 days of incubation at $37^{\circ} \mathrm{C}$ and $5 \% \mathrm{CO}_{2}$ in a humidified atmosphere. For liquid cultures, E13.5 fetal liver cells were isolated and single-cell suspensions were grown in serum free CellGro Stem Cell Growth Medium (Cell Genix) supplemented with $1 \%$ penicillin/streptomycin and GM-CSF $(10 \mathrm{ng} / \mathrm{mL})$ at a density of $1 \times 10^{6}$ cells/mL for 7 days. For morphologic analysis of the cells, cytospins were stained with May-Grünwald-Giemsa and examined with a Leica DMLB microscope (100x and 40x objectives) and Leica Application Suite Version 2.7.1 R1 software.

\section{Abs, cell staining, flow cytometry, and cell sorting}

To obtain BM cell suspensions, femurs and tibias were crushed in a mortar in PBS with 5\% FCS. Cells were passed through a 70- $\mu$ m nylon sieve, and erythrocytes were lysed. Lineagepositive $\left(\mathrm{Lin}^{+}\right)$cells were determined with Abs against the following lineage markers: $\mathrm{CD} 3 \varepsilon$, CD11b, CD45R/B220, Ly-6G (Gr-1) and Ter119. To recognize HSPC populations, BM cells were stained with Abs against c-Kit, Sca-1, CD34 and Fc $\gamma$ RII/III(CD16/32). Myeloid progenitors were defined as $\mathrm{Lin}-\mathrm{Sca}-1^{-} \mathrm{C}-\mathrm{Kit}^{+} \mathrm{CD} 34^{+} \mathrm{CD} 16 / 32^{\text {low }}$ (CMPs), Lin ${ }^{-} \mathrm{Sca}-1^{\text {low }} \mathrm{C}-$ $\mathrm{Kit}^{+} \mathrm{CD} 34^{+} \mathrm{CD} 16 / 32^{\text {hi }}$ (GMPs) and $\mathrm{Lin}^{-} \mathrm{Sca}-1^{-} \mathrm{c}-\mathrm{Kit}^{+} \mathrm{CD} 34{ }^{-} \mathrm{CD} 16 / 32^{\text {low }}$ (megakaryocyte/ 
erythroid progenitor [MEPs]). For the analysis of differentiated EYFP+ myeloid cells in BM, cells were stained with anti-CD11b and anti-Ly-6G Abs. Peripheral blood obtained by submandibular bleeding was treated with erythrocyte lysis buffer and stained with Abs against CD11b, Ly-6G and Ly-6C for the determination of granulocytes and monocytes. Spleen single-cell suspensions were stained with CD11b and Ly-6G. Macrophages were isolated from the peritoneal cavity with $1.5 \mathrm{~mL}$ washes using PBS/5\% FCS. For identification of macrophages, the cell suspensions were stained with Abs against F4/80. To identify the in vitro expansion and differentiation toward DCs, whole BM cultures were stained with Abs against MHC class II and CD11c. To sort progenitors from BM, $\mathrm{Lin}^{+}$cells were depleted before staining with the Mouse Hematopoietic Progenitor (Stem) Cell Enrichment Set- DM (BD Biosciences) according to the manufacturer's protocol. A forward-side scatter gate excluded cell debris and remaining red blood cells. All sorted populations were more than $95 \%$ pure as determined by reanalysis. A full list of Abs used for flow cytometry and suppliers is given in supplemental Table 5.

\section{Gene and miRNA expression profiling}

$\mathrm{EYFP}^{+}$GMPs were sorted into RLT buffer (QIAGEN). RNA was extracted with the RNeasy Micro Kit (QIAGEN). After one step of linear amplification with the RNA MessageAmp II aRNA Kit (Applied Biosystems/AmbionX), aRNA was labeled and hybridized on the Mouse Genome 430 Affymetrix 2.0 Array according to standard protocols. Concentrations and purity of RNA samples were determined on a NanoDrop ND-1000 spectrophotometer (Isogen Life Science). RNA integrity was confirmed on an Agilent 2100 Bioanalyzer (Agilent Technologies) with 6000 nano and pico chips. Microarray data were normalized with the Affymetrix Microarray Suite (MAS Version 5.0). All microarray data are available on the Gene Expression Omnibus under accession number GSE35844. To confirm the expression changes in some target genes, cDNA was produced from $1 \mu \mathrm{g}$ of aRNA using Superscript II (Invitrogen) and quantitative RT-PCR was performed using the QuantiTect SYBR Green PCR Kit (QIAGEN). Primers were obtained from Biolegio. The $\Delta$ Ct value of Dicer ${ }^{\Delta / \Delta}$ and Dicer $^{w t / \Delta}$ versus Dicer1 wild-type $\left(\right.$ Dicer $\left.^{w t}\right)$ cells was calculated. The fold induction was calculated by the $2^{-\Delta C t}$ method.

miRNAs were isolated using the RNeasy Plus Mini Kit and RNeasy MinElute Cleanup Kit (QIAGEN) according to manufacturer's protocols. For miRNA profiling, TaqMan Array Rodent MicroRNA A Cards Version 2.0, which enables quantification of 375 mouse miRNAs and 6 controls, were used according to the manufacturer's protocol for Megaplex Pools With Preamplification (Applied Biosystems) using the ABI PRISM 7900HT machine (Applied Biosystems).

\section{Statistics}

TargetScan Version 5.2 (http://www.targetscan.org) was used to identify putative miRNA targets. Profiling of mRNA expression was performed in triplicate for each experimental condition $\left(\right.$ Dicer $^{w t}$, Dicer $^{w t / \Delta}$ or Dicer1 $\left.{ }^{\Delta / \Delta}\right)$ and subsequently normalized with MAS5.0. 
Probe sets considered indistinguishable from the background signal were omitted from further analyses. Identification of the differentially expressed probe sets was performed using the false discovery rate (FDR)-corrected $\mathrm{p}$ values derived by Limma ${ }^{18} \cdot \mathrm{p}<(0.017)$ was considered statistically significant. We divided the necessary significance level (.05) by the number of pairwise comparisons, in our case 3. The Kolmogorov-Smirnov test was used to infer differences between cumulative distribution functions, and a $\mathrm{p}<0.05$ was considered significant. The Fisher exact test was used to infer enrichment of de-repression for mRNA targets from the identified miRNAs. A FDR-corrected $\mathrm{p}<0.05$ was considered statistically significant. All statistical analyses were performed with R Version 2.12 software (http:// www.r-project.org).

\section{RESULTS}

\section{Cebpa-Cre-driven deletion of Dicer1 does not affect the number of HSPCs}

In hematopoietic cells, Cebpa starts to be expressed at the MPP stage and defines a subpopulation that is instructed to develop toward the myeloid lineage ${ }^{2}$, making it a suitable promoter to drive Dicerl deletion for studying the role of miRNAs in myelopoiesis. Whereas the Cebpa-Cre;Dicer ${ }^{w t / f}$ mice were viable and born at Mendelian ratios, the CebpaCre;Dicer $1^{f / f l}$ mice died rapidly after birth. This phenotype can be largely explained by the fact that the Cebpa promoter is highly active during the maturation of the respiratory epithelium in late gestation ${ }^{19}$ and deletes Dicer1. Lack of Dicer1 is detrimental to these cells, similar to Sonic Hedgehog (Shh)-Cre conditional Dicerl knockout mice ${ }^{20}$.

To investigate whether Dicerl deletion affects hematopoiesis in the embryo, we isolated fetal livers at E13.5. Cells containing recombined Dicer ${ }^{f l}$ alleles $\left(\right.$ Dicer $\left.^{\Delta}{ }^{\Delta}\right)$ can be identified because they also harbor a conditional CRE reporter R26-LSL-Eyfp allele ${ }^{16}$. The E13.5 fetal livers of Dicerl mutants and wild type were indistinguishable by eye. In addition, flow cytometric analysis did not show any differences in the fraction of HSCs, hematopoietic progenitors and (Lin') $\mathrm{EYFP}^{+}$progenitors in the fetal livers of Dicerl $1^{f / f l}$ and Dicer ${ }^{\text {wt/fll }}$ mice compared with Dicer ${ }^{w t}$ controls (Figure 1A). To investigate the effects of Cebpa-Cre-driven Dicer1 ablation in hematopoietic cells in adult mice and to bypass early death, E13.5 fetal liver cells were transplanted in lethally irradiated recipients. With this protocol the percentage of chimerism in hematopoietic tissue was at least $92 \%$ in the reconstituted mice (data not shown). CRE-dependent deletion of Dicer ${ }^{f l}$ alleles in $\mathrm{EYFP}^{+}$cells was confirmed by PCR (Figure 1B). Furthermore, more than $95 \%$ of total miRNAs were depleted in Dicer1 ${ }^{\Delta / \Delta}$; $\mathrm{EYFP}^{+}$ cells (supplemental Table 1). The expression level of the remaining miRNAs was less than $10 \%$ compared with normal $\mathrm{EYFP}^{+}$control cells (supplemental Table 1), indicating that Cebpa-Cre-mediated deletion of Dicerl results in an efficient depletion of miRNAs in myeloid progenitor cells in vivo.

Previous studies showed that IFN-responsive promoter-driven Cre ( $\mathrm{Mx}$-Cre)-induced Dicerl ablation results in a complete depletion of functional HSCs ${ }^{14}$. We wondered to what extent Cebpa-driven Dicerl deletion affects the number of myeloid-committed progenitor 
A)

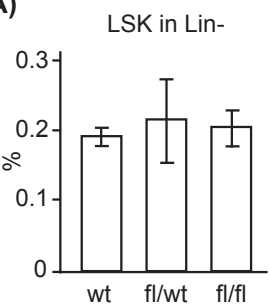

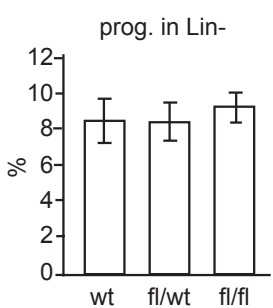

YFP ${ }^{+}$prog.

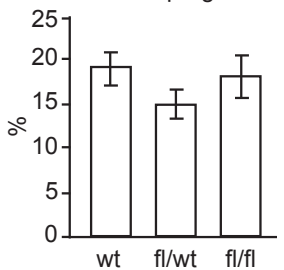

B)

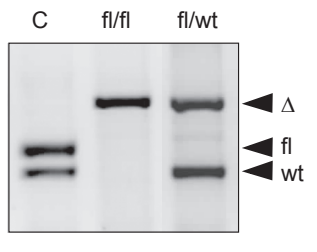

C)
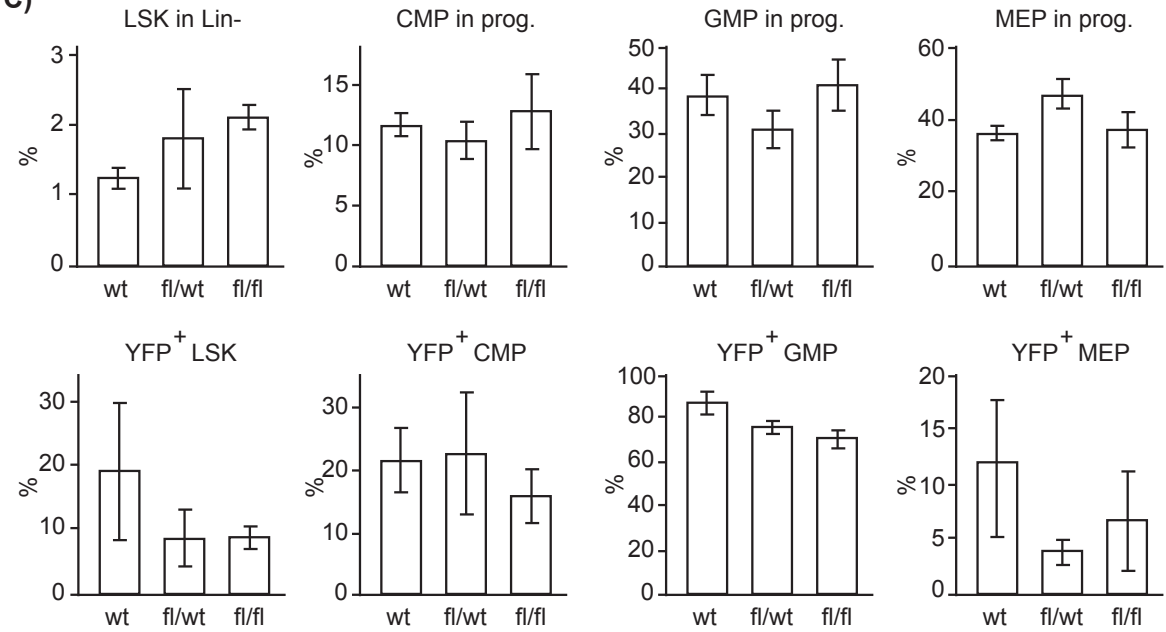

Figure 1. Cebpa-Cre-driven deletion of Dicer1 does not affect the fraction of myeloid-committed HSPCs in mice. A) Percentage of LSK cells (Lin-Scal ${ }^{+} \mathrm{C}-\mathrm{Kit}^{+}$), progenitors (Lin-Scal-C-Kit ${ }^{+}$) and percentage of $\mathrm{EYFP}^{+}$progenitor cells of Dicer ${ }^{\text {wt }}(\mathrm{n}=3)$, Dicer $1^{\text {wtflfl}}(\mathrm{n}=4)$ and Dicer $1^{\text {fl/fl }}$ cells $(\mathrm{n}=4)$ in E13.5 fetal livers. B) $\mathrm{EYFP}^{+}$cells from BM of transplanted mice were sorted by flow cytometry. DNA was isolated and analyzed by PCR. DNA fragments from Cebpa-Cre; Dicer $1^{\text {wtffl }} ; R 26-L S L-E y f p$ and Cebpa-Cre; Dicer $1^{f l f f} ; R 26-L S L-E y f p$ are indicated by fl/wt and fl/fl, respectively. Tail DNA of Dicer $1^{\text {wtfl }}$ was used as a positive PCR control (c) for the floxed and wild-type alleles. Recombined lox-p sites are indicated by $\Delta$. C) Top panel: Percentage of LSK cells (Lin-Sca $1^{+} \mathrm{C}-\mathrm{Kit}^{+}$), and CMP, GMP and MEP in the progenitor fraction (Lin-Sca1-C-Kit ${ }^{+}$of Dicer ${ }^{\text {wt }}$ BM cells ( $\left.\mathrm{n}=5\right)$, Dicer ${ }^{\text {wt/fl }}$ $(\mathrm{n}=6)$ and Dicer $1^{f / f l}$ cells $(\mathrm{n}=7)$. Bottom panel: Percentage of $\mathrm{EYFP}^{+}$cells in indicated fractions.

cells. In contrast to the results published previously for HSCs ${ }^{14}$, in the present study, Dicer1 deletion did not affect the percentage of myeloid-committed $\mathrm{EYFP}^{+}$cells in the LSK fraction significantly (Figure 1C and supplemental Figure 1). In addition, no significant differences in the fraction of $\mathrm{EYFP}^{+}$Dicer1 ${ }^{\Delta / \Delta}$ CMPs, GMPs or MEPs compared with those of Dicer1 ${ }^{w t / \Delta}$ transplanted mice and Dicer ${ }^{w t}$ mice were observed (Figure 1C). Therefore, unlike the effect of Dicer1 deletion on HSC maintenance ${ }^{14}$, Cebpa-Cre-driven Dicerl deletion did not affect the numbers of myeloid progenitors in mice. 


\section{Cebpa-Cre driven deletion of Dicer1 affects GM-CFU outgrowth, cellular replating capacity and myeloid differentiation}

We performed GM-CFU assays to determine whether deletion of Dicerl would affect the expansion and differentiation capacity of GMPs. The number of GM-CFUs obtained with Dicer $1^{\Delta / \Delta}$ progenitor cells was approximately $50 \%$ lower than with Dicer $1^{w t / \Delta}$ or Dicer ${ }^{w t}$ cells (Figure 2A). Colony size also decreased as a result of Dicerl deletion (data not shown). Morphologic analyses showed a more than 5-fold increase in the number of blast-like cells, a strongly reduced capacity of the Dicer $1^{\Delta / \Delta}$ progenitors to differentiate toward macrophages, and the appearance of dysplastic neutrophils (Figure 2B). Dicer $1^{\Delta / \Delta}$ progenitor cells gained the ability to form secondary and tertiary colonies after serial replatings, which coincided with a regained self-renewal potential, a blast-like morphology, and a strongly reduced differentiation capacity of the cells (Figure 2A,B). In GM-CSF-containing liquid cultures, $\mathrm{Lin}^{-} ;$Dicer $^{\Delta / \Delta}$ progenitors were unable to mature toward macrophages, but instead showed features of dysplastic myeloid cells, including the Pelger-Huët anomaly, which is characterized by neutrophils with a hyposegmented nucleus ( 75\% of cells) ${ }^{21}$ (Figure $2 \mathrm{C}$ ). Lin $^{-} ;$Dicer $^{\Delta / \Delta}$ BM cells failed to differentiate toward BM-derived DCs (Figure 2D). These results indicate that Dicer1 is essential for definitive maturation of GMPs toward both the neutrophil and monocyte/macrophage/BM-derived DC lineage in vitro.

\section{Cebpa-Cre-driven deletion of Dicer 1 causes myeloid dysplasia and monocyte/macrophage depletion in vivo}

Next, we investigated whether the aberrant myeloid differentiation of GMPs observed in vitro also occurs in vivo. Dicer $1^{\Delta / \Delta} \mathrm{BM}$ neutrophils showed increased levels of CD11b (a marker for myeloid cells) and a reduced Ly-6G (a marker for neutrophilic differentiation) expression compared with Dicer1 ${ }^{w t / \Delta}$ (similar to Dicerl ${ }^{w t}$; Figure 3A). Whereas Dicer1 ${ }^{\text {tt/ }}$ neutrophils appeared normal, Dicer1 ${ }^{\Delta / \Delta}$ cells showed aberrant nucleus morphologies (Figure 3B) of

Figure 2. Functional analysis of Dicer $1^{\Delta / \Delta}$ primary mouse Lin- BM cells. A) CFU-GM assay and replating of mouse Lin- BM progenitors. Cells were plated in triplicate at densities of $1 \times 10^{4}$ cells per dish in $1 \mathrm{~mL}$ methylcellulose medium containing GM-CSF (100 ng/mL). Cells were isolated from dishes, counted and replated under the same conditions. Colonies consisting of more than 50 cells were counted after 7 days of growth. Significance was calculated by comparing Dicer $1^{\Delta / \Delta}$ and Dicer $1^{w t / \Delta}$ with Dicer $1^{w t}$ control using the Mann-Whitney test (asymoptotic significance [2-tailed], ${ }^{*} \mathrm{p}<0.05$. B) Average differential cell counts (of at least 100 cells and 3 independent experiments), blast, granulocyte(-like) and macrophages. Dicer 1 control plating 1 (blasts $1 \%, \mathrm{SD}=0$, granulocytes $2 \%, \mathrm{SD}=1$, macrophages $97 \%$, SD=1). Dicer $1^{\Delta / \Delta}$ plating 1 (blast $27 \%, \mathrm{SD}=4.7$, granulocyte-like $39 \%, \mathrm{SD}=3.5$ and macrophage $34 \%, \mathrm{SD}=8.1$ ). Dicer $1^{\Delta / \Delta}$ third and forth replatings (blast $74 \%, \mathrm{SD}=3.6$, granulocyte-like $16 \%, \mathrm{SD}=3.2$ and macrophage $10 \%$, $\mathrm{SD}=4.6$ ). C) Micrographs show cells isolated from a liquid culture of mouse Lin- BM progenitors with GM-CSF for 7 days. Arrowhead indicates the pince-nez-shaped nucleus, a hallmark for the Pelger-Huët

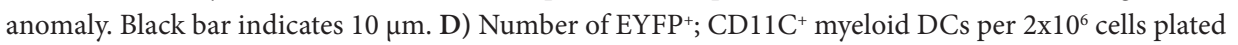
in liquid culture after 1 week of expansion $(n=3) .{ }^{\star} p<0.05$. 
A)

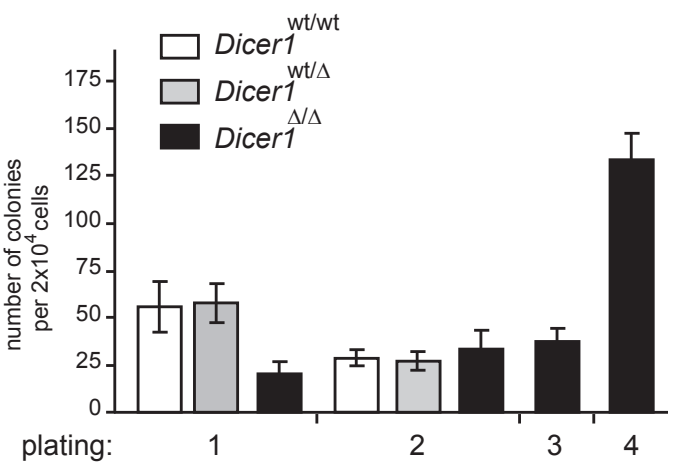

B)
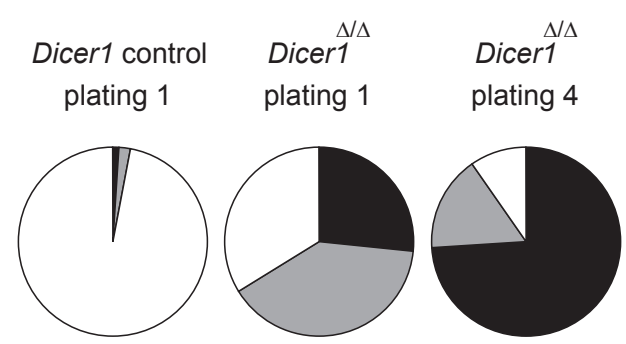

blast $\square$ granulocyte-(like) $\square$ macrophage

C)
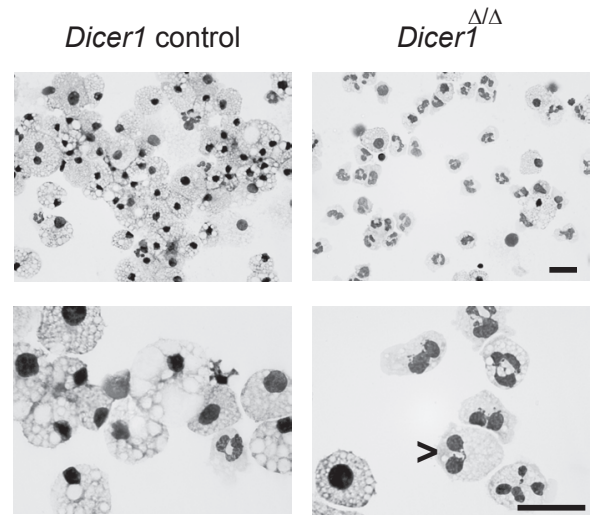

D)

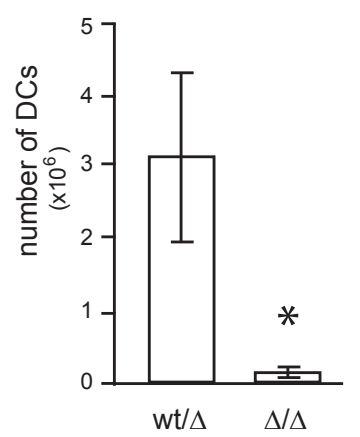




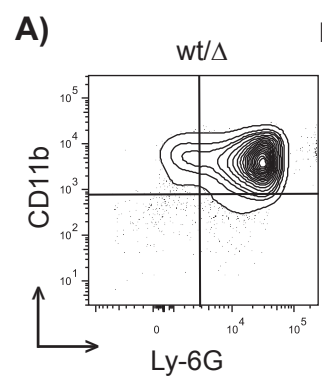

BM

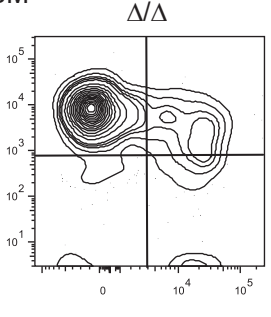

C)

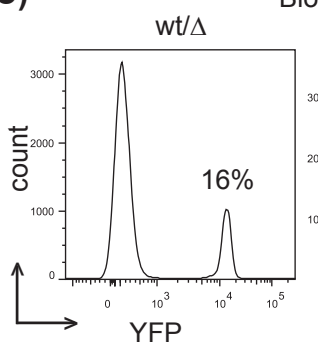

Blood

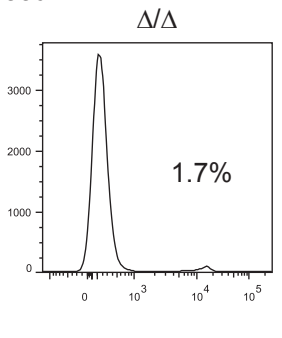

E)

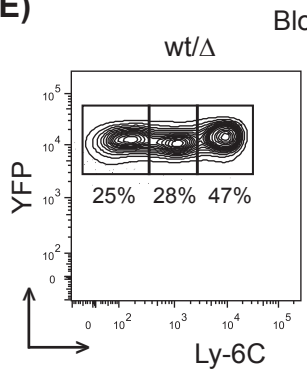

ood

$\Delta / \Delta$

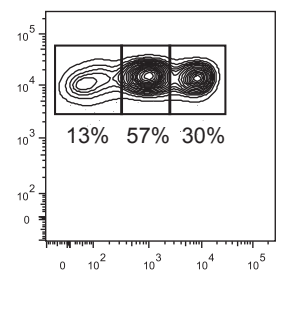

B)

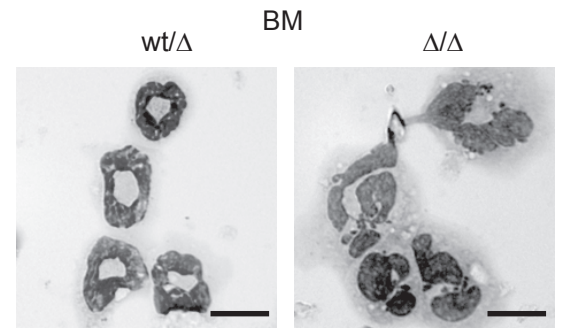

D)

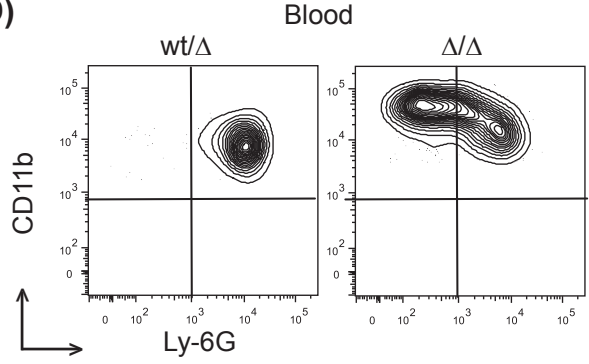

F)

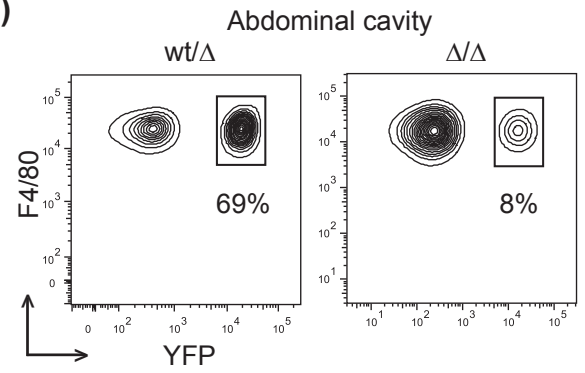

G)
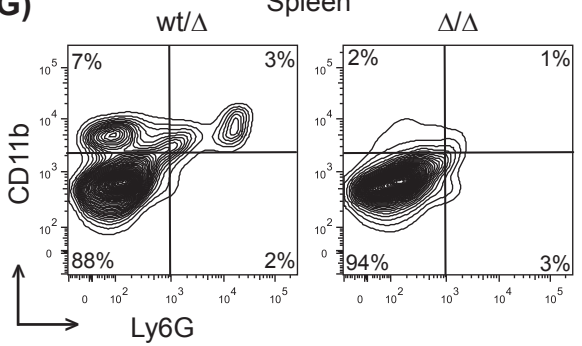

Figure 3. Cebpa-Cre-driven deletion of Dicer1 causes neutrophil dysplasia and monocyte/macrophage depletion in mice. A) FACS analysis of BM neutrophils with Abs against CD11b and Ly-6G for Dicer $1^{w t / \Delta}$ (similar to Dicer $1^{w t}$ ) and Dicer $1^{\Delta / \Delta}$ neutrophils. B) Micrographs showing morphology of Dicer $1^{w t / \Delta}$ (similar to Dicer $1^{w t}$ ) and Dicer $1^{\Delta / \Delta}$ neutrophils. Black bar indicates $10 \mu \mathrm{m}$. C) Percentage of $\mathrm{EYFP}^{+}$cells in the blood of Dicer ${ }^{w / \Delta}$ and Dicer $1^{\Delta / \Delta}$ mice. D) Analysis of peripheral neutrophils with Abs against CD11b and Ly-6G. E) Analysis of peripheral EYFP ${ }^{+}$monocytes (CD11b+, Ly-6G-) with Abs against Ly-6C. F) Analysis of $\mathrm{EYFP}^{+}$macrophages from the abdominal cavity with Abs against F4/80 Ag. G) FACS analysis of total spleen cells with Abs against CD11b and Ly6G. All analyses were performed on at least 3 independent mice. 
which approximately $20 \%$ were hyposegmented or bilobed. Furthermore, Ly- $6 \mathrm{G}^{+}$Dicer $1^{\Delta / \Delta}$ granulocytes were nearly absent in the peripheral blood and spleen (Figure 3C- D, G), suggesting that the aberrant neutrophils were incapable of emigrating from the BM.

Concerning monocytic/macrophage development, whereas Dicer $1^{\text {wt/ }}$ monocytes appeared in 3 stages of differentiation: high Ly-6C (immature), intermediate and low Ly-6C (mature) ${ }^{22}$, the relative number of mature Dicer $1^{\Delta / \Delta}$ monocytes was strongly reduced (Figure 3E). Moreover, we observed a strongly reduced percentage of $\mathrm{EYFP}^{+}$macrophages in the abdominal cavity of Dicer ${ }^{\Delta / \Delta}$ transplanted mice compared with $\mathrm{EYFP}^{+}$; Dicer ${ }^{\text {tt/ }}$ controls (Figure 3F). No CD11b+ cells could be detected in the spleen of Dicer ${ }^{\Delta / \Delta}$ transplanted mice (Figure $3 G$ ). Dicer $1^{\Delta / \Delta}$ recipients survived for at least 10 months devoid of any sign of myeloproliferative disease or leukemia development.

\section{Twenty miRNA families are active in GMPs and repress expression programs characteristic of HSCs and erythropoiesis}

To determine how deletion of Dicer1, and the resulting loss of miRNA expression, affects the gene expression landscape of GMPs, we performed gene expression analyses of Dicer1 mutant and control GMPs. miRNA expression profiling of EYFP ${ }^{+}$Dicer $^{{ }^{w t}} \mathrm{GMPs}$ identified 104 miRNAs expressed in GMPs (supplemental Table 2). To examine the activities of these miRNAs, we compared the transcriptome of Dicer1 ${ }^{w t}$, Dicer ${ }^{w t / \Delta}$ and Dicer1 ${ }^{\Delta / \Delta}$ GMPs. Transcripts with predicted binding sites for identified miRNAs tended to be up-regulated in Dicer1-null GMPs, compared with transcripts without such sites $\left(\mathrm{p}<2.2 \times 10^{-16}\right.$ by Kolmogorov-Smirnov test; Figure 4A), which is indicative of the activity of the miRNAs in these cells. Transcripts containing putative binding sites for the identified miRNAs had a significant propensity to be up-regulated in the $\operatorname{Dicer}^{\Delta / \Delta}$ cells $\left(\mathrm{p}<2.2 \times 10^{-16}\right.$ by KolmogorovSmirnov test), but not in the Dicer ${ }^{w t / \Delta}$ cells (Figure 4B). Deletion of Dicer1 in GMPs revealed 784 significant differentially expressed probe sets (FDR-corrected $\mathrm{p}<0.05$; Figure 4C). Unsupervised clustering of these probe sets showed that the gene expression pattern of Dicer ${ }^{w / /}$ GMPs was changed but still appeared very similar to wild-type GMPs (Figure 4C), again indicating that heterozygous deletion of Dicerl did not strongly affect the miRNAregulated targets in GMPs.

Cebpa-Cre-mediated deletion of Dicer1 in GMPs resulted in 300 significantly up-regulated transcripts (368 probe sets, supplemental Table 3). The up-regulation of some of these genes was confirmed by quantitative RT-PCR (supplemental Figure 2). A set of transcripts that are experimentally confirmed miRNA targets, such as Bcl2L11 (Bim) ${ }^{11}, \mathrm{~K}$-Ras and Hmga2 ${ }^{23}$, Hoxa $9^{24}$, and Cdkn1a (p21) ${ }^{25}$, also appeared to be regulated by Dicer1 in GMPs (supplemental Table 3). In agreement with data shown in Figure 4B-C, only 11 transcripts (3\%) were very sensitive to Dicer1 deletion because Dicerl heterozygosity had a significant effect on their transcript levels (supplemental Table 3). Predicted targets of 20 miRNA families were significantly enriched in the fraction of messages that were up-regulated in Dicer ${ }^{\Delta / \Delta}$ cells compared with the fraction of nonregulated targets (Table 1, FDR-corrected $\mathrm{p}<0.05$ by Fisher exact test). Of the 300 genes that were de-repressed by Dicer1 depletion, $81 \mathrm{~g}(>25 \%)$ could 
A)

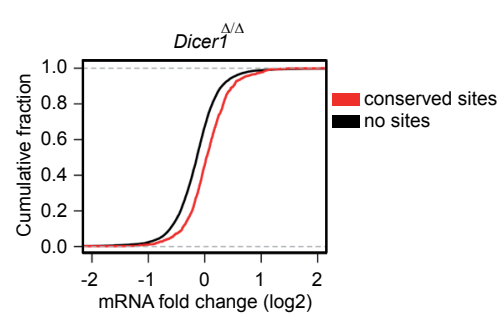

B)

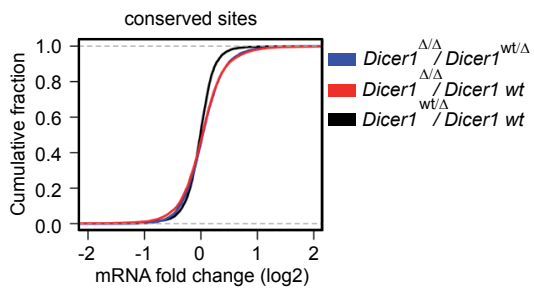

C)

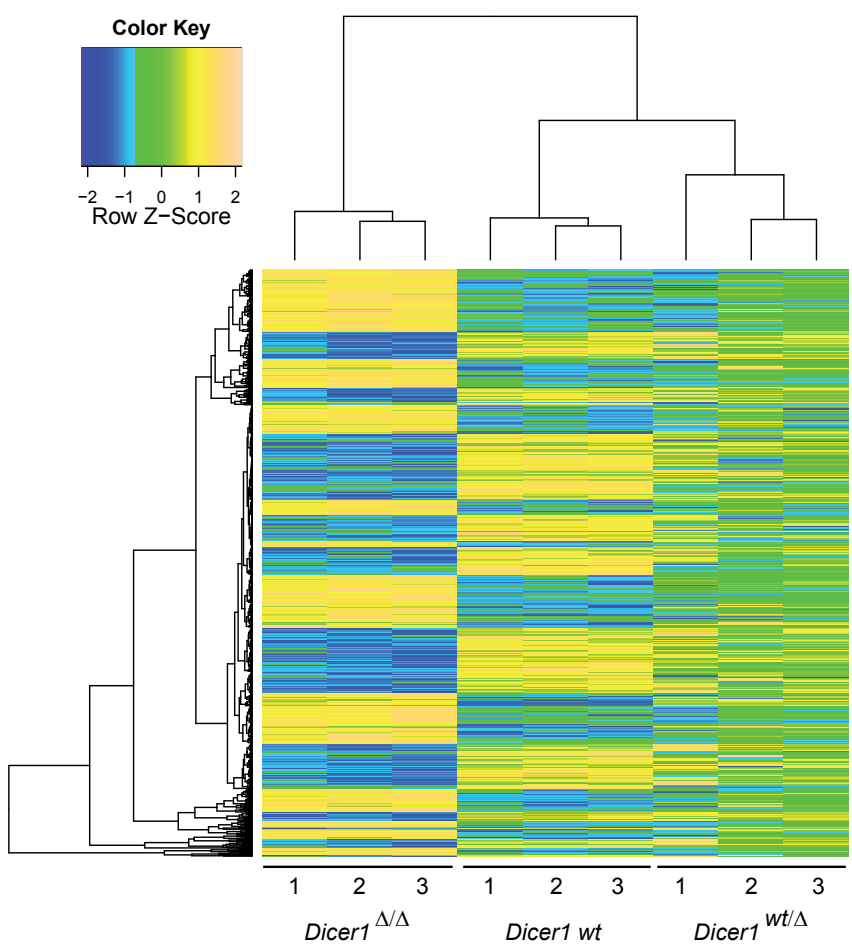

Figure 4. Cebpa-Cre-mediated Dicer1 deletion affects gene expression in GMPs. A) Cumulative distribution plot of log fold change of transcripts that contain miRNA-binding sites for identified miRNAs (supplemental Table 2) and messages that do not contain sites compared with wild-type $\left(\mathrm{p}<2.2 \times 10^{-16}\right)$. B) Cumulative distribution plot of log fold change for mRNA that contain miRNA-binding sites for the identified miRNAs (supplemental Table 2) in the indicated populations. The expression ratio of most messages in Dicer $1^{\Delta / \Delta}$ cells over Dicer $1^{w t / \Delta}$ and Dicer $1^{w t}$ are skewed toward higher positive fold changes compared with Dicer $1^{w t / \Delta}$ over Dicer $1^{w t}\left(\mathrm{p}<2.2 \times 10^{-16}\right)$. C) Significant differentially expressed genes between GMP wild-type and Dicer $1^{\Delta / \Delta}$ cells (FDR-corrected $\mathrm{p}<0.05$ ) were unsupervised clustered with GPLOTS (http://cran.r-project.org/web/packages/ gplots/index.html). 
Table 1. Active miRNA families in GMP

\begin{tabular}{|c|c|c|c|c|}
\hline & $\begin{array}{l}\text { Fold } \\
\text { enrichment }\end{array}$ & $\mathbf{P}^{\star}$ & $\begin{array}{l}\text { No. of } \\
\text { transcripts } \\
\text { regulated }\end{array}$ & $\begin{array}{l}\text { No. of regulated transcripts } \\
\text { linked to lineage-affiliated } \\
\text { signatures }\end{array}$ \\
\hline let- $7 \mathrm{~b} / \mathrm{c} / \mathrm{d} / \mathrm{e} / \mathrm{g} / \mathrm{i}$ & 1.84 & $2.452 \times 10-03$ & 55 & $9(16.4 \%)$ \\
\hline miR-10a & 2.42 & $1.388 \times 10-02$ & 16 & $3(18.8 \%)$ \\
\hline miR-15/16/195 & 1.65 & $1.032 \times 10-02$ & 57 & $8(14 \%)$ \\
\hline $\operatorname{miR}-17 / 20 / 93 / 106$ & 2.82 & $2.787 \times 10-10$ & 83 & $15(18.1 \%)$ \\
\hline $\mathrm{miR}-19 \mathrm{a} / \mathrm{b}$ & 1.93 & $6.528 \times 10-04$ & 60 & $15(25 \%)$ \\
\hline miR-25/92 & 2.37 & $1.657 \times 10-05$ & 54 & $12(22.2 \%)$ \\
\hline $\mathrm{miR}-26 \mathrm{a} / \mathrm{b}$ & 1.80 & $8.623 \times 10-03$ & 45 & $10(22.2 \%)$ \\
\hline $\operatorname{miR}-27 \mathrm{a} / \mathrm{b}$ & 1.79 & $2.452 \times 10-03$ & 59 & $12(20.3 \%)$ \\
\hline $\mathrm{miR}-30 \mathrm{a} / \mathrm{b} / \mathrm{d} / \mathrm{e}$ & 1.82 & $1.073 \times 10-03$ & 69 & $14(20.3 \%)$ \\
\hline $\mathrm{miR}-130 \mathrm{~b} / 301 \mathrm{a}$ & 1.64 & $2.679 \times 10-02$ & 42 & $8(19 \%)$ \\
\hline $\operatorname{miR}-142-3 p$ & 4.02 & $2.073 \times 10-08$ & 36 & $10(27.8 \%)$ \\
\hline $\mathrm{miR}-181 \mathrm{a} / \mathrm{c}$ & 1.71 & $9.031 \times 10-03$ & 52 & $14(26.9 \%)$ \\
\hline miR-200c & 1.68 & $9.828 \times 10-03$ & 53 & $9(17 \%)$ \\
\hline miR-203 & 1.86 & $1.388 \times 10-02$ & 33 & $5(15.2 \%)$ \\
\hline miR-222 & 2.30 & $9.025 \times 10-03$ & 21 & $5(23.8 \%)$ \\
\hline miR-223 & 2.19 & $2.547 \times 10-02$ & 17 & $4(23.5 \%)$ \\
\hline $\operatorname{miR}-320$ & 2.27 & $4.134 \times 10-04$ & 42 & $5(11.9 \%)$ \\
\hline miR-340-5p & 1.82 & $1.525 \times 10-03$ & 64 & $7(10.9 \%)$ \\
\hline miR-494 & 2.35 & $4.099 \times 10-03$ & 24 & $5(20.8 \%)$ \\
\hline miR-503 & 2.23 & $9.025 \times 10-03$ & 23 & $2(8.7 \%)$ \\
\hline
\end{tabular}

*The Fold enrichment and FDR-corrected $\mathrm{p}$ values of predicted targets in the fraction that are significantly upregulated in Dicer $\Delta / \Delta$ cells compared with the nonregulated targets. Only the significant results $(\mathrm{p}<0.05)$ of the miRNAs that are expressed in GMPs are shown. The lineage-affiliated signatures are shown in supplemental Table 4.

be linked to signatures of HSCs, MPPs and early erythropoiesis ${ }^{26}$ (supplemental Table 4). These findings imply that certain miRNA families control the switch of a cellular program for self-renewal and expansion toward a granulocyte/monocyte/macrophage differentiation program at the GMP stage.

\section{DISCUSSION}

The results of the present study show that Cebpa-Cre-driven Dicer1 deletion in myeloidcommitted progenitors, and as a result depletion of miRNAs, disrupts the differentiation program of GMPs that is required for normal myeloid development. This has been demonstrated in 3 ways. First, normal numbers of Dicerl null EYFP ${ }^{+}$myeloid-committed 
progenitors were detected by flow cytometry, indicating that depletion of miRNAs was not detrimental for these cells. Second, gene-expression profiling of Dicer1-null GMPs identified an altered gene expression landscape of GMPs, including enhanced expression of a set of genes that is characteristic for HSCs, MPPs and early erythropoiesis. These data imply a disordered differentiation program in Dicer1-null GMPs. Finally, flow cytometric analysis of myeloid cells from different hematopoietic tissues in mice showed a developmental block of monocytes, strong reduction of mature macrophages in the abdominal cavity, depletion of myeloid cells in the spleen and the presence of dysplastic neutrophils in the BM.

Recently, Raaijmakers et al. reported that deletion of Dicer1 specifically in mouse osteoprogenitors disrupts normal hematopoiesis, resulting in a myelodysplastic syndrome and secondary leukemias in mice ${ }^{13}$. In these experiments Dicerl was not deleted in HSPCs or in the myelodysplastic cells, indicating that the observed dysplasia was initiated by osteoprogenitor dysfunction ${ }^{13}$. Complementary to those findings, we demonstrate herein a myeloid progenitor cell-intrinsic role for miRNA processing in myelopoiesis, in a system that leaves the BM environment intact. Our results indicate that Dicer1 may play dual roles in the control of myelopoiesis, both of which are essential for normal myelopoiesis.

Pelger-Huët is characterized by abnormal nuclear shape and chromatin organization in blood granulocytes ${ }^{21}$. A genome-wide linkage scan identified the lamin B receptor (LBR), a member of the sterol reductase family located on the linked genomic region 1q41-43, to be mutated in patients suffering from Pelger-Huët disease ${ }^{27}$. These mutations result in decreased expression of LBR, which is strongly correlated with hyposegmentation of the nucleus in neutrophils ${ }^{27,28}$. In our model, Dicerl null neutrophils were hyposegmented, but LBR expression remained unchanged in Dicer1 null GMPs. This result suggests that other, as-yet-undefined mechanisms may be involved in the observed developmental abnormalities or that downstream LBR pathways are controlled by Dicer1 and may cause features of PelgerHuët anomaly.

In contrast to our results in GMPs, recently published data show that Dicer1 deletion in hematopoietic cells from different origins causes cell death due to derepression of mRNAs coding for proteins involved in the induction of apoptosis. For example, Dicer1 ablation in HSCs depletes functional HSCs, induces rapid apoptosis in HSPCs and results in total disruption of hematopoiesis ${ }^{14}$. These deleterious effects of miRNA depletion in HSCs can be largely circumvented by the reintroduction of a single miRNA, miR-125a, which targets the proapoptotic protein BAK $1{ }^{14}$. In addition, Dicerl ablation in early B-cell progenitors induces apoptosis at the pre-B cell state because of de-repression of the $m i R$ 17 92 proapoptotic target Bcl2L11 (also known as Bim) as the consequence of Dicer1 loss ${ }^{11}$. Strikingly, although $B c l 2 L 11$ is approximately 1.8 fold up-regulated in Dicer1 null GMPs (supplemental Table 3), this did not induce an increase in apoptosis. In T cells, Dicer1 is also essential for cell viability ${ }^{10,12,29}$, suggesting that Dicer1-dependent RNAs in HSCs and cells from lymphoid origin regulate cell survival, which is, according to our data, different in myeloid-committed progenitors. In addition to the regulation of apoptosis, Dicer1 plays 
a pivotal role in the regulation of activation, migration, lineage choice and differentiation of T cells ${ }^{10,12,29}$. To our knowledge, this is the first report describing an exclusive role for Dicer1 in the developmental switch of myeloid-committed progenitors toward mature neutrophils, macrophages and myeloid DCs.

A limitation of the Dicerl deletion models is the global depletion of miRNAs that presumably results in disruption of many cellular pathways simultaneously, which hampers the analysis of individual miRNA functions. Our data showed that Cebpa-Cre-driven Dicer1 ablation in GMPs depleted 20 active miRNA families simultaneously, resulting in de-repression of at least 300 potential miRNA targets in GMPs. Because some miRNAs regulate expression by translational inhibition without affecting mRNA stability to a detectable level, the determined level of miRNA activity is most likely an underestimation. In addition, transcripts can be regulated by multiple miRNAs, and the action of miRNAs is dependent on both miRNA and target gene levels, which complicates the functional analysis of single miRNAs in this model ${ }^{30}$. Despite the limitations of our model, a set of miRNA target genes in GMPs is normally exclusively expressed in HSCs and when derepressed due to Dicerl deletion in GMPs might explain at least in part some of the phenotypic features of the Dicer1 null GMPs. For example, HOXA9, a confirmed target of $m i R-126^{24}$, is up-regulated in Dicer1 null GMPs and forced expression in myeloid progenitors blocks differentiation and results in enhanced replating capacity ${ }^{31}$. In addition, the Let-7 target $H M G A 2{ }^{23}$ is strongly up-regulated by Dicerl depletion in GMPs, and overexpression or truncation of $H M G A 2$ has been found in patients with myelodysplastic syndromes ${ }^{32}$. In addition, the robust de-repression of the HSC-specific genes HMGA2 (8-fold) and HOXA9 (3-fold), instead of the moderate regulation shown for most miRNA targets, suggests a miRNA-driven switch-like transition from stem cell fate toward differentiation as shown for miRNAs lin-4 and let-7 targeting the genes lin-14 and lin-41, respectively, in Caenorhabditis elegans ${ }^{33}$. Therefore, our data suggest that the inability to silence stem cell genes in myeloid-committed progenitors interferes with the switch of stemness toward a myeloid differentiation program. Although these findings suggest that some miRNAs function in myeloid progenitors, an extensive miRNA add-back screen in Dicer1 null cells is needed to identify their specific role in the control of myeloid development and this is one of the challenges in the field.

In conclusion, this study has demonstrated that Dicerl ablation by C/ebpa-Cre does not affect the numbers of HSCs, CMPs, and GMPs, but results in defective GMPs, which are unable to mature toward monocytes, macrophages, and myeloid DCs, and leads instead to neutrophil dysplasia. We have identified a set of 20 highly active miRNA families in GMPs and provided evidence that Dicerl controls a gene expression program that is normally active in HSCs and MPPs, and counteracts the expression of messages that are linked to early erythropoiesis. Our data uncover a Dicerl-controlled differentiation program in GMPs that is required for normal myelopoiesis. 


\section{ACKNOWLEDGEMENTS}

The authors thank Dr. P. Leenen for providing Abs, and Prof.dr.P.A. Sharp for the Dicer1 floxed mice; N. Papazian, Dr. K. van Lom, P. van Strien, A. Prins and Dr. E. Rombouts for technical assistance; Prof.dr. H. Delwel, M. Huston, Dr. F. Cornelissen for critical reading of the manuscript; and E. Simons for assistance with the figure preparation. This work was supported by grants from the Netherlands Organisation for Scientific Research (NWO-VENI) and the Dutch Cancer Society (KWF).

\section{AUTHORSHIP}

M.F.A. and S.J.E., designed and performed the research, analyzed the data, and wrote the manuscript. N.v.B., H. d. L. and I.J.vd.B. performed the cellular and in vivo research, M.A.S., performed the bioinformatic analysis, and T.C. and I.P.T., designed the research and discussed the data. The authors declare no competing financial interests. 


\section{REFERENCES}

1. Tsukada J, Yoshida Y, Kominato Y, Auron PE. The CCAAT/enhancer (C/EBP) family of basic-leucine zipper (bZIP) transcription factors is a multifaceted highly-regulated system for gene regulation. Cytokine. 2011;54(1):6-19.

2. Wolfler A, Danen-van Oorschot AA, Haanstra JR, et al. Lineage-instructive function of C/EBPalpha in multipotent hematopoietic cells and early thymic progenitors. Blood. 2010;116(20):4116-4125.

3. Hammond SM, Bernstein E, Beach D, Hannon GJ. An RNA-directed nuclease mediates post-transcriptional gene silencing in Drosophila cells. Nature. 2000;404(6775):293-296.

4. Meenhuis A, van Veelen PA, de Looper $\mathrm{H}$, et al. MiR-17/20/93/106 promote hematopoietic cell expansion by targeting sequestosome 1-regulated pathways in mice. Blood. 2011;118(4):916-925.

5. Johnnidis JB, Harris MH, Wheeler RT, et al. Regulation of progenitor cell proliferation andgranulocytefunctionbymicroRNA-223. Nature. 2008;451(7182):1125-1129.

6. Boldin MP, Taganov KD, Rao DS, et al. miR$146 \mathrm{a}$ is a significant brake on autoimmunity, myeloproliferation, and cancer in mice. $J$ Exp Med. 2011;208(6):1189-1201.

7. Bernstein E, Caudy AA, Hammond SM, Hannon GJ. Role for a bidentate ribonuclease in the initiation step of RNA interference. Nature. 2001;409(6818):363366.

8. Bernstein E, Kim SY, Carmell MA, et al. Dicer is essential for mouse development. Nat Genet. 2003;35(3):215-217.

9. Harfe BD, McManus MT, Mansfield JH, Hornstein E, Tabin CJ. The RNaseIII enzyme Dicer is required for morphogenesis but not patterning of the vertebrate limb. Proceedings of the National Academy of Sciences of the United States of America. 2005;102(31):10898-10903.

10. Cobb BS, Nesterova TB, Thompson E, et al. $\mathrm{T}$ cell lineage choice and differentiation in the absence of the RNase III enzyme Dicer. The Journal of Experimental Medicine. 2005;201(9):1367-1373.

11. Koralov SB, Muljo SA, Galler GR, et al. Dicer ablation affects antibody diversity and cell survival in the B lymphocyte lineage. Cell. 2008;132(5):860-874.

12. Muljo SA, Ansel KM, Kanellopoulou C, Livingston DM, Rao A, Rajewsky K. Aberrant T celldifferentiation in the absence of Dicer. J Exp Med. 2005;202(2):261-269.

13. Raaijmakers $\mathrm{MH}$, Mukherjee S, Guo S, et al. Bone progenitor dysfunction induces myelodysplasia and secondary leukaemia. Nature. 2010;464(7290):852-857.

14. Guo S, Lu J, Schlanger R, et al. MicroRNA miR-125a controls hematopoietic stem cell number. Proc Natl Acad Sci U S A. 2010;107(32):14229-14234.

15. Gruber JJ, Zatechka DS, Sabin LR, et al. Ars2 links the nuclear cap-binding complex to RNA interference and cell proliferation. Cell. 2009;138(2):328-339.

16. Srinivas $S$, Watanabe T, Lin CS, et al. Cre reporter strains produced by targeted insertion of EYFP and ECFP into the ROSA26 locus. BMC Dev Biol. 2001;1:4.

17. Stockinger B, Hausmann B. Functional recognition of in vivo processed self antigen. Int Immunol. 1994;6(2):247-254.

18. Smyth G. Linear models and empirical Bayes methods for assessing differential expression in microarray experiments. Statistical Applications in Genetics and Molecular Biology. 2004;3: article 3.

19. Martis PC, Whitsett JA, Xu Y, Perl AK, Wan $\mathrm{H}$, Ikegami M. C/EBPalpha is required for lung maturation at birth. Development. 2006;133(6):1155-1164.

20. Harris KS, Zhang Z, McManus MT, Harfe BD, Sun X. Dicer function is essential for lung epithelium morphogenesis. Proc Natl Acad Sci U S A. 2006;103(7):2208-2213.

21. Cunningham JM, Patnaik MM, Hammerschmidt DE, Vercellotti GM. 
Historical perspective and clinical implications of the Pelger-Huet cell. Am J Hematol. 2009;84(2):116-119.

22. Sunderkotter C, Nikolic T, Dillon MJ, et al. Subpopulations of mouse blood monocytes differ in maturation stage and inflammatory response. J Immunol. 2004;172(7):44104417.

23. Kumar MS, Erkeland SJ, Pester RE, et al. Suppression of non-small cell lung tumor development by the let-7 microRNA family. Proc Natl Acad Sci U S A. 2008;105(10):39033908.

24. Shen WF, Hu YL, Uttarwar L, Passegue E, Largman C. MicroRNA-126 regulates HOXA9 by binding to the homeobox. Mol Cell Biol. 2008;28(14):4609-4619.

25. Ivanovska I, Ball AS, Diaz RL, et al. MicroRNAsin the miR-106b family regulate p21/CDKN1A and promote cell cycle progression. Mol Cell Biol. 2008;28(7):21672174.

26. Ng SY, Yoshida T, Zhang J, Georgopoulos K. Genome-widelineage-specifictranscriptional networks underscore Ikaros-dependent lymphoid priming in hematopoietic stem cells. Immunity. 2009;30(4):493-507.

27. Hoffmann K, Dreger CK, Olins AL, et al. Mutations in the gene encoding the lamin
B receptor produce an altered nuclear morphology in granulocytes (Pelger-Huet anomaly). Nat Genet. 2002;31(4):410-414.

28. Gravemann S, Schnipper N, Meyer H, et al. Dosage effect of zero to three functional LBR-genes in vivo and in vitro. Nucleus. 2010;1(2):179-189.

29. Zhang N, Bevan MJ. Dicer controls CD8 $8^{+}$Tcell activation, migration, and survival. Proc Natl Acad Sci U S A. 2010;107(50):2162921634.

30. Mukherji S, Ebert MS, Zheng GX, Tsang JS, Sharp PA, van Oudenaarden A. MicroRNAs can generate thresholds in target gene expression. Nat Genet. 2011;43(9):854-859.

31. Bach C, Buhl S, Mueller D, Garcia-Cuellar MP, Maethner E, Slany RK. Leukemogenic transformation by HOXA cluster genes. Blood. 2010;115(14):2910-2918.

32. Odero MD, Grand FH, Iqbal S, et al. Disruption and aberrant expression of HMGA2 as a consequence of diverse chromosomal translocations in myeloid malignancies. Leukemia. 2005;19(2):245252.

33. Bagga $\mathrm{S}$, Bracht $\mathrm{J}$, Hunter $\mathrm{S}$, et al. Regulation by let-7 and lin- 4 miRNAs results in target mRNA degradation. Cell. 2005;122(4):553563. 


\section{SUPPLEMENTARY MATERIALS}

Suppl. Table 1. List of miRNAs expressed in $E Y F P^{+} ; C D 11 b^{+}$control cells

\begin{tabular}{|c|c|c|c|c|c|}
\hline & miRNA & $\begin{array}{l}\text { Expression after } \\
\text { Dicer1 deletion }\end{array}$ & & miRNA & $\begin{array}{l}\text { Expression after } \\
\text { Dicer1 deletion }\end{array}$ \\
\hline 1 & mmu-let-7f & not detectable & 69 & mmu-miR-15b & not detectable \\
\hline 2 & mmu-miR-124 & not detectable & 70 & mmu-miR-195 & not detectable \\
\hline 3 & mmu-miR-188-3p & not detectable & 71 & mmu-miR-20a & not detectable \\
\hline 4 & mmu-miR-339-3p & not detectable & 72 & mmu-miR-125b-5p & not detectable \\
\hline 5 & mmu-miR-500 & not detectable & 73 & mmu-miR-136 & not detectable \\
\hline 6 & mmu-miR-677 & not detectable & 74 & mmu-miR-484 & not detectable \\
\hline 7 & mmu-miR-582-5p & not detectable & 75 & mmu-miR-17 & not detectable \\
\hline 8 & mmu-miR-547 & not detectable & 76 & mmu-miR-126-5p & not detectable \\
\hline 9 & mmu-miR-376b & not detectable & 77 & mmu-miR-148b & not detectable \\
\hline 10 & mmu-miR-197 & not detectable & 78 & mmu-miR-7a & not detectable \\
\hline 11 & mmu-miR-139-5p & not detectable & 79 & mmu-miR-100 & not detectable \\
\hline 12 & mmu-miR-30c & not detectable & 80 & mmu-miR-509-3p & not detectable \\
\hline 13 & mmu-let-7g & not detectable & 81 & mmu-miR-135b & not detectable \\
\hline 14 & mmu-miR-140 & not detectable & 82 & mmu-miR-222 & not detectable \\
\hline 15 & mmu-miR-106b & not detectable & 83 & mmu-miR-30a & not detectable \\
\hline 16 & mmu-miR-25 & not detectable & 84 & mmu-miR-208 & not detectable \\
\hline 17 & mmu-miR-744 & not detectable & 85 & mmu-miR-450b-5p & not detectable \\
\hline 18 & mmu-miR-103 & not detectable & 86 & mmu-miR-107 & not detectable \\
\hline 19 & mmu-miR-322 & not detectable & 87 & mmu-miR-98 & not detectable \\
\hline 20 & mmu-miR-21 & not detectable & 88 & mmu-miR-30d & not detectable \\
\hline 21 & mmu-miR-146b & not detectable & 89 & mmu-let-7i & not detectable \\
\hline 22 & mmu-miR-340-5p & not detectable & 90 & mmu-miR-101a & not detectable \\
\hline 23 & mmu-miR-18a & not detectable & 91 & mmu-miR-873 & not detectable \\
\hline 24 & mmu-miR-301a & not detectable & 92 & mmu-miR-381 & not detectable \\
\hline 25 & mmu-miR-142-5p & not detectable & 93 & mmu-miR-672 & not detectable \\
\hline 26 & mmu-miR-340-3p & not detectable & 94 & mmu-miR-181a & not detectable \\
\hline 27 & mmu-miR-221 & not detectable & 95 & mmu-miR-330 & not detectable \\
\hline 28 & mmu-miR-532-5p & not detectable & 96 & mmu-miR-99a & not detectable \\
\hline 29 & mmu-miR-148a & not detectable & 97 & mmu-miR-296-5p & not detectable \\
\hline 30 & mmu-miR-301b & not detectable & 98 & mmu-miR-465b-5p & not detectable \\
\hline 31 & mmu-miR-425 & not detectable & 99 & mmu-miR-342-3p & not detectable \\
\hline 32 & mmu-let-7e & not detectable & 100 & mmu-miR-324-5p & not detectable \\
\hline 33 & mmu-miR-29c & not detectable & 101 & mmu-miR-145 & not detectable \\
\hline
\end{tabular}




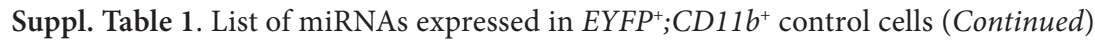

\begin{tabular}{|c|c|c|c|c|c|}
\hline & miRNA & $\begin{array}{l}\text { Expression after } \\
\text { Dicer1 deletion }\end{array}$ & & miRNA & $\begin{array}{l}\text { Expression after } \\
\text { Dicer1 deletion }\end{array}$ \\
\hline 34 & mmu-miR-15a & not detectable & 102 & mmu-miR-127 & not detectable \\
\hline 35 & mmu-miR-200c & not detectable & 103 & mmu-miR-574-3p & not detectable \\
\hline 36 & mmu-miR-93 & not detectable & 104 & mmu-miR-152 & not detectable \\
\hline 37 & mmu-miR-194 & not detectable & 105 & mmu-miR-671-3p & not detectable \\
\hline 38 & mmu-let-7d & not detectable & 106 & mmu-miR-328 & not detectable \\
\hline 39 & mmu-let-7c & not detectable & 107 & mmu-miR-544 & not detectable \\
\hline 40 & mmu-miR-339-5p & not detectable & 108 & mmu-miR-362-3p & not detectable \\
\hline 41 & mmu-miR-130b & not detectable & 109 & mmu-miR-147 & not detectable \\
\hline 42 & mmu-miR-350 & not detectable & 110 & mmu-miR-28 & not detectable \\
\hline 43 & mmu-miR-27b & not detectable & 111 & mmu-miR-186 & not detectable \\
\hline 44 & mmu-miR-10a & not detectable & 112 & mmu-miR-193b & not detectable \\
\hline 45 & mmu-miR-532-3p & not detectable & 113 & mmu-miR-150 & not detectable \\
\hline 46 & mmu-miR-320 & not detectable & 114 & mmu-let-7b & not detectable \\
\hline 47 & mmu-miR-652 & not detectable & 115 & mmu-miR-30e & not detectable \\
\hline 48 & mmu-miR-331-3p & not detectable & 116 & mmu-miR-685 & not detectable \\
\hline 49 & mmu-miR-467a & not detectable & 117 & mmu-miR-192 & not detectable \\
\hline 50 & mmu-miR-20b & not detectable & 118 & mmu-miR-34b-3p & not detectable \\
\hline 51 & mmu-miR-203 & not detectable & 119 & mmu-miR-146a & not detectable \\
\hline 52 & mmu-let-7a & not detectable & 120 & mmu-miR-126-3p & not detectable \\
\hline 53 & mmu-miR-467c & not detectable & 121 & mmu-miR-667 & not detectable \\
\hline 54 & mmu-miR-365 & not detectable & 122 & mmu-miR-546 & not detectable \\
\hline 55 & mmu-miR-423-5p & not detectable & 123 & mmu-miR-155 & not detectable \\
\hline 56 & mmu-miR-135a & not detectable & 124 & mmu-miR-361 & not detectable \\
\hline 57 & mmu-miR-30b & not detectable & 125 & mmu-miR-411 & not detectable \\
\hline 58 & mmu-miR-19a & not detectable & 126 & mmu-miR-410 & not detectable \\
\hline 59 & mmu-miR-872 & not detectable & 127 & mmu-miR-188-5p & not detectable \\
\hline 60 & mmu-miR-26b & not detectable & 128 & mmu-miR-331-5p & not detectable \\
\hline 61 & mmu-miR-142-3p & not detectable & 129 & mmu-miR-223 & $0.07 \%$ of $\mathrm{WT}$ \\
\hline 62 & mmu-miR-29a & not detectable & 130 & mmu-miR-16 & $0.29 \%$ of WT \\
\hline 63 & mmu-miR-450a-5p & not detectable & 131 & mmu-miR-24 & $0.32 \%$ of $\mathrm{WT}$ \\
\hline 64 & mmu-miR-467b & not detectable & 132 & mmu-miR-19b & $0.62 \%$ of $\mathrm{WT}$ \\
\hline 65 & mmu-miR-345-5p & not detectable & 133 & mmu-miR-191 & $0.77 \%$ of $\mathrm{WT}$ \\
\hline 66 & mmu-miR-185 & not detectable & 134 & mmu-miR-106a & $2.06 \%$ of $\mathrm{WT}$ \\
\hline 67 & mmu-miR-26a & not detectable & 135 & mmu-miR-92a & $2.23 \%$ of $\mathrm{WT}$ \\
\hline 68 & mmu-miR-27a & not detectable & 136 & mmu-miR-494 & $6.92 \%$ of WT \\
\hline
\end{tabular}


Suppl. Table 2. List of miRNAs that are expressed in GMPs

\begin{tabular}{|c|c|c|c|c|c|c|c|}
\hline & miRNA & family & $\mathrm{Ct}$ & & miRNA & family & $\mathrm{Ct}$ \\
\hline 1 & mmu-let-7e & let-7 & 24,7 & 53 & mmu-miR-194 & $\operatorname{mir}-194$ & 27,8 \\
\hline 2 & mmu-let-7g & let-7 & 25,8 & 54 & mmu-miR-196b & $\operatorname{mir}-196$ & 24,2 \\
\hline 3 & mmu-let-7i & let-7 & 27,2 & 55 & mmu-miR-199a-3p & mir-199 & 30,8 \\
\hline 4 & mmu-let-7d & let-7 & 27,8 & 56 & mmu-miR-203 & mir-203 & 27,4 \\
\hline 5 & mmu-let-7b & let-7 & 29,8 & 57 & mmu-miR-222 & $\operatorname{mir}-221$ & 20,9 \\
\hline 6 & mmu-let-7c & let-7 & 27,5 & 58 & mmu-miR-223 & $\operatorname{mir}-223$ & 19,6 \\
\hline 7 & mmu-miR-10a & $\operatorname{mir}-10$ & 30,4 & 59 & mmu-miR-24 & $\operatorname{mir}-24$ & 20,4 \\
\hline 8 & mmu-miR-101a & $\operatorname{mir}-101$ & 27,1 & 60 & mmu-miR-25 & $\operatorname{mir}-25$ & 30,4 \\
\hline 9 & mmu-miR-103 & mir-103 & 27,5 & 61 & mmu-miR-92a & $\operatorname{mir}-25$ & 21,8 \\
\hline 10 & mmu-miR-124 & $\operatorname{mir}-124$ & 30,1 & 62 & mmu-miR-26b & $\operatorname{mir}-26$ & 29,9 \\
\hline 11 & mmu-miR-125b-5p & $\operatorname{mir}-125$ & 25,8 & 63 & mmu-miR-26a & $\operatorname{mir}-26$ & 27,2 \\
\hline 12 & mmu-miR-125a-5p & $\operatorname{mir}-125$ & 25,8 & 64 & mmu-miR-27a & $\operatorname{mir}-27$ & 29,9 \\
\hline 13 & mmu-miR-126-5p & $\operatorname{mir}-126-5 p$ & 27,3 & 65 & mmu-miR-27b & $\operatorname{mir}-27$ & 30,5 \\
\hline 14 & mmu-miR-126-3p & $\operatorname{mir}-126-3 p$ & 23,2 & 66 & mmu-miR-28 & $\operatorname{mir}-28$ & 28,4 \\
\hline 15 & mmu-miR-130b & $\operatorname{mir}-130$ & 27,9 & 67 & mmu-miR-29c & $\operatorname{mir}-29$ & 24,8 \\
\hline 16 & mmu-miR-301a & $\operatorname{mir}-130$ & 30,1 & 68 & mmu-miR-29a & $\operatorname{mir}-29$ & 25,3 \\
\hline 17 & mmu-miR-133b & mir-133 & 30,6 & 69 & mmu-miR-30b & $\operatorname{mir}-30$ & 23,2 \\
\hline 18 & mmu-miR-133a & mir-133 & 24,7 & 70 & mmu-miR-30d & $\operatorname{mir}-30$ & 23,8 \\
\hline 19 & mmu-miR-138 & $\operatorname{mir}-138$ & 29,8 & 71 & mmu-miR-30e & $\operatorname{mir}-30$ & 24,8 \\
\hline 20 & mmu-miR-139-3p & $\operatorname{mir}-139-3 p$ & 27,3 & 72 & mmu-miR-30a & $\operatorname{mir}-30$ & 28,6 \\
\hline 21 & mmu-miR-139-5p & mir-139-5p & 23,6 & 73 & mmu-miR-30c & $\operatorname{mir}-30$ & 23,8 \\
\hline 22 & mmu-miR-140 & mir-140 & 26,4 & 74 & mmu-miR-301b & $\operatorname{mir}-301 b$ & 28,8 \\
\hline 23 & mmu-miR-142-3p & $\operatorname{mir}-142$ & 26,2 & 75 & mmu-miR-31 & mir-31 & 29,5 \\
\hline 24 & mmu-miR-146a & mir-146 & 23,1 & 76 & mmu-miR-320 & $\operatorname{mir}-320$ & 23,2 \\
\hline 25 & mmu-miR-146b & $\operatorname{mir}-146$ & 19,7 & 77 & mmu-miR-324-5p & $\operatorname{mir}-324-5 p$ & 31,8 \\
\hline 26 & mmu-miR-148a & $\operatorname{mir}-148$ & 28,1 & 78 & mmu-miR-328 & $\operatorname{mir}-328$ & 26,3 \\
\hline 27 & mmu-miR-152 & $\operatorname{mir}-148$ & 30,5 & 79 & mmu-miR-331-3p & $\operatorname{mir}-331-3 p$ & 26,3 \\
\hline 28 & mmu-miR-148b & $\operatorname{mir}-148$ & 30,7 & 80 & mmu-miR-339-3p & $\operatorname{mir}-339-3 p$ & 24,6 \\
\hline 29 & mmu-miR-195 & $\operatorname{mir}-15$ & 25,5 & 81 & mmu-miR-340-3p & $\operatorname{mir}-340-3 p$ & 29,1 \\
\hline 30 & mmu-miR-15b & $\operatorname{mir}-15$ & 25,7 & 82 & mmu-miR-340-5p & $\operatorname{mir}-340-5 p$ & 27,8 \\
\hline 31 & mmu-miR-16 & $\operatorname{mir}-15$ & 19,4 & 83 & mmu-miR-342-3p & $\operatorname{mir}-342-3 p$ & 23,2 \\
\hline 32 & mmu-miR-150 & $\operatorname{mir}-150$ & 20,3 & 84 & mmu-miR-365 & $\operatorname{mir}-365$ & 31,9 \\
\hline 33 & mmu-miR-494 & $\operatorname{mir}-154$ & 30,7 & 85 & mmu-miR-423-5p & $\operatorname{mir}-423-5 p$ & 31,8 \\
\hline 34 & mmu-miR-155 & $\operatorname{mir}-155$ & 23,3 & 86 & mmu-miR-425 & $\operatorname{mir}-425$ & 25,2 \\
\hline 35 & mmu-miR-106a & $\operatorname{mir}-17$ & 20,2 & 87 & mmu-miR-467a & $\operatorname{mir}-467$ & 29,5 \\
\hline 36 & mmu-miR-17 & $\operatorname{mir}-17$ & 20,9 & 88 & mmu-miR-467b & $\operatorname{mir}-467$ & 28,9 \\
\hline
\end{tabular}


Suppl. Table 2. List of miRNAs that are expressed in GMPs (Continued)

\begin{tabular}{llllllll}
\hline & miRNA & family & Ct & miRNA & family & Ct \\
\hline 37 & mmu-miR-20a & mir-17 & 23,8 & 89 & mmu-miR-484 & mir-484 & 19,9 \\
\hline 38 & mmu-miR-93 & mir-17 & 25,3 & 90 & mmu-miR-486 & mir-486 & 27,3 \\
\hline 39 & mmu-miR-106b & mir-17 & 27,5 & 91 & mmu-miR-503 & mir-503 & 28,0 \\
\hline 40 & mmu-miR-18a & mir-17 & 28,2 & 92 & mmu-miR-532-5p & mir-532-5p & 30,0 \\
\hline 41 & mmu-miR-20b & mir-17 & 24,7 & 93 & mmu-miR-547 & mir-547 & 31,4 \\
\hline 42 & mmu-miR-181c & mir-181 & 31,9 & 94 & mmu-miR-574-3p & mir-574-3p & 24,2 \\
\hline 43 & mmu-miR-181a & mir-181 & 28,2 & 95 & mmu-miR-652 & mir-652 & 31,0 \\
\hline 44 & mmu-miR-184 & mir-184 & 26,5 & 96 & mmu-miR-672 & mir-672 & 31,0 \\
\hline 45 & mmu-miR-186 & mir-186 & 22,9 & 97 & mmu-miR-676 & mir-676 & 31,3 \\
\hline 46 & mmu-miR-188-5p & mir-188 & 28,8 & 98 & mmu-miR-680 & mir-680 & 29,6 \\
\hline 47 & mmu-miR-532-3p & mir-188 & 28,5 & 99 & mmu-miR-682 & mir-682 & 26,3 \\
\hline 48 & mmu-miR-19a & mir-19 & 23,7 & 100 & mmu-miR-685 & mir-685 & 26,8 \\
\hline 49 & mmu-miR-19b & mir-19 & 21,8 & 101 & mmu-miR-744 & mir-744 & 26,0 \\
\hline 50 & mmu-miR-191 & mir-191 & 15,5 & 102 & mmu-miR-200c & mir-8 & 25,7 \\
\hline 51 & mmu-miR-192 & mir-192 & 28,5 & 103 & mmu-miR-872 & mir-872 & 29,4 \\
\hline 52 & mmu-miR-193b & mir-193 & 28,6 & 104 & mmu-miR-100 & mir-99 & 31,6 \\
\hline & $\begin{array}{l}\text { MammU6 } \\
\text { (loading cont.) }\end{array}$ & & 14,2 & & ath-miR-159a & & 40,0 \\
\hline
\end{tabular}


Suppl.Table 3. Up-regulated and not regulated expressed probe sets. Probesets shown in bold are significantly derepressed also by Dicer 1 heterozygous deletion

\begin{tabular}{|c|c|c|c|}
\hline & probes & Gene Symbol & Fold induction $\Delta \Delta / \mathrm{wt}$ \\
\hline 1 & 1438254_at & 1110007A13Rik & 1,228 \\
\hline 2 & 1434613_at & 1810013L24Rik & 1,498 \\
\hline 3 & 1425193_at & 2010106G01Rik & 1,301 \\
\hline 4 & 1452159_at & 2310001A20Rik & 1,365 \\
\hline 5 & 1452607_at & 2610030H06Rik & 1,341 \\
\hline 6 & 1455352_at & 2610101N10Rik & 1,409 \\
\hline 7 & 1423472_at & 2-Sep & 1,523 \\
\hline 8 & 1427978_at & 4732418C07Rik & 1,504 \\
\hline 9 & 1428236_at & Acbd5 & 1,797 \\
\hline 10 & 1423883_at & Acsl1 & 1,346 \\
\hline 11 & 1428585_at & Actn1 & 1,647 \\
\hline 12 & 1416094_at & Adam9 & 2,394 \\
\hline 13 & 1454918_at & Agps & 1,828 \\
\hline 14 & 1435879_at & Akt3 & 1,822 \\
\hline 15 & 1448104_at & Aldh6a1 & 1,835 \\
\hline 16 & 1422573_at & Ampd3 & 1,875 \\
\hline 17 & 1429193_at & Ankibl & 1,681 \\
\hline 18 & 1433543_at & Anln & 1,464 \\
\hline 19 & 1427077_a_at & Ap2b1 & 1,617 \\
\hline 20 & 1427442_a_at & App & 1,580 \\
\hline 21 & 1434039_at & Appbp2 & 1,398 \\
\hline 22 & 1451251_at & Appbp2 & 1,492 \\
\hline 23 & 1455166_at & Arl5b & 1,274 \\
\hline 24 & 1434949_at & Armc8 & 1,660 \\
\hline 25 & 1455113_at & Armc8 & 2,054 \\
\hline 26 & 1450685_at & Arpp19 & 1,833 \\
\hline 27 & 1416735_at & Asah1 & 1,522 \\
\hline 28 & 1450072_at & Ash11 & 1,874 \\
\hline 29 & 1426015_s_at & Asph & 3,941 \\
\hline 30 & 1427250_at & Atp2a2 & 1,231 \\
\hline 31 & 1437688_x_at & Atp6ap2 & 1,233 \\
\hline 32 & 1423662_at & Atp6ap2 & 1,301 \\
\hline 33 & 1438925_x_at & Atp6v0c & 1,285 \\
\hline 34 & 1436921_at & Atp7a & 2,450 \\
\hline 35 & 1455507_s_at & Atxn1l & 1,540 \\
\hline 36 & 1423228_at & B4galt6 & 2,163 \\
\hline
\end{tabular}


Suppl.Table 3. Up-regulated and not regulated expressed probe sets. Probesets shown in bold are significantly derepressed also by Dicer 1 heterozygous deletion (Continued)

\begin{tabular}{|c|c|c|c|}
\hline & probes & Gene Symbol & Fold induction $\Delta \Delta / \mathrm{wt}$ \\
\hline 37 & 1434352_at & B630005N14Rik & 1,509 \\
\hline 38 & 1440831_at & Bach1 & 1,636 \\
\hline 39 & 1435240_at & Baz2b & 1,289 \\
\hline 40 & 1424025_at & ВC013529 & 1,659 \\
\hline 41 & 1424026_s_at & BC013529 & 1,855 \\
\hline 42 & 1424663_at & BC017647 & 1,499 \\
\hline 43 & 1417077_at & Bcap29 & 1,397 \\
\hline 44 & 1456005_a_at & Bcl2111 & 1,788 \\
\hline 45 & 1417493_at & Bmil & 1,238 \\
\hline 46 & 1458370_at & Bmp2k & 2,531 \\
\hline 47 & 1437419_at & Bmp2k & 1,751 \\
\hline 48 & 1422490_at & Bnip2 & 1,286 \\
\hline 49 & 1454874_at & Btbd7 & 1,450 \\
\hline 50 & 1451222_at & Btf314 & 1,343 \\
\hline 51 & 1451202_at & C330007P06Rik & 1,487 \\
\hline 52 & 1417461_at & Cap1 & 2,826 \\
\hline 53 & 1451980_at & Casd1 & 1,376 \\
\hline 54 & 1435972_at & Cast & 1,325 \\
\hline 55 & 1417327_at & Cav2 & 6,869 \\
\hline 56 & 1420827_a_at & Ccng1 & 1,766 \\
\hline 57 & 1424420_at & Ccpg1 & 1,395 \\
\hline 58 & 1437670_x_at & Cd151 & 1,416 \\
\hline 59 & 1416440_at & Cd164 & 1,327 \\
\hline 60 & 1420907_at & Cd2ap & 1,723 \\
\hline 61 & 1417740_at & Cdc3711 & 1,485 \\
\hline 62 & 1434082_at & Cdk17 & 1,504 \\
\hline 63 & 1424638_at & Cdknla & 3,539 \\
\hline 64 & 1434045_at & Cdkn1b & 1,357 \\
\hline 65 & 1427630_x_at & Ceacam1 & 1,967 \\
\hline 66 & 1425538_x_at & Ceacam 1 & 2,059 \\
\hline 67 & 1426407_at & Celf1 & 1,276 \\
\hline 68 & 1427413_a_at & Celf1 & 1,467 \\
\hline 69 & 1418066_at & $\mathrm{Cfl} 2$ & 1,770 \\
\hline 70 & 1418067_at & Cfl2 & 3,370 \\
\hline 71 & 1448026_at & Chd7 & 1,707 \\
\hline
\end{tabular}


Suppl.Table 3. Up-regulated and not regulated expressed probe sets. Probesets shown in bold are significantly derepressed also by Dicer 1 heterozygous deletion (Continued)

\begin{tabular}{|c|c|c|c|}
\hline & probes & Gene Symbol & Fold induction $\Delta \Delta / \mathrm{wt}$ \\
\hline 72 & 1438606_a_at & Clic4 & 1,501 \\
\hline 73 & 1450484_a_at & Cmpk2 & 1,725 \\
\hline 74 & 1426682_at & Cnot6 & 1,666 \\
\hline 75 & 1423641_s_at & Cnot7 & 1,404 \\
\hline 76 & 1434547_at & Cpd & 1,767 \\
\hline 77 & 1420618_at & Cpeb4 & 1,737 \\
\hline 78 & 1452857_at & Crebzf & 1,433 \\
\hline 79 & 1448248_at & Crk & 1,799 \\
\hline 80 & 1450966_at & Crot & 1,381 \\
\hline 81 & 1448592_at & Crtap & 1,674 \\
\hline 82 & 1448128_at & Ctsa & 1,238 \\
\hline 83 & 1433908_a_at & $\mathrm{Cttn}$ & 7,351 \\
\hline 84 & 1423917_a_at & Cttn & 5,069 \\
\hline 85 & 1417454_at & Cul4b & 1,556 \\
\hline 86 & 1422186_s_at & Cyb5r3 & 1,702 \\
\hline 87 & 1423043_s_at & $\operatorname{Ddx} 3 \mathrm{x}$ & 1,326 \\
\hline 88 & 1448438_at & Derl2 & 1,308 \\
\hline 89 & 1454654_at & Dirc2 & 1,130 \\
\hline 90 & 1417182_at & Dnaja2 & 2,070 \\
\hline 91 & 1417191_at & Dnajb9 & 1,497 \\
\hline 92 & 1428086_at & Dnm1l & 1,341 \\
\hline 93 & 1424782_at & Dram2 & 1,541 \\
\hline 94 & 1459854_s_at & Dynlt3 & 1,458 \\
\hline 95 & 1424065_at & Edem 1 & 1,245 \\
\hline 96 & 1434331_at & Eif2c1 & 1,266 \\
\hline 97 & 1423220_at & Eif4e & 1,240 \\
\hline 98 & 1415856_at & Emb & 1,405 \\
\hline 99 & 1435264_at & Emilin2 & 1,753 \\
\hline 100 & 1424800_at & Enah & 2,196 \\
\hline 101 & 1435223_at & Erlin2 & 1,713 \\
\hline 102 & 1433702_at & Ermp1 & 1,271 \\
\hline 103 & 1449324_at & Eroll & 1,789 \\
\hline 104 & 1433514_at & Etnk1 & 1,460 \\
\hline 105 & 1417513_at & Evi5 & 1,905 \\
\hline 106 & 1417512_at & Evi5 & 2,167 \\
\hline
\end{tabular}


Suppl.Table 3. Up-regulated and not regulated expressed probe sets. Probesets shown in bold are significantly derepressed also by Dicer 1 heterozygous deletion (Continued)

\begin{tabular}{|c|c|c|c|}
\hline & probes & Gene Symbol & Fold induction $\Delta \Delta / \mathrm{wt}$ \\
\hline 107 & 1433572_a_at & Fam120a & 1,286 \\
\hline 108 & 1424683_at & Fam134b & 1,658 \\
\hline 109 & 1455429_at & Fam160b1 & 1,351 \\
\hline 110 & 1417953_at & $\operatorname{Fam} 3 c$ & 1,653 \\
\hline 111 & 1448904_at & Fam $3 \mathrm{c}$ & 1,764 \\
\hline 112 & 1431337_a_at & Fam 45a & 1,449 \\
\hline 113 & 1436842_at & Fam63b & 1,588 \\
\hline 114 & 1429503_at & Fam69a & 1,470 \\
\hline 115 & 1435315_s_at & Farl & 1,381 \\
\hline 116 & 1451558_at & Fbxw7 & 1,267 \\
\hline 117 & 1435801_at & Fktn & 1,924 \\
\hline 118 & 1443863_at & Fndc3a & 1,904 \\
\hline 119 & 1426903_at & Fndc3a & 2,807 \\
\hline 120 & 1433833_at & Fndc3b & 1,972 \\
\hline 121 & 1434002_at & Foxn3 & 1,631 \\
\hline 122 & 1427177_at & Fycol & 2,466 \\
\hline 123 & 1455915_at & Galnt4 & 1,648 \\
\hline 124 & 1452232_at & Galnt7 & 1,601 \\
\hline 125 & 1426908_at & Galnt7 & 1,645 \\
\hline 126 & 1425156_at & Gbp6 & 1,882 \\
\hline 127 & 1435749_at & Gda & 1,816 \\
\hline 128 & 1435748_at & Gda & 2,058 \\
\hline 129 & 1456581_x_at & Gdi2 & 1,169 \\
\hline 130 & 1417679_at & Gfil & 1,518 \\
\hline 131 & 1428715_at & Gfpt1 & 1,759 \\
\hline 132 & 1428681_at & Gm608 & 1,212 \\
\hline 133 & 1429559_at & Gnaq & 1,507 \\
\hline 134 & 1428940_at & Gnaq & 1,640 \\
\hline 135 & 1455729_at & Gnaq & 1,869 \\
\hline 136 & 1428939_s_at & Gnaq & 1,883 \\
\hline 137 & 1428938_at & Gnaq & 2,091 \\
\hline 138 & 1455089_at & Gng12 & 1,664 \\
\hline 139 & 1426524_at & Gnpda2 & 1,480 \\
\hline 140 & 1433546_at & Gns & 1,852 \\
\hline 141 & 1433488_x_at & Gns & 2,377 \\
\hline
\end{tabular}


Suppl.Table 3. Up-regulated and not regulated expressed probe sets. Probesets shown in bold are significantly derepressed also by Dicer 1 heterozygous deletion (Continued)

\begin{tabular}{|c|c|c|c|}
\hline & probes & Gene Symbol & Fold induction $\Delta \Delta / \mathrm{wt}$ \\
\hline 142 & 1415698_at & Golm1 & 2,231 \\
\hline 143 & 1428323_at & Gpd2 & 1,627 \\
\hline 144 & 1437171_x_at & Gsn & 1,763 \\
\hline 145 & 1456312_x_at & Gsn & 1,866 \\
\hline 146 & 1436991_x_at & Gsn & 1,907 \\
\hline 147 & 1434876_at & Gxylt1 & 1,473 \\
\hline 148 & 1420376_a_at & $\mathrm{H} 3 \mathrm{f} 3 \mathrm{~b}$ & 1,247 \\
\hline 149 & 1460367_at & Hbp1 & 1,321 \\
\hline 150 & 1434478_at & $\mathrm{Heca}$ & 1,385 \\
\hline 151 & 1427418_a_at & Hifla & 1,686 \\
\hline 152 & 1428433_at & Hipk2 & 1,559 \\
\hline 153 & 1450780_s_at & Hmga2 & 6,915 \\
\hline 154 & 1422851_at & Hmga2 & 18,200 \\
\hline 155 & 1450781_at & Hmga2 & 14,215 \\
\hline 156 & 1433443_a_at & Hmgcs1 & 1,599 \\
\hline 157 & 1433445_x_at & Hmgcs1 & 1,603 \\
\hline 158 & 1452712_at & Hnrnpa3 & 1,156 \\
\hline 159 & 1456698_s_at & Hnrpdl & 1,199 \\
\hline 160 & 1455626_at & Hoxa9 & 4,052 \\
\hline 161 & 1415889_a_at & Hsp90b1 & 1,396 \\
\hline 162 & 1452982_at & Igf1r & 1,814 \\
\hline 163 & 1433732_x_at & Igf2bp3 & 14,093 \\
\hline 164 & 1433731_at & Igf2bp3 & 15,548 \\
\hline 165 & 1422611_s_at & Igf2bp3 & 14,381 \\
\hline 166 & 1422610_s_at & $\operatorname{Igf} 2 \mathrm{bp} 3$ & 28,606 \\
\hline 167 & 1437289_at & Impad1 & 2,180 \\
\hline 168 & 1437290_at & Impad1 & 2,316 \\
\hline 169 & 1436069_at & Ing5 & 1,222 \\
\hline 170 & 1434446_at & Insr & 1,290 \\
\hline 171 & 1419041_at & Itfg1 & 1,194 \\
\hline 172 & 1452784_at & Itgav & 2,514 \\
\hline 173 & 1435023_at & Itsn 2 & 1,650 \\
\hline 174 & 1434037_s_at & Kat $2 b$ & 2,213 \\
\hline 175 & 1455816_a_at & Kctd3 & 1,281 \\
\hline 176 & 1418629_a_at & Khdrbs1 & 1,118 \\
\hline
\end{tabular}


Suppl.Table 3. Up-regulated and not regulated expressed probe sets. Probesets shown in bold are significantly derepressed also by Dicer 1 heterozygous deletion (Continued)

\begin{tabular}{|c|c|c|c|}
\hline & probes & Gene Symbol & Fold induction $\Delta \Delta / w t$ \\
\hline 177 & 1418431_at & Kif5b & 1,384 \\
\hline 178 & 1418430_at & Kif5b & 1,500 \\
\hline 179 & 1426530_a_at & Klhl5 & 1,299 \\
\hline 180 & 1449505_at & Kpna1 & 1,556 \\
\hline 181 & 1460260_s_at & Kpna1 & 1,741 \\
\hline 182 & 1419548_at & Kpna1 & 1,871 \\
\hline 183 & 1451979_at & Kras & 1,373 \\
\hline 184 & 1434000_at & Kras & 1,554 \\
\hline 185 & 1435739_at & Lats1 & 1,793 \\
\hline 186 & 1443779_s_at & Lcor & 3,658 \\
\hline 187 & 1455121_at & Lcor & 4,612 \\
\hline 188 & 1455260_at & Lcorl & 1,685 \\
\hline 189 & 1434129_s_at & Lhfpl2 & 1,745 \\
\hline 190 & 1435326_at & Lpgat1 & 1,699 \\
\hline 191 & 1440167_s_at & Lpp & 2,452 \\
\hline 192 & 1435461_at & Magi3 & 1,726 \\
\hline 193 & 1439830_at & Map3k5 & 1,614 \\
\hline 194 & 1426245_s_at & Mapre2 & 1,356 \\
\hline 195 & 1451989_a_at & Mapre2 & 1,509 \\
\hline 196 & 1456028_x_at & Marcks & 3,748 \\
\hline 197 & 1456700_x_at & Marcks & 2,607 \\
\hline 198 & 1415971_at & Marcks & 2,674 \\
\hline 199 & 1415973_at & Marcks & 2,529 \\
\hline 200 & 1427040_at & Mdfic & 1,712 \\
\hline 201 & 1423610_at & Metap2 & 1,210 \\
\hline 202 & 1434120_a_at & Metap2 & 1,223 \\
\hline 203 & 1424463_at & Mfsd6 & 2,692 \\
\hline 204 & 1424464_s_at & Mfsd6 & 3,280 \\
\hline 205 & 1435641_at & Mgat4a & 2,023 \\
\hline 206 & 1434179_at & Ml13 & 1,288 \\
\hline 207 & 1423488_at & Mmd & 1,276 \\
\hline 208 & 1453032_at & Mobkl3 & 1,430 \\
\hline 209 & 1423168_at & Mobkl3 & 1,884 \\
\hline 210 & 1424124_at & Mospd2 & 1,421 \\
\hline 211 & 1418514_at & Mtf2 & 1,215 \\
\hline
\end{tabular}


Suppl.Table 3. Up-regulated and not regulated expressed probe sets. Probesets shown in bold are significantly derepressed also by Dicer 1 heterozygous deletion (Continued)

\begin{tabular}{|c|c|c|c|}
\hline & probes & Gene Symbol & Fold induction $\Delta \Delta / \mathrm{wt}$ \\
\hline 212 & 1452608_at & Mycbp & 1,587 \\
\hline 213 & 1419648_at & Myolc & 2,003 \\
\hline 214 & 1419649_s_at & Myolc & 3,015 \\
\hline 215 & 1436051_at & Myo5a & 1,885 \\
\hline 216 & 1428453_at & Naa30 & 1,396 \\
\hline 217 & 1428410_at & Naa50 & 1,322 \\
\hline 218 & 1417624_at & Nabl & 1,651 \\
\hline 219 & 1454952_s_at & Ncapd3 & 1,100 \\
\hline 220 & 1438452_at & Nebl & 5,724 \\
\hline 221 & 1416543_at & $\mathrm{Nfe} 2 \mathrm{l} 2$ & 1,404 \\
\hline 222 & 1454919_at & Nmt2 & 2,282 \\
\hline 223 & 1420487_at & Nol7 & 1,293 \\
\hline 224 & 1456599_at & Nxt2 & 2,670 \\
\hline 225 & 1419534_at & Olr1 & 3,714 \\
\hline 226 & 1422792_at & Pafah1b2 & 1,426 \\
\hline 227 & 1451740_at & Paip1 & 3,327 \\
\hline 228 & 1425521_at & Paip1 & 19,532 \\
\hline 229 & 1428423_at & Pcgf3 & 1,779 \\
\hline 230 & 1419047_at & $\operatorname{Pcn} x$ & 1,581 \\
\hline 231 & 1448527_at & $\operatorname{Pdcd} 10$ & 1,115 \\
\hline 232 & 1448528_at & $\operatorname{Pdcd} 10$ & 1,422 \\
\hline 233 & 1433694_at & Pde3b & 1,895 \\
\hline 234 & 1423423_at & Pdia3 & 1,414 \\
\hline 235 & 1456478_at & Pgm211 & 1,404 \\
\hline 236 & 1452841_at & Pgm211 & 1,491 \\
\hline 237 & 1437067_at & Phtf2 & 1,866 \\
\hline 238 & 1416489_at & Pi4k2b & 1,553 \\
\hline 239 & 1435458_at & Pim1 & 2,208 \\
\hline 240 & 1437295_at & Pkn2 & 2,931 \\
\hline 241 & 1438677_at & Pkp4 & 1,303 \\
\hline 242 & 1417288_at & Plekha2 & 1,613 \\
\hline 243 & 1420840_at & Plekha3 & 1,345 \\
\hline 244 & 1415901_at & Plod3 & 1,730 \\
\hline 245 & 1429019_s_at & Pon2 & 1,518 \\
\hline 246 & 1450686_at & Pon2 & 1,610 \\
\hline
\end{tabular}


Suppl.Table 3. Up-regulated and not regulated expressed probe sets. Probesets shown in bold are significantly derepressed also by Dicer 1 heterozygous deletion (Continued)

\begin{tabular}{|c|c|c|c|}
\hline & probes & Gene Symbol & Fold induction $\Delta \Delta / w t$ \\
\hline 247 & 1425537_at & Ppmla & 1,852 \\
\hline 248 & 1417367_at & Ppp2ca & 1,125 \\
\hline 249 & 1428265_at & Ppp2r1b & 1,117 \\
\hline 250 & 1452056_s_at & Ppp3ca & 1,319 \\
\hline 251 & 1428473_at & Ppp3cb & 1,303 \\
\hline 252 & 1425550_a_at & Prkarla & 1,233 \\
\hline 253 & 1419700_a_at & Prom 1 & 2,229 \\
\hline 254 & 1455724_at & Prrg1 & 1,957 \\
\hline 255 & 1449342_at & Ptplb & 1,544 \\
\hline 256 & 1419642_at & Purb & 1,995 \\
\hline 257 & 1428254_at & Purb & 2,451 \\
\hline 258 & 1427992_a_at & Rab12 & 1,989 \\
\hline 259 & 1419246_s_at & Rab14 & 1,330 \\
\hline 260 & 1418622_at & Rab2a & 1,594 \\
\hline 261 & 1419945_s_at & Rab2a & 1,727 \\
\hline 262 & 1434062_at & Rabgap1l & 1,699 \\
\hline 263 & 1426476_at & Rasa1 & 1,412 \\
\hline 264 & 1418703_at & Rbms1 & 1,654 \\
\hline 265 & 1422449_s_at & $\operatorname{Rcn} 2$ & 1,438 \\
\hline 266 & 1428342_at & Rcor3 & 1,268 \\
\hline 267 & 1450784_at & Reck & 3,960 \\
\hline 268 & 1433976_at & Reep3 & 1,389 \\
\hline 269 & 1452359_at & Rell1 & 1,285 \\
\hline 270 & 1427243_at & Rell1 & 1,692 \\
\hline 271 & 1415747_s_at & Riok3 & 1,141 \\
\hline 272 & 1422650_a_at & Riok3 & 1,482 \\
\hline 273 & 1454064_a_at & Rnf138 & 1,144 \\
\hline 274 & 1419369_at & Rnf138 & 1,382 \\
\hline 275 & 1433655_at & Rnf141 & 1,352 \\
\hline 276 & 1427898_at & Rnf6 & 1,384 \\
\hline 277 & 1452767_at & Rrbp1 & 1,125 \\
\hline 278 & 1436058_at & Rsad2 & 2,345 \\
\hline 279 & 1428219_at & Rybp & 1,377 \\
\hline 280 & 1454704_at & Scarb2 & 1,476 \\
\hline 281 & 1416267_at & Scoc & 2,429 \\
\hline
\end{tabular}


Suppl.Table 3. Up-regulated and not regulated expressed probe sets. Probesets shown in bold are significantly derepressed also by Dicer 1 heterozygous deletion (Continued)

\begin{tabular}{|c|c|c|c|}
\hline & probes & Gene Symbol & Fold induction $\Delta \Delta / \mathrm{wt}$ \\
\hline 282 & 1450941_at & Sdcbp & 1,610 \\
\hline 283 & 1439882_at & Sec23ip & 3,353 \\
\hline 284 & 1433934_at & $\operatorname{Sec} 24 \mathrm{a}$ & 1,738 \\
\hline 285 & 1424925_at & Sec63 & 1,512 \\
\hline 286 & 1448108_at & Serincl & 1,676 \\
\hline 287 & 1435437_at & Setd7 & 1,469 \\
\hline 288 & 1428663_at & Sgms2 & 1,893 \\
\hline 289 & 1437503_a_at & Shisa5 & 1,441 \\
\hline 290 & 1423149_at & Skpla & 1,243 \\
\hline 291 & 1436000_a_at & Skp2 & 1,317 \\
\hline 292 & 1437033_a_at & Skp2 & 1,483 \\
\hline 293 & 1452286_at & Slain2 & 1,291 \\
\hline 294 & 1417902_at & Slc19a2 & 2,045 \\
\hline 295 & 1441315_s_at & Slc19a2 & 2,087 \\
\hline 296 & 1452717_at & Slc25a24 & 1,801 \\
\hline 297 & 1419657_a_at & Slc25a36 & 1,249 \\
\hline 298 & 1417061_at & Slc40a1 & 3,155 \\
\hline 299 & 1438673_at & Slc4a7 & 1,451 \\
\hline 300 & 1438116_x_at & Slc9a3r1 & 1,182 \\
\hline 301 & 1422486_a_at & Smad4 & 1,372 \\
\hline 302 & 1422487_at & Smad4 & 1,380 \\
\hline 303 & 1435251_at & Snx13 & 2,261 \\
\hline 304 & 1436015_s_at & Stk4 & 1,229 \\
\hline 305 & 1421664_a_at & Styx & 1,402 \\
\hline 306 & 1429711_at & Styx & 1,550 \\
\hline 307 & 1424603_at & Sumf1 & 1,333 \\
\hline 308 & 1426666_a_at & Sun1 & 1,666 \\
\hline 309 & 1454961_at & Synj1 & 1,360 \\
\hline 310 & 1426357_at & Taok1 & 1,646 \\
\hline 311 & 1455432_at & Taok1 & 2,225 \\
\hline 312 & 1430133_at & Tbcld8b & 2,080 \\
\hline 313 & 1436226_at & Tceb1 & 1,272 \\
\hline 314 & 1452213_at & Tex2 & 1,526 \\
\hline 315 & 1420895_at & Tgfbrl & 2,059 \\
\hline 316 & 1426397_at & Tgfbr2 & 2,462 \\
\hline
\end{tabular}


Suppl.Table 3. Up-regulated and not regulated expressed probe sets. Probesets shown in bold are significantly derepressed also by Dicer 1 heterozygous deletion (Continued)

\begin{tabular}{|c|c|c|c|}
\hline & probes & Gene Symbol & Fold induction $\Delta \Delta / \mathrm{wt}$ \\
\hline 317 & 1424574_at & Tmed5 & 1,572 \\
\hline 318 & 1428854_at & Tmed8 & 1,848 \\
\hline 319 & 1415741_at & Tmem165 & 1,422 \\
\hline 320 & 1452813_a_at & Tmem 188 & 1,222 \\
\hline 321 & 1451652_a_at & Tmem 188 & 1,248 \\
\hline 322 & 1451458_at & Tmem2 & 2,288 \\
\hline 323 & 1424711_at & Tmem2 & 2,372 \\
\hline 324 & 1452942_at & Tmem65 & 1,800 \\
\hline 325 & 1424454_at & Tmem87a & 4,146 \\
\hline 326 & 1453120_at & $\operatorname{Tm} x 4$ & 1,513 \\
\hline 327 & 1425036_a_at & Tnrc6a & 1,567 \\
\hline 328 & 1455128_x_at & Tnrc6a & 1,693 \\
\hline 329 & 1434898_at & Tnrc6a & 1,723 \\
\hline 330 & 1439244_a_at & Tnrc6a & 1,739 \\
\hline 331 & 1455141_at & Tnrc6a & 2,223 \\
\hline 332 & 1434899_s_at & Tnrc6a & 2,047 \\
\hline 333 & 1455333_at & Tns3 & 1,429 \\
\hline 334 & 1435526_at & Tor1aip2 & 1,915 \\
\hline 335 & 1434768_at & Tpp1 & 1,512 \\
\hline 336 & 1427407_s_at & Trip11 & 1,681 \\
\hline 337 & 1416926_at & Trp53inp1 & 2,448 \\
\hline 338 & 1420875_at & Twf1 & 1,922 \\
\hline 339 & 1428945_at & Uba6 & 1,609 \\
\hline 340 & 1417609_at & Ube2a & 1,555 \\
\hline 341 & 1416943_at & Ube2e1 & 1,222 \\
\hline 342 & 1426461_at & Ugp2 & 1,339 \\
\hline 343 & 1435325_at & Usp46 & 1,569 \\
\hline 344 & 1452011_a_at & Uxs1 & 1,731 \\
\hline 345 & 1437708_x_at & Vamp3 & 1,803 \\
\hline 346 & 1456245_x_at & Vamp3 & 1,906 \\
\hline 347 & 1415990_at & Vdac2 & 1,179 \\
\hline 348 & 1438118_x_at & Vim & 1,267 \\
\hline 349 & 1456292_a_at & Vim & 1,399 \\
\hline 350 & 1451720_at & Vps39 & 1,981 \\
\hline 351 & 1449095_at & Vps54 & 2,113 \\
\hline
\end{tabular}


Suppl.Table 3. Up-regulated and not regulated expressed probe sets. Probesets shown in bold are significantly derepressed also by Dicer 1 heterozygous deletion (Continued)

\begin{tabular}{|c|c|c|c|}
\hline & probes & Gene Symbol & Fold induction $\Delta \Delta / \mathrm{wt}$ \\
\hline 352 & 1418479_at & Vps54 & 2,079 \\
\hline 353 & 1451495_at & Wac & 1,358 \\
\hline 354 & 1452193_a_at & Wasl & 2,276 \\
\hline 355 & 1434076_at & Wdr37 & 1,466 \\
\hline 356 & 1427098_at & Wwp1 & 1,863 \\
\hline 357 & 1452299_at & Wwpl & 1,966 \\
\hline 358 & 1455111_at & Yipf6 & 1,694 \\
\hline 359 & 1426842_at & Ythdf3 & 1,349 \\
\hline 360 & 1426841_at & Ythdf3 & 1,602 \\
\hline 361 & 1428779_at & Zbtb41 & 2,474 \\
\hline 362 & 1439089_at & Zbtb41 & 2,133 \\
\hline 363 & 1449947_s_at & Zfhx3 & 2,934 \\
\hline 364 & 1433623_at & Zfp367 & 2,225 \\
\hline 365 & 1460589_at & Zfp597 & 2,233 \\
\hline 366 & 1429615_at & Zfp91 & 1,339 \\
\hline 367 & 1424670_s_at & Zfyve21 & 1,360 \\
\hline 368 & 1452970_at & Zmym2 & 1,216 \\
\hline
\end{tabular}


Suppl.Table 4. Upregulated genes in Dicer null GMPs linked to lineage-affiliated signatures as published by Samuel Yao-Ming Ng, et al, Immunity 30, 493-507, april 17, 2009.

\begin{tabular}{|c|c|c|}
\hline Gene.Symbol & sign. group & Definition \\
\hline Cav2 & 1 stem & Contains self-renewing genes expressed in \\
\hline Bach1 & 1 & HSCs (LT- + ST-) \\
\hline Hmga2 & $2 \mathrm{~s}-\mathrm{mpp}$ & No significant expression of lineage \\
\hline Hoxa9 & 2 & specific genes expressed in \\
\hline 2210010L05Rik & 2 & HSC/MPP and LMPP \\
\hline Atbf1 & 2 & \\
\hline Tgfbr2 & 2 & \\
\hline Trp53inp1 & 2 & \\
\hline Rsad2 & 2 & \\
\hline Actn1 & 2 & \\
\hline Scotin & 2 & \\
\hline $\mathrm{Cd} 151$ & 2 & \\
\hline Cttn & 3 s-ery & Eerythroid lineage specific genes primed in HSC. \\
\hline Slc40a1 & 3 & 1st wave of erythroid lineage specific expression program in \\
\hline Ampd3 & 3 & HSC/MPP and MEP. \\
\hline 2810423A18Rik & 3 & \\
\hline Tyki & 3 & \\
\hline Ches1 & 3 & \\
\hline Rcor3 & 3 & \\
\hline Hmga2 & 4 s-myly & Lymphoid and myeloid lineage specific genes primed in HSC. \\
\hline Reck & 4 & First wave of lymphoid- and myeloid-lineage -specific \\
\hline Marcks & 4 & expression program in HSC/MPP, LMPP, GMP and ProB. \\
\hline Cdknla & 4 & \\
\hline Fndc3a & 4 & \\
\hline Marcks & 4 & \\
\hline Itgav & 4 & \\
\hline Atp7a & 4 & \\
\hline Snx13 & 4 & \\
\hline Ceacam 1 & 4 & \\
\hline Fndc3b & 4 & \\
\hline Myo5a & 4 & \\
\hline Gnaq & 4 & \\
\hline Mdfic & 4 & \\
\hline AW112037 & 4 & \\
\hline 1810015C04Rik & 4 & \\
\hline LOC675366 & 4 & \\
\hline
\end{tabular}


Suppl.Table 4. Upregulated genes in Dicer null GMPs linked to lineage-affiliated signatures as published by Samuel Yao-Ming Ng, et al, Immunity 30, 493-507, april 17, 2009. (Continued)

\begin{tabular}{|c|c|c|}
\hline Gene.Symbol & sign. group & Definition \\
\hline Plekha2 & 4 & \\
\hline Hmgcs1 & 4 & \\
\hline Pcnx & 4 & \\
\hline Asah1 & 4 & \\
\hline Gfil & 4 & \\
\hline Tns3 & 4 & \\
\hline Emb & 4 & \\
\hline Vim & 4 & \\
\hline Reep3 & 4 & \\
\hline Smad4 & 4 & \\
\hline Ugp2 & 4 & \\
\hline Pkp4 & 4 & \\
\hline Klhl5 & 4 & \\
\hline Baz2b & 4 & \\
\hline Vim & 4 & \\
\hline Slc9a3rl & 4 & \\
\hline Kpnal & 6 diff & No expression with lineage specific genes. \\
\hline D6Wsu176e & 6 & Demarcating a progenitor-restricted state in GMP, MEP and \\
\hline Kif5b & 6 & ProB. \\
\hline Tmem165 & 6 & \\
\hline Pdia3 & 6 & \\
\hline Hsp90b1 & 6 & \\
\hline Sumf1 & 6 & \\
\hline Nat13 & 6 & \\
\hline Atp6ap2 & 6 & \\
\hline Metap2 & 6 & \\
\hline Itfg1 & 6 & \\
\hline Khdrbs1 & 6 & \\
\hline Asph & 7 d-ery & Erythroid progenitor-specific. \\
\hline Purb & 7 & 2rd wave of erythroid lineage specific expression program \\
\hline Scoc & 7 & in MEP. \\
\hline Golph2 & 7 & \\
\hline Wwp1 & 7 & \\
\hline Ccng1 & 7 & \\
\hline Emilin2 & 7 & \\
\hline Lhfpl2 & 7 & \\
\hline
\end{tabular}


Suppl.Table 4. Upregulated genes in Dicer null GMPs linked to lineage-affiliated signatures as published by Samuel Yao-Ming Ng, et al, Immunity 30, 493-507, april 17, 2009. (Continued)

\begin{tabular}{lll}
\hline Gene.Symbol & sign. group & Definition \\
\hline Yipf6 & 7 & \\
\hline Unc84a & 7 & \\
\hline Pon2 & 7 & \\
\hline Usp46 & 7 & \\
\hline Pon2 & 7 & \\
\hline Tpp1 & 7 & \\
\hline Nfe212 & 7 & \\
\hline Pgm211 & 7 & \\
\hline Acs11 & 7 & Myeloid progenitor-specific. \\
\hline Gm608 & 7 & 3rd wave of myeloid lineage program in GMP. \\
\hline Ppp2r1b & 7 & \\
\hline 5133401H06Rik & 8 d-my & \\
\hline Plod3 & 8 & \\
\hline Gng12 & 8 & \\
\hline Tex2 & 8 & \\
\hline Edem1 & 8 & \\
\hline Dirc2 & 8 & \\
\hline & & \\
\hline
\end{tabular}

Suppl.Table 5. List of antibodies

\begin{tabular}{llll}
\hline Antibody & Conjugate & Clone identifier & Company \\
\hline CD3e & Biotin & 145-2C11 & BectonDickinson (BD) Bioscience \\
\hline Ter119 & Biotin & Ter119 & BD Bioscience \\
\hline Gr-1 & Biotin, APC & RB6-8C5 & BD Bioscience \\
\hline CD45R/B220 & Biotin & RA3-6B2 & BD Bioscience \\
\hline CD11b & Biotin, PE & M1/70 & BD Bioscience \\
\hline c-Kit & APC & $2 B 8$ & BD Bioscience \\
\hline Sca-1 & PE-Cy7 & D7 & eBioscience \\
\hline CD16/32 & PE & $2.4 G 2$ & BD Bioscience \\
\hline CD34 & Pacific blue & RAM34 & eBioscience \\
\hline streptavidine & APC-Cy7 & & BD Bioscience \\
\hline MHC class II & Alexa Fluor 700 & M5/114.15.2 & eBioscience \\
\hline CD11c & PE-Cy7 & HL3 & BD Bioscience \\
\hline F4/80 & PE-Cy5 & 200 BM8 & eBioscience \\
\hline Ly6C & Alexa Fluor 700 & & BD Bioscience \\
\hline
\end{tabular}



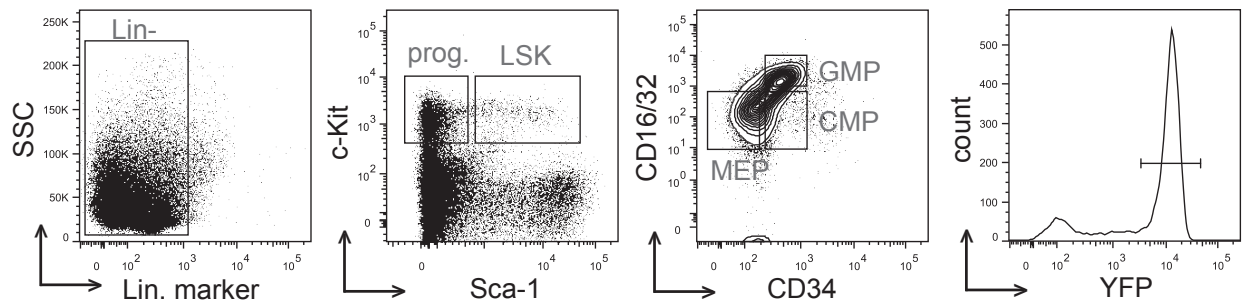

Suppl. Fig. 1. Analysis of the percentage of YFP-positive cells in the progenitor (MEPs, CMPs and GMPs) and the LSK fraction of the bone marrow of transplanted mice.

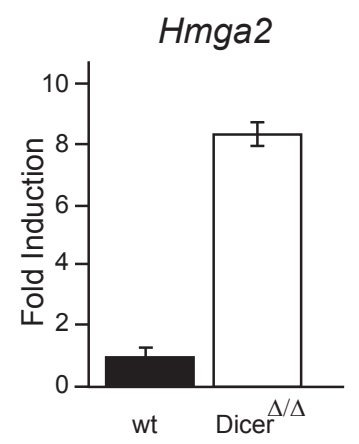

Hoxa9

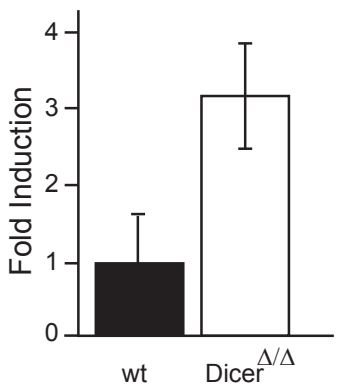

Trp53inp1

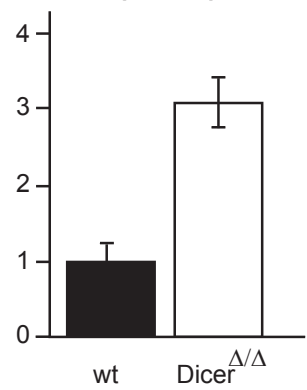

Tgfbr2

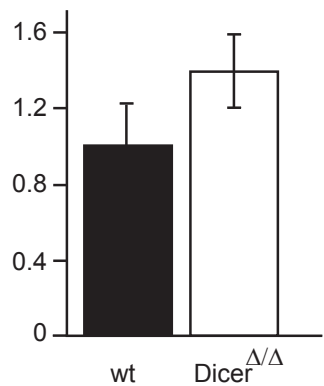

Cdkn1a

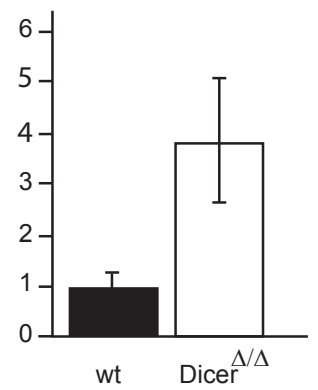

wt

Suppl. Fig. 2. Confirmation of some transcript upregulation in Dicer1 null cells by QPCR. 


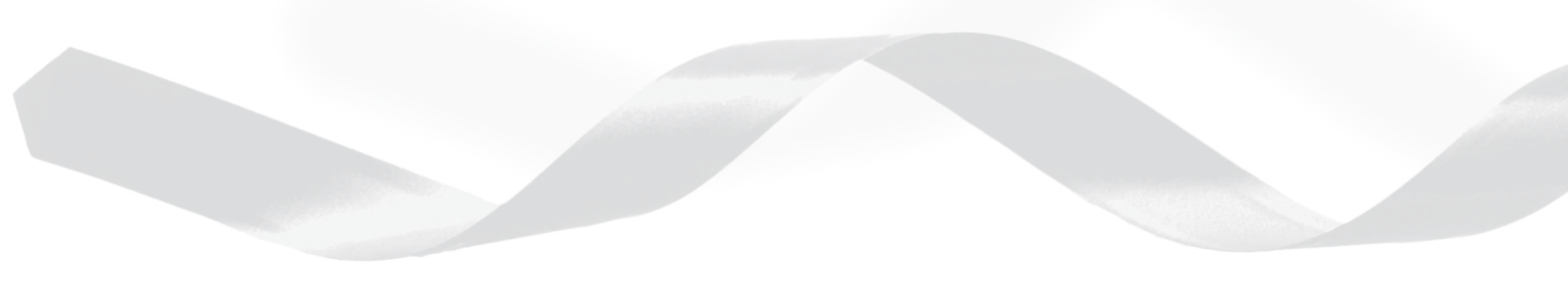




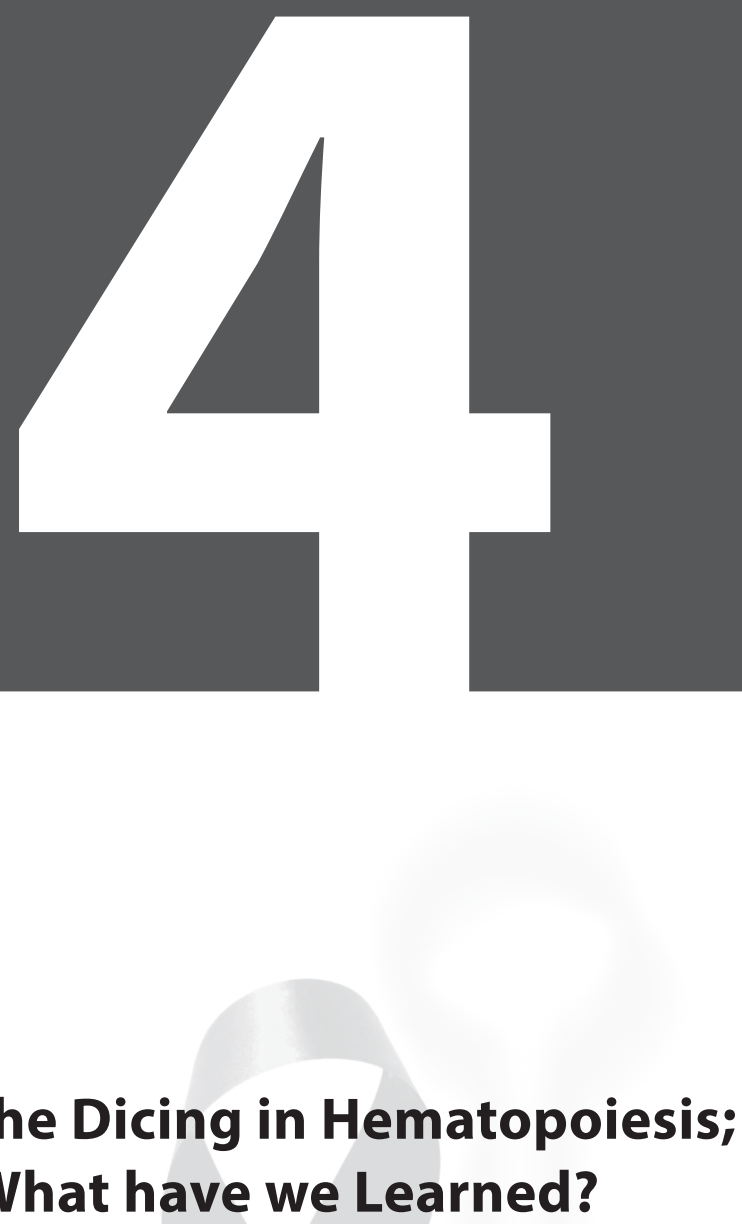

\section{Stop the Dicing in Hematopoiesis; What have we Learned?}

Mir Farshid Alemdehy and Stefan J. Erkeland

Department of Hematology, Erasmus University Medical Center, Rotterdam, the Netherlands

Cell Cycle. 2012; 11(15):2799-807 


\section{ABSTRACT}

MicroRNAs (miRNAs) belong to an abundant class of highly conserved small (22nt) noncoding RNAs. MiRNA profiling studies indicate that their expression is highly cell-type dependent. DICER1 is an essential RNase III endoribonuclease for miRNA processing. Hematopoietic cell-type and developmental stage specific Dicerl deletion models show that miRNAs are essential regulators of cellular survival, differentiation and function. For instance, miRNA-deficiency in hematopoietic stem cells and progenitors of different origins results in decreased cell survival, dramatic developmental aberrations or dysfunctions in mice. We recently found that homozygous Dicerl deletion in myeloid-committed progenitors results in an aberrant expression of stem cell genes and induces a regained self-renewal capacity. Moreover, Dicer1 deletion causes a block in macrophage development and myeloid dysplasia, a cellular condition that may be considered as a preleukemic state. However, Dicer1 null cells do not develop leukemia in mice, indicating that depletion of miRNAs is not enough for tumorigenesis. Surprisingly, we found that heterozygous Dicerl deletion in myeloid-committed progenitors, but not Dicer1 knockout, collaborates with $p 53$ deletion in leukemic progression and results in various types of leukemia. Our data indicate that Dicerl is a haploinsufficient tumorsuppressor in hematopoietic neoplasms which is consistent with the observed downregulation of miRNA expression in human leukemia samples. Here, we review the various hematopoietic specific Dicerl deletion mouse models and the phenotypes observed within the different hematopoietic lineages and cell developmental stages. Finally, we discuss the role for DICER1 in mouse and human malignant hematopoiesis. 


\section{INTRODUCTION}

DICER1 is an evolutionarily conserved member of the RNase III family of endoribonucleases. The gene encoding DICER1 is located on human chromosome $14 \mathrm{q} 32$ and mouse chromosome 12E. DICER1 is a complex protein and contains three N-terminal helicase domains (HEL1, HEL2i, HEL2), a DUF283 domain which is presumably involved in binding of double stranded RNA (dsRNA), a Platform domain, the pre-miRNA binding domain PAZ, RNase IIIa, RNase IIIb and a C-terminal double-stranded RNA binding domain (dsRBD) ${ }^{1-3}$. The RNase III domains of DICER1 cleave double-stranded RNA (dsRNA) substrates and specific precursor hairpin sequences, including so-called pre-miRNAs, into small 5'-phosphorylated RNAs of typically 21-23 nucleotides called miRNA ${ }^{4}$. Deep sequencing of 5'-phosphorylated short RNAs in ES cells showed that the miRNA is the only class of short RNAs to be fully DICER1 dependent ${ }^{5}$. However, the premature miR-451 is the single well-conserved miRNAcontaining sequence known to bypass DICER1 processing and is matured by an Argonaute- 2 (Ago-2)-dependent mechanism ${ }^{6-9}$. The DICER1-generated short RNAs bind to Argonaute proteins in the so-called RNA-induced silencing complex (RISC). This complex induces degradation or inhibits translation of homologs target mRNAs. Moreover RISC triggers gene silencing via chromatin modifications at target promoters under specific conditions such as cellular senescence ${ }^{10,11}$.

Genetic studies in plants, zebrafish and mice show that Dicerl is essential for normal development ${ }^{12-14}$. For instance, genetic deletion of Dicerl in mice results in early embryonic mortality due to depletion of the Oct-4-positive pluripotent embryonic stem cell pool at embryonic day (E) 6-E7 ${ }^{14}$. Dicer1 null ES cells are incapable of processing miRNA hairpins or dsRNAs ${ }^{5,15,16}$. However, Dicerl is dispensable for the small interfering (siRNA)-mediated gene silencing response ${ }^{16}$. Although a role for Dicer1 in centromeric silencing has been suggested, deep sequencing of small RNAs in Dicer1 null and Dicer1 wild type ES cells indicates that the production of miRNAs is the sole catalytic function of DICER1 in these cells ${ }^{5}$. To bypass embryonic lethality and to enable investigation of Dicerl functions in adult tissues in mice, a floxed Dicerl allele (Dicer $1^{f}$ ) has been generated that allows conditional deletion of Dicerl in a cell type and developmental stage-specific fashion ${ }^{17}$. To address the overall role of miRNAs in the development and function of hematopoietic cells, different hematopoietic cell stage and lineage-specific conditional Dicerl deletion strains have been used. First, we will review the phenotypic consequences of Dicerl deletion at different stages of hematopoiesis and cell types. Second, we discuss what we have learned from these models about miRNA-controlled pathways in hematopoiesis. Finally, we show evidence for Dicer1 haploinsufficient tumorsuppressor activity in mouse leukemia and discuss the role for DICER1 in human AML.

\section{THE ROLE OF DICER1 IN T- LYMPHOCYTE DEVELOPMENT}

In one of the first studies addressing the role of Dicerl in hematopoiesis in vivo, floxed Dicer1 alleles were deleted by CRE in lymphocyte-specific protein tyrosine kinase (Lck) positive 
cells. In this model, $\mathrm{Cre}$ is active at the double negative (DN) CD4-CD8- T cell developmental stage and results in Dicer1 null CD44 ${ }^{-} \mathrm{CD} 25^{-}$(DN4), CD4 ${ }^{+} \mathrm{CD} 8^{+}$and $\mathrm{CD} 4{ }^{+} \mathrm{CD} 8,{ }^{-} \mathrm{CD} 4{ }^{-} \mathrm{CD} 8$ cells (Figure 1A) ${ }^{18}$. Dicerl seems to be essential for the generation and survival of $\alpha \beta$ T-cells. However, in the surviving T-cells Dicer1 is dispensable for $\mathrm{CD}^{+}$and $\mathrm{CD} 8^{+}$-single positive lineage commitment ${ }^{18}$. These results strongly suggest that Dicerl deletion does not affect normal T-cell lineage-specific gene expression programs. In these cells, the transcriptional repression of centromeric satellite repeats and features of facultative heterochromatin are maintained in the absence of Dicer ${ }^{18}$, suggesting that survival of immature T-cells is regulated directly by a miRNA-controlled mechanism.

The CD4-Cre transgenic mouse model enables investigation of the consequences of Dicerl deletion at a later stage of T cell development (Figure 1B). These mice show four major phenotypes: (1) Dicerl is required for basic cellular processes such as proliferation and survival, as also proposed by Cobb et al. and therefore Dicerl deficiency results in decreased number of T-cells ${ }^{18,19}$. (2) Dicer1 deletion appears to favor T-cell lineage production from $\mathrm{CD} 4^{+} \mathrm{CD}^{+}$double positive stage toward $\mathrm{CD} 4^{+}$single positive peripheral T-cells over $\mathrm{CD}^{+}$single positive cells. However, this phenotype was less obvious from thymic T-cell lineage analysis. This discrepancy may be explained by the fact that $\mathrm{CD} 4$-Credriven deletion of Dicer1 does not result in complete depletion of all miRNAs, presumably due to high miRNA stability and limited cell divisions of a small fraction of CD4 ${ }^{+} \mathrm{T}$-cells, which may be different for Dicer1 null CD8 ${ }^{+}$T-cells. (3) Dicer1 null CD4 $4^{+} \mathrm{T}$-cells produce increased levels of IFN- $\gamma$, a pro-Th 1 cytokine, indicating that Dicerl controls Th1-lineage commitment ${ }^{19}$. (4) CD4-Cre; Dicer ${ }^{f / / f l}$ mice show a more than 2-fold decreased proportion of Foxp $3^{+}$regulatory T cells (Treg) ${ }^{20}$. Interestingly, these mice developed a splenomegaly and their lymph nodes were severely enlarged at the age of 3 to 4 months. Moreover, organs such as colon, lung and liver were affected by immune pathology caused by an overactive immune system, which is less severe as compared with Foxp3 knockout mice lacking functional Tregs ${ }^{20}$. However, this phenotype suggests that Dicerl-deficient Tregs are functionally aberrant as well.

Two studies revealed the role of Dicerl more specifically in the function of mature Tregs, using a Foxp3-Cre knock-in mouse (Figure 1C) ${ }^{21,22}$. Under steady state conditions, Foxp3-controlled deletion of Dicer1 has minimal effects on Treg cell development, cellular proliferation and survival in the peripheral compartments ${ }^{22}$. However, a diminished fitness of Dicer1-deficient Treg cells in the periphery was observed in a competitive experiment in mice ${ }^{21}$. Under inflammatory conditions, the immune-repressive capacity of the mutant Treg cells is markedly reduced and results in rapid fatal autoimmunity and complete failure of immune suppression activity ${ }^{21,22}$. Moreover, Dicerl deletion in Treg cells leads to the progression of fatal lymphoproliferative autoimmune syndrome with an early onset, which is indistinguishably comparable to T-cell-specific Foxp3deficiency ${ }^{21}$. The expression of putative suppressor effector molecules including CTLA4, IL-10, EBV-induced gene 3 (Ebi-3), and granzyme B was decreased by still unidentified miRNA-controlled mechanisms ${ }^{21}$. Tregs express a specific set of miRNAs including 


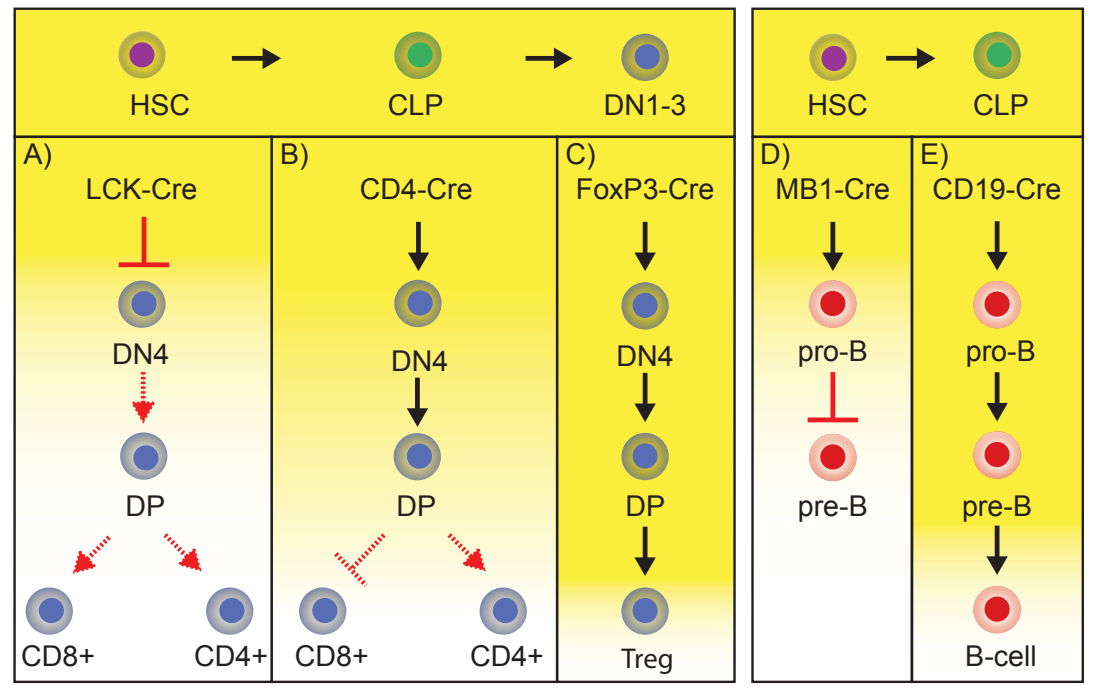

Figure 1. Schematic overview of the phenotypic characteristics of different CRE-mediated Dicer1deletion models in lymphopoiesis. A) HSCs develop via different progenitors toward mature CD4 ${ }^{+}$ or $\mathrm{CD}^{+}$single positive cells. The effects of $L C K$-Cre-mediated Dicer 1 deletion are depicted. The apparent level of Dicer1 expression is indicated by the yellow background color (yellow: normal endogenous levels; white: no Dicer1 expression). HSC: hematopoietic stem cells, CLP: common lymphoid progenitor, DN1-3: double negative stage 1 to 3 (CD4-CD8), DN4: double negative stage 4, DP: double positive $\mathrm{CD}^{+} \mathrm{CD}^{+}$cells. Phenotypic characteristics are indicated by the red arrows and lines. Dashed lines indicate less cells than in wild-type situation. B) See also A. The effects of CD4-Cre-mediated Dicer1 deletion are depicted. Phenotypic characteristics are indicated by the red arrow and lines. C) See also A. The effects of FoxP3-Cre-mediated Dicer1 deletion results in normal numbers of regulatoty T-cells (Tregs) but these cells are functionally aberrant. D) HSCs develop via indicated progenitors toward mature B-cells. The effects of MB1-Cre-mediated Dicer1 deletion are indicated by the red lines and arrow and result in developmental block from the pro-B-cell to the pre-B-cell stage. Pro-B: earliest stage of progenitor B-cell development, pre-B-cell, precursor stage of B-cell development. E) See also D. CD19-Cre-mediated deletion of Dicer1 results in mature B-cells which are functionally aberrant.

$m i R-223, m i R-155$ and $m i R-146$, which is distinct from naïve CD $4^{+} \mathrm{T}$-cells ${ }^{20}$. Therefore, the expression of these miRNAs may be under direct or indirect control of the transcription factor Foxp ${ }^{20}$. Identification of the targets that are controlled by these miRNAs in Tregs may provide new insights about the molecular pathways involved in the activity of these cells.

The role of miRNAs in invariant Natural Killer T (iNKT) cells was studied in a mouse strain by Tie2-Cre-mediated disruption of Dicer ${ }^{23}$. The Tie2 kinase is specifically expressed in hematopoietic progenitors and endothelial cells ${ }^{24}$. Similar to the immune phenotypes in CD4-Cre;Dicer1 ${ }^{f / f l}$ and Lck-Cre;Dicer1 ${ }^{f / f l}$, these mice show reduced numbers of iNKT 
cells in the thymus, spleen, and liver. Moreover, Dicer 1 deletion results in developmental abnormalities of iNKT cells ${ }^{23,25}$. In addition, Dicer1-deficient peripheral iNKT cell numbers are decreased and displayed profound defects in $\alpha$-GalCer, phorbol myristate acetate (PMA) and ionomycin-induced cellular activation and production of cytokines such as IL-4 and IFN- $\gamma^{23}$. Together, these data indicate that Dicerl controls survival at the early T-cell developmental stage. At the later stage, Dicer1 is critical for the balance of Th1/ Th2 lineage production and controls functions such as immune-repression and specific cellular activity.

\section{DICER1 FUNCTION DURING B CELL DEVELOPMENT}

Ablation of Dicerl in early B cell progenitors, mediated by the Mb1-Cre allele, which is expressed at the earliest stage of B-cell development, blocks B-cell development almost

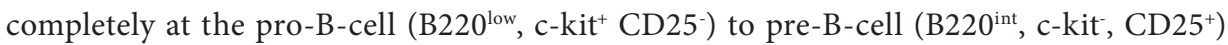
transition (Figure 1D) ${ }^{26}$. This block in $\mathrm{B}$-cell development is caused by a strong induction of apoptosis and results in total depletion of B cells in the BM and the peripheral lymphoid organs in mice ${ }^{26}$. Gene expression profiling of Abelson virus (v-Abl)-transformed Dicer1 null pro-B-cells revealed that $m i R-142-3 p$ and different members of the $m i R-17 \sim 92$ family of miRNA such as $m i R-17, m i R-19, m i R-20$ and $m i R-92$ are the most-active at the pro-B-cell stage $^{26}$. Derepression of the proapoptotic protein BIM, a confirmed target of $m i R-17 \sim 92$, was shown to be mainly responsible for the failure of the cells to respond to survival signals ${ }^{26}$. In full agreement, Ventura A and colleagues have demonstrated that deletion of the miR-17 92 in mouse hematopoietic stem cells (HSCs) leads to a cell development arrest at the pro-B to pre-B transition that is highly reminiscent of what has been observed in the Dicerl-deficient mice ${ }^{27}$.

The role of miRNAs in terminal B cell differentiation is addressed by the analysis of CD19Cre driven Dicer1-deletion mouse model (Figure 1E) ${ }^{28}$. In contrast to early MB1-Cre driven Dicer1 deletion, depletion of Dicer1 with CD19-Cre in immature $\mathrm{B}_{22} 20^{+} \mathrm{IgM}^{+}$cells does not induce cell death and allowed analysis of the role for Dicer1 in mature B cells in peripheral tissues ${ }^{28}$. In the absence of Dicerl, transitional and marginal zone B cells are overrepresented and the generation of follicular B cells is impaired ${ }^{28}$. The miR-185 is abundantly expressed in follicular B-cells and controls the expression of B cell antigen receptor (BCR) signaling effector Bruton tyrosine kinase (BtK) in activated B cells ${ }^{28}$. Dicerl-deficient B cells produce high titers of autoreactive antibodies and as a result cause autoimmune disease in aged female mice ${ }^{28}$. However, the miRNAs that control autoreactivity are still unidentified.

To investigate the role for Dicerl in antigen-activated, but not naive B cells, an activationinduced cytadine deaminase (Aicda)-Cre-mediated Dicerl deletion mouse model has been generated ${ }^{29}$. This mouse model showed that Dicer1 is required for the production of antigenspecific high-affinity antibodies during a T-cell dependent immune response ${ }^{29}$. Also, the formation of germinal center B cells is drastically impaired in Dicerl-deficient mice ${ }^{29}$. These mutant mice fail to generate memory B and long-lived plasma cells after immunization with a $\mathrm{T}$ cell-dependent antigen. This study provides evidence for Dicerl-controlled cell proliferation 
of activated germinal center B-cells by strong repression of cell cycle inhibitory genes, such as $C d k n 1 c\left(p 57^{K i p 2}\right), C d k n 2 b\left(p 16^{I N K 4 a}\right), C d k 1 a\left(p 21^{C i p 1}\right)$ and $C d k n 1 b\left(p 27^{K i p}\right){ }^{29}$. Furthermore, Dicer1 deletion in B-cells leads to massive induction of apoptosis due to derepression of the proapoptotic protein BIM1 as described for early stages of B-cell development ${ }^{29}$. Together, these data show that Dicerl controls survival of B-cells at different stages of B-cell development, regulates cellular proliferation and is critical for proper B- and plasma cell functions.

\section{THE ROLE FOR DICER1 IN NK CELL FUNCTION}

Bezman et al. induced ablation of conditional Dicer1 alleles with a tamoxifen-inducible Cre recombinase (human estrogen receptor $\left(E R^{T 2}\right)$-Cre), and studied the effects of miRNA depletion in NK cells ${ }^{30}$. This non-specific model revealed a role for Dicerl in the maintenance of survival and function of NK cells ${ }^{30}$. They found that in response to a viral infection with mouse cytomegalovirus (MCMV), the expansion of NK cells, but not the IFN- $\gamma$ production, is Dicer1 dependent, suggesting that survival but not activity of NK cells is affected by Dicer1 deficiency ${ }^{30}$. Similarly, HCD2-Cre;Dicer $1^{f l / f l}$ mice, which enable a lymphocyte-restricted Dicer1-deletion at the early stage of NK cells development also showed reduced NK-cell maturation and survival ${ }^{30,31}$. However, Dicer1 null NK cells showed enhanced degranulation and IFN- $\gamma$ production in response to cytokines such as IL-15 and IL-12, tumor target cells, activating NK cell receptor ligation, as well as during acute MCMV infection in vivo ${ }^{31}$. The $m i R-15 / 16$ family of miRNAs is potentially contributing to IFN- $\gamma$ suppression and may control dampening of NK cell functions ${ }^{31}$.

\section{DICER1 DELETION IN MYELOID-COMMITTED PROGENITORS REVEALED AN UNEXPECTED FUNCTION IN HEMATOPOIESIS}

The consequences of Dicer1 deletion in hematopoietic stem and progenitor cells (HSPCs) was first studied by breeding Dicer ${ }^{f / f l}$ with $M x$-Cre mice ${ }^{32}$. These mice express the Crerecombinase in response to interferons and are highly efficient in recombination of floxed alleles in the hematopoietic system in vivo via peritoneal injection of polyI:polyC (pIpC) ${ }^{32}$. Dicer1 ablation in these mice depletes functional HSCs, induces rapid apoptosis in HSPCs and consequently causes total disruption of hematopoiesis ${ }^{32}$. In addition, miRNA-depleted HSCs are unable to reconstitute hematopoiesis in mice ${ }^{32}$. In full agreement, Dicer $1^{f / f l}$ HSCs containing the VAVi-Cre transgene that is highly active in HSCs and efficient in deletion of floxed alleleles ${ }^{33}$, are incapable to reconstitute lethally-irradiated recipient mice (Erkeland SJ, et al., unpublished data). Together, these data show that Dicer1 is essential for HSCs survival. Interestingly, $m i R-125 a$, controls the expansion of HSCs in vivo through targeting the proapototic gene Bak1. Whether miR-125a as a single miRNA can rescue Dicer1-null HSC survival and functions remains elusive but it is more likely that multiple miRNAs are critical at this stage. 
To address the question whether miRNAs play a role in early myeloid-lineage decisions, we deleted Dicer1 in CCAAT/enhancer-binding protein alpha (C/EBPA)positive myeloid-committed progenitors in vivo (Figure 2$)^{34}$. In striking contrast to the results in HSCs and early lymphoid progenitors, we recently found that miRNA depletion does not affect the number of myeloid-committed progenitor cells in mice ${ }^{34}$. However, isolated Dicerl-deficient granulocyte-macrophage progenitors (GMPs) were defective in myeloid development and exhibited an increased self-renewal potential ${ }^{34}$. In mice, Dicer1 deletion by C/ebpa-Cre blocked monocytic differentiation, depleted macrophages and myelo-dendritic cells and caused myeloid dysplasia with morphological features of Pelger-Huet anomaly ${ }^{34}$ (Figure 2). Strikingly, monocytes express low levels of proteins involved in miRNA processing and functions such as DROSHA, AGO1 and AGO2, compared with the levels found in T-cells, and are deficient for DICER1, unless the cells are forced to differentiate toward macrophages ${ }^{35,36}$. The presence of some miRNAs in the monocytic and Dicerl-deficient cell line U937 suggests that some miRNAs can be generated by proteins other than DICER1, such as PIWIL4 ${ }^{35}$ but this hypothesis still needs proper validation. However, the fact that Dicer1-null monocytes are blocked in their differentiation in vivo indicates that Dicerl is essential at this stage and its function cannot be bypassed by other miRNA processing mechanisms.

MiRNA profiling of wild type GMPs showed that 104 miRNAs are abundantly expressed at this stage, of which at least 20 miRNA families are potentially active by reducing their target mRNA abundance ${ }^{34}$. Interestingly, of the derepressed miRNA targets in Dicerl-null GMPs, $27 \%$ are normally exclusively expressed in HSCs or are specific for multi-potent progenitors and erythropoiesis ${ }^{34}$. Unlike the results from HSCs and lymphoid progenitors showing functions of Dicer1 mainly in survival pathways, these results provide evidence for a miRNA-controlled switch of a hematopoietic stem cell program of self-renewal and expansion toward myeloid differentiation (Figure 2) ${ }^{34}$.

\section{THE ROLE FOR DICER1 IN LEUKEMIA}

Human cancer including different types of leukemia is characterized by a global reduction in miRNA expression ${ }^{37}$. The first experimental evidence for a role of global downregulation of miRNAs in cellular transformation and tumorigenesis has been presented in a $K$-Ras-induced mouse model for lung cancer ${ }^{38}$. Further studies of the role for Dicer1 in human cancer development in immune-deficient mice, strongly suggested that Dicerl is a haploinsufficient tumorsuppressor ${ }^{39}$. In this model, homozygous deletion of Dicerl is tolerated by the tumor cells, however lack of miRNAs abrogates tumor outgrowth due to strongly reduced cell proliferation capacity of the DICER1-null cells ${ }^{39}$. In agreement, heterozygous deletion of Dicerl, but not Dicerl knockout, accelerated tumor formation on a retinoblastoma-sensitized background ${ }^{40}$. In mouse B-cells, Dicerl is required for Myc-induced B-cell lymphomagenesis and survival of B-cell lymphomas ${ }^{41}$. However, in this model Dicerl is not a haploinsufficient tumor suppressor, as heterozygous deletion of Dicerl does not affect lymphoma latency and 
overall survival ${ }^{41}$. This discrepancy may indicate that the tumorsuppressing activity of DICER1 is cell type dependent.

We asked whether Dicer1 deletion enhances myeloid leukemia development in mice. In hematopoietic cells, C/ebpa starts to be expressed in early myeloid-committed progenitors, making it a suitable promoter to drive Dicerl deletion for studying the role of miRNA

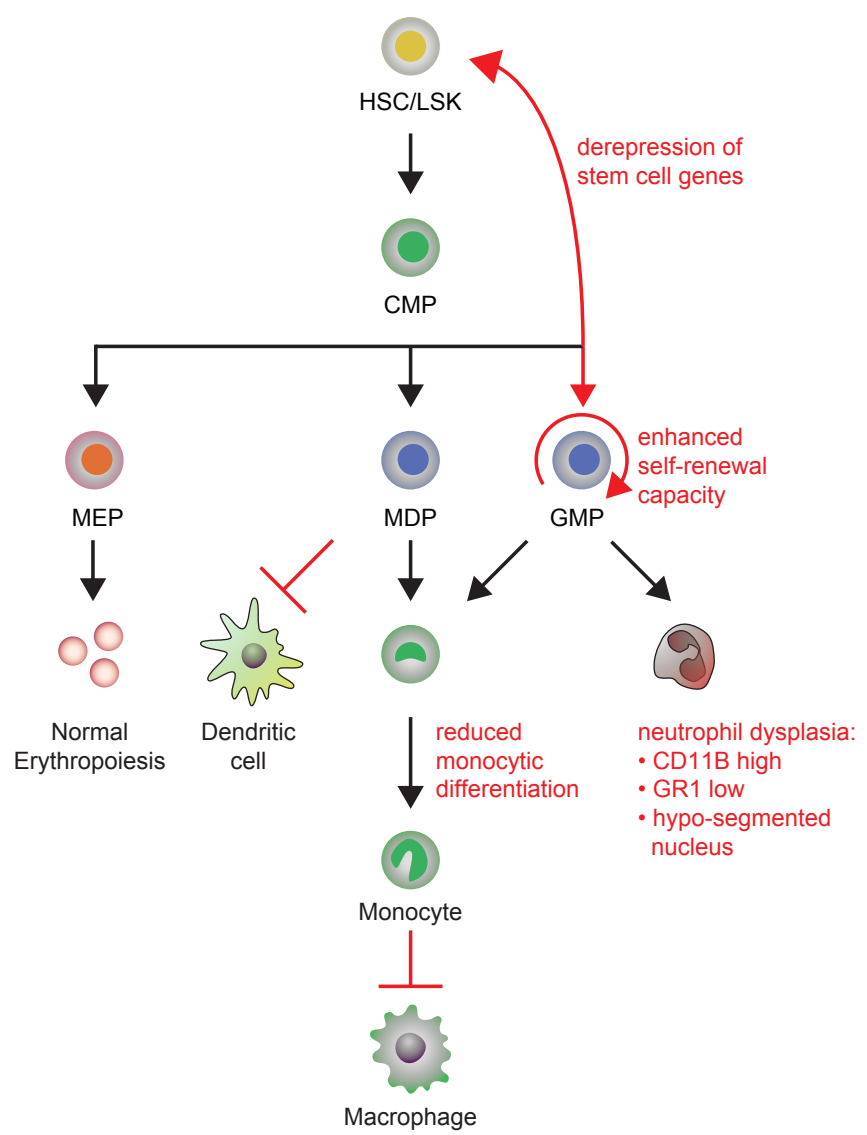

Figure 2. Schematic overview of the results of C/ebpa-Cre-mediated deletion of Dicer1 in myeloid-committed progenitors. Phenotypic characteristics are indicated in red. In short, deletion of Dicer1 results in derepression of stem cell genes in myeloid progenitors and an enhanced self-renewal capacity. Furthermore, MDPs and GMPs are blocked in macrophage and dendritic cell development. In addition, Dicer1 deletion results in neutrophil dysplasia with cells that are characteristic for Pelger-Huet anomaly. HSC/LSK: hematopoietic stem cells/Lin; $\mathrm{ScaI}^{+} ; \mathrm{Kit}^{+}, \mathrm{CMP}$ : common myeloid progenitor, GMP: granulocyte-macrophage progenitor, MEP: megakaryocytic-erythroid progenitor, MDP: macrophage-dendritic cell progenitor, CD11B: pan marker for myeloid cells, GR-1: marker for mature granulocytes. 
depletion in myeloid leukemias ${ }^{34,42}$. To circumvent prenatal lethality, we transplanted fetal liver cells from mutant and control embryos into lethally-irradiated recipient mice. While heterozygous deletion of Dicer1 in myeloid-committed progenitors does not affect myeloid development, homozygous Dicer1 deletion results in block of macrophage/dendritic cell development and myeloid-dysplasia, a cellular condition that may be considered as a preleukemic state ${ }^{34}$ (Figure 2). However, mice transplanted with either heterozygous floxed Dicerl or homozygous floxed Dicerl cells survived devoid of any signs of myeloproliferative disease or leukemia development within a year of observation, indicating that loss of Dicerl in myeloid-committed progenitors is not sufficient to initiate shortterm leukemogenesis in mice ${ }^{34}$ (Figure 3A). To further investigate whether depletion of miRNAs accelerates myeloid leukemia development in a tumor susceptible model, we crossed Dicer ${ }^{f l}$ alleles with $P 53^{f l f l}$ mice and transplanted fetal liver cells from double mutants and control embryos into lethally-irradiated recipient mice. C/ebpa-cre driven deletion of $p 53$ and hemizygous deletion of Dicer1 in mice caused development of various types of leukemias in half of the reconstituted mice with a latency of approximately 6 months (Figure 3). Only one out of eight Dicer $1^{f l f l} ; p 53^{\text {flfl } l}$ recipient mice developed a leukemia with a latency of 9 months (Figure 3A). However, PCR analysis on genomic DNA isolated from the Dicer1 ${ }^{f l f l}$ tumor cells in liver and spleen showed that the Dicerl floxed alleles were incompletely recombined (Figure 3B). These results are in full agreement with data published by Kumar et al., and strongly suggest that only reduced levels of Dicer1, but not bialleleic loss of Dicer1, may play a functional role in leukemia development ${ }^{39,40}$. However, the fact that total depletion of miRNAs does not affect the viability of myeloid progenitors in mice, may suggest that no negative selection due to reduced survival or proliferation by lack of miRNAs occurs in these cells. Together, these data provide evidence for a model in which reduced level of miRNAs is an oncogenic event in the development of leukemia but that activity of at least some miRNA species is essential for oncogenic transformation (Figure 4). This is in full agreement with experimental data showing tumor suppressing and oncogenic activities of investigated miRNAs such as $m i R-17 \sim 92$ and $m i R-125^{43}$. Moreover, miRNA expression profiling data of human cancer and AML samples are consistent with this hypothesis, as a small subset of miRNAs, including e.g. $m i R-9, m i R-125$ and $m i R-17 \sim 92$ are highly expressed whereas most other miRNAs are downregulated ${ }^{44}$.

Figure 3. Leukemia developed from C/ebpa-Cre; $p 53^{f f ;}$; Dicer ${ }^{f / w t}$ HSCs. A) Cumulative survival of mice transplanted with HSCs from fetal livers of C/ebpa-Cre; $p 53^{f / f}$; Dicer ${ }^{w t}(\mathrm{n}=8)$, C/ebpa-Cre; $p 53^{f / f}$; $\operatorname{Dicer}^{f / w t}(\mathrm{n}=12)$ and C/ebpa-Cre; $p 53^{f f f}$; Dicer $1^{f / f}(\mathrm{n}=8)$ embryos. Significance: $\mathrm{p}<0.05$ (log-rank Mantel-Cox test). B) PCR on genomic DNA extracted from tumor cells. K.O.: knockout allele, fl: floxed allele, wt: wild type allele, li: liver, BM: bone marrow, spl: spleen, con: control DNA heterozygous floxed Dicer1, neg: loading control. C) Example of tumor infiltration in liver and spleen of leukemic

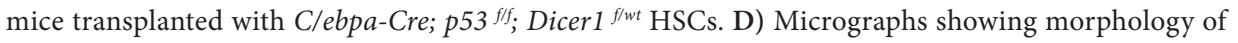
tumor cells in blood, bone marrow and Spleen. Bar indicates $10 \mu \mathrm{m}$. 
A)

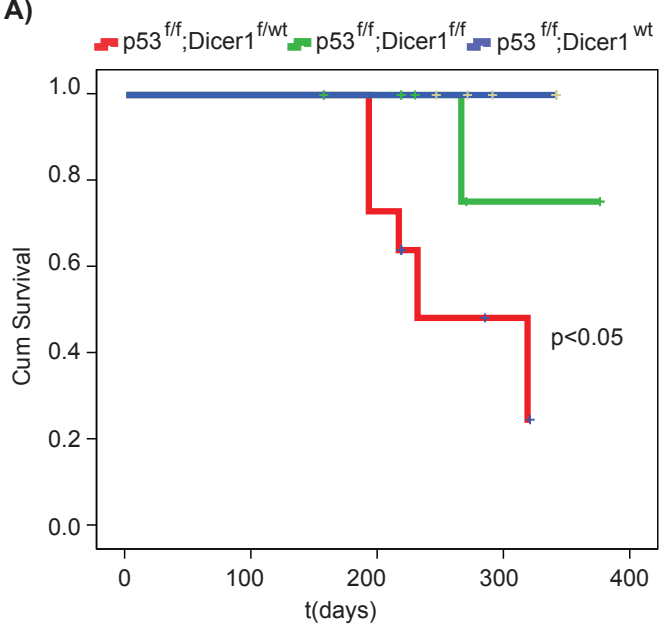

B)

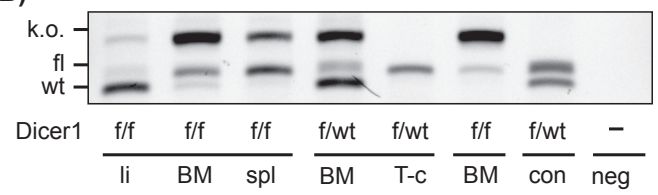

C)

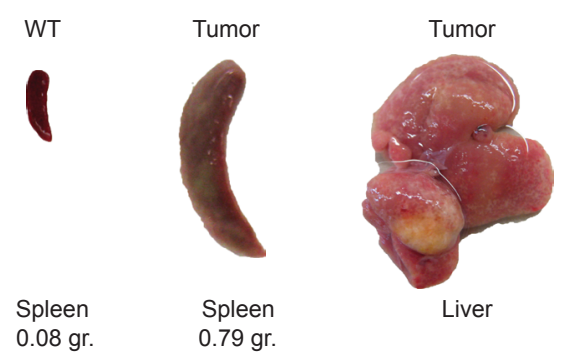

D)

Blood smear

Blood cytospin

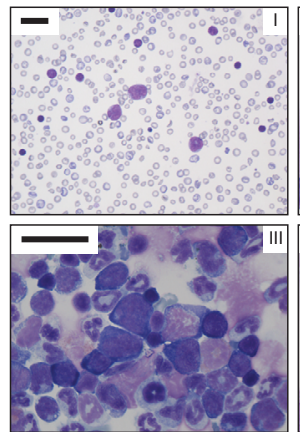

BM
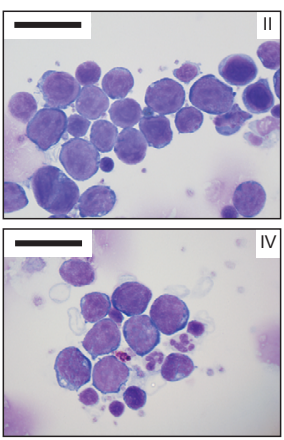

Spleen 


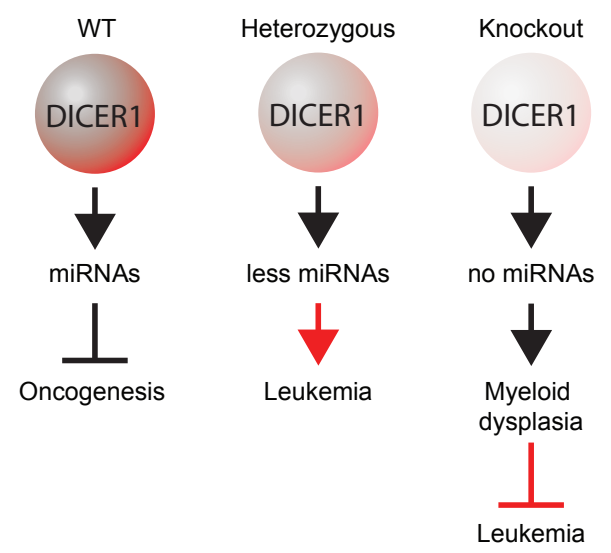

Figure 4. Model for the role of Dicer1 in leukemia development. Dicer1 knockout and as a result total loss of miRNA biogenesis, lead to myeloid dysplasia but not leukemia in a p53 knockout background. In contrast, heterozygous loss of Dicer 1 conserves the expression of a set of miRNAs needed for normal differentiation. Furthermore, our model suggests that at least some miRNA activity is needed for oncogenic transformation.

\section{DICER1 MUTATIONS IN HUMAN LEUKEMIA}

To date, the mechanism behind the reduced miRNA expression in subsets of human myeloid leukemia samples still remains elusive. One possibility is that the widespread silencing of miRNAs is the result of a defect in miRNA biogenesis caused by mutations in the gene encoding DICER1. For instance, data from Cancer Genome Project at the Wellcome Trust Sanger Institute (www.sanger.ac.uk/cosmic) show that somatic DICER1 mutations occur in different human tumors including lung carcinoma, malignant melanoma and ovarian cancer ${ }^{45}$. Recently, Hill et al., found DICER1 mutations in familial pleuro-pilmonary blastoma ${ }^{46}$. In addition, a recent study in human non-epithelial ovarian cancers revealed mutations in the codons encoding metal-binding sites within the RNase IIIb catalytic centers of DICER 1 in 30 of 102 (29\%) of the tumors ${ }^{47}$. These authors also detected mutations in 1 out of 14 non-seminomatous testicular germ-cell tumors, in 2 of 5 embryonal rhabdomyosarcomas, and in 1 of 266 epithelial ovarian and endometrial carcinomas ${ }^{47}$. The RNase III domains of DICER1 are essential for miRNA maturation, and introduced mutations in the RNase IIIa and in RNase IIIb abrogate in vitro processing of the $3 p$ and $5 p$ miRNAs respectively ${ }^{47,48}$. In agreement, transient expression experiments of mutant human DICER1 constructs in murine Dicer1-null mesenchymal stem cells showed that inactivation of the RNase IIIb domain by mutation of D1709, results in complete loss of particularly $5 \mathrm{p}$-derived mature miRNAs, including the tumor-suppressive Let-7 family of miRNAs ${ }^{49}$. This mutation is found in subsets of nonepithelial ovarian cancers. Indeed, the identified Dicerl hot spot mutations in cancer result in reduced RNase IIIb activity but retain the RNase IIIa activity, strongly 
suggesting a positive selection for the mutations that reduces Let7-tumorsuppressing activity in cancer development ${ }^{47}$.

In a first attempt to gain more functional insight into the mechanisms behind the reduced miRNA expression in AML, a panel of 45 AML samples, characterized by activation of the oncogene EVI-1 due to $\mathrm{t}(3 ; 3)(\mathrm{q} 21 ; \mathrm{q} 26)$ or inv(3)(q21q26) and poor prognosis, and five AML cell lines including U937, MOLM1, MUTZ3, KASUMI-3 and F36P were sequenced. In this panel of high risk AML samples, no mutation in Dicer1 coding sequences and untranslated regions were identified (unpublished data, Erkeland S.J., Valk P., Delwel H., Sanders M.A., Groschel S. and Hoogenboezem R., 2012). Despite the limited set of data, this result suggests that other mechanisms are involved in deregulation of miRNA expression in human AML.

\section{DIFFERENT MECHANISMS OF DICER1 ACTIVITY REDUCTION IN HUMAN LEUKEMIA}

The expression of miRNAs may be deregulated by different mechanisms in human cancer ${ }^{50}$. For instance, the activity of DICER1 may be reduced as DICER1 is frequently deleted in various human cancers ${ }^{39}$. In addition, low expression of DICER 1 independently predicted poor outcomes in ovarian cancer patients ${ }^{51}$. In chronic lymphocytic leukemia (CLL), low expression of DICER1 has been correlated with increased aggressiveness of the disease, shorter overall survival as well as reduced treatment free survival ${ }^{52}$. Notably, no such correlation between DICER1 transcript levels and disease outcome were found in human $A M L{ }^{53}$. However, there is evidence for regulation of DICER1 expression by miRNAs such as $m i R-15 a$ and $m i R-16$ in a cohort of $\operatorname{del}(13 q 14)$ in CLL ${ }^{52}$, miR-9 in Hodgkin lymphoma ${ }^{54}$, $m i R-125$ in human megakaryoblastic leukemia ${ }^{55}$ and $m i R-106 a$ in the undifferentiated primary monocytes ${ }^{35}$. Interestingly, $m i R-9, m i R-125$ and $m i R-106 a$ are frequently aberrantly expressed at high levels in human AML ${ }^{44,56}$ (and review ${ }^{43}$ ) and may control DICER1 translation, leaving mRNA levels intact. Thus, aberrant miRNA biogenesis in human AML may occur via direct miRNA-controlled feedback mechanisms on translation of DICER1 transcripts, but this hypothesis still needs proper experimental confirmation.

Reduction of miRNA expression may be controlled by other mechanisms as well. This hypothesis is supported by recently described mutations in the TAR RNA-binding protein 2 (TARBP2), a critical protein for processing of miRNAs, in sporadic and hereditary carcinomas, and the inactivating mutations in Exportin-5, which results in trap of premiRNAs in the nucleus in human cancer cells ${ }^{57-59}$. Other possible mechanisms behind aberrant miRNA expression are single nucleotide polymorphisms (SNPs) that influence processing of miRNAs ${ }^{60}$ or RNA editing of miRNA precursors that blocks cleavage by DICER1 ${ }^{61,62}$. Sequencing of factors involved in the biogenesis of miRNAs or a better understanding of miRNA expression regulation by e.g. transcription factors, epigenetic events or miRNA stability are needed to unravel the mechanisms behind the reduced miRNA activity in human AML. 


\section{CONCLUSION}

Recent data show that Dicerl is an essential factor at different stages of normal hematopoiesis. A limitation of the Dicer1-deletion models is the global depletion of miRNAs that presumably results in disruption of many cellular pathways simultaneously, which hampers the identification of the functions of individual miRNAs. Although some studies show evidence for only a few miRNAs making dominant contributions, such as miR-17 92 in B-cell development, this may be different for other cell types or even be developmental stage dependent. Overall, Dicer1 mainly controls survival and expansion at the early stages of lymphoid development and controls cellular activities at the terminal maturation stage. The function of Dicerl is different in myelopoiesis at the earliest developmental stage as Dicerl is not essential for cell viability, but instead controls essential steps in switching from the stem cell stage toward myeloid lineage development. Although the functions of some miRNAs such as $m i R-17 / 20 / 93 / 106$ and $m i R-223$, are well-described in immature and mature myeloid cells respectively ${ }^{56,63}$, the miRNA-controlled pathways that are involved at different stages of myelopoiesis are still largely elusive. Therefore, tissue and developmental stage-specific miRNA-add-back in the Dicerl-deficient models, and experimental target identification approaches may be of help for the understanding of the miRNA activities in hematopoiesis.

\section{METHODS}

\section{Mice and reconstitution experiments}

To generate the different mouse lines of interest, we first crossed C/ebpa-Cre;R26-LSLEyfp;Dicer ${ }^{w t / f l}$ mice ${ }^{34}$ with mice that contain floxed $p 53$ conditional alleles (Jackson Laboratories). Finally, C/ebpa-Cre;R26-LSL-Eyfp;Dicer1 ${ }^{1 t f l} / D i c e r 1^{f / f} ; p 53^{f l / f l}$ mice were obtained from breeding Clebpa-Cre;Dicer1 ${ }^{\text {wt/fl}} ; p 53^{f / w t}$ mice with R26-LSL-Eyfp;Dicer1 ${ }^{f / f l} ; p 53^{\text {fl/fl }}$ mice. Fetal livers were obtained on embryonic day (E) 13.5. Genotyping of Dicer1; p53; C/ebpaCre;R26-LSL-Eyfp embryos was performed by PCR assays of DNA from tail or foot biopsies. Sequences of primers are available upon request. All primers were obtained from Biolegio BV. For transplantation, 8-week-old recipient mice C57Bl/6, (Jackson Laboratories) were irradiated (8.5 Gy) and tail-vein injected with fetal liver single-cell suspensions. Typically, cells from each fetal liver were transplanted into two recipient mice. Tumorigenicity was subsequently monitored by daily examination of the transplanted mice. Mice were euthanized when moribund. All animal experiments were approved by the Animal Welfare/Ethics Committee of the Erasmus Medical Center.

\section{Antibodies, cell staining, flow cytometry and cytospins}

Peripheral blood was obtained by heart puncture at the moment of euthanasia. Bone marrow cell suspensions were prepared as described previously ${ }^{34}$. Tumor samples were prepared as single-cell suspension for cytospins or FACS analysis. For morphological analysis of the cells, cytospins were stained with May-Grünwald-Giemsa and examined with a Leica DMLB microscope (100x and 40x objectives) and Leica Application Suite software Version 2.7.1 R1. 


\section{Statistics}

Kaplan-Meier survival curves were plotted using SPSS software (SPSS, PASW, 17.0.2), and log-rank Mantel-Cox test was used to determine statistical significance.

\section{ACKNOWLEDGEMENTS}

We thank Dr. T Cupedo and Dr. M. Buitenhuis for critical reading of the manuscript and E. Simons for assistance with the preparation of the figures. We also thank Dr. K. van Lom for the microscopic analysis of leukemias. Our work was supported by grants from the Netherlands Organisation for Scientific Research (NWO-VENI) and the Dutch Cancer Society (KWF). 


\section{REFERENCES}

1. Dlakic M. DUF283 domain of Dicer proteins has a double-stranded RNA-binding fold. Bioinformatics. 2006;22(22):2711-2714.

2. Qin H, Chen F, Huan X, Machida S, Song J, Yuan YA. Structure of the Arabidopsis thaliana DCL4 DUF283 domain reveals a noncanonical double-stranded RNAbinding fold for protein-protein interaction. RNA. 2010;16(3):474-481.

3. Lau PW, Guiley KZ, De N, Potter CS, Carragher B, Macrae IJ. The molecular architecture of human Dicer. Nat Struct Mol Biol. 2012.

4. Bernstein E, Caudy AA, Hammond SM, Hannon GJ. Role for a bidentate ribonuclease in the initiation step of RNA interference. Nature. 2001;409(6818):363366.

5. Calabrese JM, Seila AC, Yeo GW, Sharp PA. RNA sequence analysis defines Dicer's role in mouse embryonic stem cells. Proc Natl Acad Sci U S A. 2007;104(46):18097-18102.

6. Cheloufi S, Dos Santos CO, Chong MM, Hannon GJ. A dicer-independent miRNA biogenesis pathway that requires Ago catalysis. Nature. 2010;465(7298):584-589.

7. Cifuentes D, Xue H, Taylor DW, et al. A novel miRNA processing pathway independent of Dicer requires Argonaute2 catalytic activity. Science. 2010;328(5986):1694-1698.

8. Yang JS, Maurin $\mathrm{T}$, Robine $\mathrm{N}$, et al. Conserved vertebrate mir-451 provides a platform for Dicer-independent, Ago2mediated microRNA biogenesis. Proc Natl Acad Sci U S A. 2010;107(34):15163-15168.

9. Yang JS, Lai EC. Dicer-independent, Ago2-mediated microRNA biogenesis in vertebrates. Cell Cycle. 2010;9(22):44554460 .

10. Ketting RF. The many faces of RNAi. Dev Cell. 2011;20(2):148-161.

11. Benhamed M, Herbig U, Ye T, Dejean A, Bischof O. Senescence is an endogenous trigger for microRNA-directed transcriptional gene silencing in human cells. Nat Cell Biol. 2012;14(3):266-275.
12. Reinhart BJ, Weinstein EG, Rhoades $M W$, Bartel B, Bartel DP. MicroRNAs in plants. Genes Dev. 2002;16(13):1616-1626.

13. Wienholds E, Koudijs MJ, van Eeden FJ, Cuppen E, Plasterk RH. The microRNAproducing enzyme Dicerl is essential for zebrafish development. Nat Genet. 2003;35(3):217-218.

14. Bernstein E, Kim SY, Carmell MA, et al. Dicer is essential for mouse development. Nat Genet. 2003;35(3):215-217.

15. Kanellopoulou C, Muljo SA, Kung AL, et al. Dicer-deficient mouse embryonic stem cells are defective in differentiation and centromeric silencing. Genes Dev. 2005;19(4):489-501.

16. Murchison EP, Partridge JF, Tam OH, Cheloufi S, Hannon GJ. Characterization of Dicer-deficient murine embryonic stem cells. Proc Natl Acad Sci U S A. 2005;102(34):12135-12140.

17. Harfe BD, McManus MT, Mansfield JH, Hornstein E, Tabin CJ. The RNaseIII enzyme Dicer is required for morphogenesis but not patterning of the vertebrate limb. Proc Natl Acad Sci U S A. 2005;102(31):10898-10903.

18. Cobb BS, Nesterova TB, Thompson E, et al. $T$ cell lineage choice and differentiation in the absence of the RNase III enzyme Dicer. J Exp Med. 2005;201(9):1367-1373.

19. Muljo SA, Ansel KM, Kanellopoulou C, Livingston DM, Rao A, Rajewsky K. Aberrant T celldifferentiation in the absence of Dicer. J Exp Med. 2005;202(2):261-269.

20. Cobb BS, Hertweck A, Smith J, et al. A role for Dicer in immune regulation. J Exp Med. 2006;203(11):2519-2527.

21. Liston A, Lu LF, O'Carroll D, Tarakhovsky A, Rudensky AY. Dicer-dependent microRNA pathway safeguards regulatory T cell function. JExp Med.2008;205(9):19932004.

22. Zhou X, Jeker LT, Fife BT, et al. Selective miRNA disruption in $\mathrm{T}$ reg cells leads to uncontrolled autoimmunity. J Exp Med. 2008;205(9):1983-1991. 
23. Zhou L, Seo KH, He HZ, et al. Tie2creinduced inactivation of the miRNAprocessing enzyme Dicer disrupts invariant NKT cell development. Proc Natl Acad Sci U S A. 2009;106(25):10266-10271.

24. Batard P, Sansilvestri P, Scheinecker C, et al. The Tie receptor tyrosine kinase is expressed by human hematopoietic progenitor cells and by a subset of megakaryocytic cells. Blood. 1996;87(6):2212-2220.

25. Fedeli M, Napolitano A, Wong MP, et al. Dicer-dependent microRNA pathway controls invariant NKT cell development. $J$ Immunol. 2009;183(4):2506-2512.

26. Koralov SB, Muljo SA, Galler GR, et al. Dicer ablation affects antibody diversity and cell survival in the B lymphocyte lineage. Cell. 2008;132(5):860-874.

27. Ventura A, Young AG, Winslow MM, et al. Targeted deletion reveals essential and overlapping functions of the miR-17 through 92 family of miRNA clusters. Cell. 2008;132(5):875-886.

28. Belver L, de Yebenes VG, Ramiro AR. MicroRNAs prevent the generation of autoreactive antibodies. Immunity. 2010;33(5):713-722.

29. Xu S, Guo K, Zeng Q, Huo J, Lam KP. The RNase III enzyme Dicer is essential for germinal center B-cell formation. Blood. 2012;119(3):767-776.

30. Bezman NA, Cedars E, Steiner DF, Blelloch $R$, Hesslein DG, Lanier LL. Distinct requirements of microRNAs in NK cell activation, survival, and function. $J$ Immunol. 2010;185(7):3835-3846.

31. Sullivan RP, Leong JW, Schneider SE, et al. MicroRNA-deficient NK cells exhibit decreased survival but enhanced function. J Immunol. 2012;188(7):3019-3030.

32. Guo S, Lu J, Schlanger R, et al. MicroRNA miR-125a controls hematopoietic stem cell number. Proc Natl Acad Sci U S A. 2010;107(32):14229-14234.

33. de Boer J, Williams A, Skavdis G, et al. Transgenic mice with hematopoietic and lymphoid specific expression of Cre. Eur J Immunol. 2003;33(2):314-325.
34. Alemdehy MF, van Boxtel NG, de Looper $H W$, et al. Dicerl deletion in myeloidcommitted progenitors causes neutrophil dysplasia and blocks macrophage/ dendritic cell development in mice. Blood. 2012.

35. Coley W, Van Duyne R, Carpio L, et al. Absence of DICER in monocytes and its regulation by HIV-1. J Biol Chem. 2010;285(42):31930-31943.

36. Klase Z, Kale P, Winograd R, et al. HIV-1 TAR element is processed by Dicer to yield a viral micro-RNA involved in chromatin remodeling of the viral LTR. BMC Mol Biol. 2007;8:63.

37. Lu J, Getz G, Miska EA, et al. MicroRNA expression profiles classify human cancers. Nature. 2005;435(7043):834-838.

38. Kumar MS, LuJ, Mercer KL, Golub TR, Jacks T. Impaired microRNA processing enhances cellular transformation and tumorigenesis. Nat Genet. 2007;39(5):673-677.

39. Kumar MS, Pester RE, Chen CY, et al. Dicer1 functions as a haploinsufficient tumor suppressor. Genes Dev. 2009;23(23):27002704.

40. Lambertz I, Nittner D, Mestdagh $P$, et al. Monoallelic but not biallelic loss of Dicer1 promotes tumorigenesis in vivo. Cell Death Differ. 2010;17(4):633-641.

41. Arrate MP, Vincent T, Odvody J, Kar $\mathrm{R}$, Jones $\mathrm{SN}$, Eischen CM. MicroRNA biogenesis is required for Myc-induced Bcell lymphoma development and survival. Cancer Res. 2010;70(14):6083-6092.

42. Wolfler A, Danen-van Oorschot $A A$, Haanstra $J R$, et al. Lineage-instructive function of C/EBPalpha in multipotent hematopoietic cells and early thymic progenitors. Blood. 2010;116(20):4116-4125.

43. Alemdehy MF, Erkeland SJ. MicroRNAs: key players of normal and malignant myelopoiesis. Curr Opin Hematol. 2012.

44. Jongen-Lavrencic M, Sun SM, Dijkstra MK, Valk PJ, Lowenberg B. MicroRNA expression profiling in relation to the genetic heterogeneity of acute myeloid leukemia. Blood. 2008;111(10):5078-5085. 
45. Forbes SA, Bhamra G, Bamford S, et al. The Catalogue of Somatic Mutations in Cancer (COSMIC). Curr Protoc Hum Genet. 2008; Chapter 10:Unit 1011.

46. Hill DA, Ivanovich J, Priest JR, et al. DICER1 mutations in familial pleuropulmonary blastoma. Science. 2009;325(5943):965.

47. Heravi-Moussavi A, Anglesio MS, Cheng SW, et al. Recurrent somatic DICER1 mutations in nonepithelial ovarian cancers. N Engl J Med. 2012;366(3):234-242.

48. Zhang H, Kolb FA, Jaskiewicz L, Westhof E, Filipowicz W. Single processing center models for human Dicer and bacterial RNase III. Cell. 2004;118(1):57-68.

49. Gurtan AM, Lu V, Bhutkar A, Sharp PA. In vivo structure-function analysis of human Dicer reveals directional processing of precursor miRNAs. RNA. 2012.

50. Deng S, Calin GA, Croce CM, Coukos G, Zhang L. Mechanisms of microRNA deregulation in human cancer. Cell Cycle. 2008;7(17):2643-2646.

51. Merritt WM, Lin YG, Han LY, et al. Dicer, Drosha, and outcomes in patients with ovarian cancer. $N$ Engl $J$ Med. 2008;359(25):2641-2650.

52. Zhu DX, Fan L, Lu RN, et al. Downregulated Dicer expression predicts poor prognosis in chronic lymphocytic leukemia. Cancer Sci. 2012;103(5):875-881.

53. Martin MG, Payton JE, Link DC. Dicer and outcomes in patients with acute myeloid leukemia (AML). Leuk Res. 2009;33(8):e127.

54. Leucci E, Zriwil A, Gregersen LH, et al. Inhibition of miR-9 de-represses $\mathrm{HuR}$ and
DICER1 and impairs Hodgkin lymphoma tumour outgrowth in vivo. Oncogene. 2012.

55. Klusmann JH, Li Z, Bohmer K, et al. miR$125 \mathrm{~b}-2$ is a potential oncomiR on human chromosome 21 in megakaryoblastic leukemia. Genes Dev. 2010;24(5):478-490.

56. Meenhuis $A$, van Veelen $P A$, de Looper $H$, et al. MiR-17/20/93/106 promote hematopoietic cell expansion by targeting sequestosome 1-regulated pathways in mice. Blood. 2011;118(4):916-925.

57. Melo SA, Ropero S, Moutinho C, et al. A TARBP2 mutation in human cancer impairs microRNA processing and DICER1 function. Nat Genet. 2009;41(3):365-370.

58. Melo SA, Moutinho C, Ropero S, et al. A genetic defect in exportin-5 traps precursor microRNAs in the nucleus of cancer cells. Cancer Cell. 2010;18(4):303-315.

59. Melo SA, Esteller M. A precursor microRNA in a cancer cell nucleus: get me out of here! Cell Cycle. 2011;10(6):922-925.

60. Sun G, Yan J, Noltner K, et al. SNPs in human miRNA genes affect biogenesis and function. RNA. 2009;15(9):1640-1651.

61. Kawahara Y, Zinshteyn B, Chendrimada TP, Shiekhattar R, Nishikura K. RNA editing of the microRNA-151 precursor blocks cleavage by the Dicer-TRBP complex. EMBO Rep. 2007;8(8):763-769.

62. Heale BS, Keegan LP, O'Connell MA. ADARs have effects beyond RNA editing. Cell Cycle. 2009;8(24):4011-4012.

63. Johnnidis JB, Harris MH, Wheeler RT, et al. Regulation of progenitor cell proliferation andgranulocytefunctionbymicroRNA-223. Nature. 2008;451(7182):1125-1129. 



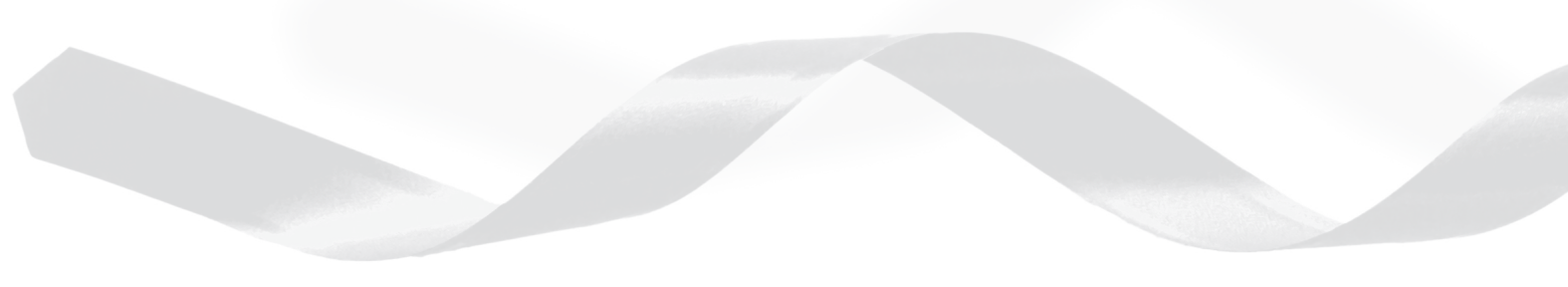




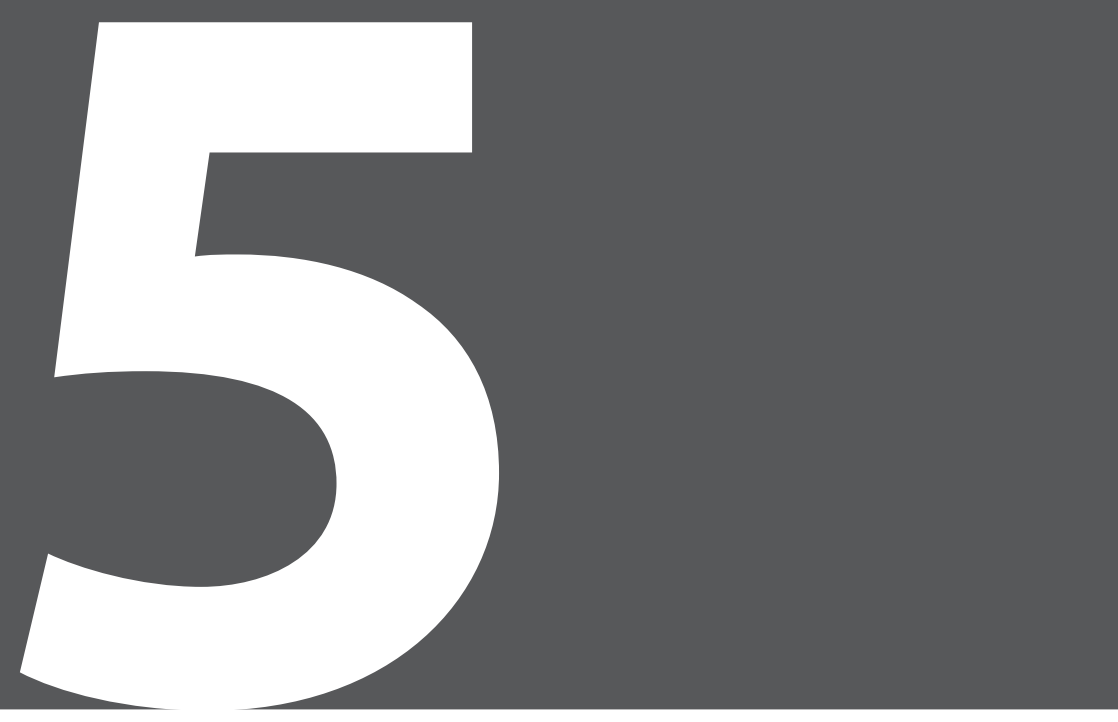

\section{Interstrand Cross-link Induced $\operatorname{miR}-139-3 p$ and miR-199a-3p have Opposite Roles in Hematopoietic Cell Expansion and Leukemic Transformation}

Mir Farshid Alemdehy' ${ }^{1}$ Jurgen R. Haanstra ${ }^{1}$, Hans W. J. de Looper ${ }^{1}$, Paulina M.H. van Strien', Judith Verhagen-Oldenampsen', Yvette Caljouw ${ }^{1}$, Mathijs A. Sanders' ${ }^{1}$, Remco Hoogenboezem',

Arnoud H. de Ru², George M.C. Janssen², Stephanie E. Smetsers' ${ }^{3}$, Marc B. Bierings ${ }^{3,4}$, Marieke von Lindern', Peter A. van Veelen ${ }^{2}$, Ivo P. Touw ${ }^{1}$ and Stefan J. Erkeland'

' Department of Hematology, Erasmus University Medical Center Cancer Institute, Rotterdam, the Netherlands; ${ }^{2}$ Department of Immunohematology and Blood Transfusion, Leiden University Medical Center, Leiden, the Netherlands; ${ }^{3}$ Wilhelmina Children's Hospital, University Medical Center Utrecht, Utrecht, the Netherlands; ${ }^{4}$ Dutch Childhood Oncology Group, the Hague, the Netherlands 


\section{ABSTRACT}

Interstrand cross-links (ICLs) are toxic DNA lesions that cause severe genomic damage during replication. In the hematopoietic system, this results in a progressive bone marrow failure (BMF) and predisposes to acute myeloid leukemia (AML). The molecular mechanisms responsible for these defects are largely unknown. Using Ercc1-deficient mice, we show that $\operatorname{Trp53}$ is responsible for ICL-induced BMF and that loss of Trp53 is leukemogenic in this model. In addition, Ercc1-deficient myeloid progenitors expressed elevated levels of miR-139$3 p$ and $m i R-199 a-3 p$ with age. These microRNAs exert opposite effects on hematopoiesis. Ectopic expression of $m i R-139-3 p$ strongly inhibited proliferation of myeloid progenitors, whereas inhibition of $m i R-139-3 p$ activity restored defective proliferation of Erccl-deficient progenitors. Conversely, inhibition of $m i R-199 a-3 p$ functions aggravated the myeloid proliferation defect in the Erccl-deficient model, whereas its enforced expression enhanced proliferation of progenitors. Importantly, $m i R-199 a-3 p$ caused AML in a pre-leukemic mouse model, supporting its role as an onco-miR. Target genes include $H u R$ for $m i R-139-3 p$ and PRDX6, RUNX1 and SUZ12 for $m i R-199 a-3 p$. The latter genes have previously been implicated as tumor suppressors in de novo and secondary AML. These findings show that, in addition to TRP53-controlled mechanisms, $m i R-139-3 p$ and $m i R-199 a-3 p$ are involved in the defective hematopoietic function of ICL-repair deficient myeloid progenitors. 


\section{INTRODUCTION}

Hematopoiesis is tightly controlled by both cell-intrinsic and -extrinsic cues. This ensures the life-long balanced blood cell production from hematopoietic stem cells (HSCs) under homeostatic conditions and allows the transient expansion of specific blood cell types in response to infections or blood loss ${ }^{1}$. Bone marrow failure (BMF) syndromes are characterized by impaired hematopoiesis, leading to single- or multi-lineage cytopenia ${ }^{2}$. Although the underlying causes of BMF syndromes are heterogeneous, they share the elevated risk to progress towards leukemia ${ }^{3}$. Ineffective repair of DNA damage is one of the major causes of BMF and leukemic transformation ${ }^{4}$. Several mouse models have shown that defective DNA repair reduces the function but not the absolute number of long-term hematopoietic stem cells (LT-HSCs) with age. For instance, in aged mice deficient in nucleotide excision repair (NER) the numbers of common myeloid progenitors (CMPs) are significantly decreased, whereas the numbers LT-HSCs remain unaltered ${ }^{5}$.

The DNA repair protein ERCC1 is active in both NER and interstrand cross-link (ICL) repair ${ }^{6}$. ERCC1 acts in a complex with XPF as a structure specific endonuclease. Mice lacking ERCC1 show accelerated aging and reduced hematopoietic reserves within 3 weeks of age ${ }^{7}$. The observation that XPA knockout mice, which are exclusively NER-deficient, did not show the accelerated bone marrow (BM) exhaustion suggested that defective ICL repair was predominantly responsible for this phenotype. Indeed, Ercc1-deficient hematopoietic progenitor cells showed the hypersensitivity to the DNA cross-linking agent mitomycin C (MMC) that is characteristic of ICL-repair deficiency ${ }^{7}$. Additional studies showed that proliferative myeloid progenitors, i.e., CMPs, granulocyte monocyte progenitors (GMPs) and megakaryocyte-erythroid progenitors (MEPs), but not the noncycling LT-HSCs or short-term (ST)-HSCs were severely reduced with progressive loss of ERCC1 activity ${ }^{8}$.

The underlying DNA-damage response (DDR) pathways responsible for the depletion of ICL-deficient hematopoietic progenitors are still largely unknown. In Fanconi anemia (FA), the best characterized clinical condition of ICL-induced BMF, it has been shown that the inflammatory cytokines TNF- $\alpha$ and IFN- $\gamma$ contribute to the BMF and are produced at increased levels in FA mouse models and in patients ${ }^{9-11}$. However, an elevated production of these and other inflammatory cytokines in FA patients was not observed in another study ${ }^{12}$. Here, we used Ercc1-deficient mice to identify additional mechanisms that contribute to ICL-induced BMF and leukemic transformation. We show that deletion of Trp53 but not Cdkn2a alleviates the loss of lineage negative (lin-) Sca1+c-kit+ (LSK) BM cells in Ercc1-deficient mice and identified TRP53 as a major gatekeeper preventing leukemic transformation of Ercc1-deficient BM cells, corroborating studies in clinical FA ${ }^{13}$. In addition, we identified two miRNAs, $m i R-139-3 p$ and $m i R-199 a-3 p$, that were expressed at enhanced levels in CMPs from Ercc1-deficient mice compared to control littermates which exert strikingly opposite effects on the proliferation of myeloid progenitors. These miRNAs were also expressed at an elevated level in CD34+ BM cells from FA patients. 
Importantly, $m i R-199 a-3 p$ caused AML in a preleukemic mouse transplantation model, establishing its role as an onco-miR. These findings uncover novel mechanisms of BMF and leukemogenesis involving miRNAs in an ICL-defective mouse model, which may bear relevance for FA.

\section{MATERIALS AND METHODS}

\section{Mice}

The $C d k n 2 a^{+/ 14}, \operatorname{Trp} 53^{+/ 15}, \operatorname{Ercc1} 1^{+/ 292}$ and $E r c c 1^{+/-}$mice have been previously described ${ }^{16}$. Ercc1 mice were generated in a F1 mixed background of C57BL/6 and FVB/n. To generate Cebpa ${ }^{\text {creffl }}$ mice, Cebpa ${ }^{f l / f 17}$ were crossed with Cebpa-cre mice ${ }^{18}$.

For transplantation experiments with Erccl-deficient cells, 12 to 14 week old recipient F1 mice (FVB/n x C57BL/6) were irradiated ( $9 \mathrm{~Gy}$ ) and transplanted by tail vein injection with $1 \times 10^{7}$ total BM cells and $1 \times 10^{5}$ spleen cells. For other transplantation experiments, 6-8 week old C57BL/6 recipient mice (The Jackson Laboratory) were irradiated (8.5 Gy) and tail-vein injected with retrovirally-transduced HSPCs (1-5x $10^{5}$ cells/mouse). Leukemia cells isolated from BM of primary recipients were injected into irradiated (5 Gy) 6-8-week old C57BL/6 mice. All animal experiments were approved by the animal Welfare/Ethics Committee of the Erasmus MC.

\section{Retroviral infection and colony assays}

MSCV-BC-miRNA vectors and virus particles were generated as described previously ${ }^{19}$. The 32D cells and BM-derived HSPCs were infected with MSCV-BC-miRNA virus using RetroNectin (Takara Bio Inc) according to manufacturer's instructions. Colony assays were performed as described ${ }^{18}$. In brief, 10.000 MSCV-transduced cells (based on EGFP expression determined by flow cytometry) or 50.000 total BM cells, per $\mathrm{mL}$ per $35 \mathrm{~mm}$ dish were plated in triplicate in methyl cellulose medium (Methocult M3234, StemCell Technologies SARL), containing human G-CSF $(0.1 \mu \mathrm{g} / \mathrm{ml})$, or mouse GM-CSF $(0.1 \mu \mathrm{g} / \mathrm{ml})$, or human Epo ( $4 \mathrm{mU} /$ $\mathrm{ml})$ plus transferrin $(0.3 \mathrm{mM})$, hemin $(0.2 \mathrm{mM})$ and mouse SCF $(0.1 \mu \mathrm{g} / \mathrm{ml})$, and puromycin $(1.5 \mu \mathrm{g} / \mathrm{mL}$, only for transduced cells). Colonies containing 50 cells or more were scored on day 7 of culture. For miRNA inhibitory experiments HSPCs were transfected with fluorescent tagged miRCURY LNA inhibitors (Exiqon) with DharmaFECT1 (Thermo Scientific). The transfection efficiency (100\%) was confirmed with flow cytometry. The colony assays were performed as described above.

\section{Patient samples}

BM HSPCs were obtained from patients as described previously ${ }^{20}$. All FA patients provided written informed consent in accordance with the Declaration of Helsinki.

See Supplemental Materials and Methods for quantitative proteomics, whole exome sequencing and data analysis, Luciferase reporter assays, Luminex experiments, antibodies, cell staining flow-cytometry and cytospins, gene- and miRNA profiling qPCR and statistics. 


\section{RESULTS}

\section{Exhaustion of Ercc 1-*292 HSPCs is caused by TRP53- rather than CDKN2A- dependent mechanisms}

Ercc1 knock-out mice are severely runted, weigh only about $20 \%$ compared to their normal littermates and die around 3 weeks of age ${ }^{16,21}$. A premature stop codon at position 292 of mouse $\operatorname{Ercc1}\left(\operatorname{Erccl}^{* 292}\right)$, causes a C-terminal deletion of 7 amino acids of ERCC1, which impairs dimerization with XPF ${ }^{16}$. The life span of $\operatorname{Erccl}^{1 / * 292}$ mice is approximately 22 weeks, and their hematopoietic phenotype is comparable to that of Ercc1 knockout mice ${ }^{8}$. The BM of $\mathrm{ErCC}^{1 / 292}$ mice contains decreased numbers of myeloid progenitors that are strongly hampered in their ability to proliferate in colony assays ${ }^{8}$. Both TRP53 and CDKN2A have been shown to regulate the DDR in HSPCs ${ }^{13,22}$. We investigated how disruption of these individual loci affects $\operatorname{Erccl}^{-/ 292}$ LSK and hematopoietic progenitor maintenance. At 3 weeks of age, Ercc1 ${ }^{-/ 292}$ BM contained less than $50 \%$ of LSKs compared with wild type (wt) (Figure 1A). Furthermore, the in vitro colony forming capacity of $\mathrm{Erccl}^{-/ 292}$ myeloid and erythroid progenitor cells was markedly reduced (Figure 1B-D). Deletion of Cdkn2a did not affect this phenotype (Figure 1A-D). In contrast, homozygous deletion of $\operatorname{Trp} 53$ in $\mathrm{Erccl}^{-/ \times 292}$ mice restored the fraction of LSK cells and granulocyte-macrophage colony forming units (CFU-GM) (Figure 1E-H). These results, showing that TRP53-driven, rather than CDKN2A-dependent DDR mechanisms cause ICL-induced loss of HSPCs, corroborate studies in clinical FA ${ }^{13}$. Under conditions of G-CSF and SCF/EPO stimulation, a partial rescue of CFU-G or BFU-E colony growth was seen (Figure 1G, 1H).

\section{Affected pathways in Ercc $1^{-/ 292} \mathrm{HSPCS}$}

To investigate how Ercc1-deficiency affects BM HSPCs at the molecular level, we performed gene expression profiling (GEP) and proteomics. Ingenuity Downstream Effect Analysis (IDEA) showed decreased activity of networks required for hematopoietic development and leukocyte differentiation in $\operatorname{Ercc1}^{-/ * 292}$ LSK BM cells at week 20 to 22 of age compared to control cells (Suppl. Figure 1A, 1B, Suppl. Table 1). Differentially expressed DDR genes included P53 and DNA damage regulated 1 (Pdrg1), Cyclin-dependent kinase inhibitor $1 a$ (Cdkn1a, p21) and Xiap-associated factor 1 (Xaf1), all TRP53-induced genes (Suppl. Table 1).

LSK cells are enriched for hematopoietic stem cells (HSCs) that are mostly non-cycling. Because of the higher proliferation rate of committed hematopoietic progenitors, the consequences of defective ICL-repair are expected to be more severe in these cells. We therefore also analyzed lineage depleted BM cells that contain HSCs and progenitor cells. GEP identified 887 differentially expressed transcripts in Erccl $^{-/ 292}$ lin- cells relative to controls (Supplemental Figure 1C, Supplemental Table 2). IDEA showed that pathways involved in cell death, the regulation of reactive oxygen species (ROS), cell cycle control, hematopoiesis and DNA repair are more prominently deregulated in Ercc1 $^{-1 / 292}$ lin- cells compared to LSKs (Supplemental Figure 1B versus 1D). Expression of TRP53 target genes, e.g. p21 and Gadd45b, was increased in $\operatorname{Erccl}^{-/ 292}$ lin- cells, indicating an activated DDR (Supplemental Table 2). 
Quantitative proteome analysis on $\operatorname{Erccl}^{-/ 292}$ and control HSPCs showed that 457 proteins were significantly differentially expressed (Supplemental Table 3). Notably, a high correlation between the changes in mRNA and protein level was observed (Supplemental Figure 1E). IDEA on these protein data showed that the main deregulated biological functions identified by proteomics are similar to those detected by gene expression profiling, i.e. pathways involved in cell death and regulation of ROS (Supplemental Figure 1F).

A

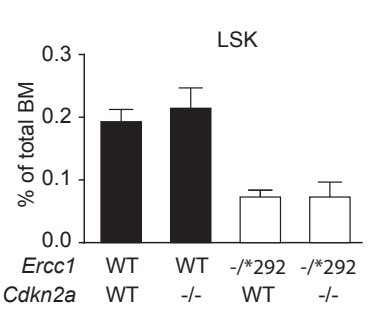

B

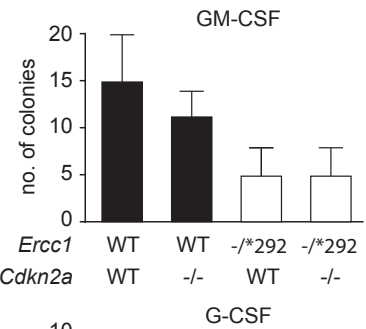

C

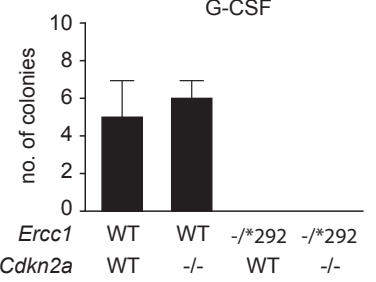

$\mathrm{D}$

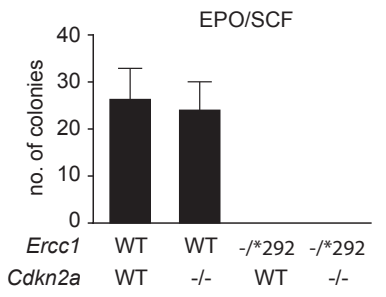

E

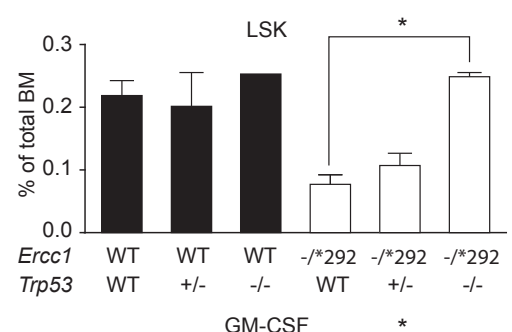

$\mathrm{F}$

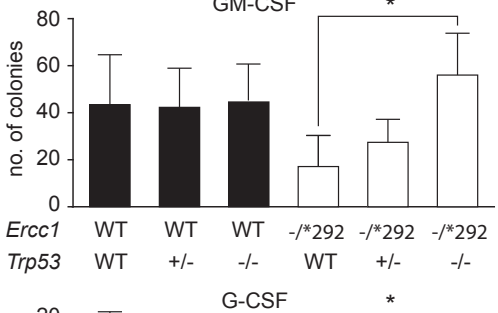

G

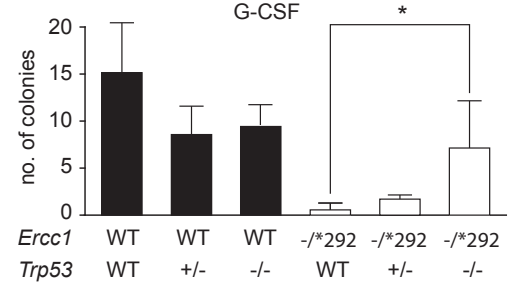

$\mathrm{H}$

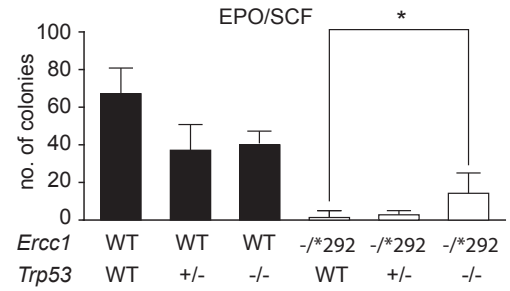

Figure 1. Loss of Trp53, but not of Cdkn2a, restores HSPC content in $\operatorname{Erccl}^{-/ 292}$ mice. A, E) LSK frequencies in lin- fractions of indicated mouse genotypes at 3 weeks of age are shown. B-D and F-H) Colony-forming units (CFU) per $5 \times 10^{4}$ unfractionated BM cells in the presence of indicated growth factors relative to the $w t$ controls are shown. All bars represent the mean and standard deviations of $\mathrm{n} \geq 3$ mice. The significance was calculated by the student $\mathrm{t}$-tests (asymptotic significance [2-tailed]) $\left({ }^{*} \mathrm{p}<0.05\right)$. 


\section{MiRNA expression in $\operatorname{Ercc}^{-1 / 292} \mathrm{HSPCs}$}

Because miRNAs play key roles in cellular stress responses, including the regulation of TRP53-dependent pathways ${ }^{23,24}$, we interrogated which miRNAs are differentially expressed in Ercc1 $^{-/ 292}$ versus Ercc1 wt LSK and lin-cells. From a panel of 365 miRNAs tested by Taqman qPCR in $\operatorname{Ercc1}^{-1 * 292}$ LSKs isolated from 20 week old mice, none was significantly altered in its expression relative to control LSKs. In contrast, in lin- Ercc1 ${ }^{-/ 292}$ cells, expression of 4 miRNAs, $m i R-139-3 p, m i R-199 a-3 p, m i R-34 a-5 p$ and $m i R-342-5 p$ was significantly elevated relative to $w t$ lin- controls ( 2 to 4 Fold, $\mathrm{p}<0.05$ ) (Figure $2 \mathrm{~A}$ ). This result suggested that expression of these 4 miRNAs is induced in cycling Ercc1 ${ }^{-1 * 292}$ progenitors enriched in the lin- fraction, rather than in the mostly non-cycling LSK fraction. To further specify which myeloid progenitor subsets express these miRNAs, we analyzed FACS-purified CMPs, GMPs and MEPs from 20 weeks old mice. In $\operatorname{Ercc1}^{-/ 292}$ CMPs, the levels of miR-34a-5p, miR-139-3p and $m i R-199 a-3 p$ were elevated relative to controls, whereas $m i R-342-5 p$ was not expressed (Figure 2B). In $\operatorname{Erccl}^{-/ 292} \mathrm{GMPs}, m i R-139-3 p$ was not expressed and only the level of $m i R$ 199a-3p was significantly elevated (Figure 2B). In Ercc1 ${ }^{-* 292}$ MEPs only the expression of $m i R-342-5 p$ was significantly induced (Figure $2 \mathrm{~B}$ ).

At week 3 of age, the levels of $m i R-34 a-5 p$ and $m i R-342-5 p$ were already significantly elevated in $\mathrm{Erccl}^{-/ * 292}$ lin- cells (Figure 2C). Crossings of $\operatorname{Erccl}^{-/ * 292}$ mice with $\operatorname{Trp}^{-1 /-}$ mice revealed that the expression of $m i R-34 a-5 p$ and $m i R-342-5 p$ was fully TRP53 dependent (Figure 2C). In contrast, the expression of $m i R-139-3 p$ and $m i R-199 a-3 p$ is only induced at week 20, when DNA damage due to unrepaired ICLs accumulates (Figure 2A, C). In support of this, the ICL-inducing agent mitomycin C (MMC) induced the expression of miR-199a-3p and $m i R-139-3 p$ in normal lin- cells (Figure 2D).

\section{Opposite roles of miR-139 and miR-199a in myeloid progenitor exhaustion and expansion}

To determine their role in myeloid cell survival, proliferation and differentiation, we ectopically expressed the miRNAs from barcoded retroviral vectors (MSCV) in the murine cell line 32D expressing human CSF3R (32D-CSF3R) ${ }^{19,25}$. In IL-3-containing expansion medium, miR-139 expressing 32D-CSF3R cells died rapidly, whereas no alteration in cell survival and proliferation was seen in cells expressing $m i R-34 a, m i R-199 a$ or $m i R-342$ (Figure 3A). When these cells were mixed in a 1:1 ratio with MSCV-EV transduced control cells and transferred to G-CSF-containing differentiation medium, miR-139 again inhibited proliferation (Figure 3B), whereas $m i R-34 a$ and $m i R-342$ had little or no effect (Figure 3B). In contrast, $m i R-199 a$ expressing $32 \mathrm{D}$-CSF3R cells had gained a competitive growth advantage in this setting (Figure 3B), suggesting that $m i R-199 a$ inhibits differentiation and/or enhances proliferation of myeloid progenitors in response to G-CSF. Similar results were obtained in primary CFU-GM colony cultures. Whereas ectopic expression of $m i R-34 a$ and $m i R-342$ did not alter, and miR-139 completely abrogated colony outgrowth, the CFU-GM colony formation capacity of miR-199a expressing BM cells was 1.5 fold ( $\mathrm{p}<0.05)$ increased (Figure 3C). 
A

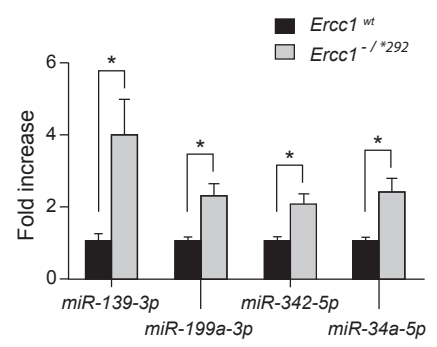

C
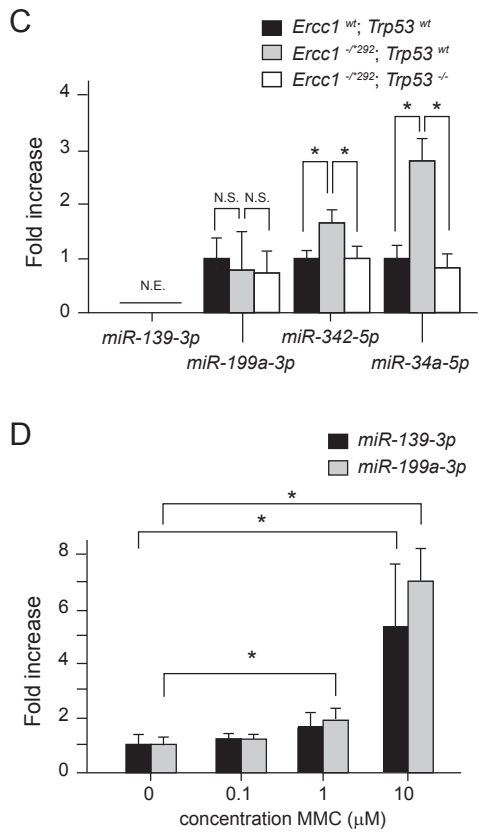

B
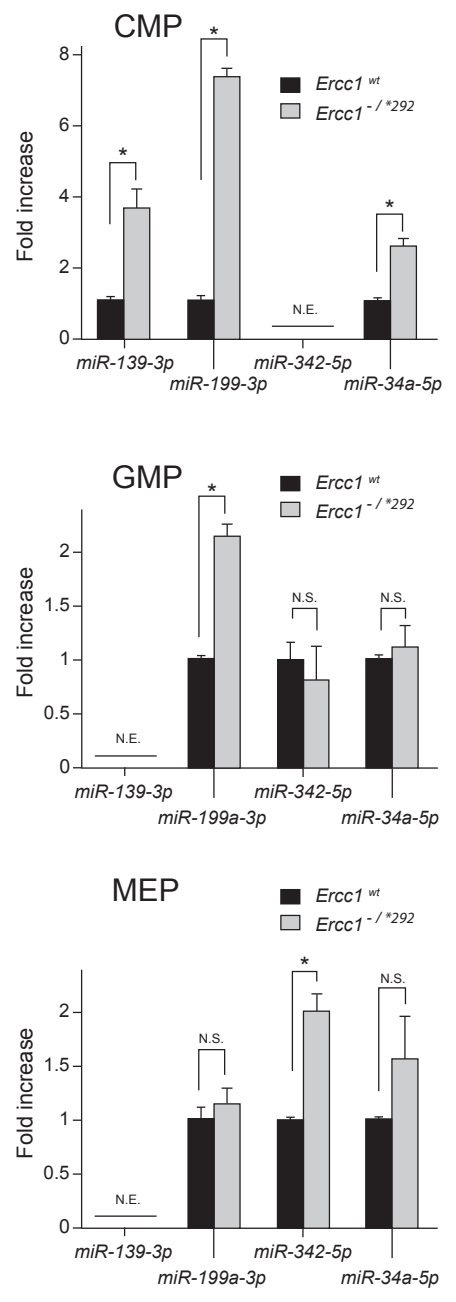

Figure 2. Differentially expressed miRNAs in $\operatorname{Ercc1}^{1 / 292}$ cells. A) The expression of miRNAs and U6 in lin- BM cells was determined by q-PCR in quadruplicate. The expression of indicated miRNAs relative to $\mathrm{U} 6$ and normalized to $w t$ controls is depicted. The error bars represent the standard deviations (SD) of 5 mice. B) The expression of indicated miRNAs relative to U6 and normalized to $w t$ is depicted for different hematopoietic progenitor subpopulations isolated from the BM of 20 weeks old mice. The error bars represent SD of three measurements. C) The expression of indicated miRNAs relative to U6 in lin- BM cells of three week old $\operatorname{Ercc1} 1^{-/ 292} ; \operatorname{Tr} p 53 w t$ mice and $\operatorname{Ercc1} 1^{-1 / 292} ; \operatorname{Tr} p 53^{-/}$and relative to $w t$ controls is shown. All bars represent the mean and SD of $\mathrm{n} \geq 3$ mice $\mathrm{D}$ ) The expression of miR-139$3 p$ and $m i R-199 a-3 p$ relative to U6 in $w t$ lin- cells and normalized to the control condition without MMC, is depicted for the indicated MMC concentrations. The error bars represent SD of three measurements. In all panels, the significance was calculated with the Mann-Whitney U test (asymptotic significance $[2$-tailed] $)\left({ }^{*} \mathrm{p}<0.05\right)$. N.E.: not expressed. N.S.: not significant. 
A

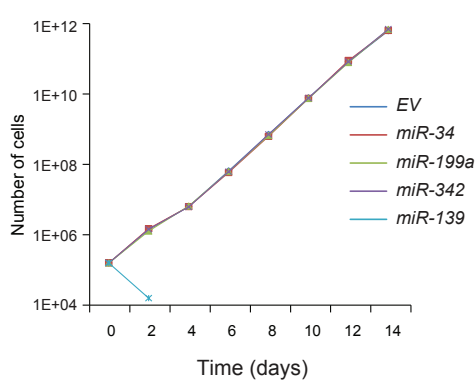

B

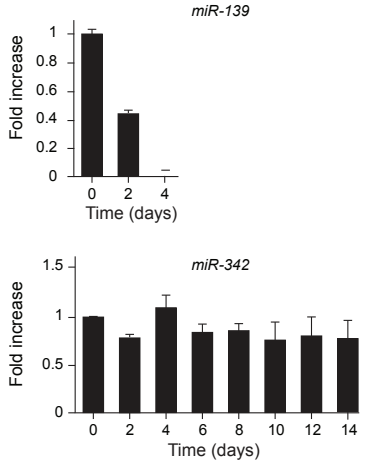

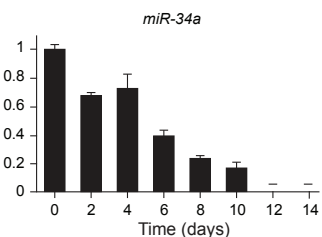

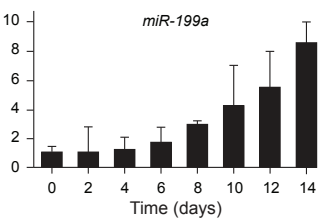

C

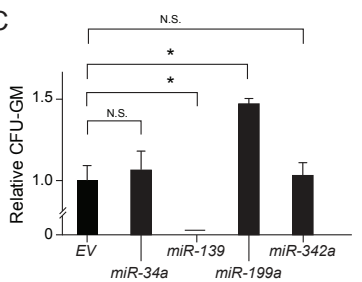

D

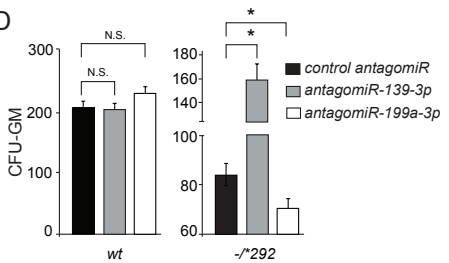

$E$

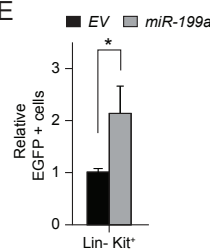

Figure 3. Expression of $m i R-139$ and $m i R-199 a$ alters the balance of HSPC loss and expansion. A) Murine 32D cells were infected with MSCV-BC vectors containing either, miR-139, miR-199a, $m i R-34 a, m i R-342$ or no miRNA (EV) as control. 32D cells expressing miRNAs were expanded in IL-3 containing medium and the number of cells at indicated time points is plotted. B) Equal numbers of 32D cells expressing indicated miRNAs were mixed with control EV-expressing 32D cells and switched to G-CSF-containing medium. Cell samples were taken at indicated time points and genomic DNA was isolated. The abundance of the different the barcodes relative to the EV barcode signal and normalized to day 0 is depicted. Representative data of three independent experiments are shown. The error bars represent $\mathrm{SD}$ of three measurements. C) Colony assays were performed with $1 \times 10^{4}$ lin- cells transduced with different miRNA expressing viruses. The number of CFU-GMs consisting of more than 50 cells after 7 days of growth relative to EV control is depicted and is a representative result of 2 independent experiments. Data represent the mean and SD of 3 plates counted. D) Same as C. The number of CFU-GM of $1 \times 10^{4}$ mouse Ercc1 $1^{-/ 292}$ and $w t$ lin- cells transfected with LNA antagomiR against $m i R-139-3 p$ and $m i R-199 a-3 p$ are shown. Data represent the mean and SD of 3 plates counted. E) Lin- cells transduced with MSCV-miR-199a or MSCV-EV and mixed with untransduced $w t$ lincells in a 1:1 ratio were transplanted in irradiated recipient mice ( $\mathrm{n}=8$ per group). The change in lin-Kit+ (LK, progenitors) fraction in the BM 10 weeks post-transplantation and relative to the EV control is shown $\left({ }^{\star} \mathrm{p}<0.05\right)$. The error bars represent $\mathrm{SD}$ of $\mathrm{n}=8$ mice. In panels $\mathrm{C}, \mathrm{D}$ and $\mathrm{E}$, the significance was calculated with the student t-test [2-tailed] $\left({ }^{\star} \mathrm{p}<0.05\right)$. 
Next, we used LNA antagomiRs to explore how inhibition of $m i R-139-3 p$ and $m i R$ $199 a-3 p$ affects the outgrowth of $\operatorname{Erccl}^{-/ 292} \mathrm{CFU}$-GM. Treatment of $\operatorname{Erccl}^{-/ 292}$ lin- cells with miR-199a-3p LNA antagomiR reduced the number of CFU-GM by $\sim 20 \%$ (Figure 3D). Conversely, miR-139-3p LNA antagomiR rescued the colony forming capacity of $\operatorname{Ercc1}^{-/ * 292}$ progenitors. Both antagomiRs had no effect on CFU-GM colony formation from normal BM (Figure 3D).

Finally, we assessed the effects of miR-199a expression on HSPC expansion in vivo, by transplanting MSCV-miR-199a and MSCV-EV infected lin- cells mixed with non-infected lin- cells in mice. Myeloid progenitor cells expressing miR-199a significantly increased in numbers over non-transduced controls at 10 weeks post-transplantation, whereas cells transduced with MSCV-EV were maintained at a similar frequency compared to input (Figure 3E). In summary, these data show that ectopic expression of $m i R-139-3 p$ inhibits and $m i R-199 a-3 p$ enhances the outgrowth of normal myeloid progenitors, both in vitro and in vivo and that antagonizing their endogenous expression in Ercc1-deficient cells restores (anti-miR-139-3p) or further aggravates (anti-miR-199a-3p) the ICL-induced phenotype.

\section{Identification of $m i R-139-3 p$ and $m i R-199 a-3 p$ targets}

Combined transcriptome and proteome analysis (Supplementary Figure 1) revealed that in ErcCl $^{-/ 292}$ lin- cells, 7 genes were down-regulated that contain predicted and evolutionary wellconserved binding sites for either miR-139-3p or miR-199a-3p in their 3'-UTRs (TargetScan, www.targetscan.org) (Supplemental Table 2 and 3). The RNA-binding protein HuR (also known as Elavl1), was the only identified target of $m i R-139-3 p$ in $\operatorname{Ercc1}^{-/ * 292} \mathrm{HSPCs}$, whereas 6 genes, Prdx6, Suz12, Pon2, Fubp1, Calu, and Runx1, contain miR-199a-3p recognition sites. To test whether $m i R-139-3 p$ and $m i R-199 a-3 p$ directly control the expression of these genes by binding to the predicted miRNA binding sites, we cloned these 3'-UTR regions downstream of a luciferase reporter (Figure 4A). Ectopic expression of $m i R-139$ and $m i R-199 a$ caused a $30 \%$ to $65 \%$ reduction of luciferase activity of all target 3'-UTR fragments tested (Figure 4B). Mutation of the predicted miRNA binding sites abolished the inhibition of luciferase activity, confirming the predicted target sites as major determinants for miR-139-3p and miR-199a$3 p$-mediated regulation (Figure 4B).

\section{MiR-139-3p, miR-199a-3p and their targets are deregulated in human ICL-repair deficient BM cells}

Because defective ICL repair is a major hallmark of FA ${ }^{26}$, we assessed the expression of $m i R-139-3 p$ and $m i R-199 a-3 p$ in CD34+ BM progenitor cells from FA patients (Supplemental Table 4). Similar to the Ercc1 ${ }^{-* 292}$ lin- cells, $m i R-139-3 p$ expression was increased in CD34+ cells from FA patient BM compared to healthy individuals (median=14.5 fold $(\mathrm{p}<0.05)$ ) (Figure 4C). Expression of $m i R-199 a-3 p$ was significantly higher in FA patients with a severe BMF (median=15.7 fold $(\mathrm{p}<0.05)$ ) than in patients with mild BMF (Figure 4C, supplemental Table 4). This is suggestive of a correlation between the severity of ICL-induced damage and the expression of $m i R-199 a-3 p$ in FA-BM. 
RNA-seq analysis on BM CD34+ cells of a FA patient with progressive BMF showed that the identified targets of $m i R-139-3 p$ and $m i R-199 a-3 p$ were downregulated in this patient compared with normal CD34+ cells (Supplemental Figure 2). Conversely, expression of GADD45B and CDKN1A, two TP53-controlled DDR genes was significantly increased in FA BM CD34+ cells (Supplemental Figure 2). To corroborate these results in a larger group of patients, we analyzed the FA Transcriptome Consortium (FTC) database (Gene Expression Omnibus, 2009, publicly available as GSE16334), containing the transcriptome data of lowdensity mononuclear BM cells from 21 FA patients and 11 healthy donors ${ }^{27}$. In this data set, expression of the target genes of $m i R-139-3 p$ and $m i R-199 a-3 p$ was again significantly lower in FA patients relative to healthy controls (Figure 4D), whereas the DDR-induced genes GADD45B and CDKN1A were upregulated (Figure 4D). These results establish that $m i R-139-3 p, m i R-199 a-3 p$ and their targets are also deregulated in ICL-repair deficient BM cells from FA patients.

\section{Loss of Trp53 uncovers the leukemogenic nature of Ercc1 deficiency}

Having initially established that genetic deletion of Trp53 rescued $\operatorname{Erccl}^{-1 * 292} \mathrm{HSPC}$ from exhaustion, we next investigated whether the loss of one Trp53 allele promotes the leukemic transformation of Ercc1-deficient HSPCs. From 51 mice transplanted with $\operatorname{Erccl}^{-1 / 292}$; $\operatorname{Trp} 53^{+/-}$ HSPCs, 41 died with an average latency of 28 weeks, while all control transplanted mice survived without symptoms (Figure 5A). Of the 31 mice that could be fully analyzed all had developed leukemia, characterized by enlarged liver, spleen or thymus. The leukemia cells had a blast-like morphology and with few exceptions expressed T-cell receptor alpha/beta rearrangements, and CD4 and CD8, indicative of T-cell leukemia (data not shown).

To identify somatic mutations and insertion/deletions (indels), 17 leukemia samples and germ line control DNAs isolated from the brain of 6 donor mice were subjected to whole exome sequencing (WES). Because the chromosomal damage caused by ICLs is repaired by error-prone non-homologous end-joining rather than homologous recombination, leukemia genomes from patients deficient in ICL-repair frequently contain gross genetic aberrations ${ }^{28}$. We developed a new algorithm (Sanders M.A., et al., 2014, manuscript in preparation), allowing for the identification of these abnormalities based on WES data sets. Sporadic patterns of copy number variations (CNVs) were seen, such as gains on chromosomes 4, 5, 11 and 15 and losses on chromosomes 3, 6-8, 13, 16 and 19 (Figure 5B). However, the copy number neutral loss of heterozygosity $(\mathrm{CNN}-\mathrm{LOH})$ of chromosome 11 caused complete loss of Trp53 in all leukemia samples analyzed (Figure 5B, 5C). Expression of $m i R-199 a-3 p$ was markedly increased (3.14 fold, $\mathrm{p}<0.05)$ in $\operatorname{Erccl}^{-{ }^{* 2} 292}$ leukemia cells, whereas $m i R-139-3 p$ was not detectable (Figure 5D).

\section{MiR-199a contributes to the development of AML}

MiR-199a-3p was expressed at elevated levels in the $\operatorname{Erccl}^{-/ * 292}$ leukemia samples (Figure 5D). Because the leukemias arising in this model are mostly of T-cell origin, we sought to investigate the consequences of enhanced $m i R-199 a-3 p$ in a mouse model prone to develop 
A
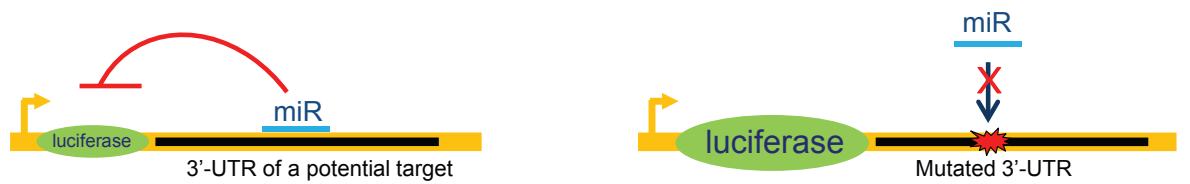

$\mathrm{B} \square$ non mutated $3^{\prime}$ UTR + EV
$\square$ non mutated $3^{\prime}$ UTR + miR-139
$\square$ mutated 3' UTR + miR-139

- non mutated $3^{\prime}$ UTR+ EV

$\square$ non mutated 3' UTR + miR-199a

C

$\square$ mutated 3' UTR + miR-199a
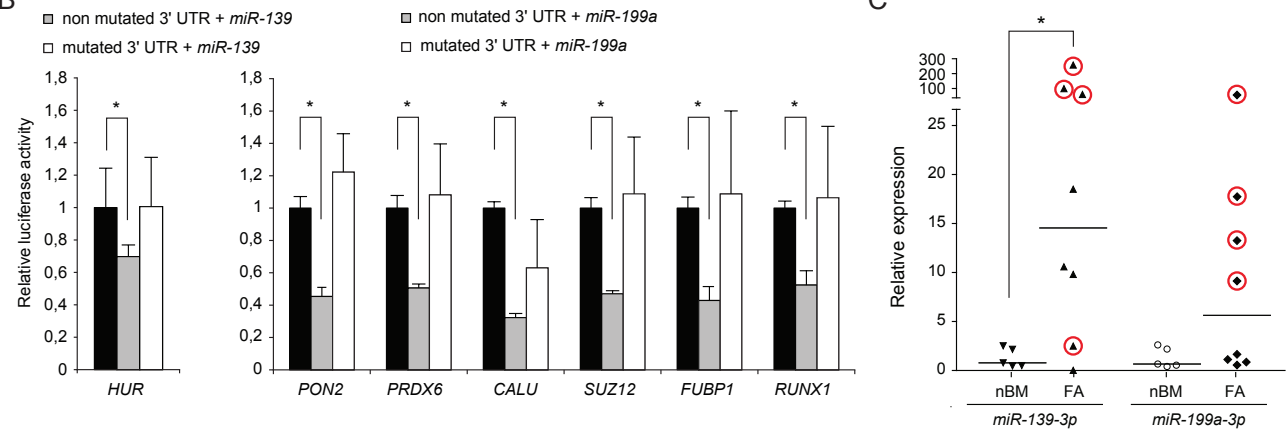

D
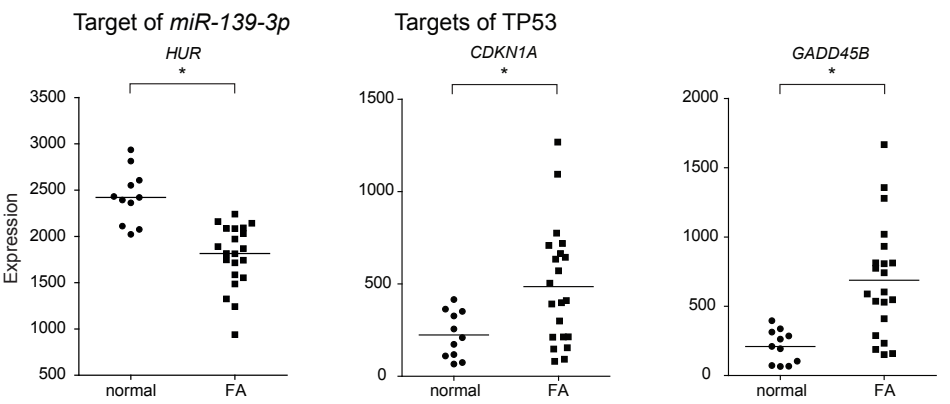

Expression of $\beta$-Actin

Targets of $m i R-199 a-3 p$
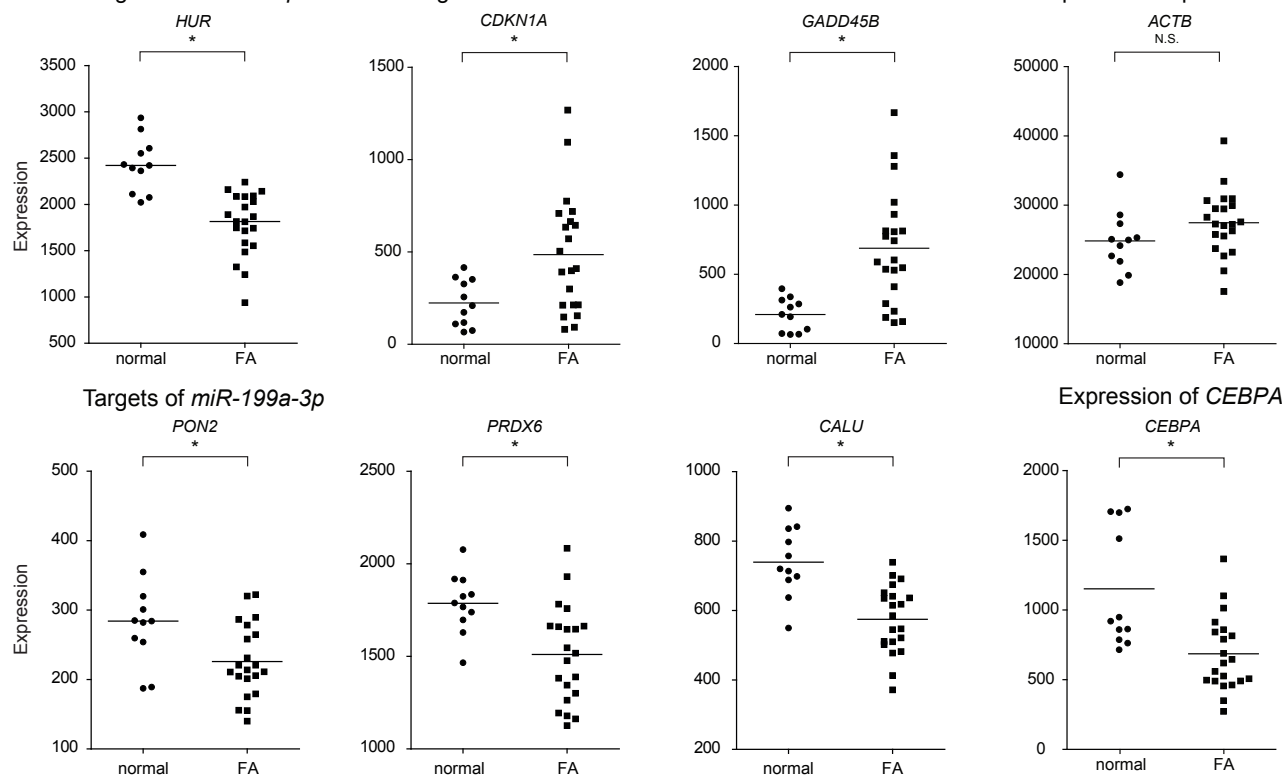

Expression of CEBPA
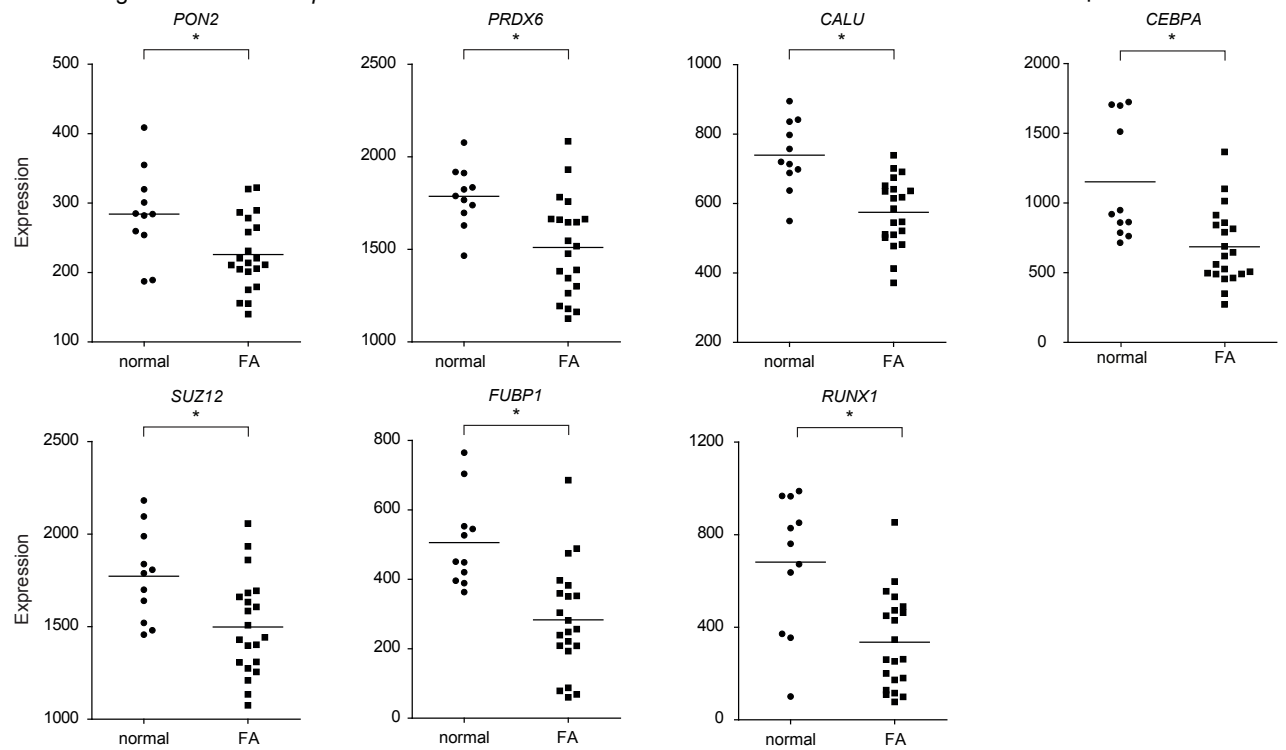
AML. CEBPA-deficient mice are defective in myeloid differentiation without displaying overt leukemia ${ }^{29}$. Because upregulation of $m i R-199 a-3 p$ in Erccl $^{-/ 292}$ mice occurs mainly in CMPs and because CEBPA expression is significantly decreased in FA patients (Figure 4D, $40 \%$ downregulated, $\mathrm{p}<0.00080)^{27}$, we reasoned that a Cebpa conditional knockout mouse model is especially suitable to investigate the leukemogenic potential of $m i R-199 a$. We used the Cebpa $a^{\text {Crefl }}$ mouse model in which the expression of Cre-recombinase is driven by the Cebpa promoter ${ }^{18}$. The Cre enzyme recombines the floxed Cebpa allele, resulting in loss of Cebpa mainly in myeloid precursors which leads to a differentiation block at CMP level. Fetal liver Cebpa $a^{\text {Creffl }}$ HSPCs were transduced with MSCV-EGFP control virus, MSCV-EGFP-miR-199a, or -miR-106, a non-oncogenic miRNA that induces expansion of HSPCs ${ }^{19,30}$, and transplanted in irradiated recipients (Figure 6A). All mice transplanted with $m i R-199 a$ transduced HSPCs ( $\mathrm{n}=5)$ developed AML within 60-200 days, whereas no malignancies occurred in mice transplanted with control cells (EV, $\mathrm{n}=9$ or $m i R-106, \mathrm{n}=4$ ) (Figure 6B). Transplantation of the leukemic cells in secondary recipients caused leukemia with a shortened latency (60-150 days) and more than 95\% blasts in the BM (Figure 6B, Supplemental Table 5). The complete loss of Cebpa expression in EGFP-positive leukemia cells was confirmed by Cebpa locus specific PCR and Cebpa expression analysis of leukemia samples (data not shown). Leukemic mice had splenomegaly, severe anemia, high percentages (70-90 \%) of blast cells in the BM (Figure 6C, Supplemental Table 5) and leukemic infiltration in peripheral blood, liver and spleen (Figure 6D, 6E). All leukemia samples expressed c-Kit and/or Scal, indicative of their immature HSPC-like state and lacked markers for terminal

Figure 4. MiR-139-3p, miR-199a-3p and their targets are aberrantly expressed in FA. A) A schematic overview of the luciferase reporter assay. The 3'-UTR region of a potential target containing the predicted miRNA binding site is cloned downstream of a luciferase reporter. Ectopic expression of the miRNA reduces the luciferase activity. Mutation of the predicted miRNA binding site abolishes the miRNA-dependent inhibition of luciferase activity. B) Luciferase reporter plasmids containing the 3'-UTR sequences of indicated targets of $m i R-139-3 p$ or miR-199a-3p with a $w t$ or mutated miRNA binding site were generated. The luciferase activities in the miRNA expressing cells and relative to the EV control are shown. Error bars represent the SD of 3 experiments. The significance was calculated with the student t-test [2-tailed]) ( $\left.{ }^{*} \mathrm{p}<0.05\right)$. C) The expression of miR-139-3p and miR-199a-3p normalized to U6 in BM CD34+ cells isolated from healthy individuals (normal (n) BM) and FA patients (FA), and relative to the average of normal BM samples are plotted. The patients with clinical progressive BMF are indicated with a red circle. The bars show the median relative expression of each group. The significance was calculated with the Mann-Whitney $U$ test (asymptotic significance [2-tailed]) $\left({ }^{*} \mathrm{p}<0.05\right)$. D) The transcript expression of indicated miR-139-3p or miR-199a-3p targets, TP53 targets i.e., $C D K N 1 A$ and $G A D D 45 B, C E B P A$, and the negative control ACTB in low-density mononuclear BM cells from $21 \mathrm{FA}$ patients (FA) and 11 healthy volunteers (normal) is shown. Data are taken from FA Transcriptome Consortium (FTC) database (Gene Expression Omnibus, 2009 and publicly available as GSE16334). The bars indicate the mean relative expression of each group. The significance was calculated with the non-paired student t.test (asymptotic significance [2-tailed]) ${ }^{*} \mathrm{p}<0.05$ ). N.S.: not significant. 
A

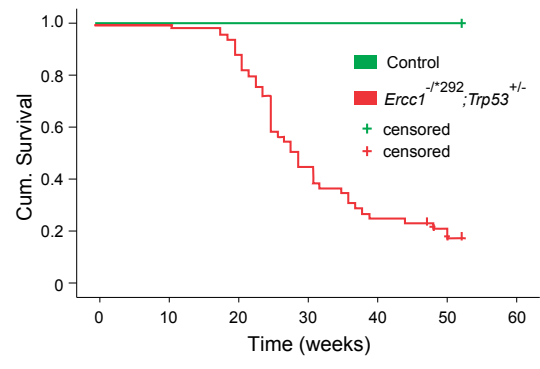

C

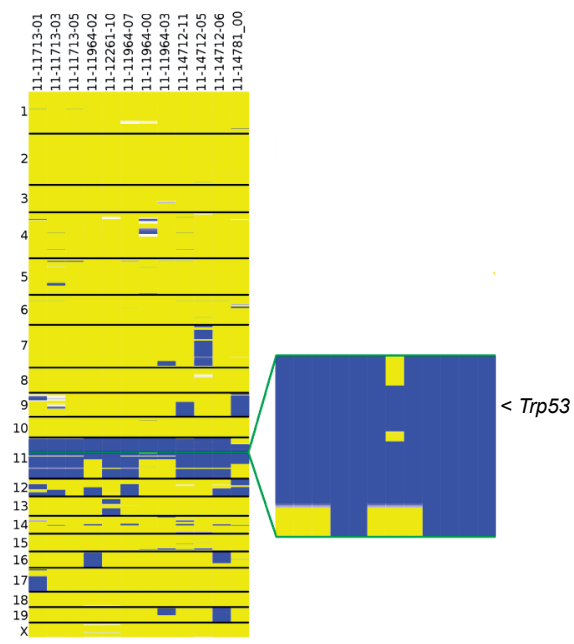

B

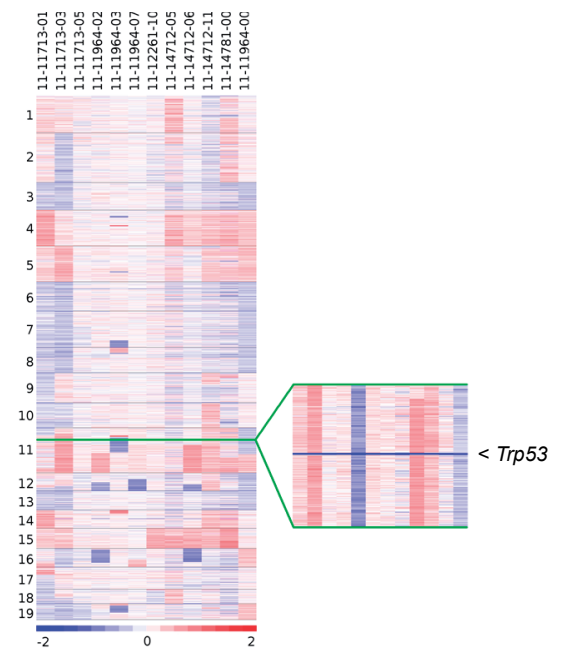

D

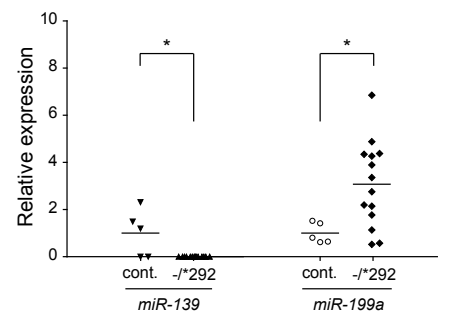

Figure 5. Development of leukemia in $\operatorname{Ercc1}^{-{ }^{-2} 292} \operatorname{Tr} p 53^{+/-}$transplanted mice. A) Kaplan-Meier plot of overall survival $\left(\operatorname{Ercc1}^{-/ * 292} \operatorname{Trp}^{+/-}(\mathrm{n}=51)\right.$; control group contained $\operatorname{Ercc1} 1^{+/-} \operatorname{Trp} 53^{+/-}$and $\left.\operatorname{Ercc1} 1^{+/ 292} \operatorname{Trp53^{+/-}}(\mathrm{n}=17)\right)$. Live animals at the end of the experiment appear as censored (+ symbols). B) Heat map of copy number variation (CNV) estimation showing consistent patterns of CNVs. The CNVs are displayed for each leukemia sample (indicated by a 9-digit number, e.g. 11-11713-01) along the genome. The autosomal chromosomes are given on the left side. Blue: loss of genetic material, red: gain of genetic material, and white: retention of genetic material. C) The loss of heterozygosity (LOH) along the genome of isolated leukemias is shown. In all leukemias, chromosome 11 harbors partial or complete LOH. Trp53 is located within regions affected by $\mathrm{LOH}$, leading to homozygous deletions. Blue: LOH; yellow: retention of heterozygosity; white: no informative SNPs. D) The expression of ICL-induced miRNAs normalized to U6 in cells isolated from $\operatorname{Ercc1}^{-/ * 292}$ leukemias relative to the average of $w t$ lin- controls is shown. Bars show the mean relative expression of each group. The significance was calculated with the Mann-Whitney U test (asymptotic significance [2-tailed]) $\left({ }^{\star} \mathrm{p}<0.05\right)$. 
myelo-monocytic differentiation (CD11b, GR1), T cells (CD4, CD8) or erythroid cells (TER119) (Figure 6F). These data establish that $m i R-199 a$ is an onco-miR that drives AML in differentiation defective preleukemic HSPCs.

\section{DISCUSSION}

In this study, we used Ercc1-deficient mice as a model to identify mechanisms involved in ICLdriven BMF and leukemic progression. There is convincing evidence that the endonuclease complex ERCC1-XPF participates in the FA ICL-repair pathway ${ }^{31}$. XPF (ERCC4) is mutated in rare cases of FA and has been renamed $F A N Q{ }^{32}$. FANCQ-ERCC1 is recruited to ICL lesions where it functions as the essential endonuclease required for repair ${ }^{26,33,34}$. Similar to the observations in FA patients ${ }^{13}$, we found that $\operatorname{Trp} 53$ is crucially involved in the exhaustion of HSPCs in $\operatorname{Erccl}^{-/ 292}$ mice. In contrast, Cdkn2a expression did not restore the colony-forming capacity of $\operatorname{Erccl}^{1 / 292}$ HSPCs. The Cdkn2a locus encodes the cyclin-dependent kinase inhibitor p16INK4a ${ }^{35}$. While being a major effector of BMF caused by the loss of ataxia telangiectasia mutated (ATM) protein ${ }^{22}$, p16INK4a thus appears dispensable for ICL-induced DDR in HSPCs, which is mainly controlled by ATM related (ATR) protein ${ }^{36}$. Cdkn2a also encodes p19 ${ }^{\mathrm{ARF}}$, which sequesters the TRP53 degradation protein MDM2. Hence, the lack of effects of $C d k n 2 a$ deletion on myeloid colony formation of $\operatorname{Erccl}^{-1 * 292}$ HSPCs also argues against a dominant role of p19ARF/MDM2-controlled TRP53 stability in HSPCs.

Loss of Trp53 was a common genetic abnormality in the $\operatorname{Erccl}^{1 / * 292}$ leukemia genomes. This is in line with studies showing that deletion of Trp53 cooperates with the loss of Fancc or Fancd 2 in tumorigenesis ${ }^{37,38}$. Loss of TP53 functions also occurs frequently in AML secondary to myeloproliferative neoplasms or MDS ${ }^{39}$. In contrast, TP53 mutations appear to be rare in ICL-repair deficient MDS/AML ${ }^{40}$, although a systematic analysis of TP53 activity that, e.g., includes epigenetic silencing of critical TP53 target genes in these patients remains to be done.

Two miRNAs, $m i R-139-3 p$ and $m i R-199 a-3 p$ that play opposite roles in $\operatorname{Erccl}^{-/ 2292} \mathrm{CMPs}$ were also found to be expressed in CD34+ cells from FA patients, suggesting that they may be involved in the hematopoietic defects seen in FA. We identified $H u R$ as a major target of $m i R-139-3 p$, and blocking its activity by antagomirs partly restored myeloid colony-formation from $\operatorname{Erccl}^{1 / 292} \mathrm{BM}$ cells. HuR has a broad pro-survival function in hematopoietic progenitors by controlling the expression of Bcl-2, Bcl-xl, Survivin, Caspase-9, Noxa and Puma ${ }^{41,42}$. HuR levels increase progressively in the transition from the chronic phase to the blast crisis of chronic myeloid leukemia ${ }^{43}$ and $H u R$ is overexpressed in subsets of AML ${ }^{44}$. Thus, one of the likely mechanisms by which miR-139-3p inhibits myeloid progenitor outgrowth of ICL-repair deficient BM cells is through inhibition of the pro-survival activities of $\mathrm{HuR}$.

Expression of $m i R-199 a-3 p$ in Cebpa-deficient HSPCs gave rise to a transplantable AML in mice, establishing its role as an onco-miR. The leukemogenic activity of miR-199a-3p is suggestive of a tumor suppressive function of its major target gene(s). PON2 and PRDX6 protect cells from oxidative stress ${ }^{45,46}$ and their repression may contribute to the excessive 
A

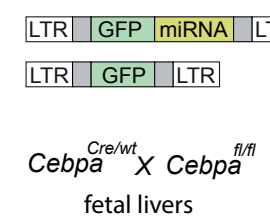

B

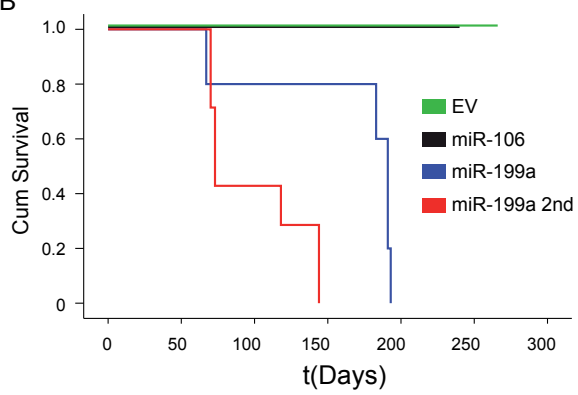

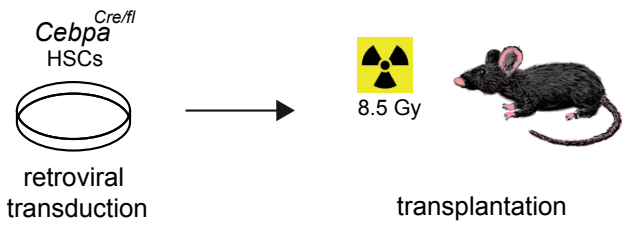

C

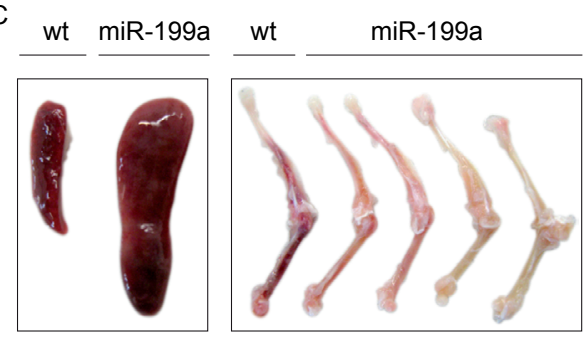

D
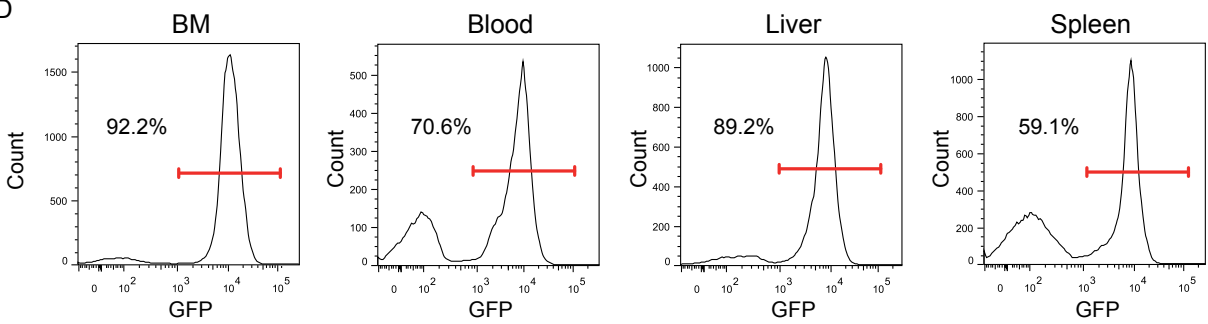

$\mathrm{E}$

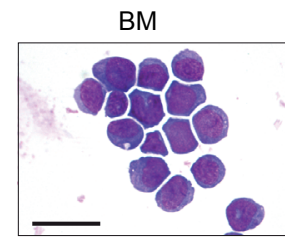

Blood Smear
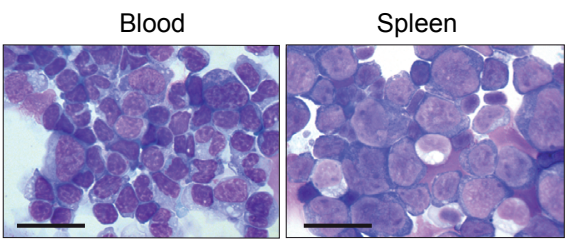

$\mathrm{F}$

Mouse 2
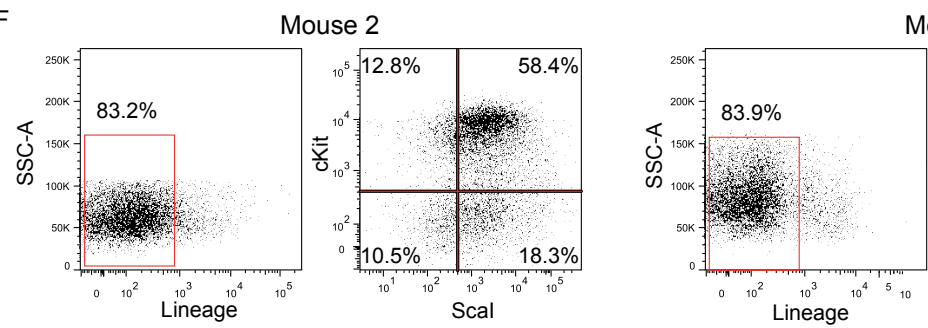

Mouse 3

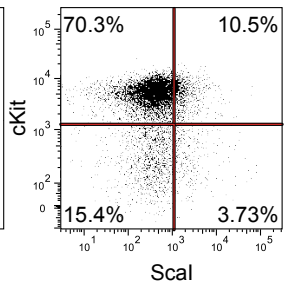

Figure 6. Forced expression of miR-199a drives leukemogenesis in mice. A) Schematic overview of the HSC transplantation experiment. HSPCs were isolated from Cebpa $a^{\text {Creff }}$ fetal livers and infected with MSCV-GFP-miRNA or with MSCV-GFP-EV control viruses. Recipient mice were lethally-irradiated ( $8.5 \mathrm{~Gy})$ and transplanted with transduced cells by tail-vein injection. B) Cumulative survival of mice transplanted with lin- cells expressing GFP with, miR-199a $(\mathrm{n}=5) \quad(\mathrm{p}<0.0005$ compared to EV $\mathrm{n}=9)$, 
ROS levels in ICL-deficient progenitors ${ }^{47}$. SUZ12 is a component of the polycomb repressor complex 2 (PRC2) involved in the silencing of multiple genes, including HOX genes ${ }^{48}$. Indeed, expression of the PRC2 target HOXA11 was increased in FA samples, whereas expression of HOXA5, which is not controlled by PRC2 ${ }^{49}$, was not changed (Supplemental Figure 3). MiR-199a-mediated repression of Suz12 may at least partly explain the increased expansion of progenitors without impairing their differentiation capacity, in line with what has been reported in a heterozygous Suz12 (Suz12 $\left.{ }^{\text {Plts/wt }}\right)$ model ${ }^{50}$. Additionally, miR-199a-3p-induced down-regulation of Runx1, a transcription factor critical for normal hematopoiesis ${ }^{51}$, may contribute to leukemogenesis. Intriguingly, Runx1 has been shown to protect hematopoietic stem and progenitor cells from oncogenic insults via a fail-safe mechanism involving BMI-1 that neutralizes oncogenic RAS signaling ${ }^{52}$. Other targets of $m i R-199 a-3 p$ that have been implicated in leukemogenesis, i.e., mTOR and CD44 ${ }^{53-55}$ were not found in our study. We cannot exclude that these targets were missed for technical reasons, e.g., the limited sensitivity of the GEP microarray and proteomics strategy used in our study. Finally, it is of interest that $m i R-199 a-3 p$ has been shown to compete with pluripotency factors in the reprogramming of mouse embryonic fibroblasts (MEFs) to induced pluripotent stem cells ${ }^{56}$. A difference between this and our study is that $m i R-199 a-3 p$ processing in MEFs depended on TRP53, contrary to what was observed in Ercc1-deficient leukemia cells (Figure 2C). This discrepancy probably reflects the complex control of miRNA activities depending on cell type, expression levels of targets and type of cellular stress ${ }^{23,57}$.

In conclusion, we have presented evidence that ICL-stress causes a loss of HSPCs through the combinatorial action of both $\operatorname{Tr} p 53$ and $m i R-139-3 p$. Elevated expression of $m i R-199 a-3 p$ appears insufficient to compensate for the exhaustion of HSPCs at the stage of BMF, but when expression of Trp53 and miR-139-3p is low or absent, miR-199a-3p acts as an onco-miR that promotes the development of AML. These findings shed new light on the molecular pathogenesis of ICL-repair deficient BMFS and transformation to leukemia and may open therapeutic avenues to reduce stem cell exhaustion and leukemic transformation, e.g., by selective use of antagomiRs.

miR-106 $(\mathrm{n}=4)$ (a non-oncogenic miRNA that promotes myeloid progenitor expansion (Meenhuis et al., 2011; Mu et al., 2009) ), GFP only, or secondary recipients of miR-199a leukemia cells (n=7) (miR-199 compared to EV $\mathrm{p}<0.0005$, and secondary transplants compared to primary tumors $\mathrm{p}<0.03$ ). The statistical significance was calculated with the log-rank Mantel-Cox test. C) Typical examples of splenomegaly and femurs and tibiae isolated from miR-199a-transplanted mice with leukemia. The pale bones indicate a severe anemia in the leukemic mice. D) Typical examples of FACS plots showing the percentage of GFP-expressing AML cells in the BM, blood, liver and spleen of the leukemic mice. E) Micrographs showing the morphology of leukemic blasts in the different hematological organs (BM, blood (blood smear), blood (erythrocyte lysis, cytospins) and spleen). Black bar indicates $10 \mu \mathrm{m}$. F) Flow cytometric analysis of GFP-positive BM cells. GFP-positive AML cells from mouse 2 are an example of a stem cell-like phenotype (c-Kit, Scal double positive), whereas the AML cells from mouse 3 have a progenitor-like (c-Kit high, Scal low) phenotype. 


\section{ACKNOWLEDGEMENTS}

This work was supported by the Dutch Cancer Society (KWF kankerbestrijding). PMHvS is supported by a ZonMw E-rare grant. SES was supported by a KIKA Children Cancer Free grant. We gratefully acknowledge the personnel of the animal facility of Erasmus MC (EDC) for mouse care, Dr. E. Rombouts, P. van Geel and N. Spierenburg-Papazian for assistance with flow cytometry and cell sorting, Dr. R. Beekman Dr. E. Bindels for experimental assistance and E. Simons for assistance with the preparation of figures. Prof. Dr. Björn Schumacher, Cologne Excellence Cluster for Cellular Stress Responses in Aging-Associated Diseases (CECAD), University of Cologne, Germany is gratefully acknowledged for providing Trp53and Cdkn2a-deficient mouse models. We thank Prof. Dr. D. Tenen for the floxed Cebpa mice. Some results are based upon data generated by The Cancer Genome Atlas managed by the NCI and NHGRI (http://cancergenome.nih.gov).

\section{AUTHOR CONTRIBUTIONS}

MFA and JRH performed experiments and analyzed data; HWJdL, PMHvS, JV-O, YC performed experiments; RH and MS processed and analyzed next generation sequencing data; AHdR, GMCJ and PAvV, designed and performed proteomics and analyzed proteomics data; SES and MBB isolated and investigated BM samples from FA patients; MvL, IPT and SJE supervised the project. MFA, JRH, IPT and SJE designed the experiments and wrote the manuscript. 


\section{REFERENCES}

1. Blank U, Karlsson G, Karlsson S. Signaling pathways governing stem-cell fate. Blood. 2008;111(2):492-503.

2. Dokal I, Vulliamy T. Inherited aplastic anaemias/bone marrow failure syndromes. Blood Rev. 2008;22(3):141-153.

3. Parikh S, Bessler M. Recent insights into inherited bone marrow failure syndromes. Curr Opin Pediatr. 2012;24(1):23-32.

4. Bakker ST, Passegue E. Resilient and resourceful: genome maintenance strategies in hematopoietic stem cells. Exp Hematol. 2013;41(11):915-923.

5. Rossi DJ, Bryder D, Seita J, Nussenzweig A, Hoeijmakers J, Weissman IL. Deficiencies in DNA damage repair limit the function of haematopoietic stem cells with age. Nature. 2007;447(7145):725-729.

6. Rahn JJ, Adair GM, Nairn RS. Multiple roles of ERCC1-XPF in mammalian interstrand crosslink repair. Environ Mol Mutagen. 2010;51(6):567-581.

7. Prasher JM, Lalai AS, Heijmans-Antonissen $C$, et al. Reduced hematopoietic reserves in DNA interstrand crosslink repair-deficient Ercc1-/- mice. EMBO J. 2005;24(4):861-871.

8. Verhagen-Oldenampsen JH, Haanstra JR, van Strien PM, Valkhof M, Touw IP, von Lindern M. Loss of erccl results in a time- and dose-dependent reduction of proliferating early hematopoietic progenitors. Anemia. 2012;2012:783068.

9. Dufour C, Corcione A, Svahn J, et al. TNFalpha and IFN-gamma are overexpressed in the bone marrow of Fanconi anemia patients and TNF-alpha suppresses erythropoiesis in vitro. Blood. 2003;102(6):2053-2059.

10. Garaycoechea JI, Patel KJ. Why does the bone marrow fail in Fanconi anemia? Blood. 2014;123(1):26-34.

11. Garbati MR, Hays LE, Keeble W, Yates JE, Rathbun RK, Bagby GC. FANCA and FANCC modulate TLR and p38 MAPKdependent expression of IL-1beta in macrophages. Blood. 2013;122(18):31973205.
12. Matsui K, Giri N, Alter BP, Pinto LA. Cytokine production by bone marrow mononuclear cells in inherited bone marrow failure syndromes. $\mathrm{Br} J$ Haematol. 2013;163(1):81-92.

13. Ceccaldi R, Parmar K, Mouly E, et al. Bone marrow failure in Fanconi anemia is triggered by an exacerbated p53/p21 DNA damage response that impairs hematopoietic stem and progenitor cells. Cell Stem Cell. 2012;11(1):36-49.

14. Serrano M, Lee H, Chin L, Cordon-Cardo C, Beach D, DePinho RA. Role of the INK4a locus in tumor suppression and cell mortality. Cell. 1996;85(1):27-37.

15. Clarke AR, Purdie CA, Harrison DJ, et al. Thymocyte apoptosis induced by p53dependent and independent pathways. Nature. 1993;362(6423):849-852.

16. Weeda G, Donker I, de Wit J, et al. Disruption of mouse ERCC1 results in a novel repair syndrome with growth failure, nuclear abnormalities and senescence. Curr Biol. 1997;7(6):427-439.

17. Zhang DE, Zhang $\mathrm{P}$, Wang ND, Hetherington CJ, Darlington GJ, Tenen DG. Absence of granulocyte colonystimulating factor signaling and neutrophil development in CCAAT enhancer binding protein alpha-deficient mice. Proc Natl Acad Sci U S A. 1997;94(2):569-574.

18. Wolfler A, Danen-van Oorschot AA, Haanstra JR, et al. Lineage-instructive function of C/EBPalpha in multipotent hematopoietic cells and early thymic progenitors. Blood. 2010;116(20):4116-4125.

19. Meenhuis A, van Veelen PA, de Looper $\mathrm{H}$, et al. MiR-17/20/93/106 promote hematopoietic cell expansion by targeting sequestosome 1-regulated pathways in mice. Blood. 2011;118(4):916-925.

20. Jongen-Lavrencic M, Sun SM, Dijkstra MK, Valk PJ, Lowenberg B. MicroRNA expression profiling in relation to the genetic heterogeneity of acute myeloid leukemia. Blood. 2008;111(10):5078-5085. 
21. McWhir J, Selfridge J, Harrison DJ, Squires $S$, Melton DW. Mice with DNA repair gene (ERCC-1) deficiency have elevated levels of p53, liver nuclear abnormalities and die before weaning. Nat Genet. 1993;5(3):217224.

22. Ito K, Hirao A, Arai F, et al. Regulation of oxidative stress by ATM is required for self-renewal of haematopoietic stem cells. Nature. 2004;431(7011):997-1002.

23. Leung AK, Sharp PA. MicroRNA functions instress responses. MolCell.2010;40(2):205215.

24. Mendell JT, Olson EN. MicroRNAs in stress signaling and human disease. Cell. 2012;148(6):1172-1187.

25. de Koning JP, Soede-Bobok AA, Ward AC, et al. STAT3-mediated differentiation and survival and of myeloid cells in response to granulocyte colony-stimulating factor: role for the cyclin-dependent kinase inhibitor p27(Kip1). Oncogene. 2000;19(29):3290-3298.

26. Crossan GP, Patel KJ. The Fanconi anaemia pathway orchestrates incisions at sites of crosslinked DNA.J Pathol.2012;226(2):326337.

27. Vanderwerf SM, Svahn J, Olson S, et al. TLR8-dependent TNF-(alpha) overexpression in Fanconi anemia group C cells. Blood. 2009;114(26):5290-5298.

28. Deans AJ, West SC. DNA interstrand crosslink repair and cancer. Nat Rev Cancer. 2011;11(7):467-480.

29. Zhang P, Iwasaki-Arai J, Iwasaki H, et al. Enhancement of hematopoietic stem cell repopulating capacity and self-renewal in the absence of the transcription factor C/ EBP alpha. Immunity. 2004;21(6):853-863.

30. $\mathrm{Mu} \mathrm{P}$, Han YC, Betel D, et al. Genetic dissection of the miR-17 92 cluster of microRNAs in Myc-induced B-cell lymphomas. Genes Dev. 2009;23(24):28062811.

31. Bhagwat N, Olsen AL, Wang AT, et al. XPFERCC1 participates in the Fanconi anemia pathway of cross-link repair. Mol Cell Biol. 2009;29(24):6427-6437.
32. Bogliolo M, Schuster B, Stoepker C, et al. Mutations in ERCC4, encoding the DNArepair endonuclease XPF, cause Fanconi anemia. Am J Hum Genet. 2013;92(5):800806.

33. Hodskinson MR, Silhan J, Crossan GP, et al. Mouse SLX4 Is a Tumor Suppressor that Stimulates the Activity of the Nuclease XPF-ERCC1 in DNA Crosslink Repair. $\mathrm{Mol}$ Cell. 2014.

34. Klein Douwel D, Boonen RA, Long DT, et al. XPF-ERCC1 Acts in Unhooking DNA Interstrand Crosslinks in Cooperation with FANCD2 and FANCP/SLX4. Mol Cell. 2014.

35. Weber JD, Taylor LJ, Roussel MF, Sherr CJ, Bar-Sagi D. Nucleolar Arf sequesters Mdm2 and activates p53. Nat Cell Biol. 1999;1(1):20-26.

36. Ceccaldi R, Briot D, Larghero J, et al. Spontaneous abrogation of the G(2) DNA damage checkpoint has clinical benefits but promotes leukemogenesis in Fanconi anemia patients. J Clin Invest. 2011;121(1):184-194.

37. Freie B, Li X, Ciccone SL, et al. Fanconi anemia type $\mathrm{C}$ and p53 cooperate in apoptosis and tumorigenesis. Blood. 2003;102(12):4146-4152.

38. Houghtaling S, Granville L, Akkari Y, et al. Heterozygosity for p53 $\left(\operatorname{Trp} 53^{+/-}\right)$ accelerates epithelial tumor formation in fanconi anemia complementation group D2 (Fancd2) knockout mice. Cancer Res. 2005;65(1):85-91.

39. Milosevic JD, Puda A, Malcovati L, et al. Clinical significance of genetic aberrations in secondary acute myeloid leukemia. Am J Hematol. 2012;87(11):1010-1016.

40. Quentin S, Cuccuini W, Ceccaldi R, et al. Myelodysplasia and leukemia of Fanconi anemia are associated with a specific pattern of genomic abnormalities that includes cryptic RUNX1/AML1 lesions. Blood. 2011;117(15):e161-170.

41. Abdelmohsen K, Lal A, Kim HH, Gorospe M. Posttranscriptional orchestration of an anti-apoptotic program by HuR. Cell Cycle. 2007;6(11):1288-1292. 
42. Ghosh M, Aguila HL, Michaud J, et al. Essential role of the RNA-binding protein HuR in progenitor cell survival in mice. $J$ Clin Invest. 2009;119(12):3530-3543.

43. Radich JP, Dai H, Mao M, et al. Gene expression changes associated with progression and response in chronic myeloid leukemia. Proc Natl Acad Sci U S A. 2006;103(8):2794-2799.

44. Topisirovic I, Siddiqui N, Orolicki S, et al. Stability of eukaryotic translation initiation factor $4 \mathrm{E}$ mRNA is regulated by $\mathrm{HuR}$, and this activity is dysregulated in cancer. $\mathrm{Mol}$ Cell Biol. 2009;29(5):1152-1162.

45. Fisher AB. Peroxiredoxin 6: a bifunctional enzyme with glutathione peroxidase and phospholipase $\mathrm{A}(2)$ activities. Antioxid Redox Signal. 2011;15(3):831-844.

46. Ng CJ, Wadleigh DJ, Gangopadhyay A, et al. Paraoxonase-2 is a ubiquitously expressed protein with antioxidant properties and is capable of preventing cell-mediated oxidative modification of low density lipoprotein. J Biol Chem. 2001;276(48):44444-44449.

47. Du W, Adam Z, Rani R, Zhang X, Pang Q. Oxidative stress in Fanconi anemia hematopoiesis and disease progression. Antioxid Redox Signal. 2008;10(11):19091921.

48. Cao R, Zhang Y. SUZ12 is required for both the histone methyltransferase activity and the silencing function of the EED-EZH2 complex. Mol Cell. 2004;15(1):57-67.

49. Abdel-Wahab O, Adli M, LaFave LM, et al. ASXL1 mutations promote myeloid transformation through loss of PRC2- mediated gene repression. Cancer Cell. 2012;22(2):180-193.

50. Majewski IJ, Blewitt ME, de Graaf CA, et al. Polycomb repressive complex 2 (PRC2) restricts hematopoietic stem cell activity. PLoS Biol. 2008;6(4):e93.

51. Okuda T, van Deursen J, Hiebert SW, Grosveld G, Downing JR. AML1, the target of multiple chromosomal translocations in human leukemia, is essential for normal fetal liver hematopoiesis. Cell. 1996;84(2):321-330.

52. Motoda L, Osato M, Yamashita N, et al. Runx1 protects hematopoietic stem/ progenitor cells from oncogenic insult. Stem Cells. 2007;25(12):2976-2986.

53. Fornari F, Milazzo M, Chieco P, et al. MiR-199a-3p regulates mTOR and c-Met to influence the doxorubicin sensitivity of human hepatocarcinoma cells. Cancer Res. 2010;70(12):5184-5193.

54. Henry JC, Park JK, Jiang J, et al. miR-199a$3 p$ targets $\mathrm{CD} 44$ and reduces proliferation of CD44 positive hepatocellular carcinoma cell lines. Biochem Biophys Res Commun. 2010;403(1):120-125.

55. Wu D, Huang $\mathrm{HJ}$, He CN, Wang KY. MicroRNA-199a-3p regulates endometrial cancer cell proliferation by targeting mammalian target of rapamycin (mTOR). Int J Gynecol Cancer. 2013;23(7):1191-1197.

56. Wang J, He Q, Han C, et al. p53facilitated miR-199a-3p regulates somatic cell reprogramming. Stem Cells. 2012;30(7):1405-1413.

57. Ebert MS, Sharp PA. Roles for microRNAs in conferring robustness to biological processes. Cell. 2012;149(3):515-524. 


\section{SUPPLEMENTARY MATERIALS AND METHODS}

\section{Quantitative proteomics}

Sample preparation: HSPCs (experiment 1: $3 \times 10^{6}$ cells, experiment 2: $5 \times 10^{6}$ cells, experiment 3: $5 \times 10^{6}$ cells) were washed with PBS and lysed in ST lysis buffer (5\% SDS, $100 \mathrm{mM}$ Tris-Cl $\mathrm{pH}$ 7.6). DTT (0.5M) was added to a concentration of $100 \mathrm{mM}$. The sample was incubated for $4 \mathrm{~min}$ at $90^{\circ} \mathrm{C}$. Samples were processed using filter-aided sample preparation on $30 \mathrm{kDa}$ Microcon filters as previously described ${ }^{1}$.

Reductive amination: Peptide concentration was determined using the bicinchoninic acid protein assay (Pierce). Twenty-five $\mu$ g peptide was labeled by reductive amination essentially as described ${ }^{2}$. Peptides from Ercc1 ${ }^{-/ 292}$ and Ercc1 control cells were sequentially labeled on the same C18 extraction cartridge (HLB 1cc Oasis, Waters Corporation) with either of the dimethyl isotopologues. Briefly, peptides from $\operatorname{Erccl}^{-{ }^{*} 292}$ were diluted in $1 \mathrm{ml} 0.1 \%$ (vol/ vol) formic acid, applied to the column, washed twice with $0.1 \%$ (vol/vol) formic acid and labeled with five $0.5 \mathrm{ml}$ aliquots of labeling mixture 'light', applied in 2-minute intervals. The column was washed twice with $0.1 \%$ (vol/vol) formic acid followed by application of peptides from Ercclcontrol cells and its labeling with the 'medium' dimethyl isotopologue. Finally the differentially labeled peptides were eluted from the column with $400 \mu \mathrm{l} 80 \%$ (vol/vol) acetonitrile, $0.1 \%$ (vol/vol) formic acid and freeze-dried. 'Light' dimethyl labeling mixture consists of formaldehyde $\left(37 \%\right.$ (wt/vol) in $\mathrm{H}_{2} \mathrm{O}$, Sigma Aldrich) and sodium cyanoborohydride (Fluka), 'medium' labeling mixture consists of formaldehyde-D2 (20\% (wt/vol) in $\mathrm{D}_{2} \mathrm{O}$, Isotec) and sodium cyanoborohydride.

Strong cation exchange chromatography (SCX): SCX separations were performed on a home-made SCX column ( $320 \mu \mathrm{m}$ ID, $15 \mathrm{~cm}$, polysulfoethyl A 3 um, Poly LC). Peptides were applied to the column and washed for $10 \mathrm{~min}$ with solvent A (water, 35\% acetonitrile, $0.1 \%$ TFA) at $4 \mu \mathrm{l} / \mathrm{min}$. The column was developed with a linear gradient to reach $100 \%$ solvent $\mathrm{B}$ $(250 \mathrm{mM} \mathrm{KCl}, 35 \%$ acetonitrile, $0.1 \%$ TFA) in $15 \mathrm{~min}$, followed by $100 \%$ solvent C ( $500 \mathrm{mM}$ $\mathrm{KCl}, 35 \%$ acetonitrile, $0.1 \% \mathrm{TFA}$ ) in the next $15 \mathrm{~min}$. After $5 \mathrm{~min}$ at $100 \%$ solvent $\mathrm{C}$, the column was conditioned with solvent $\mathrm{A}$. About twenty $4 \mu \mathrm{l}$-fractions were collected in vials prefilled with $100 \mu \mathrm{l} 3 \%$ acetonitrile, $0.1 \%$ formic acid.

On-line nanoHPLC-tandem mass spectrometry: SCX fractions were analyzed by nano-flow liquid chromatography using an Agilent 1100 HPLC binary system (Agilent Technologies), using the setup as described ${ }^{3}$ and coupled on-line to a 7-tesla LTQ-FT Ultra mass spectrometer (Thermo Fisher Scientific). The end of the nano-column was drawn to a tip (internal diameter $\sim 5 \mu \mathrm{m}$ ), from which the eluent was sprayed into the mass spectrometer. Peptides were trapped at $5 \mu \mathrm{l} / \mathrm{min}$ on a $1 \mathrm{~cm}$ column $(100-\mu \mathrm{m}$ ID; ReproSil-Pur C18-AQ, $3 \mu \mathrm{m})$, and eluted to a $15 \mathrm{~cm}$ column $(50-\mu \mathrm{m}$ ID; ReproSil-Pur C18-AQ, $3 \mu \mathrm{m})$ at $150 \mathrm{nl} / \mathrm{min}$ in a 120 minutes gradient 
from 0 to $50 \%$ acetonitrile in $0.1 \%$ formic acid. All chromatographic columns were prepared in-house. The mass spectrometer was operated in data-dependent mode, automatically switching between MS and MS/MS acquisition. Full scan MS spectra were acquired in the FT-ICR with a resolution of 25,000 at a target value of 3,000,000. The five most intense ions were then isolated for collision induced dissociation in the linear ion trap at a target value of 10,000, and placed on the dynamic exclusion list for 45 seconds. Nano-HPLC MS/MS experiments of the biological replicates were run in duplicate.

Data analysis: Raw files were processed using two different software packages, Proteome Discoverer (v1.2.0.208) (Thermo Fisher Scientific) and MaxQuant (version 1.2.2.5) (www.maxquant.org), for relative quantitation. In Proteome Discoverer, peak lists were generated using default settings, and searched with the MASCOT search engine v2.2.04 (Matrix Science) against the IPImouse387 database (trypsin, precursor tolerance $10 \mathrm{ppm}$, fragment tolerance $0.5 \mathrm{Da}$ ), with static modification carbamidomethyl (Cys), and dynamic modifications oxidation (Met), light (d0)-dimethylation (Lys and N-terminus) and heavy (d4)-dimethylation (Lys and N-terminus).

MaxQuant was used with the default settings against the same database with the same parameters as for the mascot search. The only difference was the precursor tolerance, which was $20 \mathrm{ppm}$ in MaxQuant. In each experiment, the proteins with a PEP value $>0.05$ when analyzed by MaxqQuant, were discarded.

Protein fold changes between Ercc1 ${ }^{-/ 292}$ HSPCs and Erccl control HSPCs were calculated with PD and Maxquant based on at least 2 counts per protein. The protein fold changes were discarded in case of a relative variability of $>30 \%$ between different counts in each experiment. In addition, protein fold changes from PD and Maxquant were compared and if the results from different programs were contradictory i.e., showing upregulation in one program and downregulation in the other, proteins were discarded. With this procedure we identified 2000 (experiment 1), 1685 (experiment 2), and 1310 (experiment 3) proteins. In total, we identified 457 proteins to be up- or down- regulated in at least 2 out of 3 experiments. The final fold change shows the average of different experiments analyzed by either Proteome Discoverer or MaxQuant software packages.

To correlate the protein names-output from the proteomics data with the expression data-based gene names on the MMU array we developed a software package that scans the NCBI, Ensembl and Swiss- Prot databases. In this way 97\% of the MaxQuant-identified proteins could be linked to the expression data. Normalization and mapping were performed by the use of BrainArray annotation. Associations to predicted targets of related miRNA's were inferred using TargetScan.

\section{Whole exome sequencing (WES)}

Sequencing libraries from the leukemias were prepared using the Sure-select target enrichment mouse exome capture (G7550B, Agilent Technologies) according to manufacturer's protocol (Version 2.3, January 2011; for Illumina sequencing kit). In short, 
$3 \mu \mathrm{g}$ genomic DNA was sheared to fragments of approximately 170 base pairs using the Covaris S-series Single Tube Sample Preparation System, Model S2 (Covaris). Fragment sizes were determined on a Bioanalyzer (Agilent Technologies). Adapter ligated libraries were prepared according to the manufacturer's protocol using the Paired-End Genomic DNA Sample Prep Kit (Illumina). Of the adaptor-ligated library $\sim 6$ pM was sequenced (101 bp; paired-end) along with 1\% Phix control with a v2 flow cell on a Hiseq2000 (Illumina). In the second cohort exome capture was performed using the NimbleGen SeqCap EZ exome library MM9 according to manufacturer's protocol (NimbleGen SeqCap EZ Library SR User's Guide v3.0, November 2011). Adapter ligation and amplifications were done with Illumina Truseq DNA sample Preparation v2 (protocol August 2011). Mouse Cot-1 DNA (Life technologies) was used during hybridization. For sequencing a v3 flow cell was used. Brain DNA from the 6 donor $\operatorname{Ercc1}^{-{ }^{*} 292}$ donor mice, used for BM transplantation was sequenced to filter out germ-line single nucleotide polymorphisms (SNP's) and indels from the leukemia genomes.

WES data analysis: Paired-end sequence alignment was done using the Burrows and Wheeler aligner (BWA ${ }^{4}$. The copy number variation (CNV) profiles were determined by an inhouse constructed package called CNVsvd (M. Sanders et al, 2014, submitted). In short, the algorithm extracts the fragment count information from aligned paired-end reads. Subsequently, it determines the variance components from the count profiles of the control samples which are used to filter the noise from the count profiles of the tumor samples. Finally, the count distribution of the control samples is used to estimate the copy number from the count information of the tumor samples.

\section{Luciferase reporter assays}

The wild-type 3'UTR fragments were cloned behind the Firefly Luciferase gene of the pGL3promoter vector (Promega). Mutations were introduced with Quick change site-directed mutagenesis kit (Agilent Technologies). HEK293 cells were transfected with pGL3-3'UTR and Renilla control vectors with Fugene6 transfection reagent (Roche). For dual luciferase reporter assays, cell were lysed and analyzed according to the manufacturer's instruction (Promega) with a Victor multi-label counter. 


\begin{tabular}{ll}
\hline Primers for 3’UTR cloning: \\
\hline PRDX6 hsa fw XbaI & AATCTAGATGTGAGCCAGAGGATGTCAGC \\
\hline PRDX6 hsa rv ApaI & AAGGGCCCAATGGGTGACAGGAGAGGACG \\
\hline PRDX6 mmu fw XbaI & AATCTAGAAGCCGTGGGTCCTTGC \\
\hline PRDX6 mmu rv ApaI & AAGGGCCCTCTCCCTATGTCAGTGCTCTCC \\
\hline SUZ12 mmu fw XbaI & AATCTAGATAGGATGGTAAAGCAAGAGAAACAG \\
\hline SUZ12 mmu rv ApaI & AAGGGCCCTCTGATGGTGGTGGAATGAAAT \\
\hline RUNX1 mmu fw XbaI & AATCTAGAGAAGACGCAGCCCATCCT \\
\hline RUNX1 mmu rv ApaI & AAGGGCCCTCCAGACATCTTCAACGCAAT \\
\hline PON2 mmu fw XbaI & AATCTAGAATCCAGCGAGAAAGAAGAAAGC \\
\hline PON2 mmu rv ApaI & AAGGGCCCGCTGAACACTGGAAGGCTGA \\
\hline FUBP1 mmu fw XbaI & AATCTAGATATGGATGCAGACGACTTGATG \\
\hline FUBP1 mmu rv ApaI & AAGGGCCCGAAATAGCCAAATACAACAGAAAAG \\
\hline CALU mmu fw XbaI & AATCTAGAGACAGAGGAACCTACATTTCTTCA \\
\hline CALU mmu rv ApaI & AAGGGCCCTCAACAGGCAAGAGAAAGCATT \\
\hline HuR 3'UTR_f1 XbaI & AATCTAGAtactctgggatgcaaccgac \\
\hline HuR 3'UTR_rl ApaI & AAGGGCCCTGAGTGAGCAGGAGGTGGCA \\
\hline HuR 3'UTR_f2 XbaI & AATCTAGAgatgacgggcttgtagcacc \\
\hline HuR 3’UTR_r2 ApaI & AAGGGCCCGCCAGCAACTAGAACCTTGATG \\
\hline
\end{tabular}

\begin{tabular}{ll}
\hline $\begin{array}{l}\text { Primers used for } \\
\text { mutagenesis: }\end{array}$ & MRE1 \\
\hline PRDX6 hsa fw XbaI & GGTTTTTAGGTTGCTATATCACTGGCTTATTAAATGAAAATGGC \\
\hline PRDX6 hsa rv ApaI & GCCATTTTCATTTAATAAGCCAGTGATATAGCAACCTAAAAACC \\
\hline PRDX6 mmu fw XbaI & ATGTAGATCGCTCGCTATAATAATGGGTCATTAAATGGAAATG \\
\hline PRDX6 mmu rv ApaI & CATTTCCATTTAATGACCCATTATTATAGCGAGCGATCTACAG \\
\hline SUZ12 mmu fw XbaI & CAACAGAAAGTGGTTTCATTAATGGCACGGATAGCTTTTTATTC \\
\hline SUZ12 mmu rv ApaI & GAATAAAAAGCTATCCGTGCCATTAATGAAACCACTTTCTGTTG \\
\hline RUNX1 mmu fw XbaI & GCTTTGGGTCATTTTTTAATTAATGTATTTCCACAAAGAAATCCC \\
\hline RUNX1 mmu rv ApaI & GGGATTTCTTTGTGGAAATACATTAATTAAAAAATGACCCAAAGC \\
\hline PON2 mmu fw XbaI & CCT GCT GGG CTT GTG CAG GAA TAA TGA TAG ATA ACA CTT G \\
\hline PON2 mmu rv ApaI & CAA GTG TTA TCT ATC ATT ATT CCT GCA CAA GCC CAG CAG G \\
\hline FUBP1 mmu fw XbaI & CCC CCC TTT TTT TTT ATT TTG AAA ATG TAC AAA ATA ACT \\
\hline FUBP1 mmu rv ApaI & CAG AAA TAT TAA CCT CCT ATC ATT ATT GAT AGT TAT TTT \\
\hline
\end{tabular}




\begin{tabular}{ll}
\hline $\begin{array}{l}\text { Primers used for } \\
\text { mutagenesis: }\end{array}$ & MRE1 \\
\hline CALU mmu fw XbaI & $\begin{array}{l}\text { CTC TGG TTT CAC ATA AAA TTG CGC TGC AGA GAC TGT TAT } \\
\text { TAC AAA CTT TTT AA }\end{array}$ \\
\hline CALU mmu rv ApaI & $\begin{array}{l}\text { TTA AAA AGT TTG TAA TAA CAG TCT CTG CAG CGC AAT TTT } \\
\text { ATG TGA AAC CAG AG }\end{array}$ \\
\hline HuR 3’UTR_f1 XbaI & $\begin{array}{l}\text { CTA ACA CGC GTT TCA TTC AAT GTA TAC ACA GAC TGG GTA } \\
\text { GCA AAA AAA }\end{array}$ \\
\hline HuR 3’UTR_r1 ApaI & $\begin{array}{l}\text { TTT TTT TGC TAC CCA GTC TGT GTA TAC ATT GAA TGA AAC } \\
\text { GCG TGT TAG }\end{array}$ \\
\hline HuR 3'UTR_f2 XbaI & AGG AAC ATT CTC ATT GTA TGT GGT AGC CGC TGT TTG AAC AGC \\
\hline HuR 3’UTR_r2 ApaI & GCT GTT CAA ACA GCG GCT ACC ACA TAC AAT GAG AAT GTT CCT \\
\hline PRDX6 hsa fw XbaI & CATTCATACATCAGCACTCTACTAGTTCTGTTTGAAATATGTT \\
\hline PRDX6 hsa rv ApaI & AACATATTTCAAACAGAACTAGTAGAGTGCTGATGTATGAATG \\
\hline PRDX6 mmu fw XbaI & CTGTCACAGTGCCCAATGACTGGCTCTCTTTG \\
\hline PRDX6 mmu rv ApaI & CAAAGAGAGCCAGTCATTGGGCACTGTGACAG \\
\hline
\end{tabular}

\section{Luminex experiments}

The 32D cells expressing human colony-stimulating factor 3 (CSF3)-receptor were expanded as described ${ }^{5}$. GFP-positive MSCV-BC-miRNA 32D cell populations were sorted with FACSAria II cell sorter (Becton-Dickinson Biosciences). MiRNA expressing cell populations were mixed in a 1:1 ratio, further expanded in RPMI medium supplemented with FCS and IL-3 (1:1000, supernatant) or switched to CSF3-containing medium. Luminex experiments were performed as described previously ${ }^{6}$.

\section{Antibodies, cell staining, flowcytometry and cytospins}

Peripheral blood was obtained by heart puncture at the moment of euthanasia. BM samples were prepared as described previously ${ }^{7}$. For morphological analysis of tumor cells, cytospins were stained with May-Grünwald-Giemsa and examined with a Leica DMLB microscope (40X objective) and Leica Application Suite Version 2.7.1 R1 Software. For flow cytometric analyses, cells were stained with combinations of antibodies as described previously ${ }^{7}$. Cell populations were determined with $\mathrm{BD}^{\mathrm{m}}$ LSR II Flow Cytometer System (Becton-Dickinson Biosciences). Data was analyzed with FlowJo (Tree Star, Ashland, OR). For live cell gating, cells were stained with 7-AAD (Invitrogen). HSPC subpopulations were gated as described ${ }^{8}$.

\section{Gene and miRNA expression profiling and $\mathrm{QPCR}$}

LSK fractions of the BM of 3 Ercc1 ${ }^{-/ * 292}$ and 3 littermate-matched Ercc1-proficient (Ercc1 ${ }^{+/ 292}$ or $\mathrm{Erccl}^{+/}$) control mice were sorted on a FACSAria II instrument (Becton-Dickinson). BM HSPCs were isolated as previously described ${ }^{7}$. HSPCs were lysed in Trizol and total 
RNA was isolated with Trizol reagent according to manufacturer's protocol (Invitrogen). Quality control of total RNA was done with RNA 6000 Nano assay on the Aligent 2100 Bioanalyzer (Aligent). Concentrations and purity of the RNA samples were determined with a NanoDrop ND-1000 spectrophotometer (Isogen Life Science). Gene- and miRNAexpression arrays, using Mouse Genome 430 Affymetrix 2.0 Array and Taqman Array Rodent or Human MicroRNA A Cards Version 2.0 (Applied Biosystems) respectively, were performed as previously described ${ }^{7}$. Single miRNA expression assays, using Taqman single real-time miRNA and U6 qPCR reactions (Applied Biosystems), were performed as previously described ${ }^{7}$.

\section{Statistics}

Gene expression profiling: Profiling of mRNA expression was performed in multiplicate ( $3 \mathrm{x}$ in LSKs and 5x in HSPCs) for each experimental condition $\left(\operatorname{Erccl}^{1 / \alpha_{292}}\right.$ or $\left.\operatorname{Erccl}^{w t}\right)$. The data were subsequently normalized with MAS5.0. Probe sets considered indistinguishable from the background signal were omitted from further analyses. Identification of the differentially expressed probe sets was performed using the FDR corrected p-values. A p-value $<0.05$ was considered statistically significant.

MiRNA profiling: The expression of miRNAs determined by Taqman Array Rodent or Human MicroRNA A Cards Version 2.0 (Applied Biosystems) was normalized by the average expression value of 4 U6 snRNA probesets available on the cards. QPCR analysis on single miRNAs and U6 expression levels were determined in triplicate. Differentially expressed miRNAs were determined using the Mann-Whitney U test (asymptotic significance [2-tailed]). A p-value $<0.05$ was considered statistically significant. The fold induction was calculated by the $2^{-\Delta \Delta \mathrm{Ct}}$ method. 


\section{REFERENCES}

1. Wisniewski JR, Zougman A, Nagaraj N, Mann M. Universal sample preparation method for proteome analysis. Nat Methods. 2009;6(5):359-362.

2. Boersema PJ, Raijmakers R, Lemeer S, Mohammed S, Heck AJ. Multiplex peptide stable isotope dimethyl labeling for quantitative proteomics. Nat Protoc. 2009;4(4):484-494.

3. Meiring MS, Litthauer D, Harsfalvi J, van Wyk V, Badenhorst PN, Kotze HF. In vitro effect of a thrombin inhibition peptide selected by phage display technology. Thromb Res. 2002;107(6):365-371.

4. Li H, Durbin R. Fast and accurate short read alignment with BurrowsWheeler transform. Bioinformatics. 2009;25(14):1754-1760.

5. de Koning JP, Soede-Bobok AA, Ward AC, et al. STAT3-mediated differentiation and survival and of myeloid cells in response to granulocyte colony-stimulating factor: role for the cyclin-dependent kinase inhibitor p27(Kip1). Oncogene. 2000;19(29):3290-3298.

6. Meenhuis A, van Veelen PA, de Looper $\mathrm{H}$, et al. MiR-17/20/93/106 promote hematopoietic cell expansion by targeting sequestosome 1-regulated pathways in mice. Blood. 2011;118(4):916-925.

7. Alemdehy MF, van Boxtel NG, de Looper $\mathrm{HW}$, et al. Dicer1 deletion in myeloidcommitted progenitors causes neutrophil dysplasia and blocks macrophage/ dendritic cell development in mice. Blood. 2012;119(20):4723-4730.

8. Wolfler A, Danen-van Oorschot AA, Haanstra JR, et al. Lineage-instructive function of C/EBPalpha in multipotent hematopoietic cells and early thymic progenitors. Blood. 2010;116(20):4116-4125. 


\section{SUPPLEMENTAL FIGURES AND TABLES}

A

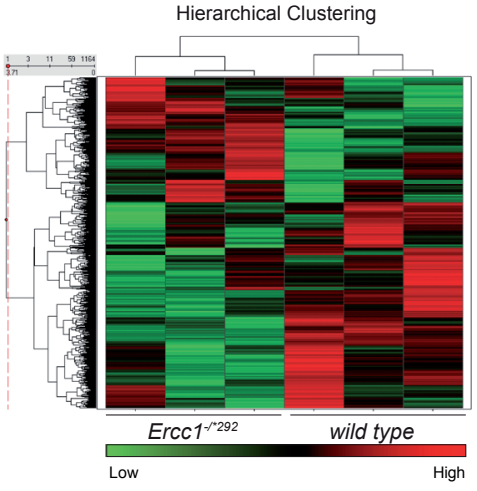

в

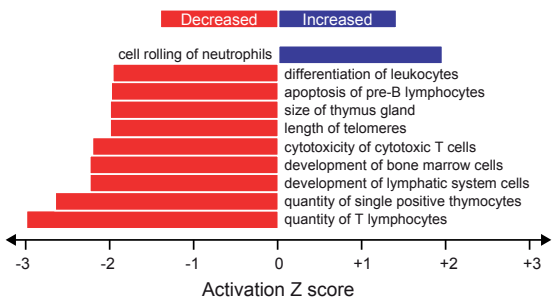

$E$

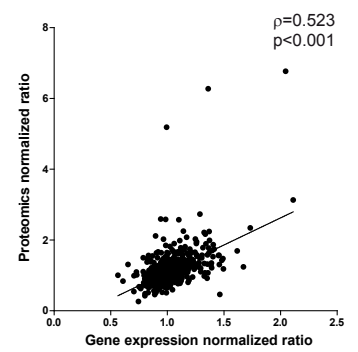

$\mathrm{F}$
C

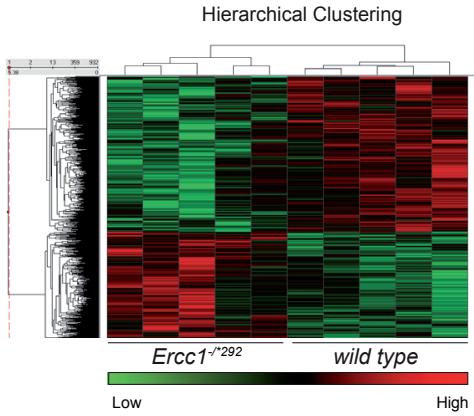

D
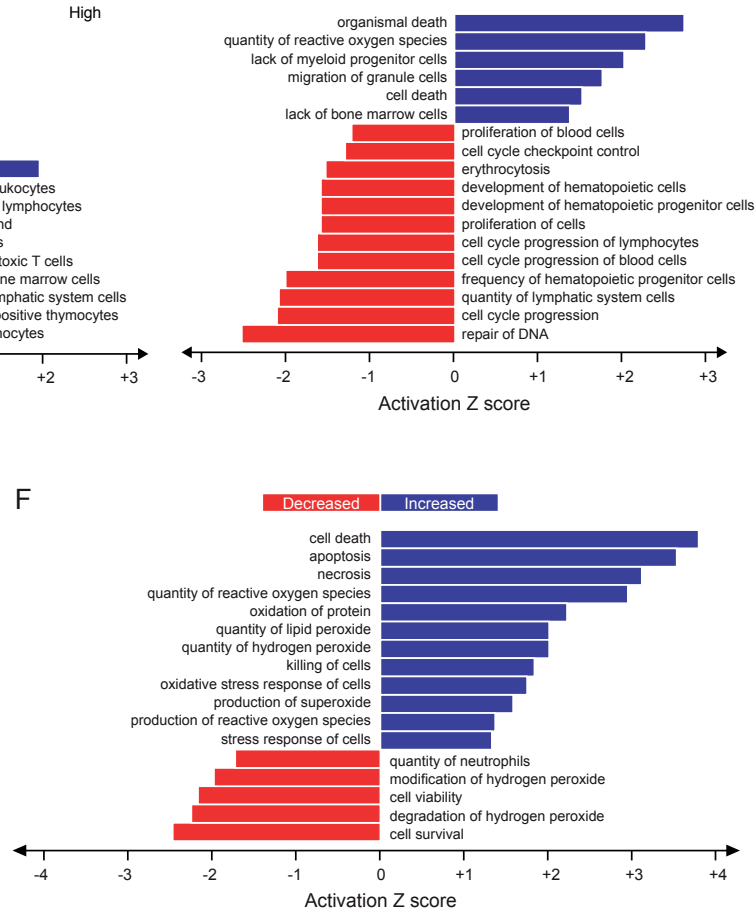

Supplemental Figure 1. Gene expression analysis of Ercc1-proficient and -deficient HSPCs. A) Unsupervised clustering of differentially expressed genes (FDR-corrected $p<0.05$ ) in LSK cells from 20-22 week old Ercc1 ${ }^{-1292}$ mice and $w t$ littermates. The scale bar shows the normalized expression $\mathrm{z}$-scores and indicates an increased (red) or decreased (green) expression relative to the row mean (black). B) Altered biological functions of differentially expressed genes in $\operatorname{Ercc1}^{-1 / 292}$ LSK cells identified by IDEA. C) Unsupervised clustering of significant differentially expressed genes (FDR-corrected $\mathrm{p}<0.05)$ in $\operatorname{Ercc}^{-/ 1292}$ and $w t$ Lin- BM cells. D) Altered biological functions of differentially expressed genes in $\operatorname{Ercc1}^{1 / 292}$ Lin- BM cells identified by IDEA. E) Example of the correlation of the ratio's determined by gene expression profiling and proteomics. Line shows the Pearson correlation. F) Altered biological functions of differentially expressed proteins in $\operatorname{Erccl}^{-/ 292}$ Lin- BM cells identified by IDEA. 
nBM $\square$ FA

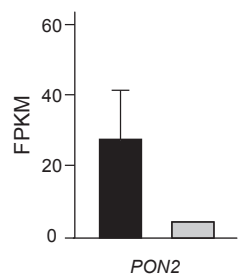

Targets of miR-199a-3p

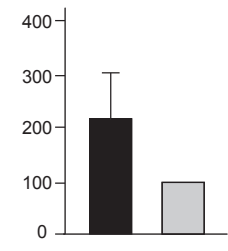

PRDX6

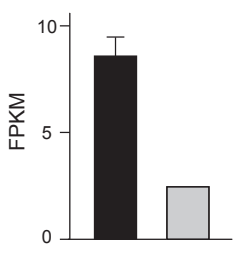

sUZ12

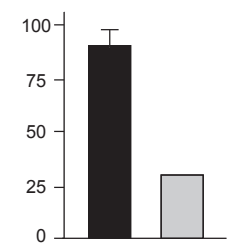

FUBP1

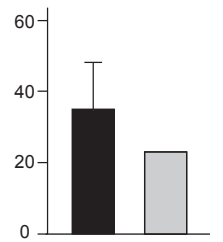

CALU

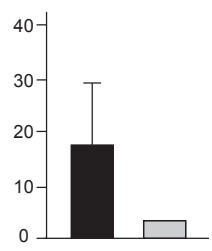

RUNX1
Target of $m i R-139-3 p$

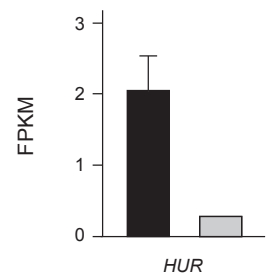

Expression of $\beta$-Actin

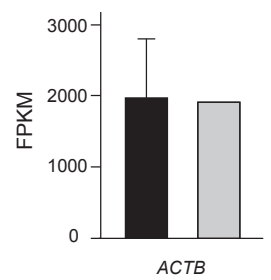

Targets of TP53
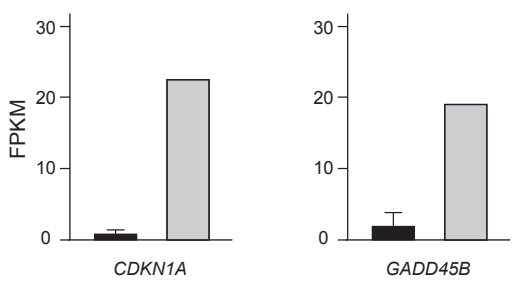

Supplemental Figure 2. Identified targets of $m i R-139-3 p$ and $m i R-199 a-3 p$ are transcriptionally deregulated in FA. RNA from CD34+ cells isolated from the BM cells of a FA patient with progressive BMF (patient nr. 5 in Suppl.Table 4) is sequenced by Illumina. The number of bases mapped to the genome for FA and controls are in the same range (data not shown). The expression of HUR (identified target of miR-139-3p), PON2, PRDX6, CALU, SUZ12, FUBP1 and RUNX1 (identified targets of miR-199a-3p), and also CDKN1A and GADD45B (targets of TP53) is compared in CD34+ BM cells obtained from FA patient (grey bars) with CD34+ BM cells from 3 healthy volunteers (black bars).The expression of Beta-ACTIN is shown as a negative control. 


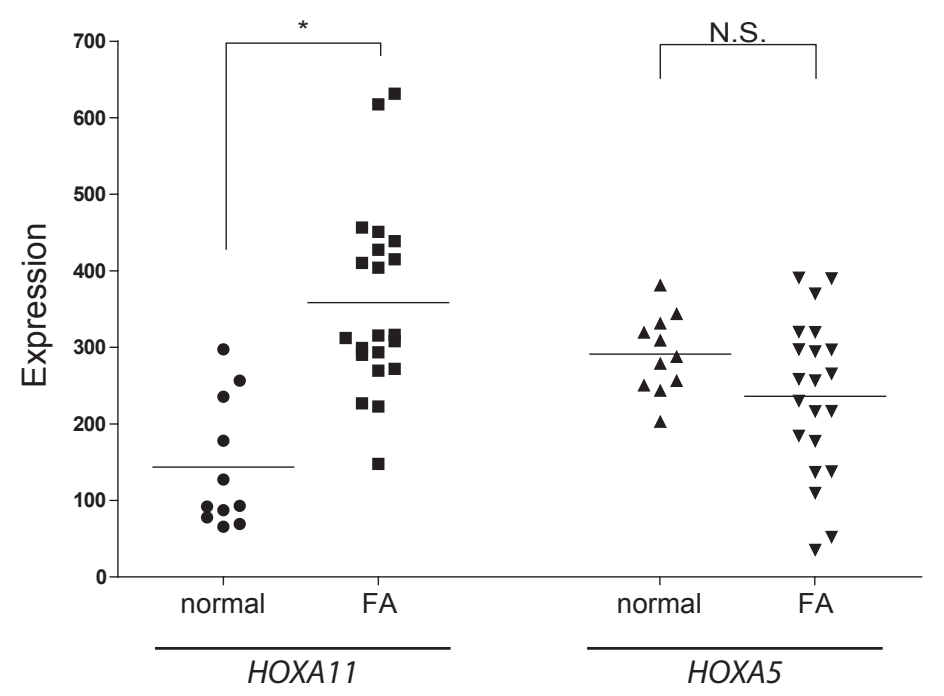

Supplemental Figure 3. Expression of the PRC2 target HOXA11 is increased in the BM of FA patients. Transcript expression of HOXA11 and HOXA5 in low-density mononuclear BM cells from 21 FA patients (FA) and 11 healthy volunteers (normal). Data are taken from FA Transcriptome Consortium (FTC) database (Gene Expression Omnibus, 2009 and publicly available as GSE16334). Lines show the mean of each group. Significance was calculated by comparing the expression level in healthy controls with the level in FA patients with the non-paired student t.test (asymptotic significance $[2$-tailed $\left.]){ }^{*} \mathrm{p}<0.05\right)$. 
Supplemental Tables 1-3 are accessible online via:

http://hema13.erasmusmc.nl/Farshid/Table\%20S1.xlsx

http://hema13.erasmusmc.nl/Farshid/Table\%20S2.xlsx

http://hema13.erasmusmc.nl/Farshid/Table\%20S3.xlsx

Supplemental Table 4. Clinical characteristics of FA patients

\begin{tabular}{|c|c|c|c|c|c|}
\hline case & $\begin{array}{l}\text { affected } \\
\text { FA gene }\end{array}$ & $\begin{array}{l}\text { mutation } \\
\text { I }\end{array}$ & $\begin{array}{l}\text { mutation } \\
\text { II }\end{array}$ & $\begin{array}{l}\text { effect } \\
\text { I }\end{array}$ & $\begin{array}{l}\text { effect } \\
\text { II }\end{array}$ \\
\hline 1 & $F A N C-C$ & c.67delG & c.67delG & p.Asp23Ilefs ${ }^{\star} 23$ & p.Asp23Ilefs ${ }^{\star} 23$ \\
\hline 2 & $F A N C-A$ & c. $2852 \mathrm{G}>\mathrm{A}$ & c. $3624 \mathrm{~T}>\mathrm{C}^{(1)}$ & p.Arg951Gln & p.Ser1208Ser ${ }^{(2)}$ \\
\hline 3 & $F A N C-A$ & c. $487 \mathrm{delC}$ & c. $2851 \mathrm{C}>\mathrm{T}$ & p.Arg163Valfs ${ }^{\star} 29$ & p.Arg951Trp \\
\hline 4 & $F A N C-A$ & exon31-35 del $l^{(3)}$ & c. $2851 \mathrm{C}>\mathrm{T}$ & - & p.Arg951Trp \\
\hline 5 & $F A N C-A$ & c. $2852 \mathrm{G}>\mathrm{A}$ & c.3788_3790del & p.Arg951Gln & p.Phe1263del \\
\hline 6 & $F A N C-A$ & c. $2852 \mathrm{G}>\mathrm{A}$ & c.3788_3790del & p.Arg951Gln & p.Phe1263del \\
\hline 7 & $F A N C-C$ & c.67delG & c.67delG & p.Asp23Ilefs*23 & p.Asp23Ilefs*23 \\
\hline 8 & $F A N C-C$ & c.67delG & c. $553 \mathrm{C}>\mathrm{T}$ & p.Asp23Ilefs ${ }^{\star} 23$ & p.R185* \\
\hline
\end{tabular}

Description of mutations based on cDNA sequence. GenBank reference sequences FANCA: NM_000135; FANCC: NM_000136. ${ }^{1}$ synonymous; ${ }^{2}$ aberrant splicing, Hum Mutat. 2008 Jan;29(1):159-66; ${ }^{3}$ exons absent by MLPA, breakpoints unknown, effect: probably non sense mediated decay; ${ }^{4} \mathrm{MDS}$ morphologically not excluded; ${ }^{5}$ material not representative, mixed with blood. $\mathrm{Hb}=$ haemoglobin; $\mathrm{PLT}=$ platelet count; $\mathrm{WBC}=$ white blood cell count. Patients 5 and 6 are siblings. §Received allogeneic stem cell transplantation.

Supplemental Table 5. Analysis of blood, BM and spleen derived from leukemic mice transplanted with CEBPA ${ }^{\text {fl/Cre }}$; miR-199a cells

\begin{tabular}{|c|c|c|c|}
\hline Characteristic & Normal level & $\begin{array}{l}\text { Primary leukemia } \\
\text { Median (range) }\end{array}$ & $\begin{array}{l}\text { Secondary leukemia\# } \\
\text { Median (range) }\end{array}$ \\
\hline Survival (Days) & & $191 \quad(67-193)$ & $73 \quad(70-144)$ \\
\hline WBC $\left(\times 10^{9} / 1\right)$ & $3-15$ & $2.8 \quad(2.8-9.2)$ & $44.3 \quad(2.9-57.5)$ \\
\hline $\mathrm{RBC}\left(\mathrm{x} 10^{12} / 1\right)$ & $5-12$ & $4.87 \quad(0.87-5.61)$ & $3.27 \quad(1.91-5.1)$ \\
\hline $\mathrm{HGB}(\mathrm{mmol} / \mathrm{l})$ & $6.9-11.2$ & $3.2 \quad(1.4-6.2)$ & $4.9 \quad(2.5-6.9)$ \\
\hline $\operatorname{HCT}(1 / 1)$ & $0.360-0.520$ & $0.153(0.06-0.329)$ & $0.249(0.115-0.356)$ \\
\hline Blast in BM (\%) & $1 \%$ & $79.8 \quad(70.7-98.0)$ & $(95-100)$ \\
\hline Spleen weight (g) & $0.09-0.17$ & $0.35 \quad(0.21-0.41)$ & $0.68 \quad(0.48-1.4)$ \\
\hline
\end{tabular}

* $\mathrm{n}=5, \# \mathrm{n}=7$

WBC: white blood cells, RBC: red blood cells, HGB: hemoglobin, HCT: hematocrit, BM: bone marrow. 


\begin{tabular}{|c|c|c|c|c|c|}
\hline Blood & Blood & Blood & & & \\
\hline $\begin{array}{l}\text { anemia } \\
\mathrm{Hb}(\mathrm{mmol} / \mathrm{L})\end{array}$ & $\begin{array}{l}\text { trombopenia } \\
\text { PLT }\left(\times 10^{9} / \mathrm{L}\right)\end{array}$ & $\begin{array}{l}\text { leucopenia } \\
\text { WBC }\left(\times 10^{9} / \mathrm{L}\right)\end{array}$ & $\begin{array}{l}\text { Bone marrow } \\
\text { morphology }\end{array}$ & cytogenetics & conclusion \\
\hline mild 7.3 & yes 111 & no 5.8 & $\begin{array}{l}\text { mild dysplasia, } \\
\text { no MDS }\end{array}$ & $\begin{array}{l}\text { no } \\
\text { abnormalities }\end{array}$ & mild BMF \\
\hline mild 7.7 & yes 67 & yes 2.9 & $\begin{array}{l}\text { mild dysplasia, } \\
\text { no MDS }\end{array}$ & no abnormalities & mild BMF \\
\hline mild 7.2 & yes 43 & no 5.3 & $\begin{array}{l}\text { mild dysplasia, } \\
\text { no MDS }\end{array}$ & no abnormalities & mild BMF \\
\hline mild 7.1 & yes 62 & no 6.8 & $\begin{array}{l}\text { mild dysplasia, } \\
\text { no MDS }\end{array}$ & no abnormalities & mild BMF \\
\hline yes 6.1 & yes 30 & yes 3.0 & dysplasia ${ }^{(4)}$ & no abnormalities & progressive BMF \\
\hline mild 7.3 & yes 133 & yes 3.0 & mild dysplasia $^{(4)}$ & no abnormalities & progressive BMF \\
\hline mild 8.3 & yes 21 & yes 2.5 & not available ${ }^{(5)}$ & no abnormalities & Severe BMFS \\
\hline not available & not available & not available & not available & not available & Severe BMF\$ \\
\hline
\end{tabular}




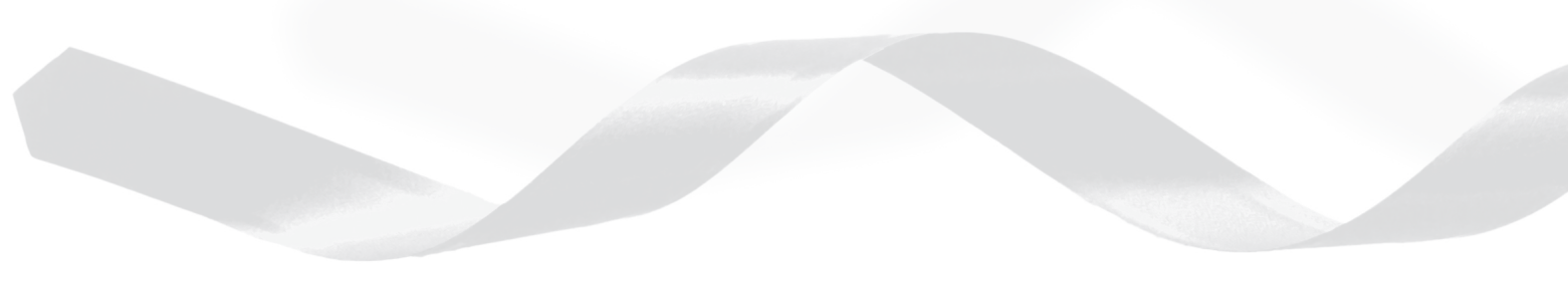




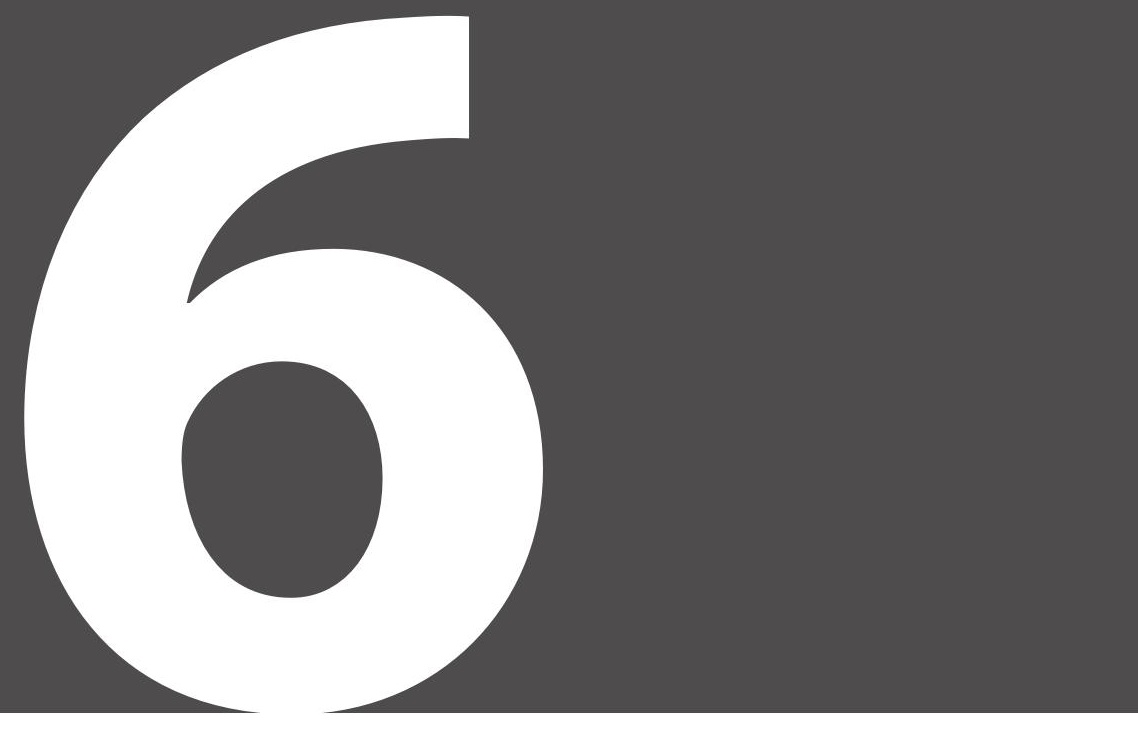

Summary and General Discussion 



\section{SUMMARY}

This thesis contains two main experimental parts. In the first part we asked whether Dicerl, the gene encoding a crucial RNase III enzyme for microRNA (miRNA) maturation, is essential for normal myelopoiesis. In Chapter 3, we addressed this question by deletion of Dicer1 in murine $\mathrm{C} / \mathrm{EBPa}$-positive myeloid-committed progenitors. In striking contrast to the results in hematopoietic stem cells (HSCs), miRNA depletion in myeloid-committed progenitor did not significantly affect the number of multipotent progenitors (MPPs), common myeloid progenitors (CMPs), megakaryocyte/erythroid progenitors (MEPs) and granulocyte/ monocyte progenitors (GMPs) in mice. However, Dicerl-deficient GMPs were defective in myeloid development and exhibit an increased self-renewal potential in vitro. In mice, Dicerl deletion in myeloid committed progenitor cells blocked monocytic differentiation, depleted macrophages and myelo-dendritic cells (DCs), and caused myeloid dysplasia with morphological features of Pelger-Huet anomaly, a benign hematopoietic disorder leading to defect of terminal neutrophil differentiation ${ }^{1}$. MiRNA profiling of wild type GMPs showed that 104 miRNAs are abundantly expressed at this stage. In Dicer1-null GMPs, predicted targeted transcripts of at least 20 miRNA families were significantly higher expressed, suggesting that these miRNAs are active in GMPs. Interestingly, of the de-repressed miRNA targets in Dicer1-null GMPs 27\% are normally exclusively expressed in HSCs or are specific for MPPs and erythropoiesis. Thus, unlike the results from HSCs and other hematopoietic cell fractions (reviewed in Chapter 4) showing functions of Dicer1 mainly in survival pathways, these results provide evidence for a miRNA-controlled switch of a stem cell program of self-renewal and expansion, towards myeloid differentiation.

The depletion of miRNAs caused by deletion of Dicer1 in C/EBP $\alpha$ positive myeloid progenitor cells blocked monocytic/macrophage differentiation and resulted in production of dysplastic myeloid cells, a condition that may be considered as a preleukemic state. However Dicer1-null myeloid progenitors did not develop leukemia in mice after 1 year of monitoring, indicating that total depletion of miRNAs does not lead to leukemia. In agreement, in Chapter 4, we showed that homozygous Dicer1 deletion did not collaborate with loss of Trp53 in leukemic progression. In striking contrast, mice transplanted with heterozygous Dicer1 and Trp53-null alleles developed frank leukemias. Thus, we provided evidence for a model in which Dicerl heterozygosity, causing reduced levels of miRNAs, is an oncogenic event in the leukemia development, but expression of at least some miRNAs is needed for leukemogenesis.

In the second experimental part of this thesis, we addressed the question whether deregulation of miRNA expression upon interstrand cross-link (ICL) DNA damage could be involved in bone marrow failure (BMF) and leukemia. In Chapter 5, we showed that 2 miRNAs, miR-139-3p and miR-199a-3p, play a key role in BMF and leukemic transformation. Hematopoietic progenitors from FA patients and from mice deficient for ERCC1, an endonuclease functioning downstream of FA pathway and essential for ICL repair, expressed elevated levels of $m i R-139-3 p$ and $m i R-199 a-3 p$ during BMF. MiR-139-3p induced cell death 
and its expression declined during leukemic progression, whereas miR-199a-3p expression remained high and induced acute myeloid leukemia (AML) in mice. Inactivation of $m i R-139$ $3 p$ expressed in Ercc1-deficient hematopoietic stem and progenitor cells (HSPCs) restored their reduced proliferative capacity, whereas inhibition of $m i R-199 a-3 p$ further aggravated the proliferation defect of Erccl-deficient HSPCs. Combined transcriptome and proteome analyses to identify targets revealed that $m i R-139-3 p$ controls the expression of the RNA binding protein (RBP) HUR, whereas miR-199a-3p inhibits the expression of SUZ12 and $R U N X 1$, genes that are involved in human AML. These findings uncover a major involvement of $m i R-139-3 p$ and $m i R-199 a-3 p$ in the pathogenesis of ICL-induced BMF and leukemic transformation.

\section{GENERAL DISCUSSION}

\section{2-1. MiRNAs involved in normal myeloid development}

In Chapter 3, we showed that miRNAs are required for normal myelopoiesis. Disruption of their biogenesis by deletion of Dicerl in myeloid progenitors blocks monocyte differentiation and leads to neutrophil dysplasia. The consequences of Dicerl deletion at different stages of hematopoiesis and the role of Dicer1 in leukemia development are discussed in detail in Chapter 4. A limitation of the Dicer1-deletion model is that it disrupts the biogenesis of virtually all miRNAs, which prohibits investigation of the role of individual miRNAs. Strategies to unravel the contribution of single miRNAs to myelopoiesis are discussed in sections 2-6-1 and 2-6-2.

\section{2-2. ICL-induced upregulation of miR-139-3p and miR-199a-3p}

In Chapter 5, we showed that expression of $m i R-139-3 p$ and $m i R-199 a-3 p$ is enhanced upon ICL DNA damage in HSPCs. MiR-199 is a vertebrate specific miRNA family containing 3 paralogs known as $m i R-199 a-1, m i R-199 a-2$ and $m i R-199 b$, localized on human chromosomes 19, 1 and 9, and mouse chromosomes 9, 1 and 2 respectively ${ }^{2}$. All miR-199 genes are located on the opposite strand in introns of Dynamin (Dnm) genes and are expressed independently of $\mathrm{Dnm}$ transcription, indicating that they are controlled by independent promoters ${ }^{2}$. Within Dnm3, $m i R-199 a$ is coexpressed with $m i R-214$ as a common primary 6 -kb transcript in mouse, human and zebrafish ${ }^{3}$. MiR-139 is an intronic miRNA, located on the sense strand of the PDE2A gene on chromosome 11 in human and chromosome 7 in mouse (miRBase, www.mirbase.org), within a highly conserved sequence. The molecular mechanism driving $m i R-139-3 p$ and $m i R-199 a-3 p$ expression upon ICL DNA damage is still elusive. The elevated levels of $m i R-139-3 p$ and $m i R-199 a-3 p$ could be the consequence of transcriptional upregulation, modified pri-miRNA processing, increased stability of the mature miRNA or combinations of these. In order to investigate the possibility of the transcriptional upregulation, the expression of host genes as well as co-expressed miRNAs were analyzed. Dnm2, Dnm 3 or Pde2a were not differentially expressed in Ercc $^{-1 * 292}$ HSPCs compared to controls (Chapter 5, supplementary Table 2). MiR-199a-5p was not expressed 
in HSPCs of Ercc1 deficient or proficient mice. MiR-214 and miR-139-5p were expressed in HSPCs but their expression levels were not increased upon ICL stress. These data suggest that the expression of $m i R-199 a-3 p$ and $m i R-139-3 p$ is not induced at the transcriptional level. TP53 has been reported to bind to endonuclease DROSHA and to facilitate the processing of primary miRNAs to precursor miRNA ${ }^{4,5}$. Although we have shown that miR-199a-3p and $m i R-139-3 p$ are not direct targets of Trp53 (Chapter 5), our data do not rule out that these miRNAs are upregulated as a result of Trp53-induced post-transcriptional regulation. Finally, the upregulation of $m i R-199 a-3 p$ and $m i R-139-3 p$ could be the consequence of miRNA modifications that may influence the stability of the miRNA. For instance, adenylation or 2'-O-methylation of the 3'-end of miRNA have been reported to increase miRNA stability ${ }^{6,7}$. Several enzymes such as GLD2, TUT4 and XRN2 are implicated in these modifications 8. These enzymes were not differentially expressed between HSPCs of Ercc1-deficient and proficient mice (Chapter 5, supplementary Tables 2 and 3), but their activity may be different upon ICL damage. Therefore, post-transcriptional modification may still be involved in the upregulation of $m i R-199 a-3 p$ and $m i R-139-3 p$.

\section{2-3. Target of miR-139-3p}

Using a combination of gene expression arrays and proteomics, we identified Elavl1 (HuR) as a target of $m i R-139-3 p$ in HSPCs upon ICL-induced stress (Chapter 5). HuR is a member of the embryonic lethal abnormal vision Drosophila-like ELAV family of RBP ${ }^{9}$. HuR elicits a broad anti-apoptotic function by regulating the expression of many target RNAs ${ }^{10}$. Relevant for our study is that HuR controls the expression of genes involved in DNA damage response, including the tumor suppressor $p 53$, cyclins $A, B 1$ and $D 1$, proto-oncogenes $c$-Fos and $c-M y c$, cyclin-dependent kinases inhibitors $p 21$ and $p 27$, and anti-apoptotic $B c l-2{ }^{11}$. Reduction of HuR levels decreases cell expansion and survival of hematopoietic progenitors by downregulation of survival factors, such as BCL-2, BCL-XL and Survivin, whereas apoptotic inducers, such as CASPASE-9, and the TP53 targets NOXA and PUMA are upregulated ${ }^{12}$. Thus, repression of HuR may well explain all the observed effect of miR-139-3p on cell growth.

$\mathrm{HuR}$ also influences miRNAs activities, in both positive and negative ways. HuR may interact with mRNA targets of miRNAs. Binding of HuR near a miRNA recognition sequence may interfere or stimulate the miRNA binding. For example, HuR binding to AU-rich elements on 3'-UTR of CAT1 mRNA, blocks the complementary site for miR-122 and thereby relieves the mRNA from repression ${ }^{13}$. However, HuR may also stimulate miRNA activity by recruiting miRNAs to the 3'-UTRs of target genes. For instance, HuR promotes the interaction between Let-7 and the $c-M y c$ 3'-UTR, and thereby represses the expression of $c-M y c^{14}$.

\section{2-4. Targets of miR-199a-3p}

We identified Suz12 as a target of the ICL-induced miR-199a-3p. SUZ12 is a critical component of the Polycomb Repressive Complex 2 (PRC2), which is responsible for di- and tri-methylation of Histone 3 at lysine 27 (H3K27) ${ }^{15}$. SUZ12 is required for histone methyltransferase activity 
and gene silencing functions of PRC2 ${ }^{16}$. PRC2 consists of multiple proteins, including the methyltransferase enhancer of Zeste 2 (EZH2) and the Embryonic Ectoderm Development protein (EED), and interacts with Addition of Sex Combs-Like 1 (ASXL1). Each component of the PRC2 complex is essential for mammalian development ${ }^{17-19}$. Furthermore, members of the PRC2 complex are frequently mutated in cancers including hematological neoplasms ${ }^{20}$. Inactivating $E Z H 2$ mutations are found in approximately $12 \%$ of myelodysplastic syndrome (MDS)/ myeloproliferative neoplasm (MPN) patients ${ }^{21}$. Also, mutations and deletions of $S U Z 12$ have been identified at a low frequency in myeloid neoplasms ${ }^{22}$.

In our experiments, EZH2 levels were also decreased in miR-199a-3p overexpressing human AML cell line (HL-60) and primary mouse leukemia cells (Figure 1A and 1B), which is consistent with previous reports showing that SUZ12 stabilizes other PRC2 components ${ }^{18}$. Moreover, it has been reported that a heterozygous mutation in Suz12 (Suz12 $\left.2^{\text {Plt/wt }}\right)$ enhances expansion of HSPCs without impairing their differentiation capacity ${ }^{23}$. Thus, the repression of Suz12 by miR-199a-3p may in part explain the enhanced expansion of HSPCs.

Peroxiredoxin-6 (PRDX6) and Paraoxonase-2 (PON2) are two other targets of miR-199a$3 p$ that were identified in our study. PRDX6 is a member of the thiol-specific antioxidant protein family ${ }^{24}$. This protein is a dual function enzyme with peroxidase and phospholipase activities ${ }^{24}$. PRDX6 is involved in redox regulation of the cell by reduction of hydrogen peroxide and short chain organic, fatty acid and phospholipid hydroperoxides ${ }^{24}$. PON2 encodes a member of the paraoxonase gene family, which includes three known paraoxonases located adjacent to each other on the long arm of chromosome 7. PON2 is ubiquitously expressed in human tissues, is membrane-bound, acts as a cellular antioxidant protecting cells from oxidative stress and prevents the cell-mediated oxidation of LDL ${ }^{25}$. Moreover, the

A)

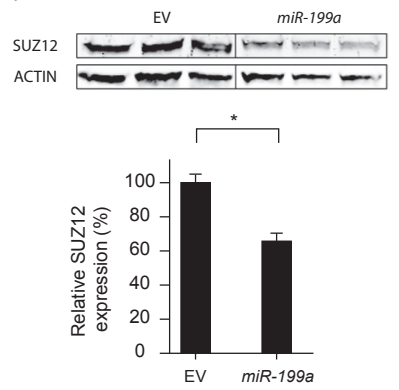

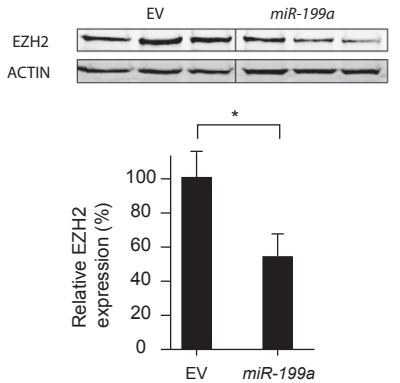

B)

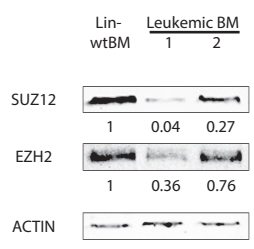

Figure 1. MiR-199a represses endogenous SUZ12 and EZH2 expression in human HL60 and mouse Cebpa-null leukemic cells. A) Protein levels of SUZ12 and EZH2 decreased significantly upon introduction of miR-199a in HL-60 human AML cell lines. The normalized quantifications are shown in bar plots. Significance were calculated with student t-test [2-tailed]) $\left({ }^{*} \mathrm{p}<0.05\right)$. B) Protein levels of SUZ12 and EZH2 in the lineage negative BM cells of leukemic mice, transplanted with miR-199a expressing Cebpa-null cells, or in the lin- BM of wt control mice are shown (the mouse model is explained in Chapter 5). 
overexpression of PON2 decreased the oxidative stress in the cells which were treated with hydrogen peroxide or oxidized phospholipids ${ }^{26}$. Thus, PRDX6 and PON2 play important roles in antioxidant stress responses. Oxidative stress, defined as an imbalance between the production and elimination of reactive oxygen species (ROS) is considered as an important pathogenic factor in BMF and leukemia progression in FA patients ${ }^{27}$. Therefore, the repression of PRDX6 and PON2 by miR-199a-3p may play a crucial role in the incapacity of FA-HSPCs to cope with oxidative stress and may contribute to the onset of BMF and its progression towards leukemia.

\section{2-5. Expression and prognostic significance of $m i R-139-3 p$ and $m i R$ - $199 a-3 p$ in human AML}

Having established that $m i R-199 a-3 p$ is an onco-miR in mouse myeloid leukemia and that miR-139-3p expression is lost in $\operatorname{Ercc1}^{-/ 292}$; Trp53-deficient leukemias (Chapter 5), we asked whether the combined absence of $m i R-139-3 p$ and enhanced expression of $m i R-199 a-3 p$ is a more common feature of AML. Two unique cell lines, SB1690CB and FA-AML1, both characterized by bi-allelic BRCA2/FANCD1 mutations, have previously been established from FA/AML patients ${ }^{28,29}$. Similar to mouse $\operatorname{Ercc1}^{-1 * 292}$ leukemia, miR-139-3p was not detectable in these cell lines, whereas miR-199a-3p expression was elevated compared with normal BM CD34+ cells (Figure 2A).

We analyzed the expression of $m i R-199 a-3 p$ and $m i R-139-3 p$ in 177 clinical AML samples randomly picked from our biobank. Expression of $m i R-139-3 p$ was undetectable in 175 and very low in the remaining 2 samples, whereas the U6 loading control was detected at high levels in all samples ( $\mathrm{Ct}=20.6+/$ - 1.1) (Table 1). Analysis of RNA-seq data of $275 \mathrm{AML}$ samples from The Cancer Genome Atlas (TCGA, https://tcga-data.nci.nih.gov/tcga/) confirmed that $m i R-139-3 p$ is not or very lowly expressed in AML (data not shown). MiR-199a-3p expression was variable in our biobank samples (Table 1, Figure 2B) and in the TCGA cases (data not shown). No significant correlation was seen between miR-199a-3p expression and the most frequent cytogenetic markers $(\mathrm{t}(8 ; 21), \mathrm{t}(15 ; 17)$, inv(16) and 11q23) and molecular abnormalities. We then divided the 177 AML cases from our biobank in two groups based on the expression level of $m i R-199 a-3 p$, i.e., above and below the median expression. AML cases with high miR-199a-3p expression were significantly enriched among AML patients lacking mutations in NPM1, DNMT3A and IDH2 (Table 1). Kaplan-Meier survival analysis showed that AML patients with high miR-199a-3p expression had a significantly shorter overall survival $(\mathrm{p}<0.05)$ than patients with low or no miR-199a-3p expression (Figure 2C).

Next, we performed a multivariate survival analysis with the Cox proportional hazard model considering the following variables: favorable karyotype (i.e. $t(15 ; 17)$, inv $(16), t(8 ; 21))$, FLT3-ITD, FLT3-TKD, NPM1 mutation, CEBPA double mutants, IDH1 mutation, IDH2 mutation, DNMT3A mutation, age (continuous), white blood cell count (continuous), abnormalities involving $M L L$ and miR-199a-3p (dichotomized on the median expression level). Variables were included based on a step-wise manner using the Akaike Information Criterion (AIC) ${ }^{30}$. We found that high miR-199a-3p expression is an independent marker for 
adverse overall survival $(\mathrm{p}=0.022$, hazard ratio $(\mathrm{HR})=1.66)$ (Table 2). Increased expression of $m i R-199 a$ has been associated with poor prognosis in AML ${ }^{31}$. Our study showed that high $m i R-199 a-3 p$ expression, but not miR-199a-5p, has prognostic significance in AML.

A)

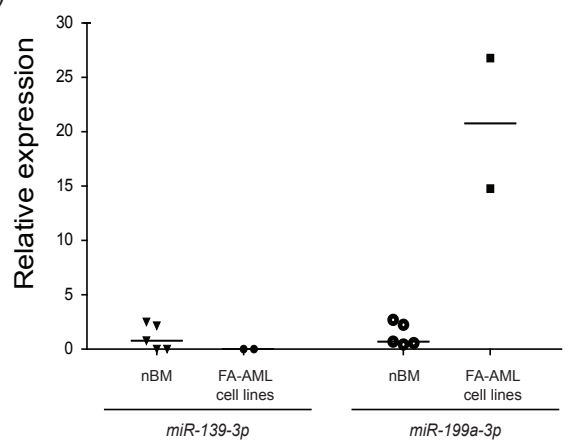

C)

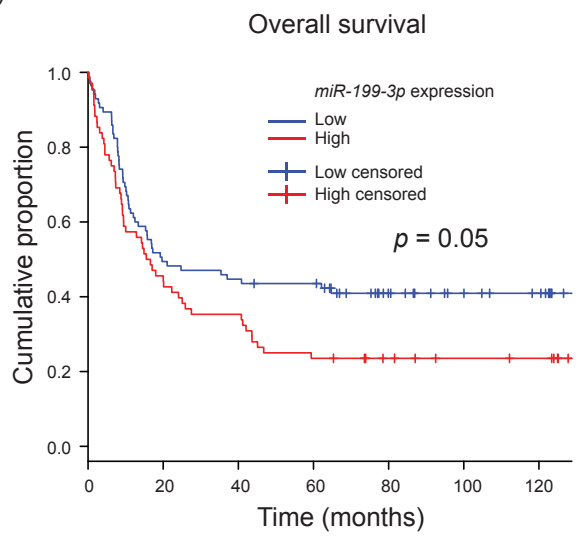

B)

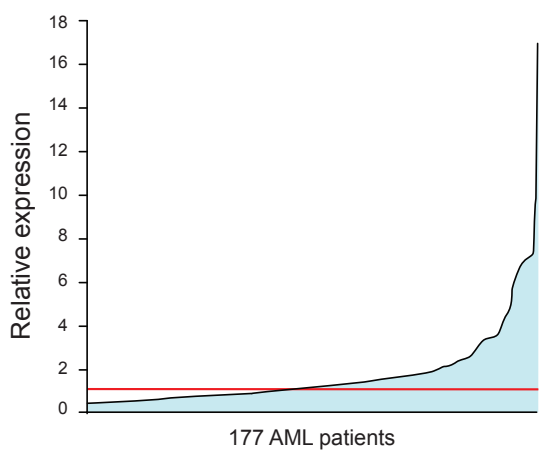

D)

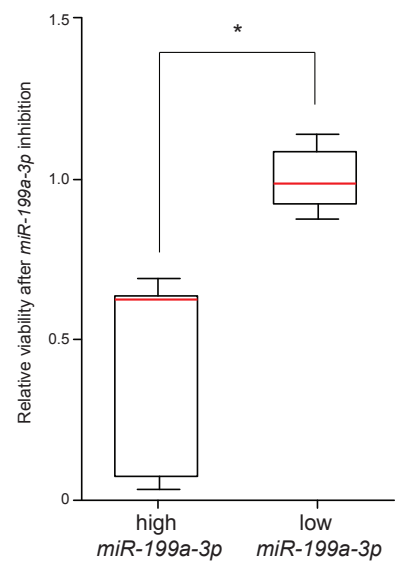

Figure 2. Expression and prognostic significance of $m i R-199 a-3 p$ in human AML. A) Expression of $m i R-139-3 p$ and $m i R-199 a-3 p$ normalized to $s n U 6$ in BM CD34+ cells isolated from healthy individuals (nBM) and FA-AML cell lines SB1690CB and FA-AML1 relative to the average of nBM samples are shown. Bars show the median of each group. B) MiR-199a-3p expression in AML samples relative to U6 $(\mathrm{n}=177)$ are plotted. The relative expression levels are normalized to the median level as indicated by the red line. C) Kaplan-Meier curves of overall survival of AML patients with high (red) or low (blue) expression of miR-199a-3p. The log-rank test was used to calculate the significance of the difference between survival curves. D) The viability of BM cells obtained from AML patients with high ( $\mathrm{n}=7$ samples) and low ( $\mathrm{n}=5$ samples) miR-199a-3p expression, after miR-199a-3p inhibition with antagomiRs and relative to the viability value of scrambled control antagomiR treated cells is shown. Cell viability was assessed using the CellTiter-Glo luminescent cell viability assay (Promega), 24 hours post transfection of LNA antagomiRs, according to manufacturer's protocol. The transfection efficiency of at least $50 \%$ was confirmed by flow cytometry. The red line indicates the median values of each group. 
Table 1. Clinical, cytogenetic and molecular characteristics of the cohort of newly-diagnosed AML

\begin{tabular}{|c|c|c|c|c|c|}
\hline $\operatorname{Sex}(N=177)$, no. $(\%)$ & \multicolumn{2}{|c|}{$\begin{array}{l}\text { Low } m i R-199 a-3 p- \\
\text { expressing patients }\end{array}$} & \multicolumn{2}{|c|}{$\begin{array}{l}\text { High } m i R-199 a-3 p- \\
\text { expressing patients }^{*}\end{array}$} & $\begin{array}{l}P \\
0.0881 \dagger\end{array}$ \\
\hline Male & 46 & $(50 \%)$ & 47 & $(50 \%)$ & \\
\hline Female & 43 & $(51 \%)$ & 41 & $(49 \%)$ & \\
\hline Age $(N=177), y$ & & & & & $0.8223 \neq$ \\
\hline Median (range) & 49 & $(15-72)$ & 48 & $(17-77)$ & \\
\hline Transplantation status & & & & & $0.3338 \$$ \\
\hline Allogeneic transplantation & 31 & & 22 & & $0.1895 \dagger$ \\
\hline Autologous transplantation & 9 & & 12 & & $0.4952 \dagger$ \\
\hline none & 49 & & 54 & & $0.4471 \dagger$ \\
\hline FAB classification & & & & & $0.0204 \$$ \\
\hline M0 & 3 & & 1 & & - \\
\hline M1 & 22 & & 14 & & $0.1910 \dagger$ \\
\hline M2 & 13 & & 31 & & $0.0017 \dagger$ \\
\hline M3 & 0 & & 4 & & $0.0590 \dagger$ \\
\hline M4 & 17 & & 16 & & $1 \dagger$ \\
\hline M5 & 26 & & 15 & & $0.0743 \dagger$ \\
\hline M6 & 1 & & 0 & & - \\
\hline Secondary AML (RAEB-t) & 5 & & 5 & & $1 \dagger$ \\
\hline Not determined & 2 & & 2 & & - \\
\hline \multicolumn{6}{|l|}{ Cytogenetic abnormalities } \\
\hline $\mathrm{t}(15 ; 17)$ & 0 & $(0 \%)$ & 4 & $(4.5 \%)$ & $0.0590 \dagger$ \\
\hline $\mathrm{t}(8 ; 21)$ & 2 & $(2.2 \%)$ & 6 & $(6.8 \%)$ & $0.1684 \dagger$ \\
\hline Inv.(16) & 3 & $(3.4 \%)$ & 9 & $(10.2 \%)$ & $0.0805 \dagger$ \\
\hline $11 \mathrm{q} 23$ & 3 & $(3.4 \%)$ & 8 & $(9.1 \%)$ & $0.1322 \dagger$ \\
\hline $3 q$ & 4 & $(4.5 \%)$ & 3 & $(3.4 \%)$ & $1 \dagger$ \\
\hline $7 \mathrm{q}$ & 5 & $(5.6 \%)$ & 6 & $(6.8 \%)$ & $0.7664 \dagger$ \\
\hline $\mathrm{t}(6 ; 9)$ & 0 & $(0 \%)$ & 2 & $(2.3 \%)$ & $0.2458 \dagger$ \\
\hline$t(9 ; 22)$ & 3 & $(3.4 \%)$ & 1 & $(1.1 \%)$ & $0.6207 \dagger$ \\
\hline $\mathrm{t}(9 ; 11)$ & 1 & $(1.1 \%)$ & 3 & $(3.4 \%)$ & $0.6203 \dagger$ \\
\hline+8 & 4 & $(4.5 \%)$ & 9 & $(10.2 \%)$ & $0.1620 \dagger$ \\
\hline$-5 /-5 q /-7 /-7 q$ & 6 & $(6.7 \%)$ & 5 & $(5.7 \%)$ & $1 \dagger$ \\
\hline Complex & 2 & $(2.2 \%)$ & 5 & $(5.7 \%)$ & $0.2778 \dagger$ \\
\hline Normal karyotype & 51 & $(57.3 \%)$ & 32 & $(36.4 \%)$ & $0.0067 \dagger$ \\
\hline Other & 16 & $(18.0 \%)$ & 16 & $(18.0 \%)$ & $1 \dagger$ \\
\hline
\end{tabular}


Table 1. Clinical, cytogenetic and molecular characteristics of the cohort of newly-diagnosed AML (Continued)

\begin{tabular}{llllll}
\hline & $\begin{array}{l}\text { Low } m i R-199 a-3 p- \\
\text { expressing patients }\end{array}$ & \begin{tabular}{l} 
High $\begin{array}{l}\text { miR-199a-3p- } \\
\text { expressing patients }\end{array}$ \\
\hline Other molecular abnormalities
\end{tabular} & & & \\
\hline FLT3-ITD & 28 & $(31.5 \%)$ & 24 & $(27.3 \%)$ & $0.6212 \dagger$ \\
\hline FLT3-TKD & 10 & $(11.2 \%)$ & 8 & $(9.1 \%)$ & $0.8945 \dagger$ \\
\hline NPM1 & 40 & $(44.9 \%)$ & 22 & $(25 \%)$ & $0.0072 \dagger$ \\
\hline DNMT3A & 29 & $(32.6 \%)$ & 15 & $(17.0 \%)$ & $0.0230 \dagger$ \\
\hline CEBPA_double & 4 & $(4.5 \%)$ & 7 & $(8.0 \%)$ & $0.3708 \dagger$ \\
\hline CEBPA_silenced & 5 & $(5.6 \%)$ & 1 & $(1.1 \%)$ & $0.2108 \dagger$ \\
\hline IDH1 & 6 & $(6.7 \%)$ & 8 & $(9.1 \%)$ & $0.5909 \dagger$ \\
\hline IDH2 & 15 & $(16.9 \%)$ & 3 & $(3.4 \%)$ & $0.0049 \dagger$ \\
\hline NRAS & 10 & $(11.2 \%)$ & 10 & $(11.2 \%)$ & $1 \dagger$ \\
\hline KRAS & 1 & $(1.1 \%)$ & 0 & $(0 \%)$ & - \\
\hline EVI1 overexpression & 10 & $(11.2 \%)$ & 11 & $(12.5 \%)$ & $0.8204 \dagger$ \\
\hline ASXL1 & 2 & $(2.2 \%)$ & 6 & $(6.8 \%)$ & $0.1685 \dagger$ \\
\hline
\end{tabular}

FAB, French-American-British. ${ }^{\star}$ Cutoff used for high and low $m i R-199 a-3 p$ expression was the median of all AML. $\dagger P$ values are based on Fisher exact tests; $¥ P$ value is based on Mann-Whitney $U$ tests; $§ P$ values are based on $\chi^{2}$ tests.

Finally, we investigated the functional significance of enhanced miR-199a-3p levels in AML cells (Table 3). Inhibition of $m i R-199 a-3 p$ by antagomiR-199a-3p significantly decreased the viability of AML blasts with high miR-199a-3p expression, but had no effect on AML samples with low $m i R-199 a-3 p$ levels (Figure 2D). These results indicate that $m i R-199 a-3 p$, when aberrantly expressed, is critical for survival of AML blasts.

\section{2-6. Future directions}

\section{2-6-1. MiRNA add-back}

In Chapter 3, in silico analyses of gene and miRNA expression profiles suggest that a set of 20 miRNAs is highly active in GMPs. Different approaches could be applied to investigate the contribution of each single miRNA to myelopoiesis. Adding-back of miRNAs in Dicer1null progenitor cells is one of them. To investigate the function of individual miRNAs in Dicer1-null cells, pre-miRNAs need to bypass the Dicer1-dependent processing. For this, we can employ the alternative processing mechanism of $m i R-451 . M i R-451$ is the only miRNA reported to be Dicerl-independent and is processed by Ago-2 instead ${ }^{32,33}$. The structure of the pre-miR-451 hairpin differs from other miRNAs. The mature miR-451 sequence is extended to the loop of the hairpin. Furthermore, the length of the hairpin stem is shorter compared with other pre-miRNAs. These differences lead to a non-canonical processing mechanism of $m i R-451^{32,33}$. Testing structural mimics of $m i R-451$, showed that for the 
Table 2. High miR-199a-3p expression is an independent prognostic factor for overall survival in AML based on the multivariate Cox regression hazard model.

\begin{tabular}{lllll}
\hline Marker & Hazard ratio & Lower bound 95\% CI & Upper bound 95\% CI & P-value \\
\hline NPM1 & 0.253944 & 0.15408 & 0.4185 & $7.60 \mathrm{E}-08$ \\
\hline CEBPA_DM & 0.176413 & 0.06223 & 0.5001 & 0.0011 \\
\hline FLT3_ITD & 1.648418 & 1.05903 & 2.5658 & 0.02683 \\
\hline Age $^{*}$ & 1.016535 & 1.00257 & 1.0307 & 0.02018 \\
\hline Wbc* & 1.008561 & 1.00445 & 1.0127 & $4.40 \mathrm{E}-05$ \\
\hline favo & 0.412988 & 0.21487 & 0.7938 & 0.00799 \\
\hline abn11q23 & 0.456555 & 0.19724 & 1.0568 & 0.06711 \\
\hline miR-199a-3p & 1.66494 & 1.07484 & 2.579 & 0.02242 \\
\hline IDH2 & 1.625292 & 0.85445 & 3.0915 & 0.13874 \\
\hline
\end{tabular}

For the construction of the multivariate Cox proportional hazard model the following variables were considered: favorable karyotype (i.e. $\mathrm{t}(15 ; 17)$, inv(16), t(8;21)), FLT3-ITD, FLT3-TKD, NPM1 mutation, CEBPA double mutants, IDH1 mutation, IDH2 mutation, DNMT3A mutation, age, white blood cell count (wbc), abnormalities involving MLL , miR-199a-3p (dichotomized on the median expression level).

*Continuous variable

Table 3. Characteristics of patients in viability test.

\begin{tabular}{lll}
\hline & Low miR-199a-3 $p^{*}$ & High $m i R-199 a-3 p^{*}$ \\
\hline Sex & 2 & 2 \\
\hline Female & 3 & 5 \\
\hline Age & $43(38-54)$ & $54(31-68)$ \\
\hline Median (range) & & \\
\hline WBC $\left(\mathbf{x 1 0}{ }^{9} /\right.$ L) & $84(5,8-263,4)$ & $21,5(2-37,1)$ \\
\hline Median (range) & $\cdot$ & $\cdot$ \\
\hline Transplantation status & 3 & 2 \\
\hline No transplantation & 0 & 1 \\
\hline Autologous transplantation & 2 & 4 \\
\hline Allogenic transplantation & $\cdot$ & $\cdot$ \\
\hline FAB classification & 0 & 0 \\
\hline M0 & 2 & 2 \\
\hline M1 & 0 & 3 \\
\hline M2 & 0 & 0 \\
\hline M3 & 1 & 1 \\
\hline M4 & 1 & 1 \\
\hline M5 & 0 & 0 \\
\hline M6 & & \\
\hline
\end{tabular}


Table 3. Characteristics of patients in viability test. (Continued)

\begin{tabular}{|c|c|c|}
\hline & Low $m i R-199 a-3 p^{*}$ & High $m i R-199 a-3 p^{*}$ \\
\hline Secondary AML (RAEB-t) & 1 & 0 \\
\hline Other/unknown & 0 & 0 \\
\hline \multicolumn{3}{|l|}{ Cytogenetic abnormalities } \\
\hline $\mathrm{t}(15 ; 17)$ & . & . \\
\hline $\mathrm{t}(8 ; 21)$ & . & . \\
\hline $\operatorname{inv}(16)$ & . & 1 \\
\hline $11 \mathrm{q} 23$ & 1 & . \\
\hline $3 q$ & . & . \\
\hline $7 \mathrm{q}$ & . & . \\
\hline $\mathrm{t}(6 ; 9)$ & . & . \\
\hline $\mathrm{t}(9 ; 22)$ & . & . \\
\hline $\mathrm{t}(9 ; 11)$ & 1 & . \\
\hline 18 & . & 2 \\
\hline$-5 /-5 q /-7 /-7 q$ & . & . \\
\hline complex & . & 1 \\
\hline Normal karyotype & 3 & 3 \\
\hline other & 1 & 1 \\
\hline \multicolumn{3}{|l|}{ Other molecular aberrations } \\
\hline FLT3ITD & 3 & 1 \\
\hline FLT3TKD835 & . & 2 \\
\hline NPM1 mutation & 1 & 4 \\
\hline NRAS & . & 1 \\
\hline KRAS & . & . \\
\hline CEBPA_silenced & & . \\
\hline CEBPA_SM & 1 & 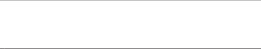 \\
\hline CEBPA_DM & . & . \\
\hline EVI1_overexpression & 1 & . \\
\hline ASXL1 & . & . \\
\hline IDH1 & . & 2 \\
\hline IDH2 & . & . \\
\hline DNMT3A_mut & . & 2 \\
\hline
\end{tabular}

WBC indicates white blood cell count; and FAB, French-American-British.

${ }^{*}$ Cutoff used for high and low miR-199a-3p expression was the median of all AML. 
alternative Ago2-dependent miRNA biogenesis pathway, the structure, but not the sequence of $m i R-451$ is required ${ }^{32,33}$. In other words, by replacing the mature sequence of $m i R-451$ in the $m i R-451$ precursor structure with sequences encoding other miRNAs, it is possible to generate miRNAs in a Dicerl-independent manner. We used this approach to produce Let-7g miRNA in Dicer1-null cells (Figure 3). Let-7g was one of the miRNAs identified to

A)

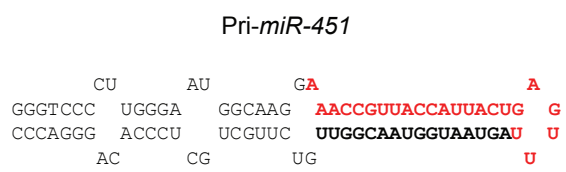

Mature Let-7g

UGAGGUAGUAGUUUGUACAGUU

Pri-Let-7g

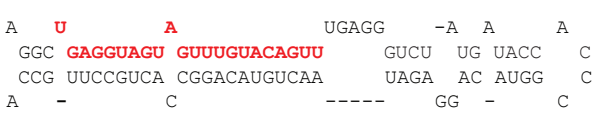

Ago2-Let-7g

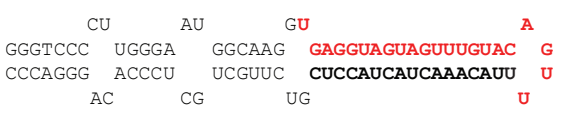

B)

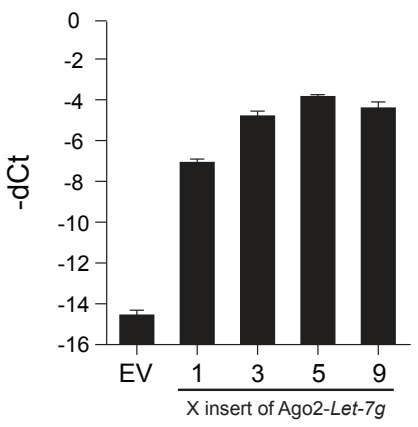

C)
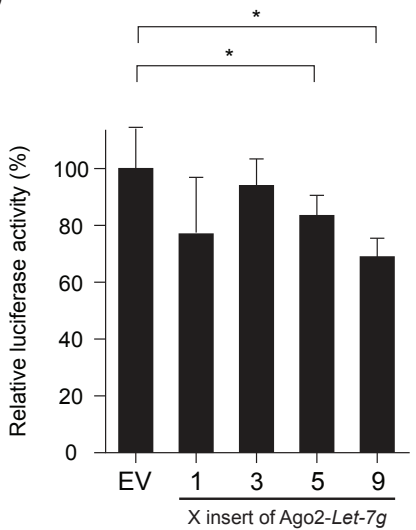

Figure 3. Production of Dicer1-independent $L e t-7 g$. A) Sequence and secondary hairpin structure of Pri-miR-451, Pri-Let-7g and designed Ago2-Let-7g hairpin, and mature Let-7g sequence. The sequence of the mature miRNA is depicted in red. The modified nucleotides of Pri-miR-451 in order to make Ago2-Let-7g, without changing the hairpin structure, are shown in bold. B) Relative expression levels of Let-7g mature transcripts in Dicer1 knockout murine mesenchymal stem cells (MSCs) after transduction of the retroviral expression vector (MSCV-BC-miRNA) containing 1, 3, 5 or 9 inserts of Ago2-Let-7g. Expression is presented as - $\mathrm{dCt}$ values measured by quantitative RT-PCR using snU6 RNA as loading control. The error bars represent standard deviations (SD) of $n=3$ experiments. C) Luciferase reporter plasmids containing 3 binding sites for Let- $7 g$ behind the luciferase coding sequence were generated. The luciferase activity values of the cells co-expressing luciferase reporter plasmid and MSCV-BC containing 1, 3, 5 or 9 inserts of Ago2-Let- $7 g$ relative to the EV control are shown. Error bars represent the $\mathrm{SD}$ of $\mathrm{n}=5$ experiments. Data were analyzed by student $\mathrm{t}$-test [2-tailed]) $\left({ }^{*} \mathrm{p}<0.05\right)$. 
be active during myelopoiesis. Interestingly, HMGA2 and HOXA9, both known targets of Let-7g involved in the stemness of HSC, were de-repressed and upregulated in Dicer1-null GMPs and may explain the enhanced self-renewal capacity of Dicer1-null progenitors. We replaced the sequence of $m i R-451$ by Let-7g and mimicked the pre-miR-451 structure and length (Ago2-Let-7g) (Figure 3A) and cloned the Ago2-Let-7g sequence in an expression vector (MSCV-BC) ${ }^{34}$. MiRNA q-PCR showed that mature Let-7g miRNA is produced in Dicer1 knockout murine mesenchymal stem cells (MSCs) from this vector (Figure 3B). Also, Ago2-Let-7g was active in luciferase reporter assay (Figure 3C). Thus, these results show that this expression system can be applied to add back single miRNAs in Dicerl-null myeloid progenitor cells.

\section{2-6-2. Inactivation of single miRNAs}

Another approach to address the involvement of single miRNAs in myelopoiesis is to inactivate single miRNAs, or miRNA family, in myeloid progenitors. Gene-targeting methods enable us to delete miRNA encoding regions in the genome and investigate the consequences on cell behavior. The so-called clustered regularly interspaced short palindromic repeats (CRISPR)/Cas9 nuclease system has been shown to facilitate RNAguided site-specific (sgRNAs) DNA cleavage in human and mouse cell lines, mouse ES cells and even in one-cell embryos with high efficiency ${ }^{35,36}$. The double strand breaks generated will then be repaired by error prone non-homologues end joining or homology-directed repair (HDR) pathways, resulting in mutant cells carrying deletions or defined alterations at the cut sites ${ }^{37}$. To show the feasibility of this technology to delete miRNA encoding region in the genome of hematopoietic cells, we deleted the coding region of $m i R-139$, in the murine myeloid progenitor cell line 32D (Figure 4). To reduce off-target activity, we used a combination of a new mutant of Cas9, the so-called Cas9 nickase (Cas9n), with paired guide RNAs to introduce targeted double strand breaks (Figure $4 \mathrm{~A}$ ) ${ }^{37}$. With this approach we were able to knockout a $1 \mathrm{~kb}$ fragment containing the full miR-139 coding sequences in $32 \mathrm{D}$ cell line as confirmed by Sanger sequencing (Figure 4B and 4C). These results indicate that we are able to generate miRNA knockout cells by CRISPR and that the sgRNA combination can be used to generate miR-139 knockout mouse embryos. The recently generated Cas 9 knock in mouse allows wide range application of CRISPR technology for genome editing in vivo by tissue specific delivery of $\operatorname{sgRNAs}{ }^{38}$. In this way, by expressing a library of sgRNAs against a set of miRNA encoding loci in HSPCs of Cas9 knock in mice, and subsequently transplantation of these cells in recipient mice, we can investigate the functions of single miRNAs in myelopoiesis.

\section{2-6-3. Identification of miRNA targets}

MiRNA target identification and elucidation of critical downstream pathways are still major challenges in the field. MiRNAs are predicted to control many target mRNAs, most of which are only moderately repressed. Slight repression of multiple genes that act in the same network may have significant effects together on cellular processes. Detection of these slight expression differences needs accurate experimental approaches followed by 


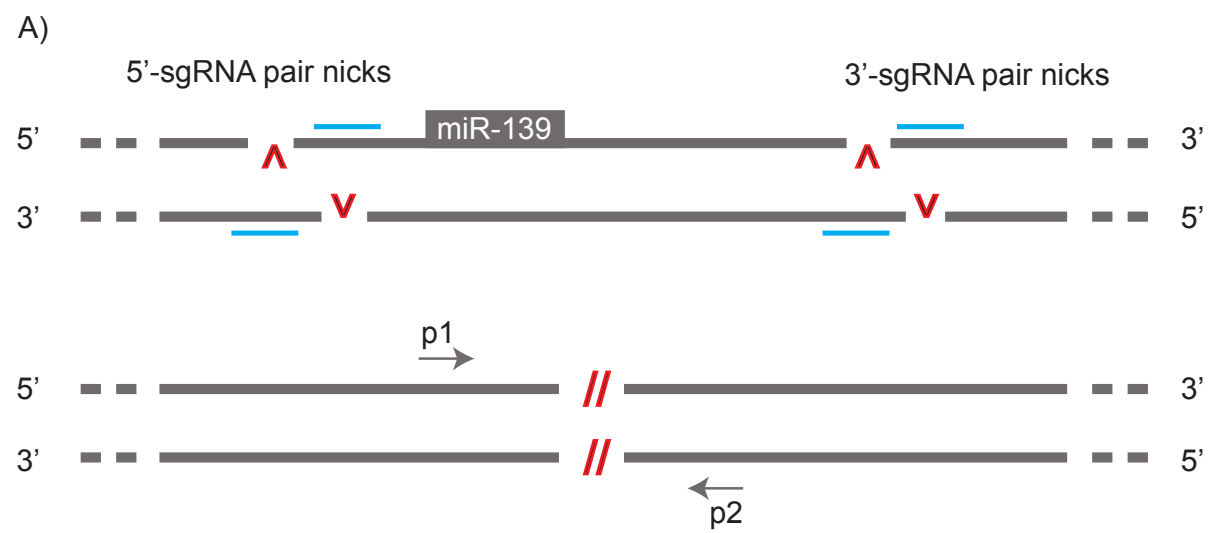

B)

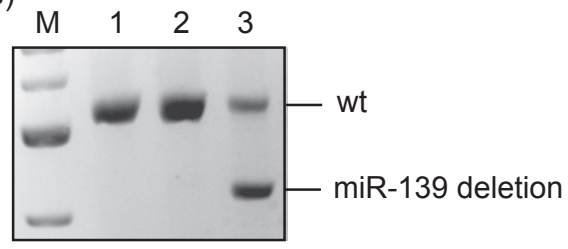

C)

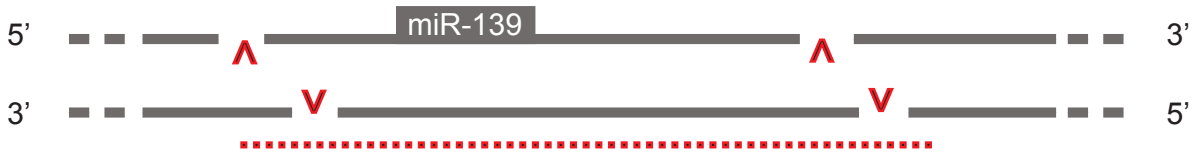

deleted fragment

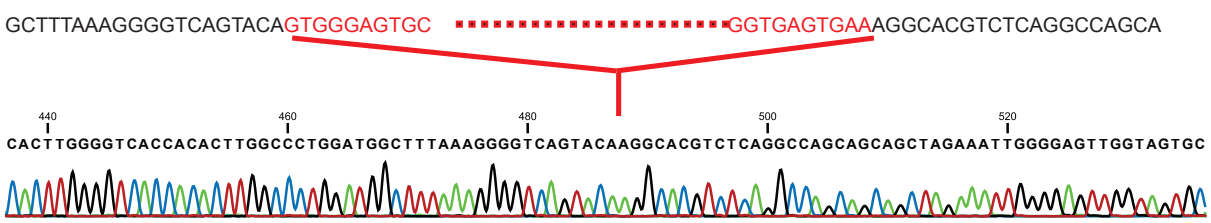

Figure 4. Double nicking with CAS9n facilitates genomic miR-139 deletion. A) Schematic overview of CAS9n-mediated targeting of miR-139. sgRNAs are depicted in blue. The nicking sites are depicted in red. Genomic deletions will be determined by PCR. B) 32D cells were transfected with plasmids expressing the miR-139-locus specific sgRNAs and CAS9n by electroporation. Genomic DNA from the transfected 32D cell subpopulations was used as a template for PCR primer 1 and primer 2 (A). Samples 1 and 2 are control populations showing only a large wt band. Sample 3 contains miR-139 knockout cells as determined by the lower band. C) The miR-139 deletion band was isolated out of the gel, cloned in TOPO-PCR cloning vector. The expected genomic deletion was confirmed by Sanger sequencing. 
A) PAR-CLIP-SEQ

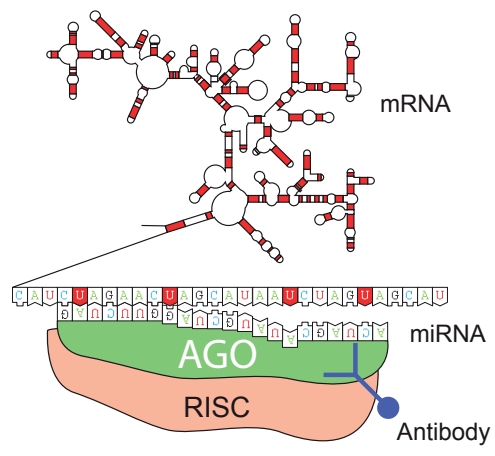

B) I. human CD34+

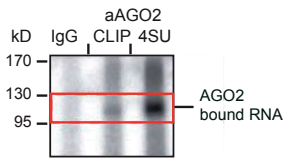

II. mouse 32D

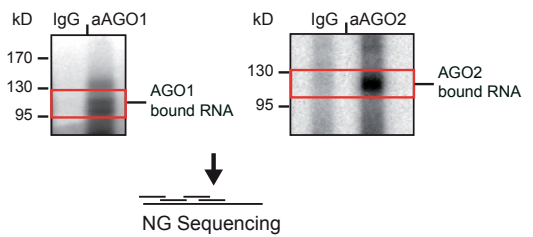

C)

\begin{tabular}{|c|c|c|c|}
\hline 3'UTR EDEM3 & \# & reads & $\mathrm{T}->\mathrm{C}$ \\
\hline \multicolumn{4}{|l|}{ СTTATAATTTTAGAGGGGGGTAGAATTTAGTAAATATT } \\
\hline$\ldots \ldots \ldots$ TAGAGGGGGGTAGAATTC $\ldots \ldots \ldots$ & & 3 & 1 \\
\hline$\ldots \ldots \ldots \ldots$ CAGAGGGGGGTAGAATTT $\ldots \ldots \ldots$ & & 17 & 1 \\
\hline$\ldots \ldots \ldots$. . . . & & 9 & 0 \\
\hline$\ldots \ldots \ldots \ldots$ AGAGGGGGGTAGAATTT $\ldots \ldots \ldots$ & & 10 & 0 \\
\hline$\ldots \ldots \ldots \ldots$ GAGGGGGGTAGAATTT $\ldots \ldots \ldots$ & & 2 & 0 \\
\hline$\ldots \ldots \ldots$ TAGAGGGGGGTAGA $\ldots \ldots \ldots \ldots$ & & 9 & 0 \\
\hline 3'UTR SEMA7A & $\#$ & reads & $\mathrm{T}->\mathrm{C}$ \\
\hline \multicolumn{4}{|l|}{ TGTTATAACTTAGGCTAAACTGTGAAAATTCCGCACCCC } \\
\hline$\ldots . .$. TAACTTAGGCTAAACTGTGAAAATCCCG..... & & 4 & 1 \\
\hline$\ldots . .$. AACTTAGGCTAAACTGTGAAAATCCCG. . . . . & & 8 & 1 \\
\hline$\ldots \ldots \ldots \ldots$ CTAAACTGTGAAAACTCCG . . . . & & 10 & 1 \\
\hline ....... AACTTAGGCTAAACTGTGAAAATTCC...... & & 6 & 0 \\
\hline $\operatorname{miR}-30 a-e-5 p$ & \# & reads & $\mathrm{T}->\mathrm{C}$ \\
\hline \multicolumn{4}{|l|}{ TGCATTGACTGCTGAGAGCTCCTGTTTACTAAGCAAGCT } \\
\hline$\ldots . .$. AСTGCTGAGAGCCCCTGTTTACTAAG..... & & 8 & 1 \\
\hline$\ldots . .$. . АСTGCTGAGAGCTCCTGTTTACCAAG . . . . & & 10 & 1 \\
\hline
\end{tabular}

Figure 5. Photoactivatable ribonucleoside-enhanced cross-linking immunoprecipitation followed by deep sequencing (PAR-CLIP-SEQ). A) Cells will be expanded overnight in expansion medium containing photo-activatable nucleoside 4-thioridine (4SU). 4SU-labeled transcripts (miRNA and target RNA) will be UV-cross-linked to RNA-binding proteins. RNA in immunoprecipitated complexes will be radiolabeled and loaded on gel. B) Examples of audiographs of indicated samples and antibodies are shown. Bands were cut from the gel and RNA was isolated and prepared for Illumina RNA deep sequencing. C) Examples of identified miRNAs and their targets. The extracted sequence reads were mapped to the human genome and publicly available RNA databases. In red are depicted the T to $\mathrm{C}$ transitions caused by $4 \mathrm{SU}-\mathrm{UV}$ cross-linking. The red line indicates the binding motifs of identified miRNAs. 
high sensitivity profiling of the transcriptome or proteome. More direct approaches for miRNA target identification have previously been described. For instance, photoactivatable ribonucleoside-enhanced cross-linking immunoprecipitation followed by deep sequencing (PAR-CLIP-SEQ), allows determination of direct miRNA-bound mRNA targets ${ }^{39}$. In this method, using specific antibodies against AGO proteins, the main components of RISC complex, the cross-linked miRNA and their target sequences will be co-immunoprecipitated and subsequently identified by RNA sequencing ${ }^{39}$ (Figure 5).

We applied this method on human CD34+ and murine 32D cells. Cells were labeled with photoactivatable nucleoside 4-thioridine (4SU) overnight in HSPC expansion medium, lyzed and specific antibodies against AGO1 and AGO2, the most abundantly expressed member of AGO proteins in HSPCs, were used (Figure 5). We also used an optimized cDNA library preparing protocol (also called iCLIP) ${ }^{40}$ followed by Illumina small RNA deep-sequencing. The extracted sequence reads were mapped to the genome and publicly available RNA databases. The miRNA binding sites (seed matches) on the target mRNAs were determined by bioinformatic analyses. This bioinformatic pipeline allows for identification and quantification of AGO-bound miRNAs, their direct RNA targets and the sites of interaction (Figure 5). In this way, transcripts that are relevant for pathways involved in hematopoiesis, and hematopoietic malignancies can be selected for further investigation.

In Chapter 5, we applied a combination of proteomics and gene expression arrays to identify the targets of $m i R-199 a-3 p$ and $m i R-139-3 p$ upon ICL DNA damage. The gene regulation by miRNAs is mediated by translational inhibiton or by promoting mRNA degradation, but the relative contributions of translational inhibition and mRNA degradation on the outcome are still largely unknown. Destabilization of target mRNAs is the predominant reason for reduced protein output ${ }^{41}$. However, transcriptome profiling is not an appropriate method to identify the minority of targets which are only hampered at translation level, but these genes may still be highly relevant. Furthermore, since the final effect of a miRNA on its target gene is a change in protein expression, proteomic approaches are still relevant tools for identification of few targets that are mainly blocked at the translation level. Recent proteomics technologies such as labeling of amino acids with stable isotopes are appropriate methods to identify the change of protein levels upon inhibition or induction of miRNAs ${ }^{42,43}$. Nevertheless, by using this approach, the direct and indirect targets of miRNAs cannot be distinguished. Another pitfall of proteomic approaches is the low sensitivity. This is due to the limited capacity to detect low-abundance peptides. Together, considering the pitfalls of each approach, a combination of PAR-CLIP, proteomics and RNA sequencing protocols could give essential insights into the direct targets regulated by miRNAs.

The presence and activity of the AGO protein as well as other RNA interfering factors such as DICER1 in the cell nucleus, demonstrate that miRNAs may be active in the nucleus ${ }^{44}$. Consistently, certain mature miRNAs have been reported to re-enter the nucleus after the final step of maturation in the cytoplasm ${ }^{45}$. Some recent publications show that miRNAs target nuclear non-coding (nc) RNAs including other miRNA primary transcripts, as well as long ncRNAs ${ }^{46}$. For instance, nuclear located $m i R-709$ is reported to target pri-miR-15a/16-1 
and suppress its maturation to pre-miR-15a and pre-miR-16 ${ }^{47}$. Also a circular ncRNA, the antisense transcript of CDR1 is cleaved by nucleus-enriched miR-671 in an AGO2-dependent manner, which results in the decrease of corresponding CDR1 sense transcript ${ }^{48}$. MiRNAs are also reported to regulate gene expression in hematopoietic cells via transcriptional gene silencing ${ }^{49,50}$. To identify genomic targets of miRNAs, chromatin immunoprecipitation (ChIP) with specific antibodies against AGO protein has been performed. Including antibodies against histone markers of active and silenced chromatin state will unravel the effect of the miRNA on the epigenetic status of the miRNA bound genomic loci ${ }^{49,50}$.

\section{2-6-4. Translational relevance and potential of miRNAs in therapeutic settings}

Aberrant expression levels of different miRNAs are associated with different stage of onset, progression and outcome of human cancers, including AML ${ }^{51,52}$. These findings suggest that miRNA expression profiles are potential indicators for diagnosis or prognosis. More importantly, identification of miRNA-controlled pathways and studying their roles in AML pathogenesis may lead to recognition of novel intervention points for AML therapy. For instance, functional identification of oncogenic miRNAs in AML may allow therapeutic targeting by using inhibitory small RNAs against these miRNAs or their downstream targets ${ }^{53}$. One recent example of an advanced miRNA therapeutic in human disease is the locked nucleic acid (LNA)-modified anti-miR-122 inhibitor sequence for treatment of patients with Hepatitis- $\mathrm{C}$ virus (HCV) infection ${ }^{54}$. In fact, subcutaneous delivery of the LNA miR-122 inhibitor effectively suppressed HCV replication in monkeys without evidence of toxicity ${ }^{55}$. The subcutaneous delivery of the miR-122 LNA inhibitor was then tested in a clinical phase-II study on 36 patients with chronic HCV infection ${ }^{56}$. The results of this study showed an LNA inhibitor dose-dependent reduction in HCV RNA levels without any dose-limiting adverse events ${ }^{56}$. Another recent study show therapeutic potential of $m i R-155$ inhibition using 8-mer LNA oligonucleotides complementary to the miRNA seed region in the treatment of B-cell leukemia in mice ${ }^{57}$. These results highlight the potential of miRNA inhibitors for therapeutic targeting in hematological malignancies. In Chapter 5 , we showed that deregulated expression of $m i R-199 a-3 p$, which is observed at BMF stage of FA, plays a major role in the malignant transformation of BM HSPCs. FA-AML cannot be treated with standard protocols because FA patients do not tolerate high dosages of chemotherapeutic agents ${ }^{58}$. We showed that transfection with antagomiR-199a-3p did not affect expansion and differentiation of wt HSPCs, suggesting low toxicity of this agent. Thus, the inhibition of the oncogenic $m i R-199 a-3 p$ by antagomiRs may be a new opportunity to prevent the transition of BMF towards leukemia.

On the other hand, the fact that global downregulation of miRNAs is observed in many human cancers ${ }^{59}$ and that heterozygous deletion of Dicerl contributes to leukemogenesis (Chapter 4), indicates that it may be beneficial to deliver tumor-suppressing miRNAs. For instance, recent data showed suppression of non-small cell lung tumor development by reintroduction of Let-7 in tumor cells ${ }^{60-62}$. Recently, lipid-based nano-particles were used for systemic delivery of tumor-suppressing miRNA expressing vectors or miRNA mimics to 
cancer cells and showed efficient elimination of cancer cells in a dose-dependent manner and without detectable toxicity in mouse models for ovarian, pancreatic and lung cancers ${ }^{63-65}$. This liposome technology is now being used to deliver synthetic double strand mimics of $m i R-34 a$ in a phase-I trial in patients with primary liver cancer or metastatic cancer with liver involvement ${ }^{66}$. This suggests that this approach may be successful for AML treatment as well. For example, delivery of Let-7c promotes granulocytic differentiation in AML cell lines as well as in primary AML blasts in culture, and could be an interesting approach ${ }^{67}$. The loss of miR-139-3p seems to be a common event in the onset of malignant transformation. Therefore, delivering of this miRNA could be of benefit in preventing the outgrowth of leukemic cells.

The increasing knowledge about the functions of miRNAs may open doors for new drug development. Small interfering RNAs may be used to target aberrant factors that control miRNA activities in AML. Up to date, more than 50 RNA-based therapeutics have reached clinical testing and have demonstrated promising results in the treatment of viral infections, genetic disorders and cancers including leukemia ${ }^{68}$. Therefore, in vivo experimental models for AML should be generated to enable testing and further developing of small-RNA based therapeutic protocols, which may ultimately lead to a better treatment of this disease. 


\section{REFERENCES}

1. Cunningham JM, Patnaik MM, Hammerschmidt DE, Vercellotti GM. Historical perspective and clinical implications of the Pelger-Huet cell. American Journal of Hematology. 2009;84(2):116-119.

2. Desvignes T, Contreras A, Postlethwait JH. Evolution of the miR199-214 cluster and vertebrate skeletal development. RNA Biol. 2014;11(4):281-294.

3. Loebel DA, Tsoi B, Wong N, Tam PP. A conserved noncoding intronic transcript at the mouse Dnm3 locus. Genomics. 2005;85(6):782-789.

4. Suzuki HI, Yamagata K, Sugimoto K, Iwamoto T, Kato S, Miyazono K. Modulation of microRNA processing by p53. Nature. 2009;460(7254):529-533.

5. Wang J, He Q, Han C, et al. p53facilitated miR-199a-3p regulates somatic cell reprogramming. Stem Cells. 2012;30(7):1405-1413.

6. Katoh T, Sakaguchi Y, Miyauchi K, Suzuki T, Kashiwabara S, Baba T. Selective stabilization of mammalian microRNAs by 3 ' adenylation mediated by the cytoplasmic poly(A) polymerase GLD-2. Genes Dev. 2009;23(4):433-438.

7. Li J, Yang Z, Yu B, Liu J, Chen X. Methylation protects miRNAs and siRNAs from a 3'-end uridylation activity in Arabidopsis. Curr Biol. 2005;15(16):1501-1507.

8. Kai ZS, Pasquinelli AE. MicroRNA assassins: factors that regulate the disappearance of miRNAs. Nat Struct Mol Biol. 2010;17(1):5-10.

9. Abdelmohsen K, Pullmann R, Jr., Lal A, et al. Phosphorylation of $\mathrm{HuR}$ by $\mathrm{Chk} 2$ regulates SIRT1 expression. Mol Cell. 2007;25(4):543-557.

10. Abdelmohsen K, Lal A, Kim HH, Gorospe M. Posttranscriptional orchestration of an anti-apoptotic program by HuR. Cell Cycle. 2007;6(11):1288-1292.

11. Kim HH, Abdelmohsen $\mathrm{K}$, Gorospe $\mathrm{M}$. Regulation of $\mathrm{HuR}$ by DNA Damage
Response Kinases. J Nucleic Acids. 2010;2010.

12. Ghosh M, Aguila HL, Michaud J, et al. Essential role of the RNA-binding protein $\mathrm{HuR}$ in progenitor cell survival in mice. $J$ Clin Invest. 2009;119(12):3530-3543.

13. Bhattacharyya $\mathrm{SN}$, Habermacher R, Martine U, Closs EI, Filipowicz W. Relief of microRNA-mediated translational repression in human cells subjected to stress. Cell. 2006;125(6):1111-1124.

14. Kim HH, Kuwano Y, Srikantan S, Lee EK, Martindale JL, Gorospe M. HuR recruits let-7/RISC to repress c-Myc expression. Genes Dev. 2009;23(15):1743-1748.

15. Margueron R, Reinberg D. The Polycomb complex PRC2 and its mark in life. Nature. 2011;469(7330):343-349.

16. Cao R, Zhang Y. SUZ12 is required for both the histone methyltransferase activity and the silencing function of the EED-EZH2 complex. Mol Cell. 2004;15(1):57-67.

17. O'Carroll D, Erhardt S, Pagani M, Barton SC, Surani MA, Jenuwein T. The polycomb-group gene Ezh2 is required for early mouse development. Mol Cell Biol. 2001;21(13):4330-4336.

18. Pasini D, Bracken AP, Jensen MR, Lazzerini Denchi E, Helin K. Suz12 is essential for mouse development and for EZH2 histone methyltransferase activity. EMBO J. 2004;23(20):4061-4071.

19. Shumacher A, Faust C, Magnuson T. Positional cloning of a global regulator of anterior-posterior patterning in mice. Nature. 1996;383(6597):250-253.

20. Radulovic V, de Haan G, Klauke K. Polycomb-group proteins in hematopoietic stem cell regulation and hematopoietic neoplasms. Leukemia. 2012.

21. Ernst T, Chase AJ, Score J, et al. Inactivating mutations of the histone methyltransferase gene EZH2 in myeloid disorders. Nat Genet. 2010;42(8):722-726.

22. Brecqueville M, Cervera N, Adelaide J, et al. Mutations and deletions of the SUZ12 
polycomb gene in myeloproliferative neoplasms. Blood Cancer J. 2011;1(8):e33.

23. Majewski IJ, Blewitt ME, de Graaf CA, et al. Polycomb repressive complex 2 (PRC2) restricts hematopoietic stem cell activity. PLoS Biol. 2008;6(4):e93.

24. Fisher AB. Peroxiredoxin 6: A Bifunctional Enzyme with Glutathione Peroxidase and Phospholipase A2 Activities. Antioxidants \& Redox Signaling. 2010;15(3):831-844.

25. Rajkovic MG, Rumora L, Barisic K. The paraoxonase 1, 2 and 3 in humans. Biochem Med (Zagreb). 2011;21(2):122-130.

26. Ng CJ, Wadleigh DJ, Gangopadhyay A, et al. Paraoxonase-2 is a ubiquitously expressed protein with antioxidant properties and is capable of preventing cell-mediated oxidative modification of low density lipoprotein. J Biol Chem. 2001;276(48):44444-44449.

27. Du W, Adam Z, Rani R, Zhang X, Pang Q. Oxidative stress in Fanconi anemia hematopoiesis and disease progression. Antioxid Redox Signal. 2008;10(11):19091921.

28. Ikeda H, Matsushita M, Waisfisz Q, et al. Genetic reversion in an acute myelogenous leukemia cell line from a Fanconi anemia patient with biallelic mutations in BRCA2. Cancer Res. 2003;63(10):2688-2694.

29. Meyer S, Fergusson WD, Whetton AD, et al. Amplification and translocation of $3 q 26$ with overexpression of EVI1 in Fanconi anemia-derived childhood acute myeloid leukemia with biallelic FANCD1/BRCA2 disruption. Genes Chromosomes Cancer. 2007;46(4):359-372.

30. Akaike H. A new look at the statistical model identification. Automatic Control, IEEE Transactions on. 1974;19(6):716-723.

31. Garzon R, VoliniaS, Liu CG, etal.MicroRNA signatures associated with cytogenetics and prognosis in acute myeloid leukemia. Blood. 2008;111(6):3183-3189.

32. Cheloufi S, Dos Santos CO, Chong MM, Hannon GJ. A dicer-independent miRNA biogenesis pathway that requires Ago catalysis. Nature. 2010;465(7298):584-589.
33. Cifuentes D, Xue H, Taylor DW, et al. A novel miRNA processing pathway independent of Dicer requires Argonaute2 catalytic activity. Science. 2010;328(5986):1694-1698.

34. Meenhuis A, van Veelen PA, de Looper $\mathrm{H}$, et al. MiR-17/20/93/106 promote hematopoietic cell expansion by targeting sequestosome 1-regulated pathways in mice. Blood. 2011;118(4):916-925.

35. Ran FA, Hsu PD, Wright J, Agarwala V, Scott DA, Zhang F. Genome engineering using the CRISPR-Cas9 system. Nat Protoc. 2013;8(11):2281-2308

36. Wang H, Yang H, Shivalila CS, et al. Onestep generation of mice carrying mutations in multiple genes by CRISPR/Cas-mediated genome engineering. Cell. 2013;153(4):910918.

37. Ran FA, Hsu PD, Lin CY, et al. Double nicking by RNA-guided CRISPR Cas9 for enhanced genome editing specificity. Cell. 2013;154(6):1380-1389.

38. Platt Randall J, Chen S, Zhou Y, et al. CRISPR-Cas9 Knockin Mice for Genome Editing and Cancer Modeling. Cell. 2014;159(2):440-455.

39. Hafner M, Landthaler M, Burger L, et al. Transcriptome-wide identification of RNAbinding protein and microRNA target sites by PAR-CLIP. Cell. 2010;141(1):129-141.

40. Sugimoto Y, Konig J, Hussain S, et al. Analysis of CLIP and iCLIP methods for nucleotide-resolution studies of protein-RNA interactions. Genome Biol. 2012;13(8):R67.

41. Guo H, Ingolia NT, Weissman JS, Bartel DP. Mammalian microRNAs predominantly act to decrease target mRNA levels. Nature. 2010;466(7308):835-840.

42. Boersema PJ, Raijmakers R, Lemeer S, Mohammed S, Heck AJ. Multiplex peptide stable isotope dimethyl labeling for quantitative proteomics. Nat Protoc. 2009;4(4):484-494

43. Wisniewski JR, Zougman A, Nagaraj N, Mann M. Universal sample preparation method for proteome analysis. Nat Methods. 2009;6(5):359-362. 
44. Gagnon Keith T, Li L, Chu Y, Janowski Bethany A, Corey David R. RNAi Factors Are Present and Active in Human Cell Nuclei. Cell Reports. 2014;6(1):211-221.

45. Hwang HW, Wentzel EA, Mendell JT. A hexanucleotide element directs microRNA nuclear import. Science. 2007;315(5808):97100.

46. Chen X, Liang H, Zhang C-Y, Zen K. miRNA regulates noncoding RNA: a noncanonical function model. Trends in Biochemical Sciences. 2012;37(11):457-459.

47. Tang R, Li L, Zhu D, et al. Mouse miRNA-709 directly regulates miRNA-15a/16-1 biogenesis at the posttranscriptional level in the nucleus: evidence for a microRNA hierarchy system. Cell Res. 2012;22(3):504515.

48. Hansen TB, Wiklund ED, Bramsen JB, et al. miRNA-dependent gene silencing involving Ago2-mediated cleavage of a circular antisense RNA. EMBO J. 2011;30(21):44144422.

49. Zardo G, Ciolfi A, Vian L, et al. Polycombs and microRNA-223 regulate human granulopoiesis by transcriptional control of target gene expression. Blood. 2012;119(17):4034-4046.

50. Benhamed M, Herbig U, Ye T, Dejean A, Bischof O. Senescence is an endogenous trigger for microRNA-directed transcriptional gene silencing in human cells. Nat Cell Biol. 2012;14(3):266-275.

51. Jongen-Lavrencic M, Sun SM, Dijkstra MK, Valk PJ, Lowenberg B. MicroRNA expression profiling in relation to the genetic heterogeneity of acute myeloid leukemia. Blood. 2008;111(10):5078-5085.

52. Nana-Sinkam P, Croce CM. MicroRNAs in diagnosis and prognosis in cancer: what does the future hold? Pharmacogenomics. 2010;11(5):667-669.

53. Stenvang J, Silahtaroglu AN, Lindow M, Elmen J, Kauppinen S. The utility of LNA in microRNA-based cancer diagnostics and therapeutics. Semin Cancer Biol. 2008;18(2):89-102.
54. Elmen J, Lindow M, Silahtaroglu A, et al. Antagonism of microRNA-122 in mice by systemically administered LNA-antimiR leads to up-regulation of a large set of predicted target mRNAs in the liver. Nucleic Acids Res. 2008;36(4):1153-1162.

55. Elmen J, Lindow $M$, Schutz $S$, et al. LNA-mediated microRNA silencing in non-human primates. Nature. 2008;452(7189):896-899.

56. Janssen HLA, Reesink HW, Lawitz EJ, et al. Treatment of HCV Infection by Targeting MicroRNA. New England Journal of Medicine. 2013;368(18):1685-1694.

57. Zhang Y, Roccaro AM, Rombaoa C, et al. LNA-mediated anti-miR-155 silencing in low-grade B-cell lymphomas. Blood. 2012;120(8):1678-1686.

58. Kee Y, D'Andrea AD. Molecular pathogenesis and clinical management of Fanconi anemia. $J$ Clin Invest. 2012;122(11):3799-3806.

59. Lu J, Getz G, Miska EA, et al. MicroRNA expression profiles classify human cancers. Nature. 2005;435(7043):834-838.

60. Kumar MS, Erkeland SJ, Pester RE, et al. Suppression of non-small cell lung tumor development by the let-7 microRNA family. Proc Natl Acad Sci US A. 2008;105(10):39033908.

61. Esquela-Kerscher A, Trang P, Wiggins JF, et al. The let-7 microRNA reduces tumor growth in mouse models of lung cancer. Cell Cycle. 2008;7(6):759-764.

62. Trang P, Medina PP, Wiggins JF, et al. Regression of murine lung tumors by the let7 microRNA. Oncogene. 2010;29(11):15801587.

63. Goldberg MS, Xing D, Ren Y, Orsulic S, Bhatia SN, Sharp PA. Nanoparticlemediated delivery of siRNA targeting Parp1 extends survival of mice bearing tumors derived from Brcal-deficient ovarian cancer cells. Proc Natl Acad Sci U S A. 2011;108(2):745-750.

64. Pramanik D, Campbell NR, Karikari C, et al. Restitution of tumor suppressor 
microRNAs using a systemic nanovector inhibits pancreatic cancer growth in mice. Mol Cancer Ther. 2011;10(8):1470-1480.

65. Trang $\mathrm{P}$, Wiggins JF, Daige CL, et al. Systemic delivery of tumor suppressor microRNA mimics using a neutral lipid emulsion inhibits lung tumors in mice. $\mathrm{Mol}$ Ther. 2011;19(6):1116-1122.
66. Bouchie A. First microRNA mimic enters clinic. Nat Biotech. 2013;31(7):577-577.

67. Pelosi A, Careccia S, Lulli V, et al. miRNA let-7c promotes granulocytic differentiation in acute myeloid leukemia. Oncogene. 2012.

68. Burnett JC, Rossi JJ. RNA-based therapeutics: current progress and future prospects. Chem Biol. 2012;19(1):60-71. 


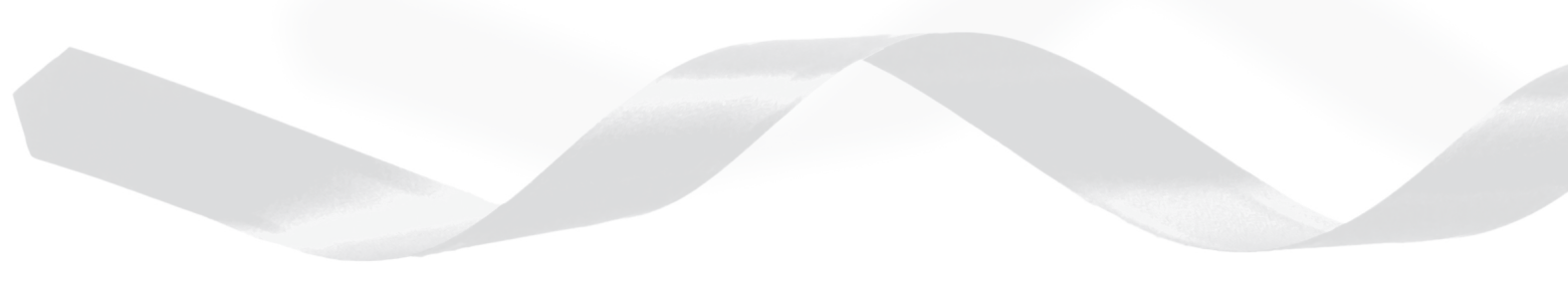




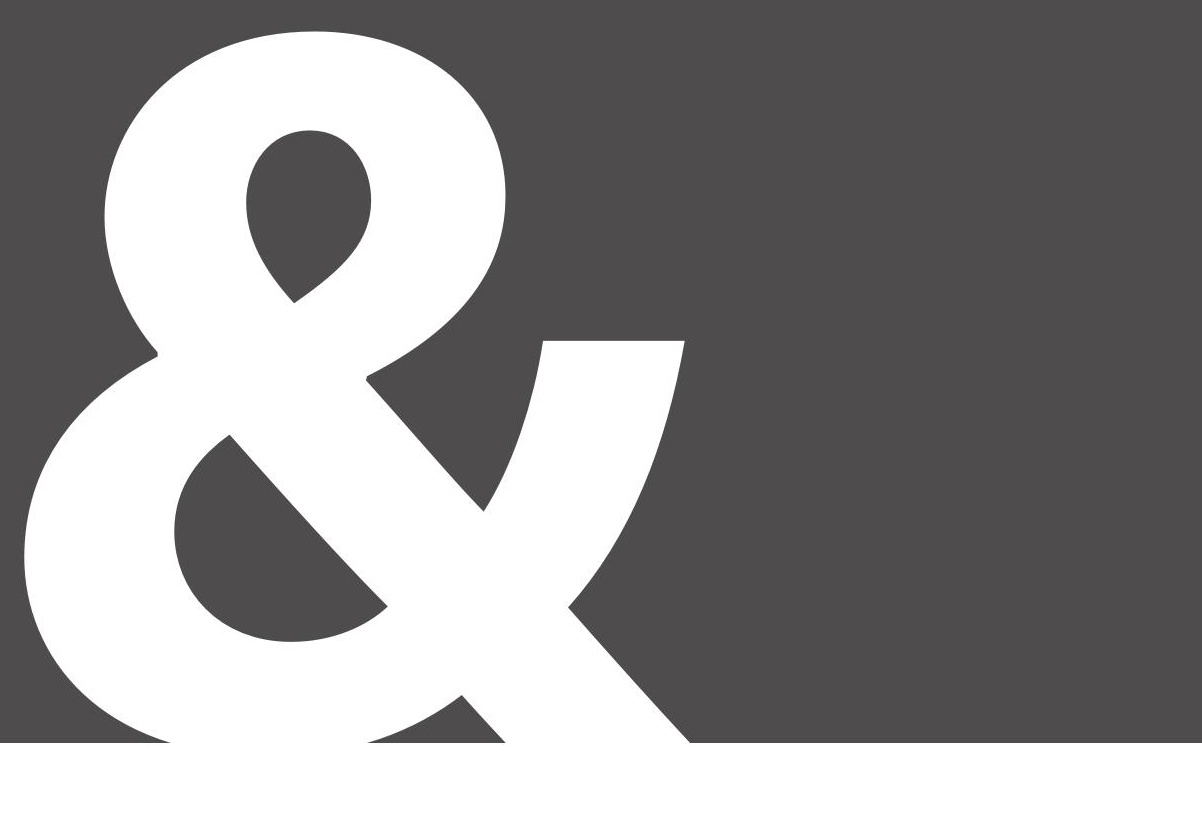

Addendum 



\section{LIST OF ABBREVIATIONS}

$4 \mathrm{SU}$

$\mathrm{Ab}$

AGM

AIC

AML

ARE

BER

$\mathrm{BM}$

BMF

CFU

CFU-GM

ChIP

CLL

CLP

CMP

CNN-LOH

$\mathrm{CNV}$

CRISPR

DC

DDR

DN

DSB

dsRNA

EGFP

ES cell

EV

EYFP

FA 4-thioridine

antibody

aorta-gonad-mesonephros

Akaike information criterion

acute myeloid leukemia

AU-rich element

base excision repair

bone marrow

bone marrow failure

colony-forming unit

granulocyte-macrophage colony-forming unit

chromatin immunoprecipitation

chronic lymphocytic leukemia

common lymphoid progenitor

common myeloid progenitor

copy number-neutral loss of heterozygosity

copy number variation

clustered regularly interspaced short palindromic repeats

dendritic cell

DNA-damage response

double-negative

double strand break

double-stranded RNA

enhanced green fluorescent protein

embryonic stem cell

empty vector

enhanced yellow fluorescent protein

Fanconi anemia 
FDR

FTC

G-CSF

GEP

GMP

$\mathrm{HCV}$

HDR

HSC

ICL

IDEA

LNA

LPS

LSK

LSL

LT-HSC

MCMV

MDS

MEF

MEP

miRNA

MMC

MPN

MPP

MSC

NER

NK cells

nt

PAR-CLIP

pIpC false discovery rate

Fanconi anemia transcriptome consortium

granulocyte colony-stimulating factor

gene expression profiling

granulocyte monocyte progenitor

hepatitis- $\mathrm{C}$ virus

homology-directed repair

hematopoietic stem cell

interstrand cross-link

Ingenuity downstream effect analysis

locked nucleic acid

lipopolysaccharide

lineage negative (Lin-) Scal+ c-Kit+

loxp-flanked stop sequence

long-term hematopoietic stem cell

mouse cytomegalovirus

myelodysplatic syndrome

mouse embryonic fibroblast

megakaryocyte-erythroid progenitor

microRNA

mitomycin C

myeloproliferative neoplasm

multipotent progenitor

mesenchymal stem cell

nucleotide excision repair

natural killer cells

nucleotide

photoactivatable ribonucleoside-enhanced cross-linking immunoprecipitation

polyI:polyC 
PMA phorbol myristate acetate

PRC polycomb repressive complex

pre-miRNA precursor microRNA

pri-miRNA primary microRNA

RBD RNA binding domain

RBP RNA binding protein

RISC RNA-induced silencing complex

RNAi RNA interference

ROS reactive oxygen species

SD standard deviation

siRNA small interfering RNA

SNP single nucleotide polymorphism

ST-HSC short-term HSC

TCGA the cancer genome atlas

Treg regulatory $\mathrm{T}$ cell

UTR untranslated region

WES whole exome sequencing

WT wild type 



\section{NEDERLANDSE SAMENVATTING}

Hematopoëse (bloedcelvorming) is een continu proces waarin hematopoëtische stam- en voorlopercellen vermenigvuldigen en differentiëren naar volwassen bloedcellen. Hematopoëse wordt sterk gecontroleerd door een netwerk van groeifactoren en de hematopoëtische niche in het beenmerg. Verstoring van de balans tussen proliferatie, differentiatie en celdood kan leiden tot verschillende hematopoëtische aandoeningen zoals beenmerg falen, gekarakteriseerd door verstoorde bloedaanmaak, of leukemie, gekarakteriseerd door ongecontroleerde expansie van ongedifferentieerde bloedcellen.

MicroRNAs (miRNAs) behoren tot een klasse van niet-coderende RNAs die de expressie van genen reguleren. Dit proefschrift bevat twee experimentele gedeelten. In het eerste deel hebben we de vraag gesteld of Dicer1, het gen wat codeert voor het cruciale RNAse III enzym voor het verwerken van langere voorlopersequenties naar miRNAs, essentieel is voor normale myelö̈de bloedcelvorming. In hoofdstuk 3 hebben we dit onderzocht door het gen wat codeert voor DICER1 specifiek in myeloïde voorlopercellen te verwijderen. In tegenstelling tot de resultaten in hematopoëtische stamcellen (HSCs) had het verwijderen van het Dicerl gen in myeloïde voorlopercellen geen significant effect op het aantal multipotente voorlopercellen (MPPs), algemene myeloïde voorlopercellen (CMPs), megakaryocyte/ erythroïde voorlopercellen (MEPs) en granulocyte/monocyte voorlopercellen (GMPs) in de muis. Echter, Dicer1 knockout GMPs waren niet in staat om uit te rijpen tot volwassen myeloïde cellen en hadden een verhoogde zelfvernieuwingscapaciteit. Verwijdering van Dicer1 in myeloïde voorlopercellen verhinderde de differentiatie van monocyten, macrofagen en dendritische cellen en veroorzaakte myelö̈de dysplasie met morfologische kenmerken van de Pelger Huët afwijking (een goedaardige hematopoëtische aandoening wat een defect in neutrofiele differentiatie veroorzaakt). We hebben gevonden dat 104 miRNAs hoog tot expressie komen in normale GMPs. In Dicer-knockout GMPs kwamen voorspelde targets van tenminste 20 miRNA families significant hoger tot expressie, wat sterk suggereert dat deze miRNAs actief zijn in GMPs. Interessant is dat 27\% van deze miRNA-gereguleerde transcripten normaal alleen in HSCs tot expressie komen of specifiek zijn voor MPPs en rode bloedcellen. Dus, hoewel de resultaten in HSCs en andere bloedcellen fracties voornamelijk functies van Dicer1 in overlevingsmechanismen laten zien (beschreven in Hoofdstuk 4), hebben wij bewijs verkregen voor een miRNA-gecontroleerde omschakeling van een stamcelprogramma van zelfvernieuwing en celdeling naar myeloïde differentiatie.

In hoofdstuk 4, laten we zien dat totale verlies van Dicerl niet samenwerkt met het verlies van het tumor remmende gen P53 in leukemie-ontwikkeling. In plaats daarvan ontwikkelde de muizen die getransplanteerd waren met heterozygote Dicerl deletie en P53 nul allelen ernstige leukemie. Deze experimenten lieten zien dat verminderde concentratie van miRNAs een oncogene gebeurtenis is en dat tenminste sommige miRNAs nodig zijn voor het leukemie proces.

In het tweede gedeelte van dit proefschrift hebben we de vraag gesteld of de deregulatie van miRNA expressie als gevolg van DNA-koppelingsschade een rol speelt in beenmerg 
falen en leukemie. In hoofdstuk 5 hebben we de activiteiten van 2 miRNAs, $m i R-139$-3p en miR-199a-3p beschreven. Beiden miRNAs kwamen verhoogd tot expressie in Fanconi anemie. $M i R-139-3 p$ induceerde celdood en de expressie van $m i R-139-3 p$ was verlaagd in leukemie, terwijl de expressie van miR-199a-3p verhoogd bleef en acute leukemie veroorzaakte in de muis. Remming van $m i R-139-3 p$ expressie in Ercc1-knockout voorlopercellen herstelde de verminderde proliferatiecapaciteit, terwijl de remming van $m i R-199 a-3 p$ het proliferatieve defect van Ercc1-knockoutcellen verergerde. Gecombineerde genexpressie- en eiwitanalyse voor de identificatie van targets, onthulde dat miR-139-3p de expressie van het RNA-bindend eiwit HUR reguleert, en dat miR-199a-3p de expressie van de AML genen SUZ12 en RUNX1 remt. Deze bevindingen laten zie dat $m i R-139-3 p$ en $m i R-199 a-3 p$ een belangrijke rol spelen in het ziekteverloop van Fanconi anemie en de transformatie naar leukemie. 


\section{WORDS OF THANKS}

....and that is how another season of my life comes to its end. The realization of this season was not possible without the help and support of many people and it gives me great pleasure in acknowledging them.

I wish to thank, first and foremost, my supervisor: Dear Stefan, many thanks for letting me be a member of your team, for your supervision and for your patience. Your guidance made my life in science enjoyable. Out of science, our wonderful trips, football chats and exciting ski lessons also gave me so many nice memories. You were not only an exceptional scientific mentor, but also an excellent person I am really proud of having as a friend. I would also like here to thank Sabine, who always warmly welcomed me, and wish all the best for Lars and Koen.

Dear Ivo, I would like to thank you for your continuous support through all these years. Your sense of criticism is always a great example of scientific way of thinking for me. I am thankful for your aspiring guidance, invaluably constructive criticism and friendly advice during my time at hematology department.

I would like to express my gratitude to the members of my thesis reading committee, Dr. Marieke von Lindern, Prof. Leendert Looijenga and Dr. Erik Wiemer for careful reading of my thesis and sharing their critical and illuminating inputs. Dear Marieke, I am also sincerely grateful for sharing with me your truthful and illuminating views on a number of issues related to my manuscript. Furthermore, my deepest appreciation to Prof. Ruud Delwel, Prof. Gerard de Haan, Prof. Sjaak Philipsen and Dr. Marc Bierings, the members of my large thesis committee, for their time and attention.

Dear Hans, we both started our carrier at Erasmus MC together. I enjoyed your company in the lab and it was always a pleasure for me to work with you. It was great that we could grow together in Stefan's lab. I wish you all the best in your career in science as well as in sport. Dear Paulette, your technical expertise always helped me when I was blocked in an experiment. I really appreciate your help and support. Dear Hans and Paulette, also thanks for being with me all along the promotion day as my "paranimfen". Nicole and Yvette, thanks for all your patience in showing me how to work with smaller organisms, for all your helps and for giving grateful technical support, which made the lab work more fun, and of course efficient for me. Nahuel and Jana, thank you for helping me to bring my projects a few steps further. I wish you lots of luck during your PhD period, and further in your professional and personal life.

My warm thanks belong also to all my fellow $\mathrm{PhD}$ students, postdocs, research analysts, technicians and group leaders in hematology department, for offering me pleasant friendly moments, for constructive scientific and non scientific discussions, technical help and mental support and for a lot of good memories we shared during last five years. I wish you all good luck.

Special thanks to all the people in $13^{\text {th }}$ floor of Erasmus MC that provided me technical and administrative support over the last years. Dear Ans, Leenke, Annelies, Egied, Jan, 
Thomasia and Natasja, I have caused quite some work for you. Thank you for all your assistance during these years.

I was so lucky to have great office mates during my $\mathrm{PhD}$ training, and I am thankful to all of them. Elnaz, who helped me find my first steps in Erasmus MC and in Hematology department, and Lucila and Athina, with whom I shared the office for the majority of my time at $13^{\text {th }}$ floor. It is great to see your adorable, little family now, and wish you lots of luck in your career. I also shared the office with Kean and Piotr for the last few months of my stay at the department. Thank you for making the office such a pleasant place and I wish you all the best for your future.

During my PhD-training, I was a member of Molecular Medicine postgraduate school (MolMed) and I learned a lot from the courses, seminars and workshops offered and organized by MolMed. Representing the whole team, I would like to thank Frank and Joris for these exciting opportunities and valuable trainings.

The Iranian community of the Erasmus MC, thank you good friends for your personal support. You made me feel at home. It was great that we got to know each other here and hopefully despite the distance, our friendships will go on.

The work presented in this thesis would have been impossible without many collaborators. Therefore, I would like to express my warm thanks to Dr. Peter van Veelen, Dr. George Janssen, and the rest of van Veelen group at LUMC, as well as to Dr. Marc Bierings and to Stephanie from Wilhelmina Children's Hospital (UMCU).

From September 2014 I have been working at NKI in Amsterdam and already, just after a few months, I really feel knowing you guys for a long time and enjoy working with you. Heinz, thanks for your comprehension during the busy period of time I experienced, and for your personal and scientific support. Muhammad, Paul, Mark, Alessandra and Bas, we will hopefully go for a couple of years of fun in producing good quality science together, as always said by Heinz.

Maman and Baba, there is no word to explain my feeling about you. Though Confucius said "While one's family are alive, one should not travel to distant places", you are always supportive and encourage me to follow my dreams. I always feel lucky to have you as parents. Thank you for all your patience, for the lovely environment you made for us at home and for all love you gave me.

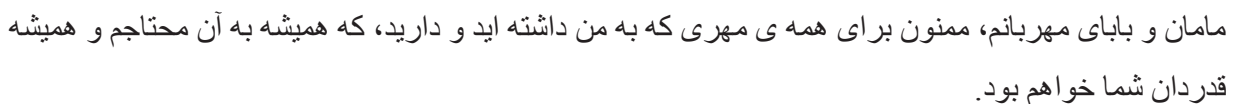

Mrs. and Mr. Moghadasi, because of you, I never felt being far from home. I always was welcomed warmly in the family, which is now a part of my new big family. Thanks a lot. Farzaneh, Ali, Farnaz, Anoushiravan, Maryam and Ali, thanks for being, on top of family members, best friends for me and Setareh.

Every journey starts with preparation steps. My preparation for $\mathrm{PhD}$ period was done in Belgium. Without the support of my aunts, uncles and cousins, it was impossible to be 
in the way I am following today. I would like to express the deepest appreciation to all of them, as well as to all my good friends and colleagues in Belgium.

And finally, I would like to thank my love, Setareh. Dear Setareh, I thank you for your support, your care and your smile, which not only help me go through all the difficulties, but also make all my moments so precious. I feel the luckiest to share my life with you. During last days of preparation of this book, an exceptional tiny happiness came to our life. Little Ryan, you are an unlimited source of joy and motivation for your parents. Our best of love to you.

Writing these words made me recall lots of nice memories for being together and working with a lot of amazing people in Erasmus MC, hematology department or Erkeland lab. I did not show my appreciations in more detail by naming them all one by one, but they will always be in my mind and heart. Thank you all!

Farshid Alemdehy

March 2015 



\section{CURRICULUM VITAE}

Farshid Alemdehy was born in Tehran, Iran, on 28 July 1976. After receiving his high school diploma from the National Organization for Development of Exceptional Talents (NODET, Tehran, Iran), he studied microbiology at University of Tehran and gained his Bachelor of Science degree in 1998 (Tehran, Iran). He then moved to Belgium and studied bioengineering in biotechnology. After completing a research project on immunomodulatory properties of a recombinant lactic acid bacterium against the dust mite allergy, performed in the Institute of Molecular Biology and Medicine (IBMM, Gosselies, Belgium), he gained the degree of Master of Science with distinction, from Université Libre de Bruxelles (ULB, Brussels, Belgium). He worked for a short period in CARAH (Applied Agronomic Research Centre of province of Hainaut, Ath, Belgium) as a research assistant. He then moved to the Netherlands in 2010 and started his $\mathrm{PhD}$ in the group of Dr. Stefan Erkeland in Hematology Department, Erasmus University Medical Center, in Rotterdam. During his PhD training, he studied the role of microRNAs in normal and malignant myelopoiesis. In September 2014 he started working on a post-doctoral project on the non-coding role of stable immunoglobulin transcripts in establishing allelic exclusion and B cell development, in the group of Dr. Heinz Jacobs in the Netherlands Cancer Institute in Amsterdam, the Netherlands.

\section{AWARDS}

- American Society of Hematology Abstract Achievement Award (2012), 53 $3^{\text {rd }}$ ASH annual meeting

- Best Poster Award (2013), 1 $7^{\text {th }}$ Molecular Medicine Day

- Lady TATA Memorial Trust International Award for Research in Leukaemia (2014)

\section{LIST OF PUBLICATIONS}

- Alemdehy, M. F., van Boxtel, N. G., de Looper, H. W., van den Berge, I. J., Sanders, M. A., Cupedo, T., Touw, I. P., and Erkeland, S. J. (2012). Dicer1 deletion in myeloidcommitted progenitors causes neutrophil dysplasia and blocks macrophage/dendritic cell development in mice. Blood 119, 4723-4730.

- Alemdehy, M. F., and Erkeland, S. J. (2012). MicroRNAs: key players of normal and malignant myelopoiesis. Current opinion in hematology 19, 261-267.

- Alemdehy, M. F., and Erkeland, S. J. (2012). Stop the dicing in hematopoiesis: What have we learned? Cell Cycle 11, 2799-2807.

- Alemdehy, M. F., Haanstra, J. R., de Looper H. W., van Strien P. M. H., VerhagenOldenampsen J., Caljouw Y., Sanders M. A., Hoogenboezem R., de Ru A. H., Janssen G. M. C., Smetsers S. E., Bierings M. B., von Lindern M., van Veelen P. A., Touw I. P. and Erkeland S. J. Interstrand cross-link induced miR-139-3p and miR-199a-3p have opposite roles in hematopoietic cell expansion and leukemic transformation. Submitted

- Alemdehy M. F., Erkeland S. J. MicroRNAs in normal and malignant myelopoiesis, A chapter of the book :" MicroRNA in Regenerative Medicine", Elsevier, In press. 



\section{Erasmus MC}

Universitairinedisch Centrum Rotterdam
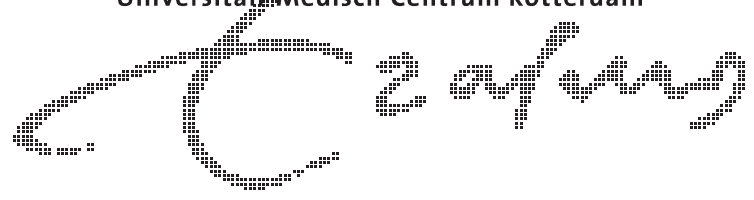

\section{PHD PORTFOLIO SUMMARY}

\section{Summary of $\mathrm{PhD}$ training and teaching activities}

Name PhD student: Mir Farshid Alemdehy

Erasmus MC Department: Hematology

Research School: Molecular Medicine (MolMed)
PhD period: Mai 2010-August 2014 Promotor: Prof.Dr. Ivo P. Touw Supervisor: Dr. Stefan J. Erkeland

\begin{tabular}{lcc}
\hline 1.PhD training & Year & ECTS \\
\hline General academic/research skills & & \\
\hline Research Management for PhDs/Postdocs & 2010 & 1 \\
\hline Laboratory animal science & 2011 & 3 \\
\hline Basic introduction course on SPSS & 2011 & 0.6 \\
\hline Photoshop \& Illustrator CS5 workshop & 2011 & 0.3 \\
\hline English biomedical writing and communication & 2011 & 4 \\
\hline Indesign CS5 workshop & 2012 & 0.15 \\
\hline In-depth courses and workshops & 2010 & 1.2 \\
\hline workshop on Basic data analysis on gene expresison arrays (BAGE) & 2011 & 1 \\
\hline Scientific workshop on AML molecular & 2013 & 1.8 \\
\hline Basic and translational oncology & 2013 & 0.7 \\
\hline Basic course on R & 2013 & 1.6 \\
\hline Analysis of microarray and RNA seq data & 2014 & 1 \\
\hline Molecular aspects of hematological disorders & & \\
\hline Scientific meetings department of hematology & $2010-2014$ & 1.3 \\
\hline Erasmus hematology lecture & $2010-2014$ & 4 \\
\hline Workdiscussion & &
\end{tabular}




\begin{tabular}{|c|c|c|}
\hline \multicolumn{3}{|l|}{ 1.PhD training } \\
\hline & Year & ECTS \\
\hline AIO/Postdoc meeting & $2010-2014$ & 1.6 \\
\hline Journal club & $2010-2014$ & 2 \\
\hline \multicolumn{3}{|l|}{ Seminars and conferences } \\
\hline Dutch Hematology Congress & 2011-2014 & 1.8 \\
\hline Molecular Medicine Day & 2011-2014 & 1.2 \\
\hline $53^{\text {rd }}$ ASH annual meeting & 2011 & 1 \\
\hline Keystone Symposia: MicroRNAs and Non-Coding RNAs and Cancer & 2011 & 1 \\
\hline Keystone Symposia: Non-Coding RNAs in development and Cancer & 2013 & 1 \\
\hline \multicolumn{3}{|l|}{ Presentations } \\
\hline Workdiscussion (department of hematology, 9X) & 2010-2014 & 4.5 \\
\hline Journal club presentation (department of hematology, 4X) & 2011-2014 & 2 \\
\hline AIO/Postdoc meeting (department of hematology, 3X) & $2010-2014$ & 1.5 \\
\hline $5^{\text {th }}$ Dutch Hematology Congress (oral) & 2011 & 1 \\
\hline $15^{\text {th }}$ Molecular Medicine Day (oral) & 2011 & 1 \\
\hline & Cancer (poster) & 1 \\
\hline $53^{\text {rd }}$ ASH annual meeting (oral) & 2011 & 1 \\
\hline \multicolumn{2}{|l|}{ Cancer (poster) } & 1 \\
\hline $17^{\text {th }}$ Molecular Medicine Day (poster) & 2013 & 1 \\
\hline $8^{\text {th }}$ Dutch Hematology Congress (oral) & 2014 & 1 \\
\hline Molecular aspects of hematological disorders (oral) & 2014 & 1 \\
\hline \multicolumn{3}{|l|}{ 2.Teaching activities } \\
\hline Supervising Master's thesis & 2013-2014 & 3 \\
\hline \multicolumn{3}{|l|}{ Other } \\
\hline Organizing Hematology $\mathrm{PhD}$ lunch with invited speakers & 2011-2012 & 0.2 \\
\hline Total & & 50.45 \\
\hline
\end{tabular}

